\title{
INVESTIGATING THE ROLE OF ENVIRONMENTAL MANAGEMENT SYSTEMS STANDARDS AND MANAGEMENT SYSTEMS SOFTWARE IN ENHANCING ORGANIZATIONAL LEARNING
}

\author{
by
}

\author{
Randolph Onyema Ibe \\ B.Sc., Abia State University, Nigeria, 1994 \\ M.Sc., Technical University of Hamburg, Germany, 2003 \\ A dissertation \\ presented to Ryerson University \\ in partial fulfillment of the \\ requirements for the degree of \\ Doctor of Philosophy \\ in the Program of \\ Environmental Applied Science and Management
}

Toronto, Ontario, Canada, 2017

(C) Randolph Ibe 2017 


\section{Author's Declaration}

I hereby declare that I am the sole author of this dissertation. This is a true copy of the dissertation, including any required final revisions, as accepted by my examiners.

I authorize Ryerson University to lend this dissertation to other institutions or individuals for the purpose of scholarly research.

I further authorize Ryerson University to reproduce this dissertation by photocopying or by other means, in total or in part, at the request of other institutions or individuals for the purpose of scholarly research.

I understand that my dissertation may be made electronically available to the public. 


\title{
INVESTIGATING THE ROLE OF ENVIRONMENTAL MANAGEMENT SYSTEMS STANDARDS AND MANAGEMENT SYSTEMS SOFTWARE IN ENHANCING ORGANIZATIONAL LEARNING
}

\author{
Randolph Onyema Ibe \\ Doctor of Philosophy, 2017 \\ Environmental Applied Science and Management \\ Ryerson University
}

\begin{abstract}
The purpose of this research was: to explore the organizational learning capabilities of the ISO 14001 standard and environmental management systems software (EMS-based software); to investigate whether EMS-based software has the necessary features to assist organizations with the implementation and maintenance of their environmental management system/standard; and to gain an understanding as to the functionality of the standard and software based on the experience of users. In order to achieve the objectives of this study, a questionnaire was used to survey individuals within organizations in Canada and the United States of America that were registered to the ISO 14001:2004 standard and that used EMS-based software. The results of this study suggest that the ISO 14001:2004 standard may have certain capabilities that may have the effect of enhancing organizational learning. The results also highlight some of the strengths as well as challenges users may have regarding the requirements/elements of the standard. The study also provides preliminary insights and observations as to the functionality, performance and learning capabilities of EMS-based software. However, due to the low response rate, and the use of non-probability sampling, generalizations of the results of this study will have to be made with caution. Nevertheless, this study furthers organizational learning-oriented research and understanding concerning standards and software in a preliminary and practical way in certain respects. First, the study provides scholars and organizations with a broader view regarding the
\end{abstract}


application of the standard and software to environmental management - that is, as a means to improve learning - which arguably could enable them to better understand and improve the processes of learning within organizations. This could translate to an improvement in an organization's competitive advantage and an improvement in environmental performance and thus enhanced environmental protection. Second, the study offers insights regarding possible improvements that could be made to the standard and software, which would be of benefit to the organizations that use the standard and software and to the developers of EMS-based software. Finally, the study contributes to the relatively limited available research on the learning capabilities associated with and functionality of environmental management standards and software. 


\section{Acknowledgements}

First of all, I would like to say a big thank you to my supervisor, Dr. Kernaghan Webb for his support and guidance which enabled me to carry out this research study.

I also wish to acknowledge Intelex Technologies Inc. and Mitacs-Accelerate for the partial funding of this research and most importantly for their input with respect to the review of the research instrument (questionnaire) and the methodology on the whole.

I am grateful to Dr. Alasdair Goodwill for allowing me participate in his course from which I gained knowledge that was valuable to my research. I wish to also thank the members of my supervisory committee, Dr. Cory Searcy and Dr. Philip Walsh for their assessment of the dissertation, and to the external examiner, Prof. Irene Henriques.

Finally, a big thank you to my parents and siblings for their moral support over the years and also to my cohorts and to all my friends, too numerous to mention who supported me in one way or the other. 


\section{Table of Contents}

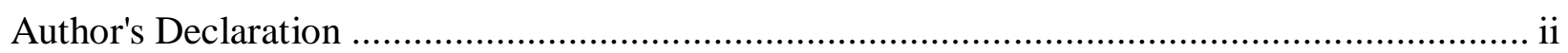

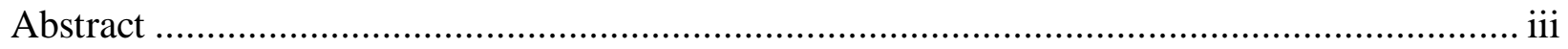

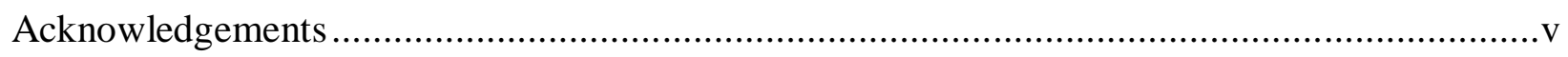

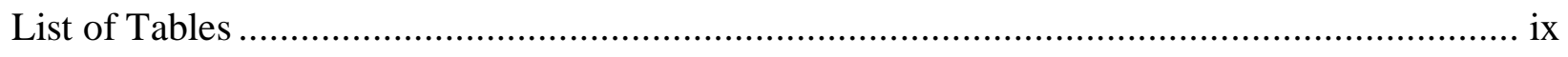

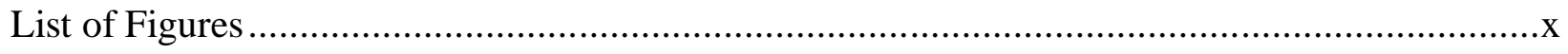

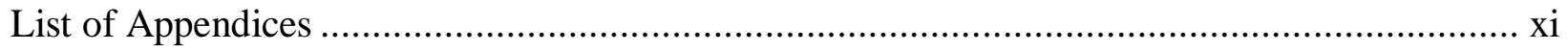

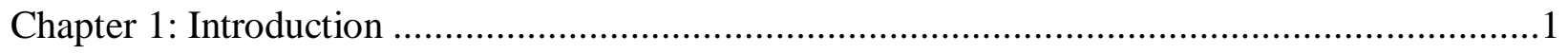

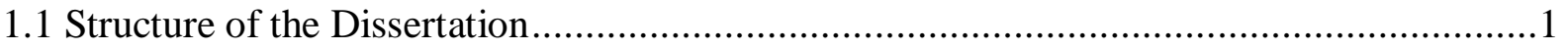

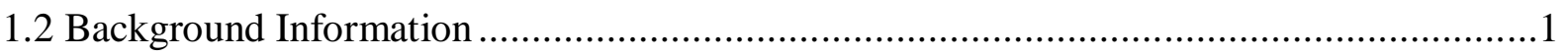

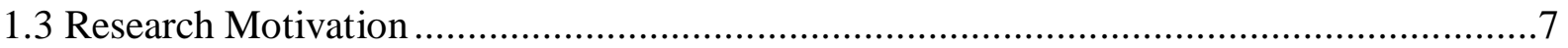

1.4 Research Objectives........................................................................................ 9

Chapter 2: Literature Review and Theoretical Analysis ........................................................ 13

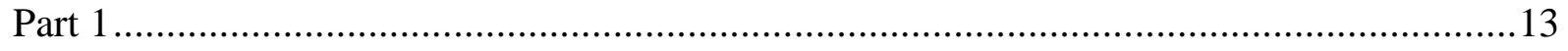

2.1 Literature Review on Environmental Management Systems, the ISO 14001 Standard and

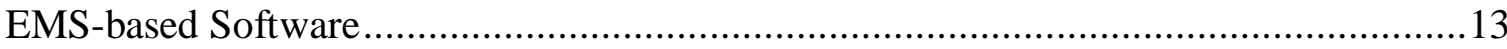

2.1.1 Environmental Management Systems ............................................................... 13

2.1.2 The ISO 14001 Environmental Management Systems Standard ............................15

2.1.3 Environmental Management Systems Software ................................................32

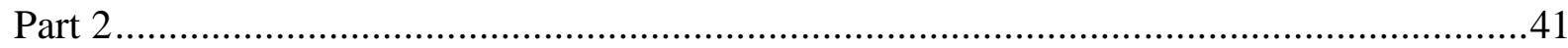

2.2 Literature Review on Organizational Learning and the Learning Organization...............41

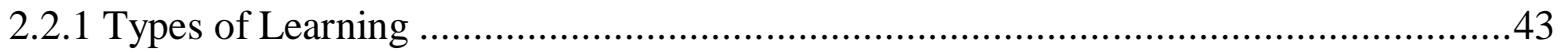

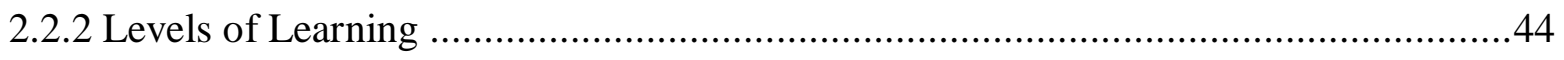

2.2.3 Further Scholarly contributions on Organizational Learning ....................................46

2.2.4 Benefits of Organizational Learning ................................................................58

2.2.5 Factors that impede Organizational Learning .....................................................59

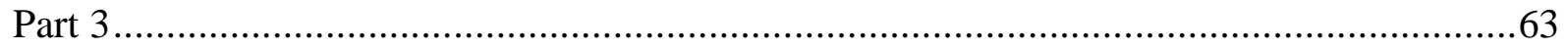

2.3 The ISO 14001 Standard, EMS-based Software, and Organizational Learning: Making the

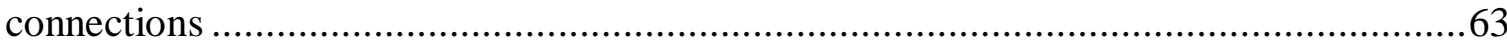

2.3.1 The ISO 14001:2004 Environmental Management Systems Standard and

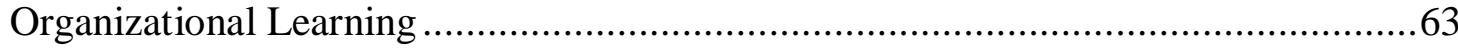

2.3.2 Environmental Management Systems Software and Organizational Learning ...........93

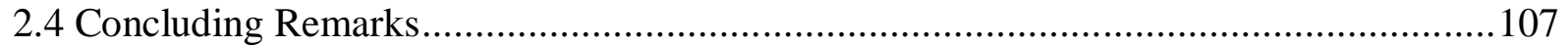

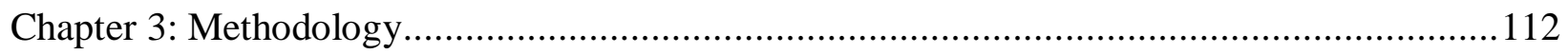

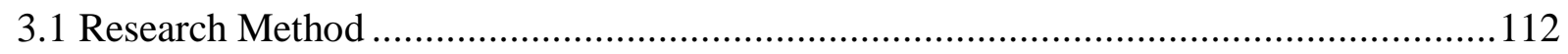

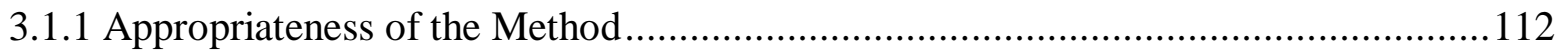

3.1.2 Limitations of the Method ..................................................................... 112

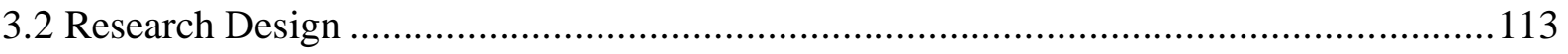

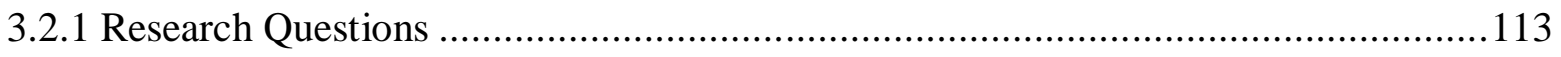




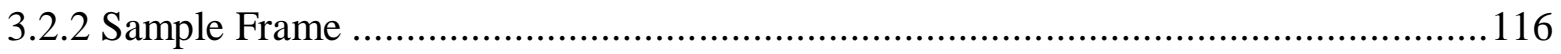

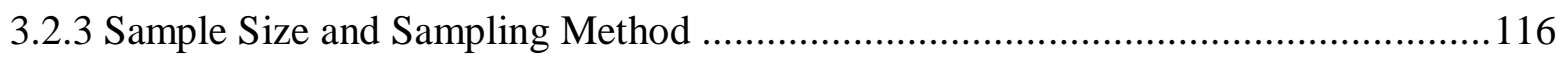

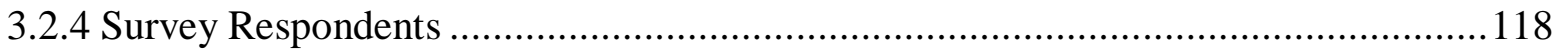

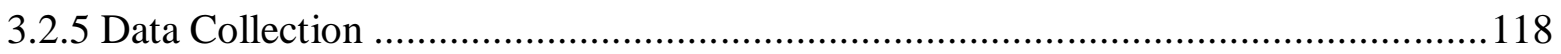

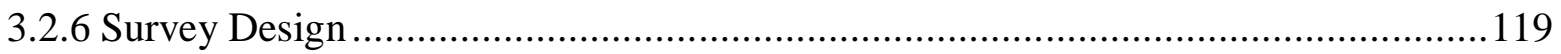

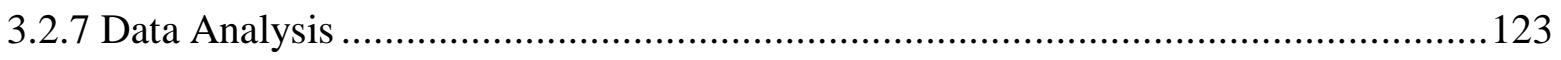

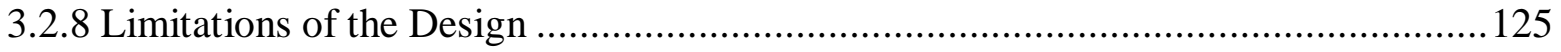

3.2.9 Reliability and Validity as applied to the Survey Research Method..........................125

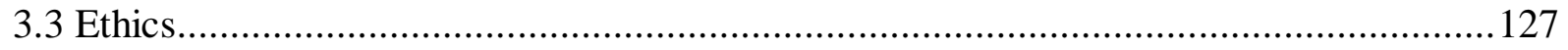

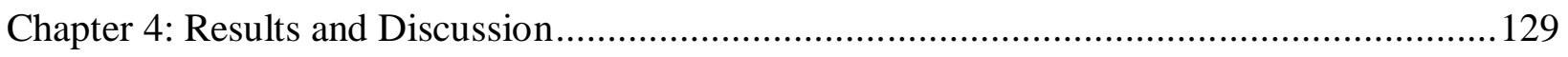

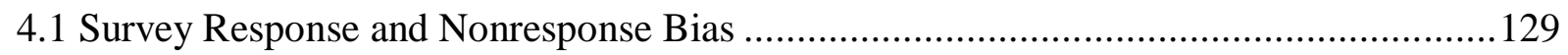

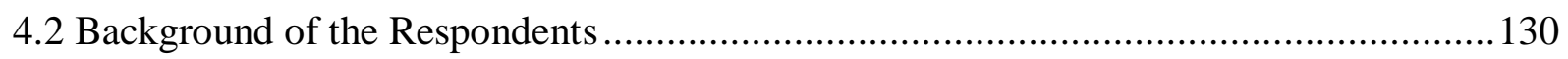

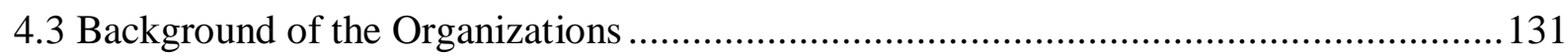

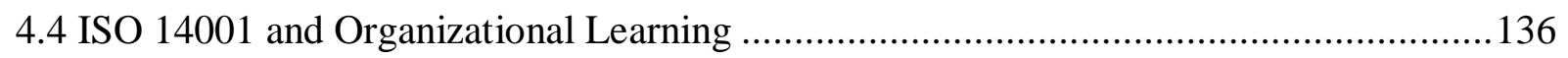

4.4.1 ISO 14001 as a facilitator of the four constructs of Organizational Learning ............136

4.4.2 ISO 14001:2004 as a facilitator of Organizational Learning and in turn Environmental

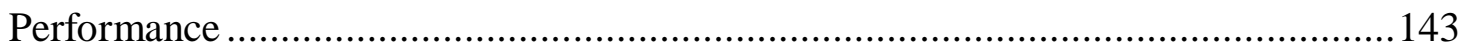

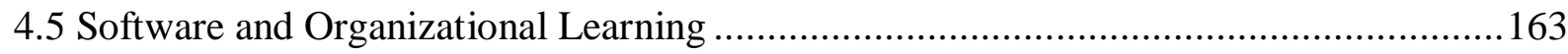

4.5.1 Software as a facilitator of the four constructs of Organizational Learning ...............163

4.5.2 Software as a facilitator of Organizational Learning and in turn Environmental

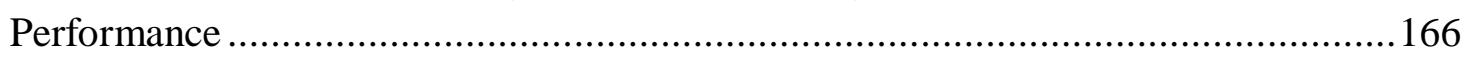

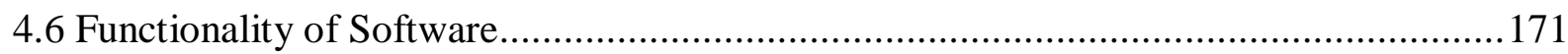

4.6.1 Capability of EMS-based Software to assist with the ISO 14001 Standard...............172

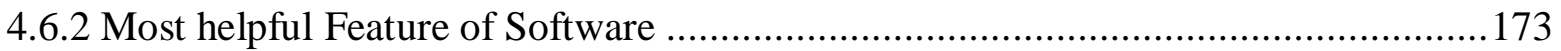

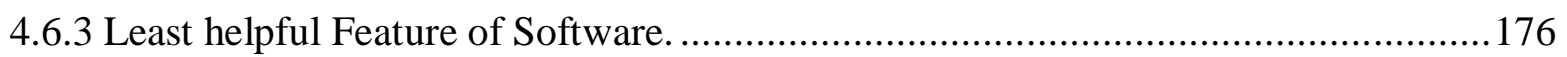

4.6.4 Ease or Difficulty with respect to the Implementation of the Software ......................178

4.6.5 Suggestions for Improvement of the Functionality of Software...............................180

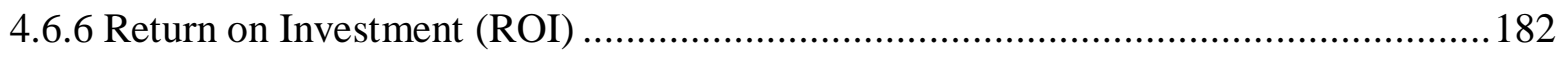

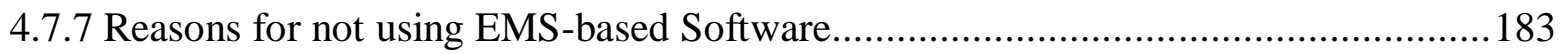

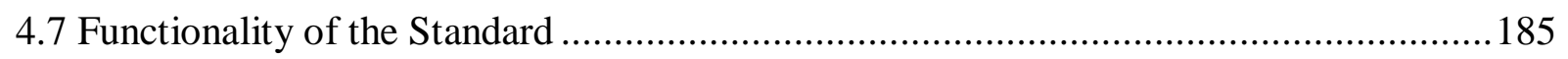

4.7.1 Most helpful Feature/Requirement of the ISO 14001:2004 Standard........................186

4.7.2 Least helpful Feature/Requirement of the ISO 14001:2004 Standard .......................194

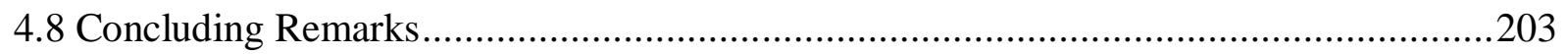

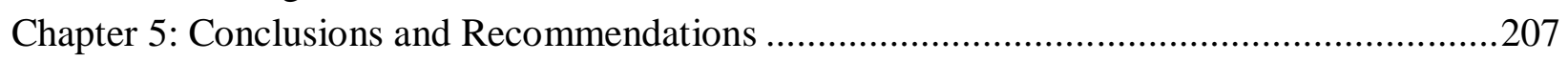

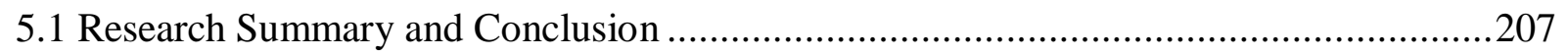

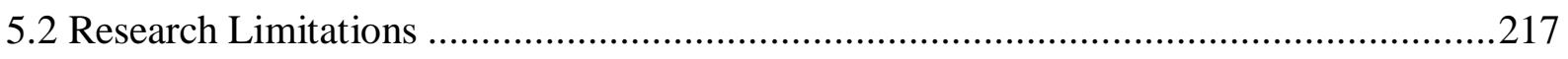

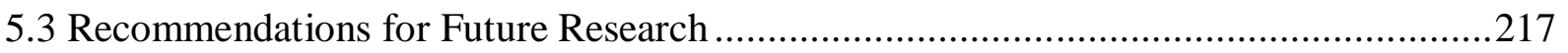

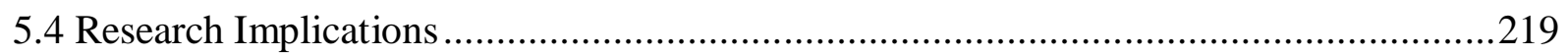

Appendix A: Research Instrument and Ethical Approval .....................................................221

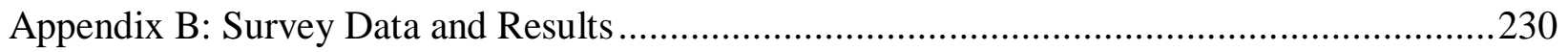




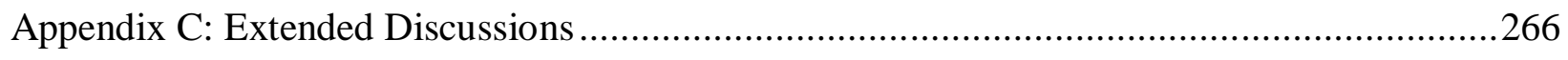

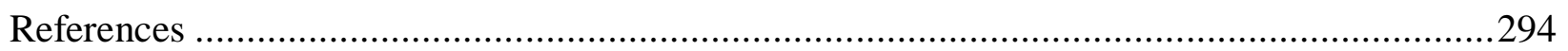




\section{List of Tables}

Table 2.1 Comparison of the structure between ISO 14001:2004 and ISO

14001:2015

Table 2.2 World top ten countries for ISO 14001 certificates in 2014 (Adapted

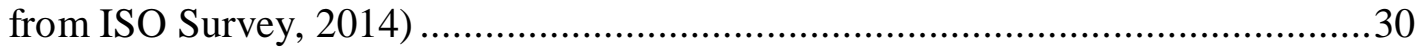

Table 2.3 Constructs and processes of organizational learning by Huber (1991)..................47

Table 2.4 The seven learning orientations and their learning approaches on a continuum (Adapted from DiBella and Nevis (1998)) .......................................53

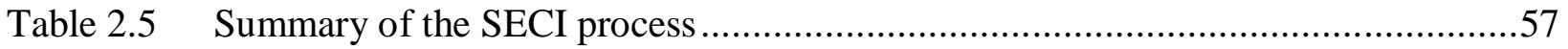

Table 4.1 Summary of responses regarding the ISO 14001 standard's ability to influence the four constructs based on individual scores

Table 4.2 Summary statistics regarding the ISO 14001 standard's ability to influence the four constructs based on amalgamated scores

Table 4.3 Summary statistics regarding the ISO 14001 standard's ability to influence the four constructs based on mean values

Table 4.4 Comparing the opinions of respondents from private and public sector organizations on the effect of ISO 14001 on the four constructs (using total scores of the four statements per respondent)....

Table 4.5 Comparing the opinions of respondents from private and public sector organizations on the effect of ISO 14001 on the four constructs (using mean values for each statement).

Table 4.6 Assessing the opinions of respondents from organizations of different sizes on the effect of ISO 14001 on the four constructs (using total scores for the four statements per respondent)

Table 4.7 Learning mechanisms/conditions that were brought about by the standard's ability to facilitate the four constructs of organizational learning

Table 4.8 Summary statistics regarding the ability of EMS-based software to facilitate the four constructs based on amalgamated scores. .164

Table 4.9 Learning mechanisms/conditions that were brought about by the ability of EMS-based software to facilitate the four constructs of organizational learning

Table 4.10 Summary of return on investment of EMS-based software 183 


\section{List of Figures}

Figure 2.1 Requirements of the ISO 14001:2004 standard and continual improvement

Figure 2.2 Total number of ISO 14001 certifications worldwide (Adapted from ISO Survey, 2014).

Figure 2.3 Total number of certifications in Canada and USA (Data obtained from

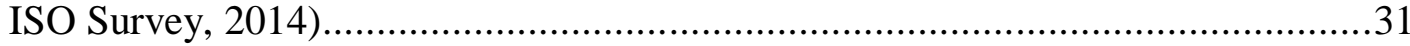

Figure 2.4 Senge's (2006) five disciplines of organizational learning ................................51

Figure 2.5 The building blocks of the learning organization by Garvin (1993) ....................52

Figure 2.6 Elements of the integrated approach and their relation to the learning cycle (Adapted from DiBella and Nevis (1998)) ...............................................54

Figure 2.7 The three stages of organizational learning as proposed by Daft and

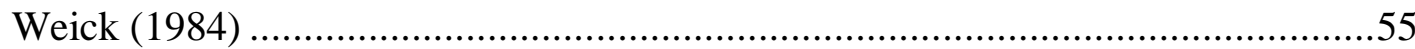

Figure 2.8 The three layers of the knowledge creation process (Adapted from Nonaka, Toyama, et al. (2001)) ..................................................................56

Figure 2.9 Single-loop and double-loop learning episodes of ISO 14001 (Adapted from Epstein and Roy $(1997))$.................................................................... 80

Figure 2.10 Requirements of the ISO 14001:2004 standard as they relate to Huber's (1991) four constructs of organizational learning ...............................91

Figure $3.1 \quad$ Research question diagram ................................................................ 114

Figure 4.1 Age of organizations that participated in this study ....................................133

Figure 4.2 Number of years that participating organizations were registered to ISO 14001:2004

Figure 4.3 Requirements of the ISO 14001:2004 standard that were found to facilitate Huber's (1991) four constructs of organizational learning

Figure 4.4 Features of EMS-based software that may assist with the implementation and maintenance of the ISO 14001 standard

Figure 4.5 Requirements/features of the ISO 14001:2004 standard that were found to be most helpful....

Figure 4.6 Requirements/features of the ISO 14001:2004 standard that were found to be least helpful 


\section{List of Appendices}

Appendix A: Research Instrument and Ethical Approval..............................................2221

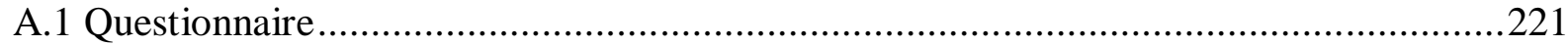

A.2 Proof of Ethical Approval ...............................................................................229

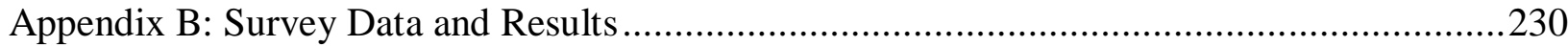

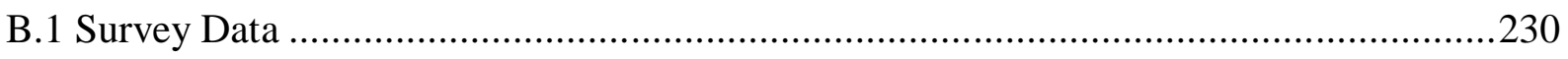

Table B.1 List of job titles of participants for this study ..........................................230

Table B.2 Industry sector based on raw data and number of organizations .....................231

Table B.3 NAICS industry sector and number of organizations ..............................231

Table B.4 Other management systems/standards used by participating

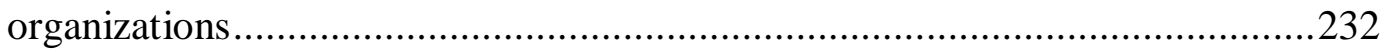

Figure B.1 Number of years spent by the respondents in their respective positions

Table B.5 Summary statistics regarding the ability of ISO 14001:2004 standard to influence organizational learning based on industry sector using total scores

Table B.6 Summary of descriptive data of the requirements/features of the standard that were found most helpful by respondents .

Table B.7 Summary of descriptive data of the requirements/features of the standard that were found least helpful by respondents ................................2235

B.2 Results .................................................................................................... 235

B.2.1 ISO 14001:2004 as a facilitator of Organizational Learning and in turn Environmental

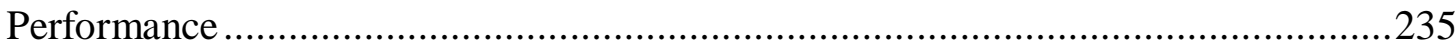

B.2.2 Software as a facilitator of Organizational Learning and in turn Environmental

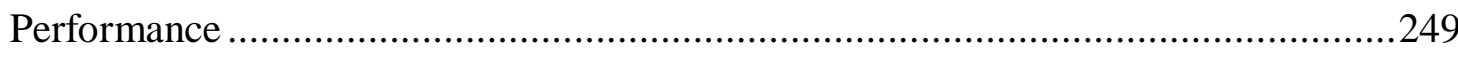

B.2.3 Functionality of the ISO 14001:2004 Standard..........................................253

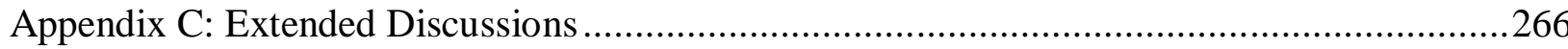

C.1 Requirements of the ISO 14001:2004 Standard .................................................266

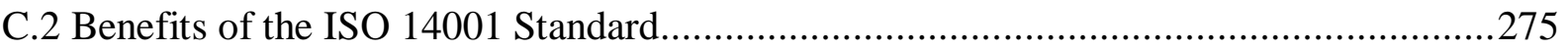

Table C.1 Summary of the benefits of the ISO 14001 standard and the

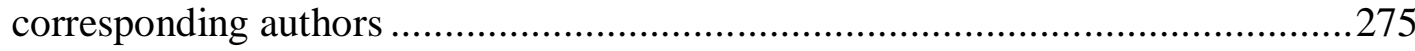

C. 3 Contributions from Scholars on Organizational Learning .....................................2277

C.3.1 Huber's (1991) Constructs and their Subconstructs .........................................277

C.3.2 Senge's (2006) Five Disciplines of a Learning Organization ...............................281

C.3.3 Garvin's (1993) Building Blocks of a Learning Organization................................283

C.3.4 The Learning Processes, Learning Orientations and Facilitating Factors by DiBella

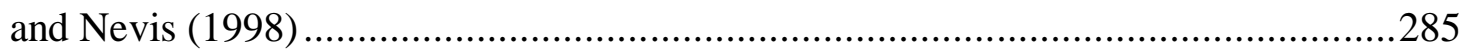

C.3.5 The Three Stages of Learning by Daft and Weick (1984) ...................................290

C.3.6 Knowledge Creation by Nonaka, Toyama, et al. (2001) .....................................290 


\section{Chapter 1: Introduction}

\subsection{Structure of the Dissertation}

The research dissertation is comprised of five chapters. In Chapter One, the objectives, methodology and research questions of the study are briefly set out; some basic information concerning the ISO 14001 standard, EMS-based software and organizational learning is provided; and the research motivation for the study is outlined. Chapter Two is a literature review and analysis of key elements of this thesis, comprising the following: a review of the ISO 14001 standard to include its requirements, changes incorporated into the new version (2015), its benefits and limitations; an overview of EMS-based software, its benefits and limitations; a review of the concepts of organizational learning and the learning organization; a review of the relationship between the ISO 14001 standard and organizational learning from a theoretical stand point; and a review of the relationship between information technology and EMS-based software, and organizational learning also from a theoretical stand point. Chapter Three sets out the research methodology. In Chapter Four, the results of the survey questionnaire are set out and examined. Chapter Five provides a summary of the thesis and conclusions.

\subsection{Background Information}

As noted above, some basic information concerning the ISO 14001 standard, EMS-based software and organizational learning is provided in this introductory chapter in order to give the reader the necessary background for the more detailed discussions that are included in the next chapters. Based on the data provided in the 2014 ISO Survey, the number of organizations worldwide that have adopted the ISO 14001 standard has increased from 13,994 (in 1999) to 324,184 (in 2014) with an increase of 7 percent between 2013 and 2014. The reason for its worldwide adoption may be due to the fact that globalization has caused environmental problems to move across national boundaries and onto the international stage (Huang \& Shih, 2009), thus leading to organizations searching for environmental management guidance that is considered acceptable on a global level. Other reasons may be due to the pressure from regulators, the increase in financial performance that may arise from marketing green products, and the increase in awareness of the general public on environmental issues (Burström, 2002). The ISO 14001 standard is a voluntary international standard that was developed by the International 
Organization for Standardization (ISO) in 1996 (ISO 14001:2004) with its latest revision published in 2015 (www.iso.org). It was developed to assist organizations in setting up their environmental management system (EMS) (Montabon, Melnyk, Sroufe, \& Calantone, 2000) with the hope that it will lead to the improvement in environmental performance (Potoski \& Prakash, 2005). According to wording in the standard, the development of the EMS and the improvement in environmental performance is intended to lead to improved protection of the environment and the prevention of pollution (ISO 14001:2004). The standard attempts to achieve its goals by focusing on management commitment, continuous improvement, the training of staff, establishing preventive and corrective actions (Liyin, Hong, \& Griffith, 2006; Montabon et al., 2000; Reverdy, 2007) and a host of other elements. The standard is said to enable the organization to integrate environmental issues with the daily activities of the organization (Reverdy, 2007).

As suggested by some authors, many organizations tend to adopt the ISO 14001 standard just for the sake of getting registered or to meet customer or client demands (Burström, 2002; Epstein \& Roy, 1997), and therefore fail to fully integrate the standard into their organization as a method of managing corporate environmental impacts (Epstein \& Roy, 1997). In doing so, organizations tend to overlook the potential of such management systems standards to contribute to their overall corporate management goals. One such potential is their ability to be used as mechanisms to enhance the process of organizational learning (that is, the organization's capacity to learn), which in turn enhances the organization's competitive advantage (Burström, 2002; Epstein \& Roy, 1997). Organizational learning is a process that enables organizations to establish competencies that are hard to imitate, and serves as a means for organizations to enhance innovation and to improve their performance (DiBella, Nevis, \& Gould, 1996; Fiol \& Lyes, 1985; Real, Leal, \& Roldán, 2006). It “emphasizes managerial vision, leadership, communication, and teamwork within human systems" (Robey, Boudreau, \& Rose, 2000, p. 127), and is of importance, especially because of the ever changing environment in which organizations find themselves (Kloot, 1997). When organizations learn, they are in a better position to adapt to the rapid changes in their environment (Huber, 1991), and in turn more likely to survive (Kloot, 1997). Organizational learning "requires that structures and strategies are uncoupled from existing paradigms and recoupled to new ones" (Kloot, 1997, p. 48). It therefore 
requires a change in behaviour by members of an organization, which is important because learning to a certain degree entails a permanent change in the organization's behavior (Burström, 2002). The use of EMS standards such as ISO 14001 could assist in this change. In addition to the implementation of EMS standards as a way of encouraging organizational learning, some of the other ways in which organizational learning is promoted in organizations include developing training programs, hiring knowledgeable staff, the use of information technology, and putting in place a research and development department that explores environmental performance issues (Kane \& Alavi, 2007).

With respect to the use of environmental management systems standards as a learning mechanism, some authors have suggested that the ISO 14001 environmental management systems standard can contribute to the capacity of an organization to learn by creating systems and processes that assist learning activities (Burström, 2002; Epstein \& Roy, 1997; Petts, Herd, \& O’heocha, 1998; Roelker-Denker, 2011). For instance, the ISO 14001 standard through some of its requirements can facilitate the training of employees, the promotion of awareness, the quick and efficient distribution of knowledge and exchange of ideas which all contribute to the learning process of an organization. Also, the single-loop and double-loop learning characteristics used by Argyris and Schön (1978) to describe learning episodes are said to be manifested during the implementation and management of the ISO 14001 environmental management system standard (Epstein \& Roy, 1997; Roelker-Denker, 2011). Furthermore, an environmental management system is said to bring to bear a few of the attributes found in a learning organization such as "making people (managers and non-management) accountable and responsible for their actions; providing support to the development of knowledge, capabilities and skills including through training; and stressing the need for commitment to the performance objectives by everyone" (Petts et al., 1998, p. 717). The implementation of the standard also helps facilitate the creation and distribution of knowledge as well as facilitate the coordination between the environmental department and other departments within the organization (Reverdy, 2007). The position that the ISO 14001 environmental management systems standard can serve as a learning mechanism for organizations is also supported by the description for an organizational learning mechanism (OLM) as "institutionalized structural and procedural arrangements that allow organizations to systematically collect, analyze, store, disseminate, and 
use information that is relevant to the effectiveness of the organization" (Lipshitz, Popper, \& Oz, 1996, p. 293). On a different note, it is also suggested that such standards may not stimulate learning, especially double-loop learning because they are said to be too formal in structure, too prescriptive especially for the public sector (Burström, 2002; Strachan, 1997), facilitate a centralized organizational structure that is said to not favor learning (Moxen \& Strachan, 2000; Strachan, 1997), and lead to an increase in bureaucracy within the organization (Boiral, 2002; Reverdy, 2007).

As is the case with management systems standards, some authors also suggest that information technology (IT) in the form of computer-aided systems (CAS), information systems, and so forth, have positive effects on organizational learning (Goodman \& Darr, 1998; Kane \& Alavi, 2007; Moynihan \& Landuyt, 2009; Robey et al., 2000; Ruiz-Mercader, Merono-Cerdan, \& Sabater-Sanchez, 2006; Tippins \& Sohi, 2003). However, a less studied perspective pertains to the inter-relation between environmental management systems software (EMS-based software) and organizational learning, and the functionality of such software products. Specifically, does ISO 14001 environmental management systems software have the ability to enhance organizational learning as well as the necessary features to assist organizations in meeting the terms of the standard? Robey et al. (2000) argue that information technology has the capability to support organizational learning because it is able to facilitate the four constructs of organizational learning: information acquisition, information dissemination, shared interpretation (when members of an organization have a consensus on the meaning of information disseminated to them) and organizational memory. This notion is supported by the study conducted by Tippins and Sohi (2003), in which it was suggested that information technology is positively related to organizational learning because it provides the necessary mechanisms for achieving the four constructs of organizational learning. As is the case with the ISO 14001 standard, information technology may also facilitate single-loop and double-loop learning in an organization and thus enhance the learning process (Kane \& Alavi, 2007). Information technology also has the ability to promote learning because it helps facilitate communication (Goodman \& Darr, 1998; Real et al., 2006; Robey et al., 2000; Senge, 2006), reflection, and the training of employees (Real et al., 2006). Again, as with most new projects, the implementation of a new information technology system may also promote learning (Pentland, 1995). 
Furthermore, following the description of an organizational learning mechanism (OLM) provided earlier, information technology can also be characterized as a learning mechanism for organizations (Moynihan \& Landyut, 2009). Finally, with respect to knowledge and its creation within an organization, information technology may serve as a means to facilitate knowledge creation by assisting with the processes of socialization (sharing of tacit knowledge), externalization (conversion of tacit knowledge to explicit knowledge), combination (conversion of explicit knowledge to more complex explicit knowledge), and internalization (conversion of explicit knowledge to tacit knowledge) (Nonaka, Reinmoller \& Toyama, 2001; Real et al., 2006). As with the ISO 14001 standard, information technology may also be a barrier to learning (Gill, 1995; Pawlowsky, Forslin, \& Reinhardt, 2001; Robey et al., 2000). For instance, the ability of an organization to scan and interpret information from its external environment may become limited when information technology is used to replace certain roles played by humans over time (Gill, 1995).

Apart from the financial benefits that a learning organization stands to gain (Day, 1994b; Slater \& Narver, 1995), the need for organizations to learn is even more pressing given the increasingly complex nature of issues that requires one to integrate ecological, technological, economic, social and cultural aspects of societal development (Burström, 2002; Strachan, 1997). Furthermore, the learning process within an organization ought not to occur by chance but should be intentionally put in place with the goal of improving performance (Crossan, Lane, White, \& Djurfeldt, 1995) As such, the subject of the use of the ISO 14001 standard and EMSbased software as a learning strategy is deserving of further investigation.

There have also been articles suggesting that specialized software packages (environmental management systems software inclusive) have features that can assist organizations with the implementation and maintenance of management systems/standards (Gidwani, 2015; Global Environment and Technology Foundation, 2004; Ismail, 2012; Leavoy \& Waggott, n.d.), however, for the most part such articles can be characterized as industry promotional projects or white papers. One study does highlight the fact that not all EMS-based software products have the ability to assist organizations as some were too prescriptive, unadaptable to the unique needs of organizations, have a complicated user interface, and do not address all the requirements of 
the standard (Global Environment and Technology Foundation, 2004). Another study suggests that software management system tools cannot be easily integrated with other software products being used by organizations (Gidwani, 2015). Furthermore, specialized software products are said to be segmented because they do not provide a one-stop solution that covers a wide variety of management processes in an organization such as health and safety, risk management and so on (Alnes, Economides, Kong, \& Peyraud, 2014). For these reasons and others, the market for these products is considered by some scholars to be segmented and not yet mature enough with respect to the developers (vendors) and the users of such software (e.g., Leif, 2014). Users of these products are said to be not mature enough because they do not seek software that has the ability to fulfill most of their organization's needs (Leif, 2014). With this in mind, users are advised to examine the functional coverage and technical capabilities of such software products before they decide to purchase them (Alnes et al., 2014; Leif, 2014). Also, it has been suggested that vendors need to evaluate their products and determine how they can make them more functional for users, by, for example working closely with them (Argent \& Grayson, 2001). While acknowledging these potential limitations, it is suggested that robust environmental management systems and standards can be maintained with the assistance of EMS-based software products (Global Environment and Technology Foundation, 2004; Ismail, 2012; Leavoy \& Waggott, n.d.). There has been an increase in the use of such software products, which is said to be due in part to the ever increasing and changing regulations, and the need for organizations to be compliant to such regulations (Leif, 2014) as well as the fact that many organizations are striving to improve their environmental performance (Alnes, et al., 2014).

For this study, the software products under examination will be referred to as EMS-based software. These are software packages specifically designed to assist organizations with the implementation and maintenance of some or all of the requirements and features of the ISO 14001 standard or environmental management system. Software that is used to assist with management systems on the whole (environmental management systems inclusive) in areas such as quality, health and safety, and corporate social responsibility will be referred to as specialized or customized software in this dissertation. A few definitions/descriptions of such software products as mentioned in some articles are presented as follows: Leif (2014) describes such products with respect to environmental management as software used "for managing the 
processes and generating the reports necessary to comply with environmental regulations, such as the U.S. Environmental Protection Agency's (EPA’s) Title V (Clean Air Act)” (p. 1). In some cases, they are referred to as off-the-shelf software products that are "specifically designed to support an organization's development, implementation, and subsequent management of its EMS" (Global Environment and Technology Foundation, 2004, p. 2). Finally, such software products are also said to be "solutions that support the process of collecting, tracking, reporting and analyzing CSR data" (Alnes et al., 2014, p. 2). However, for this research, the emphasis is on environmental management and not the broader field of corporate social responsibility (CSR).

The ISO 14001 standard, despite its many benefits such as improving stakeholder relations, corporate image, internal procedures, environmental performance, and market share (Poksinska, Dahlgaard, \& Eklund, 2003), has been said to have its share of limitations. For instance, it is said that it may not necessarily lead to an improvement in environmental performance because its requirements are too broad and not strict enough, and the fact that it is not a performance standard (Bansal \& Bognar, 2002). Also, organizations are said to face difficulties when implementing some of the elements and requirements of the standard, some of which include obtaining commitment from top management (Psomas, Fotopoulos, \& Kafetzopoulos, 2011), obtaining adequate resources (Liyin et al., 2006), and the requirements for documentation, identification of aspects and impacts, and training (Poksinska et al., 2003; Psomas et al., 2011). Organizations were also found to have difficulties understanding the standard's language (Christensen \& Rasmussen, 1998). On the other hand, certain factors or requirements were said to facilitate the success of the standard's implementation such as the identification of environmental aspects, employee training, commitment from top management (Poksinska et al., 2003), and employee participation (Carlsson \& Carlsson, 1996). As such, it was also of interest to examine the experiences of users of the standard in North America and to determine what changes the standard may require to make it more functional for them.

\subsection{Research Motivation}

As evidenced in the literature, the ISO 14001 standard serves as a guideline for the implementation and maintenance of an organization's environmental management system with the end goal being to improve the organization's environmental performance. Also, an 
organization that learns has the potential to improve its performance, its competitive advantage, and its profitability. Furthermore, a few scholars have suggested that the standard through some of its requirements/elements has the ability to enhance learning as well as the ability to hinder learning. However, theoretical and empirical research on this topic is rather limited. As such, it was of value to investigate whether or not the widely adopted ISO 14001 standard through its requirements has the ability to play a broader role beyond compliance, that is, to enhance learning in an organization. Also, given the divergent views on the concept of organizational learning, the research undertaken here attempts to understand whether the standard could facilitate learning based on the contributions from different scholars in the field of organizational learning. Despite the many claimed benefits of ISO 14001, the standard is also said to have a number of limitations, and it has come under criticism from scholars and practitioners alike. With this in mind, the undertaking of research to understand what challenges users may be facing was of value as a possible foundation for suggestions concerning how improvements could be made to the standard.

EMS-based software products are being promoted as the way forward for organizations to facilitate the implementation and maintenance of the environmental management system/standard and thus improve their environmental performance. Available research that is said to confirm whether such software products actually provide the benefits as claimed by their developers are mainly in the form of white papers and industry promotional projects. Bearing this in mind, it was felt that further investigation concerning whether or not EMS-based software can be of value to an organization would be of value. In order for this to be achievable, the author of this thesis decided that research would need to evaluate the features of the software in order to determine if they meet the needs of the user in terms of implementing and maintaining the standard, obtain suggestions for improvement, determine whether the software is user friendly, and determine whether they pay for themselves. Given the high cost of EMS-based software, the latter point is of value because it could be the determining factor as to whether a company purchases the software or not. Also, as discussed elsewhere in this thesis, it has been suggested in the literature that information technology (including software) could play a vital role with respect to enhancing organizational learning. However, research studies on the possible role that EMS-based software may play in this regard is lacking. As such, it was also of interest 
to investigate whether EMS-based software has the ability to enhance learning in an organization.

Although learning is seen by many as an important goal for organizations, what makes learning particularly useful for an organization is whether it can be translated into an improvement in performance, be it environmental, financial, or concerning internal processes. As such, exploring whether learning that is facilitated by the standard and EMS-based software can lead to an improvement in performance (as perceived by the users) was also considered a useful underlying goal of the research.

Finally, the fact that the research area has immediate practical implications for the field of environmental management and the welfare of the environment and the public on the whole is another reason why the research undertaken here on this topic has been pursued. This is so because the findings can potentially be utilized by organizations that use the standard and the software and it can potentially be of value for the organizations that develop such standards and software with the end goal being improved standards and software and the reduction of the environmental impact of an organization's activities, products, and services. Furthermore, from a scholarly standpoint, given the complex nature of environmental problems and the importance of learning and the potential role it can play in helping solve such problems, the need to shed more light on the nature of organizational learning in environmental contexts is also considered a valuable aim.

\subsection{Research Objectives}

A major objective of this research was to explore the organizational learning capabilities of the ISO 14001 environmental management systems standard and environmental management systems software. In order to meet this objective, research questions were formulated. With respect to the ability of the standard to enhance organizational learning, the research question that was formulated is as follows:

Q1: Does the ISO 14001 environmental management systems standard have the ability to facilitate the acquisition, distribution, interpretation, and storage of useful environmental information and therefore contribute to organizational learning? 
With respect to the ability of EMS-based software to enhance organizational learning, the research question that was formulated is as follows:

Q2: Do environmental management systems software packages have the ability to facilitate the acquisition, distribution, interpretation, and storage of useful environmental information and therefore contribute to organizational learning?

The research study also aimed to gain insights as to whether the standard and EMS-based software in facilitating the four constructs of organizational learning, could lead to an improvement in performance within the organization. As such, the respondents were asked the following questions:

1.) If you are of the opinion that the standard leads to improved acquisition of useful information, could you comment on how this improvement affected organizational learning that influenced performance within your organization?

2.) If you are of the opinion that the software leads to improved acquisition of useful information, could you comment on how this improvement affected organizational learning that influenced performance within your organization?

The same question above was asked with respect to information dissemination, information interpretation, and organizational memory. The questions also served as follow-up questions to research questions Q1 and Q2 above.

Also, in order to gain an understanding of the experiences of organizations that have adopted the standard, a secondary goal of this research was to better understand which requirements/elements of the standard users found most and least helpful and why. As such respondents were asked the following questions:

1.) What would you say is the most helpful feature/requirement of the ISO 14001 standard? Please could you briefly explain why you found this feature/requirement most helpful?

2.) What would you say is the least helpful feature/requirement of the ISO 14001 standard? Please could you briefly explain why you found this feature/requirement least helpful? 
The study also aimed to gain insights with respect to the integration of environmental management systems with other management systems such as quality management systems. Another objective of this research was to explore whether environmental management systems software (information technology or IT) packages have the features needed to assist firms in meeting the terms of environmental management systems standards. In other words, do EMSbased software have features that assist with documentation, auditing, training management and a host of others. In order to determine the aforementioned, the following research question was formulated:

Q3: Do environmental management systems software products have the necessary features that enable them to assist organizations in implementing and maintaining the ISO 14001 management system standard?

The study also aimed to understand the user's experiences with such software products. In order to do so respondents were asked the following questions:

1.) What would you say is the most helpful feature of the software in terms of its ability to assist you in meeting the requirements of the ISO 14001 standard? Please could you briefly explain why you found this feature most helpful?

2.) In your opinion what is the least helpful feature of the software in terms of its ability to assist you in meeting the requirements of the ISO 14001 standard? Please could you briefly explain why you found this feature least helpful?

Other questions explored the changes users thought should be made in order to improve the functionality of such software products, how easy or difficult it was to implement the software, and whether the software provided a return on investment (ROI). Finally, the study was also intended to further contribute to the literature on the linkages between both environmental management system standards and information technology (software) and organizational learning.

In order to achieve the objectives of this research study as mentioned above, a questionnaire with closed-ended statements and open-ended questions was designed. The questionnaire is presented in appendix A. Organizations that had their EMS certified to the ISO 14001 standard as well as 
those that used EMS-based software were the primary targets of this research study. However, for this study, not all the organizations that were certified to ISO 14001 used EMS-based software. Employees (e.g., environmental managers, environmental directors, etc.) that were most likely to work with ISO 14001 and EMS-based software were requested to fill out the questionnaire. The questionnaire was sent out to the respondents primarily by email. A total of 76 ISO 14001 registered organizations participated in this study. Some of the limitations of the study include the likelihood that the sample frame may not be representative of the entire target population because of the fact that nonprobability sampling was used to select the sample frame, and due to the low response to the survey; the fact that only one respondent per organization was surveyed, and as such, this could lead to a limited account of the phenomena being studied; and the fact that it was a cross sectional study which implies that it will not be able to determine whether the implementation of the standard and EMS-based software could lead to an improvement in organizational learning over time. Also, the research study did not directly measure organizational learning nor performance, but rather obtained the perceptions of respondents with respect to whether the standard has the ability to influence the aforementioned four constructs of organizational learning in the organizations for which they worked, and whether performance was enhanced or not by an improvement in organizational learning.

With this background, we are now in a position to begin the more in-depth exploration of the above subjects in the following chapters. 


\section{Chapter 2: Literature Review and Theoretical Analysis}

This chapter is comprised of three parts. In Part 1, a literature review on environmental management systems, the ISO 14001 standard and EMS-based software is presented. In Part 2, a literature review on organizational learning is provided. In Part 3, background information presented in Part 1 and Part 2 as well as from the extant literature are used to present a discussion on the potential relationship between the ISO 14001 standard and organizational learning, and EMS-based software and organizational learning. The chapter ends with concluding remarks.

\section{Part 1}

2.1 Literature Review on Environmental Management Systems, the ISO 14001 Standard and EMS-based Software

\subsubsection{Environmental Management Systems}

The number of organizations that are using an environmental management system has increased over the years as evidenced by the number of organizations that have adopted voluntary tools such as ISO 14001 (see Figure 2.2). This may be due to the diminishing returns associated with simply complying with command and control regulations (Fiorino, 1999; Potoski \& Prakash, 2005), such that organizations are looking for guidance which extends beyond regulatory compliance. On the one hand, some organizations complain that the cost of compliance to regulations is high, which in turn is said to negatively affect productivity and profits (Jaffe, Peterson, Portney, \& Stavins, 1995; Walley \& Whitehead, 1994). On the other hand, regulators complain that the command and control process is resource and enforcement intensive, which in turn affects the frequency and efficiency of their monitoring process. The latter issue has been made more difficult in situations where there is a decrease in government agency budgets (Henriques \& Sadorsky, 2008; Webb, 2004; Wood \& Waterman, 1993 ).

An environmental management system forms part of an organization's overall management system and is used by organizations to systematically, efficiently, and effectively manage their environmental issues (Bansal \& Bognar, 2002; Kirkland \& Thompson, 2002). The EMS guides organizations on how to set up their structure, assign roles and responsibilities, and develop 
practices, procedures, processes and assign resources, which in turn enables the organization to practice good environmental management (Bansal \& Bognar, 2002).

Several environmental voluntary tools/standards are available to assist organizations in implementing and maintaining their EMS. They include the British standard (BS7750), the European Union Eco-Management and Audit Scheme (EMAS), and the International Organization for Standardization's (ISO) international environmental standard (ISO 14001). There are industry specific standards such as Responsible Care developed by the chemical sector (Bansal \& Bognar, 2002). However, given its widespread use, for this study the ISO 14001 international standard is the focus of attention.

An environmental management system is said to assist organizations in reducing or controlling the organization's environmental impacts (Bansal \& Bognar, 2002; da Silva \& de Medeiros, 2004; Psomas et al., 2011) and at the same time reduce cost or enhance productivity (Bansal $\&$ Bognar, 2002). The lower costs are said to arise from improvements such as source reductions, process intensification, and improved waste management. The suggestion has been made that the reductions in cost may outweigh the cost of implementing the EMS thereby leading to a win-win situation for the organization and the environment as a whole (Bansal \& Bognar, 2002). Organizations that have an EMS are also said to be less prone to liabilities because it enables them to identify new environmental impacts that may have been missed in the past. The EMS also facilitates the integration of environmental management into the overall management system of the firm (Psomas et al., 2011). It prompts organizations to not only comply with regulations but to ensure that they are up to date with changes to such regulations (Bansal \& Bognar, 2002; Psomas et al., 2011) and up to date with the latest technology and know-how. As such, should regulations change drastically, organizations will not have to make extensive alterations to their processes unlike their counterparts that just comply with regulations alone (Bansal \& Bognar, 2002). Finally, an environmental management system may facilitate the sharing of new knowledge across departments (Bansal \& Bognar, 2002; Darnall, Henriques, \& Sadorsky, 2008), encourage team work (Darnall et al., 2008), and serve as a means for organizations to obtain technical knowledge from stakeholders (Henriques and Sadorsky, 2008), and thus could promote learning within the organization. However, despite the benefits mentioned above, it is still 
uncertain as to whether there is a relationship between environmental management systems and environmental performance and most especially economic performance as the determination of both relationships is said to be complicated (Darnall et al., 2008; Schaltegger \& Synnestvedt, 2002; Schylander \& Martinuzzi, 2007; Wagner, Schaltegger, \& Wehrmeyer, 2001).

\subsubsection{The ISO 14001 Environmental Management Systems Standard}

\subsubsection{Overview}

The ISO 14001 standard is a voluntary international standard that was developed by the International Organization for Standardization (ISO) in 1996 (Bansal \& Bognar, 2002; ISO 14001:2004; Poksinska et al., 2003; Potoski \& Prakash, 2005; Psomas et al., 2011). It was first revised in 2004 (ISO 14001:2004; Psomas et al., 2011), and again in 2015 (BSI group, 2015; Www.iso.org).

According to an article prepared by the BSI Group (2015), the major difference between the new and old version is the structure. The new version has the high level structure that will apply to all ISO management systems standards in the future. As a result of this change, ISO 14001:2015 has 10 clauses in comparison to the 4 clauses in ISO 14001:2004, with the sub-clauses in clause 4 of the 2004 version being redistributed amongst the 10 clauses (BSI Group, 2015). The change in structure was said to be done so that ISO 14001 can be easily aligned with other ISO standards that have the same high level structure (BSI Group, 2015; ISO, 2015). Some of the other main changes as mentioned in the article include the addition of two new requirements, namely, the determination of the organization's context, and the determination of the risks and opportunities that are relevant to the organization; the making of leadership and top management's role, and the determination of the needs and expectations of interested parties clauses of their own; the non-usage of the term preventive action; the combination of the requirements, documentation, control of documents, and control of records under a new term called documented information; and the change of the term legal and other requirements to compliance obligations: legal and other requirements is said to be also captured under the clause, context of the organization (BSI Group, 2015). 
With respect to the requirement to understand the organization and its context, the organization is required to determine the internal and external issues that affect its ability to achieve the overall objective of the EMS (BSI Group, 2015). This is to include not only the organization's activities, products, and services that affect the environment, but also the factors that could affect the organization in itself, such as pre-existing land contamination, adverse weather conditions, and so on. With respect to the requirement to identify risks and opportunities, the organization is to take a broader approach to risk management to include identification of aspects and impacts. The risks can be seen as having a positive or negative effect on the environment. The determination of the organization's context and its relevant risks and opportunities is said to incorporate the former requirement to identify preventive actions, hence its removal. Furthermore, the standard in itself is to be seen as a preventive measure especially now that it places a lot of emphasis on risk assessment and management (BSI Group, 2015).

With respect to the change of the term "legal and other requirements", the 2015 version of the standard states that the

phrase "compliance obligations" replaces the phrase "legal requirements and other requirements to which the organization subscribes" used in the previous edition of this International Standard. The intent of this new phrase does not differ from that of the previous edition. (ISO 14001:2015, Annex A, p. 19)

Also, in trying to clarify the use of the new term "documented information" as well as the use of the former terms, records and documentation, the 2015 version of the standard states that documented information now replaces the nouns "documentation", "documents" and "records" used in previous editions of this International Standard. To distinguish the intent of the generic term "documented information", this International Standard now uses the phrase "retain documented information as evidence of...." to mean records, and "maintain documented 
information" to mean documentation other than records. (ISO 14001:2015, Annex A, p.

Also, the new version of the standard no longer refers to the terms environmental targets and management representative (www.praxiom.com). However, "the concept of 'target' used in previous editions of this international standard is captured within the term 'environmental objectives"' (ISO 14001:2015, Annex A, p. 20), and can be used to determine if the organization has achieved its environmental objectives (ISO 14004:2016), and top management is still required to assign environmental duties and responsibilities to one or more persons in the organization (ISO 14001:2015; ISO 14004:2016; www.praxiom.com). The new version is also said to place a stronger emphasis on performance (BSI Group, 2015) and to have a focus on lifecycle thinking, in which the development and end-of-life stages of products and services are taken into consideration (ISO, 2015). Although organizations can now be certified to the new version of the standard, those that currently have the ISO 14001:2004 certification have 3 years from the date of the final publication (which was September 2015) to transition to the new version (ISO, 2015).

Table 2.1 Comparison of the structure between ISO 14001:2004 and ISO 14001:2015

\begin{tabular}{|c|c|}
\hline 2004 & 2015 \\
\hline 1. $\quad$ Scope & 1. $\quad$ Scope \\
\hline 2. $\quad$ Normative references & 2. $\quad$ Normative references \\
\hline 3. $\quad$ Terms and definitions & 3. $\quad$ Terms and definitions \\
\hline $\begin{array}{ll}\text { 4. Environmental management system } \\
\text { requirements }\end{array}$ & 4. Context of the organization \\
\hline 4.1 $\quad$ General requirements & $\begin{array}{l}\text { 4.1 Understanding the organization and its } \\
\text { context }\end{array}$ \\
\hline 4.2 $\quad$ Environmental policy & $\begin{array}{ll}4.2 & \text { Understanding the needs and } \\
& \text { expectations of interested parties }\end{array}$ \\
\hline 4.3 Planning & $\begin{array}{l}\text { 4.3 Determining the scope of the } \\
\text { environmental management system }\end{array}$ \\
\hline 4.3.1 Environmental aspects & 4.4 Environmental management system \\
\hline 4.3.2 Legal and other requirements & 5. $\quad$ Leadership \\
\hline 4.3.3 Objectives, targets and programs & 5.1 Leadership and commitment \\
\hline $4.4 \quad$ Implementation and operation & 5.2 Environmental policy \\
\hline $\begin{array}{l}\text { 4.4.1 Resources, roles, responsibilities and } \\
\text { authority }\end{array}$ & $\begin{array}{l}\text { 5.3 Organizational roles, responsibilities } \\
\text { and authorities }\end{array}$ \\
\hline
\end{tabular}


Table 2.1 Continued

\begin{tabular}{|c|c|}
\hline 2004 & 2015 \\
\hline 4.4.2 Competence, training and awareness & 6. $\quad$ Planning \\
\hline 4.4.3 Communication & $\begin{array}{ll}6.1 & \text { Actions to address risks and } \\
\text { opportunities }\end{array}$ \\
\hline 4.4.4 Documentation & 6.1.1 General \\
\hline 4.4.5 Control of documents & 6.1.2 Environmental aspects \\
\hline 4.4.6 Operational control & 6.1.3 Compliance obligations \\
\hline 4.4.7 Emergency preparedness and response & 6.1.4 Planning action \\
\hline 4.5 Checking & $\begin{array}{l}\text { 6.2 Environmental objectives and planning } \\
\text { to achieve them }\end{array}$ \\
\hline 4.5.1 Monitoring and measurement & 6.2.1 Environmental objectives \\
\hline 4.5.2 Evaluation of compliance & $\begin{array}{l}\text { 6.2.2 Planning actions to achieve } \\
\text { environmental objectives }\end{array}$ \\
\hline $\begin{array}{l}\text { 4.5.3 Nonconformity, corrective action and } \\
\text { preventive action }\end{array}$ & 7. $\quad$ Support \\
\hline 4.5.4 Control of records & 7.1 Resources \\
\hline 4.5.5 Internal audit & 7.2 Competence \\
\hline 4.6 Management review & 7.3 Awareness \\
\hline & 7.4 Communication \\
\hline & 7.4.1 General \\
\hline & 7.4.2 Internal communication \\
\hline & 7.4.3 External communication \\
\hline & 7.5 Documented information \\
\hline & 7.5.1 General \\
\hline & 7.5.2 Creating and updating \\
\hline & 7.5.3 Control of documented information \\
\hline & 8. $\quad$ Operation \\
\hline & 8.1 Operational planning and control \\
\hline & 8.2 Emergency preparedness and response \\
\hline & 9. $\quad$ Performance evaluation \\
\hline & $\begin{array}{ll}9.1 & \begin{array}{l}\text { Monitoring, measurement, analysis and } \\
\text { evaluation }\end{array} \\
\end{array}$ \\
\hline & 9.1 .1 General \\
\hline & 9.1.2 Evaluation of compliance \\
\hline & 9.2 Internal audit \\
\hline & 9.2.1 General \\
\hline & 9.2.2 Internal audit program \\
\hline & 9.3 Management review \\
\hline & 10. Improvement \\
\hline & 10.1 General \\
\hline & 10.2 Nonconformity and corrective action \\
\hline & 10.3 Continual improvement \\
\hline
\end{tabular}

Since the changes to the 2004 version of the standard do not have any significant effect on the underlying goals and outcomes of this study, the ISO 14001:2004 version will still be referred to 
in this dissertation. Furthermore, it was in use at the time when the survey for this research was conducted and as such, the responses obtained from participants was based on the 2004 version.

The main aim of the ISO 14001:2004 standard is to "support environmental protection and pollution prevention in balance with socio-economic needs", and it applies "to all types and sizes of organization(s) and to accommodate diverse geographical, cultural and social conditions" (ISO 14001:2004, p. v). It was also developed in the hope that it would unify environmental practices on an international level and therefore reduce the problems associated with having to deal with conflicting national environmental requirements (Montabon et al., 2000). ISO 14001 is the only standard of the ISO 14000 series of standards and guidelines to which organizations can be registered. Nevertheless, the other ISO 14000 standards and guidelines, which cover areas such as environmental auditing (ISO 19011), environmental labeling and declarations (14020 \& 14021), environmental performance evaluation (ISO 14031), life-cycle assessment (14040-43, 14048-49), environmental aspects with respect to product standards (ISO Guide 64, ) and greenhouse gas management (ISO 14064 parts 1, 2 and 3) do serve as supporting tools for the implementation and maintenance of an organization's EMS (ISO, 2009; Epstein \& Roy, 1997). Together they can provide environmental and economic benefits such as a decrease in the use of raw materials/resources, a decrease in energy consumption, an improvement in the efficiency of processes, waste reduction leading to a reduction in disposal costs, and the reuse of recoverable resources. They help firms take a proactive approach to managing their environmental impacts and serve as a reflection of an organization's good environmental management practices (ISO, 2009).

Organizations use the standard as a guideline on how to set up the elements of an effective EMS (Montabon et al., 2000; Psomas et al., 2011) and involves developing an environmental policy, setting objectives and targets, putting programs in place to meet the objectives and targets, monitoring and measuring the effectiveness of the programs, correcting problems if they arise, and reviewing the entire EMS in order to improve on it where necessary (Liyin et al., 2006; Montabon et al., 2000; Psomas et al., 2011; Tibor \& Feldman, 1996). As with an environmental management system, the ISO 14001 standard serves as a guide for organizations on how to set up their organizational structure; undertake planning activities; determine roles, responsibilities 
and resources; and develop procedures, practices and processes, which are all required in order to implement and maintain their environmental policy (Marimon, Heras, \& Casadesus, 2009; Psomas et al., 2011). However, it is not clear whether the reasons for adoption of the standard by firms is in line with the original intentions of its developers (Chavan, 2005; Psomas et al., 2011).

An organization may decide to get its environmental management system certified to the standard by a third party (registrar) or it may simply declare to the public that it follows the guidelines of the standard (Bansal \& Bognar, 2002; Montabon et al., 2000; Poksinska et al., 2003; Potoski \& Prakash, 2005; Psomas et al., 2011). Also, the entire organization or a facility or a unit/department can be registered to the standard (Bansal \& Bognar, 2002; Montabon et al., 2000).

It is important to note that ISO 14001:2004 does not focus on performance improvement but rather on improving management processes (Bansal \& Bognar, 2002; Montabon et al., 2000; Poksinska et al., 2003; Psomas et al., 2011). In other words it does not focus on outcomes (Bansal \& Bognar, 2002; Montabon et al., 2000), for example, specific pollutants, but on processes (Montabon et al., 2000): its primary focus is on continual improvement (Bansal \& Bognar, 2002; Chavan, 2005; Psomas et al., 2011). It is felt that better environmental management will translate into better environmental performance (Potoski \& Prakash, 2005; Tibor \& Feldman, 1996). As such, if an organization is able to meet the requirements of the standard, its environmental performance should invariably improve (Bansal \& Bognar, 2002; Montabon et al., 2000). However, Poksinska et al. (2003) state that certification will not necessarily lead to improved performance but that the standard does serve as evidence for an organization's customers that they are practicing good environmental management (Poksinska et al., 2003). While data demonstrating improved environmental performance as a result of use of the ISO 14001 standard is not widely available (Schylander \& Martinuzzi, 2007), the new version is nevertheless said to have a stronger emphasis on performance (BSI Group, 2015) than the 2004 version.

The absence of a comprehensive global list of organizations who are using and/or have their EMS certified to ISO 14001 could be explained by the fact that ISO is not directly responsible 
for registering organizations to its standards; instead, several registrars exist globally that register organizations; maintaining such a list may be very expensive; organizations may change registrars when it is time to renew their certificate, which could make keeping track of registered users challenging; and organizations may use more than one registrar to certify the various standards that exist within their organization (www.the9000store.com/ISO-9000-registeredcompanies).

Finally, ISO does not report companies whose certificates have been withdrawn (Henriques, Husted, \& Montiel, 2013), however, they provide the number of withdrawn certificates based on country (ISO Survey). The list is however not comprehensive.

\subsubsection{Requirements of the Standard}

The ISO 14001:2004 standard has six main requirements/subclauses under clause 4 which if adhered to are intended to improve the management processes of an organization and thereby presumably lead to an improvement in environmental performance. The ability of the standard to facilitate learning in organizations, which is part of what this research seeks to investigate, revolves around these requirements. A brief description of each requirement/subclause is presented in Appendix C. Figure 2.1 below shows a snapshot of the requirements of the standard and the continual improvement process.

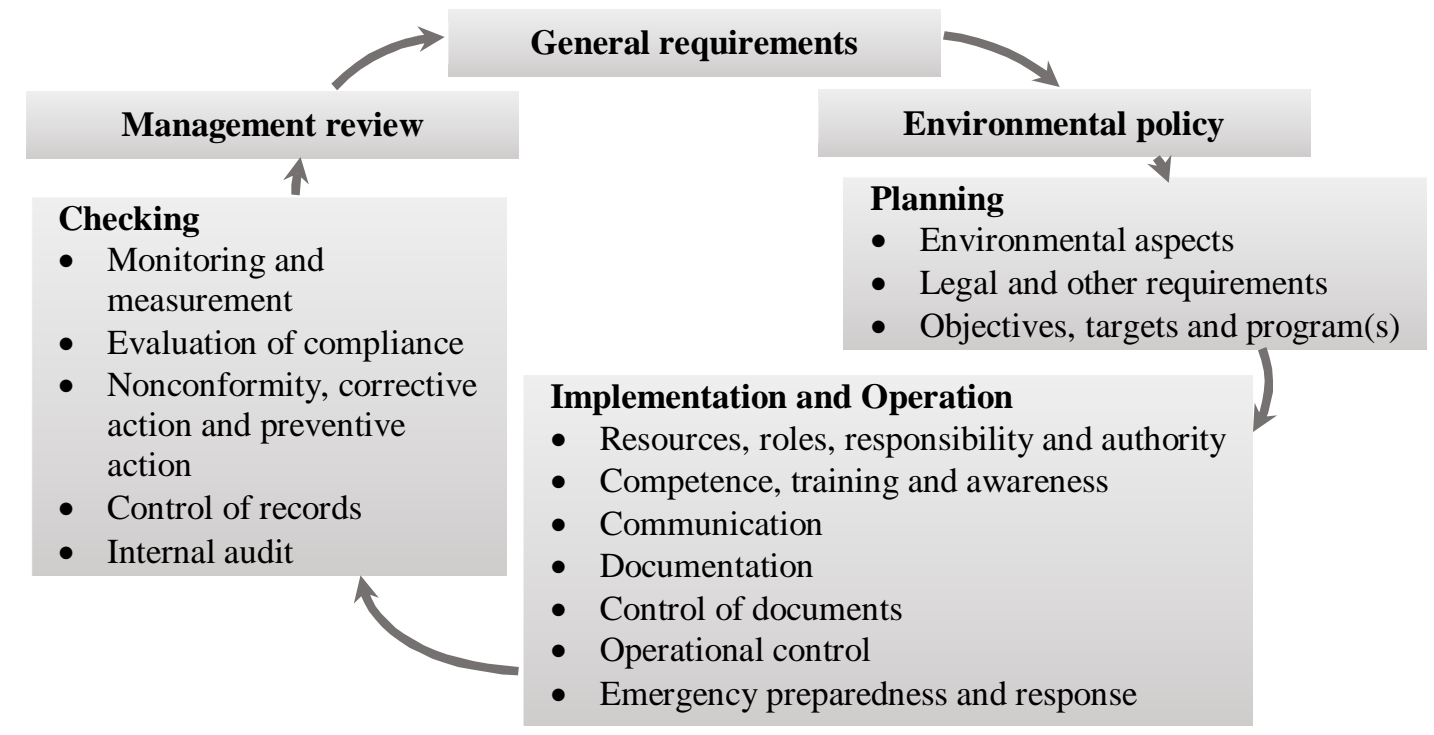

Figure 2.1 Requirements of the ISO 14001:2004 standard and continual improvement 


\subsubsection{Benefits of the ISO 14001 Standard}

Based on a review of the literature, organizations have much to gain by certifying their EMS to the ISO 14001 standard. Whether or not organizations are actually reaping such benefits is still an issue for debate and further research (Hwee Nga, 2009). Studies have been conducted in order to determine the benefits of the standard. A few of the studies are briefly discussed below.

On reviewing the literature on the benefits of using the standard, Poksinska et al. (2003) stated that although environmental improvements were cited in some studies as a benefit flowing from use of the standard, an improvement in stakeholder relations and organizational control were the most reported benefits of the standard. From their own study, they observed that organizations registered to the standard felt that it helped improve their corporate image, environmental performance and internal procedures such as record keeping, documentation and review of management procedures. They also observed that organizations that were seen as environmental stewards may be more likely to attract more customers and suppliers, especially those that are environmentally conscious. Customer satisfaction, increased market share and employee morale were seen as moderate benefits as determined by their study (Poksinska et al., 2003).

Also, based on two case studies, it was determined that the ISO 14001 standard has the ability to contribute to sustainable development (Fortuński, 2008; Sebhatu \& Enquist, 2007), especially in situations where command and control mechanisms were found to be weak (Fortuński, 2008).

Some studies showed that the ISO 14001 standard led to the reduction in energy consumption, higher safety for workers, the upgrading and adoption of technology, and the encouragement and facilitation of activities that entailed technological innovation (Radonjič \& Tominc, 2006). The results of another survey determined that certification of the EMS to the standard led to an improvement of an organization's economic and environmental performance and had a positive influence on customer satisfaction (Ann, Zailani, \& Wahid, 2006). Psomas et al. (2011) found that the most significant benefits of the standard were improvement in waste processing, improvement in the relationship with the organization's community, improvement in performance, and a better market position. The adoption of sustainable practices was seen as a less significant benefit. 
Based on a survey conducted by Turk (2009) of Turkish companies, it was determined that the standard led to an improvement in environmental awareness and standardisation in environmental management, a reduction in environment impacts, and served as a means for sustainable environmental development (Turk, 2009). Chin, Chiu, and Tummala (1999) determined that a reduction in liabilities, improvement in corporate image and staff morale were some of the advantages of the standard. An increased profitability was also found to be a benefit of the standard (Chin et al., 1999). As with the previous author, del Brio, Fernandez, Junquera, and Vazquez (2001) also found that corporate image was important to companies that adopted the standard. They also found that legal compliance was at the top of the list of its benefits (del Brio et al., 2001).

Another case study reported that the implementation of the standard led to a change in the culture or behaviour of employees to include managers and employees. The study found an increase in environmental awareness especially as it relates to environmental aspects and impacts, and regulations. An increase in operational efficiency and effectiveness was also observed (Rondinelli \& Vastag, 2000). Potoski and Prakash (2005) compared registered and nonregistered organizations in their study and reported that organizations that were registered saw improvements in environmental regulatory compliance compared to their non-registered counterparts. Boiral and Sala (1998) found the standard to be of benefit because it brought about a systematic process of managing activities, it led to a better control over work procedures that had potential impacts as well as employee behaviour, and it could improve an organization's image and competitive advantage (Boiral \& Sala, 1998).

In the study conducted by Schylander and Martinuzzi (2007), it was reported that the ISO 14001 implementation process improved the environmental awareness of both top management and other employees of the organizations studied and led to environmental issues being brought to the forefront along with other corporate issues. With respect to what they refer to as direct environmental effects (i.e., use of raw materials, waste, etc.), they observed the highest improvements in waste and recycling. They also showed that there is a high correlation between environmental awareness and improvement in energy consumption and waste and recycling. This led them to conclude that environmental improvements are brought about by high organizational 
commitment and a proactive environmental culture. Cost savings was achieved by the majority of the companies they studied especially with respect to waste management as most of the companies were now reducing, dividing and sorting their waste. Resource optimization also brought about cost savings via efficient packaging, use of raw materials, and use of energy for their processes. Other expected benefits such as achieving and maintaining legal compliance, better environmental performance and improved efficiency in handling environmental activities were fulfilled (Schylander \& Martinuzzi, 2007).

Table C.1 in Appendix C lists a number of benefits as mentioned in the literature and includes those that were determined via studies (note: the list is not an exhaustive one).

\subsubsection{Limitations of the Standard}

Despite its many benefits, the ISO 14001:2004 standard has come under criticism for what are said to be its limitations or weaknesses.

First, as mentioned earlier, organizations can have their environmental management system certified by an approved third party organization, which purports to demonstrate that they have met all the terms and requirements of the standard, and there are many registrars in various countries as well as worldwide with varying levels of skills and integrity and thus the standard may or may not be applied uniformly (Bansal \& Bognar, 2002; Morrison et al., 2000 ). Furthermore, the guidelines (if any) given to registrars by the different accreditation bodies around the world tend to be different, which means that the certification process may differ from region to region (Burdick, 2001). These disparities could lead to various interpretations of the standard and detract from the perception that the standard is useful.

Second, the standard is not a performance standard but rather focuses on improving management processes as a means to monitor environmental activities (Bansal \& Bognar, 2002; Montabon et al., 2000; Poksinska et al., 2003; Psomas et al., 2011). As such, an organization's performance could drop even when its EMS is certified (Bansal \& Bognar, 2002). In fact, based on the aforementioned, it has been suggested that the ISO 14001:2004 standard might be more valuable if it is to be used only for internal purposes (Poksinska et al., 2003). Furthermore, the 
enhancement of the internal processes of an organization is said to be made possible through the implementation of an environmental management system (Darnall et al., 2008).

Third, because of the standard's one size fits all nature in which it tries to accommodate all types of organizations in all geographic areas, it is said that its requirements are somewhat diluted and not rigid enough to improve performance unlike other standards such as EMAS (Bansal \& Bognar, 2002). For instance, a company can decide to set easy objectives and targets that they know they can easily achieve (Poksinska et al., 2003) and still meet the requirements of the standard in the same way that another company that sets tougher objectives and targets will meet the requirements of the standard. Also, the standard can be adopted by any firm including those with poor compliance records (Potoski \& Prakash, 2005).

Fourth, firms that have their EMS certified may come under more scrutiny than firms with a noncertified EMS because they are more than likely to have a well documented system in place and could be seen as bragging about their performance (Bansal \& Bognar, 2002). As a result, organizations may be discouraged to have their EMS certified because of the fear of exposing issues that have legal implications and also because of the cost to clean up such issues should they be discovered (Bansal \& Bognar, 2002; Kirkland \& Thompson, 1999).

Fifth, unlike the other voluntary programs like the EMAS, and with the exception of the ISO 14001 requirement of publication of an organization's environmental policy, firms are not required by ISO 14001:2004 to publicly report on their environmental management system (Gleckman \& Krut, 1997; Morrison et al., 2000; Webb, 2004). As a result, external stakeholders who learn that an organization is certified to ISO 14001 may be given the wrong impression regarding the environmental performance of the organization. Certification may therefore not be a useful means to show performance especially among stakeholders who know that the standard is not a performance standard (Poksinska et al., 2003).

Sixth, the ISO 14001 standard was developed through a multistakeholder process that included multinational corporations. Due to the past scandals especially in the accounting industry, 
environmental groups and the public on the whole may be suspicious of self-regulation (Dogui, Boiral, \& Heras-Saizarbitoria, 2014; Potoski \& Prakash, 2005).

Seventh, the standard has been criticised for not involving strong sanctions for those that do not comply. The standard only requires that companies recertify every three years and withdraws a company's certification for nonconformance. Furthermore, ISO does not publish the names of the organizations that had their certificates withdrawn, which may ensure that organizations maintain their certification (Henriques et al., 2013). Also, companies can still maintain their certification without having to prove that they are complying with regulations: all they have to do is commit to doing so while maintaining the environmental management system (Henriques et al., 2013; Potoski \& Prakash, 2005).

Finally, the standard is said to be too bureaucratic and difficult to interpret and translate and thus put into practice (Kirkland \& Thompson, 1999; Schylander \& Martinuzzi, 2007). This limitation could lead to a variety of interpretations by the different registrars worldwide. Schylander and Martinuzzi (2007) reported that the text of the 1996 version needed to be more clear and observed from their study that besides the environmental policy, which was easy to put into practice, organizations found legal and other requirements most difficult to work with, however, this difficulty was observed during the implementation phase and was said to pay off down the road (Schylander \& Martinuzzi, 2007).

\subsubsection{Challenges pertaining to the implementation and maintenance of the ISO 14001 Standard}

Organizations are said to face certain challenges when implementing and maintaining adherence to the ISO 14001 standard, many of which have to do with its requirements. As mentioned by Psomas et al. (2011), some of the challenges encountered with the implementation of the standard include the added responsibilities for employees, which might not be necessarily welcomed by such employees; obtaining the commitment of top and middle management, and other employees (Poksinska et al., 2003; Psomas et al., 2011); top management not devoting enough time and resources for its implementation (Chavan, 2005; del Brio et al., 2001; Psomas et al., 2011), especially since a lot of time and resources is required (Liyin et al., 2006); and the 
belief that the environmental management system does not need to be continuously reviewed (Chavan, 2005; Psomas et al., 2011). Turk (2009) also found that obtaining the commitment of top management was one of the main difficulties encountered by organizations: they observed that top management did not take criticism well and that they were not open to research.

The organization may not have qualified personnel (Psomas et al., 2011; Turk, 2009) and thus lack knowledge with respect to environmental issues (del Brio et al., 2001). As such, they may end up having to hire one or use a consultant which both add to the cost of implementation and maintenance. The added cost (Chin et al., 1999; del Brio et al., 2001; Liyin et al., 2006; Poksinska et al., 2003; Psomas et al., 2011; Turk, 2009) to include cost to setup and maintain the standard could be discouraging for companies (Chin et al., 1999; Psomas et al., 2011; Turk, 2009).

Organizations are also challenged with the added bureaucracy (Ann et al., 2006; Kirkland \& Thompson, 1999; Psomas et al., 2011; Schylander \& Martinuzzi, 2007) and heavy documentation (Ann et al., 2006; Poksinska et al., 2003; Psomas et al., 2011; Turk, 2009) that comes with the implementation and maintenance of the standard.

Liyin et al. (2006) found that companies in the construction industry in Hong Kong were having difficulty improving performance for the following reasons: the companies were weighing the cost against environmental performance; there was a lack of environmental culture in the industry; there was little or no support from clients; and the conflict between implementing environmental projects as part of regular construction projects (Liyin et al., 2006; Psomas et al., 2011).

Other challenges that organizations are said to encounter include fulfilling some of the requirements of the standard such as the identification of environmental aspects and impacts, employee training, conducting periodic audits, implementing corrective actions, developing or reviewing standard procedures and ensuring that the standard procedures are followed (Poksinska et al., 2003; Psomas et al., 2011). Companies were also said to have difficulties 
understanding the standard especially those adopting it for the first time (Christensen \& Rasmussen, 1998).

Among the challenges faced, the identification of aspects was found to be most difficult while documentation, periodic audits, corrective actions and developing standard procedures were considered as less difficult (Psomas et al., 2011). Similarly, Poksinska et al. (2003) reported that the identification of aspects, training, documentation and periodic audits required the most effort to undertake.

Following up on the stated challenges and limitations associated with ISO 14001 described by various authors above, a line of enquiry undertaken as part of this research asked the following two questions:

What would you say is the least helpful feature/requirement of the ISO 14001 standard? Please could you briefly explain why you found this feature/requirement least helpful?

\subsubsection{Important factors for the successful implementation and maintenance of the ISO 14001 Standard}

A few studies have been conducted on firms that are seeking or have attained certification in order to determine what factors/requirements were seen as most important for success. Chin and Pun (1999) and Christensen and Rasmussen (1998) stated that top management commitment is one of the most important requirements for success. Chin and Pun (1999) stated that top management commitment is more important than the environmental policy and management reviews because top management is responsible for communicating the need for the EMS and for encouraging employees to come on board. The participation of top management was also seen as important because they are responsible for developing the environmental policy and for setting the objectives and targets (Poksinska et al., 2003).

The results obtained by Poksinska et al. (2003) showed that the most important requirements/factors affecting implementation of the standard are ranked as follows: aspects identification, training, top management commitment and documentation. Evidence of training 
being an important factor was shown in the number of employees that were trained (81 - 100 percent). Those factors having moderate importance were the establishment of standard procedures and employee commitment. The identification of aspects was seen as most important because it enabled an organization to identify its potential impacts on the environment and thus assist them in setting objectives and targets. Training facilitated the spread of awareness as it relates to the environment and how their jobs impacted the environment as well as ways in which to deal with those impacts (Poksinska et al., 2003). In addition to documentation and document control, and training and awareness, Chin and Pun (1999), also mentioned organizational structure and definition of responsibilities as being important factors for success.

Employee participation was also seen as being crucial for success with respect to implementing voluntary standards (Carlsson \& Carlsson, 1996; Christensen \& Rasmussen, 1998; Karltun, Axelsson, \& Eklund, 1998) because employees play an important role in the development and implementation of the environmental management system. It was suggested that if employees are involved in the creation of procedures they would be more likely to follow them (Poksinska et al., 2003). The external audit was also seen as important because it keeps organizations on track and ensures that they carry out their responsibilities (Potoski \& Prakash, 2005).

Finally, an interesting finding by Poksinska et al. (2003) was that the majority of their respondents were of the opinion that having ISO 9001 certification helped facilitate the process for ISO 14001 certification. This may be due to some of the similarities in the two standards (e.g., the plan do check act approach and the requirement of documentation), and thus having ISO 9001 certification could provide some amount of experience which employees could utilize when implementing ISO 14001. Furthermore, Darnall et al. (2008) suggested that having a quality management system, which they argue provides an organization with "complementary knowledge-based capabilities" (p. 367) could facilitate the implementation of an environmental management system. They go further to state that a health and safety management system could play a similar role in this regard.

Building on the discussion of success factors of various authors that is summarized above, a line of enquiry undertaken as part of this research included the following survey question: 
What would you say is the most helpful feature/requirement of the ISO 14001 standard? Please could you briefly explain why you found this feature/requirement most helpful?

\subsubsection{Adoption Trends of the ISO 14001 Standard}

Based on the 2014 ISO Survey (shown in Figure 2.2 below), the number of ISO 14001 certificates has grown over the years with East Asia and Pacific $(166,441)$ and Europe $(123,849)$ contributing the most to the number of certifications in 2014. In fact, since 1999, both regions have always had the highest number of certifications on a yearly basis. Canada and the United States of America (USA), which were the focus of this study had 2,101 and 6,586 certificates respectively in 2014. Both countries saw an uneven increase in certification between 1999 and 2014 with a decrease in certification in 2007, 2009, 2010 and 2013 (a decrease in 3 certificates from 2012) for Canada and 2007, 2008 and 2010 for the USA (see Figure 2.3 below). The USA made the list of top ten countries for ISO 14001 certificates in 2014 with China topping the list with 117,758 certificates (See Table 2.2).

Table 2.2 World top ten countries for ISO 14001 certificates in 2014 (Adapted from ISO Survey, 2014)

\begin{tabular}{|c|c|c|}
\hline \multicolumn{3}{|c|}{ ISO 14001 certificate top 10 Countries in 2014 } \\
\hline 1 & China & 117758 \\
\hline 2 & Italy & 27178 \\
\hline 3 & Japan & 23753 \\
\hline 4 & United Kingdom & 16685 \\
\hline 5 & Spain & 13869 \\
\hline 6 & Romania & 9302 \\
\hline 7 & France & 8306 \\
\hline 8 & Germany & 7708 \\
\hline 9 & USA & 6586 \\
\hline 10 & India & 6446 \\
\hline
\end{tabular}




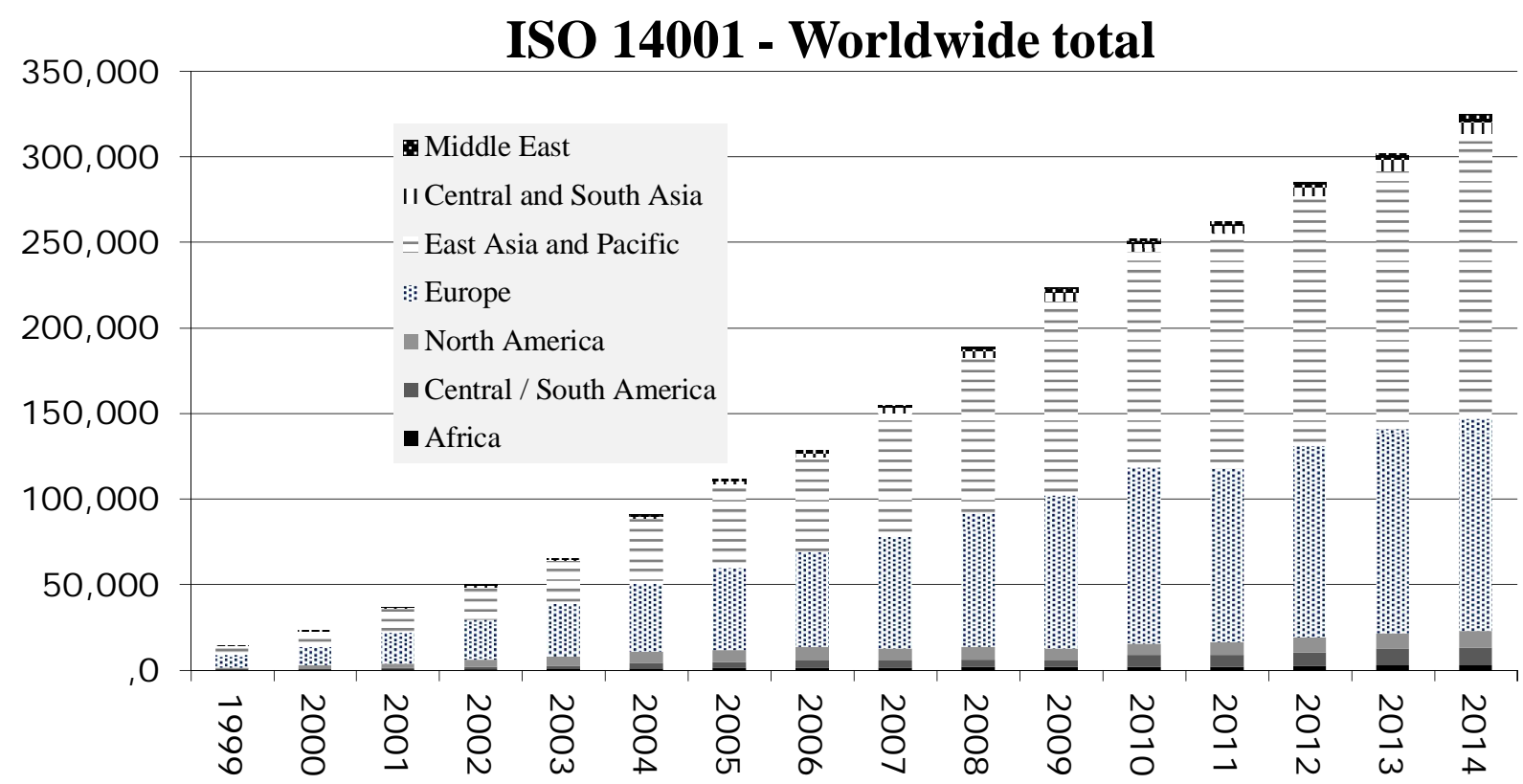

Figure 2.2 Total number of ISO 14001 certifications worldwide (Adapted from ISO Survey, 2014)

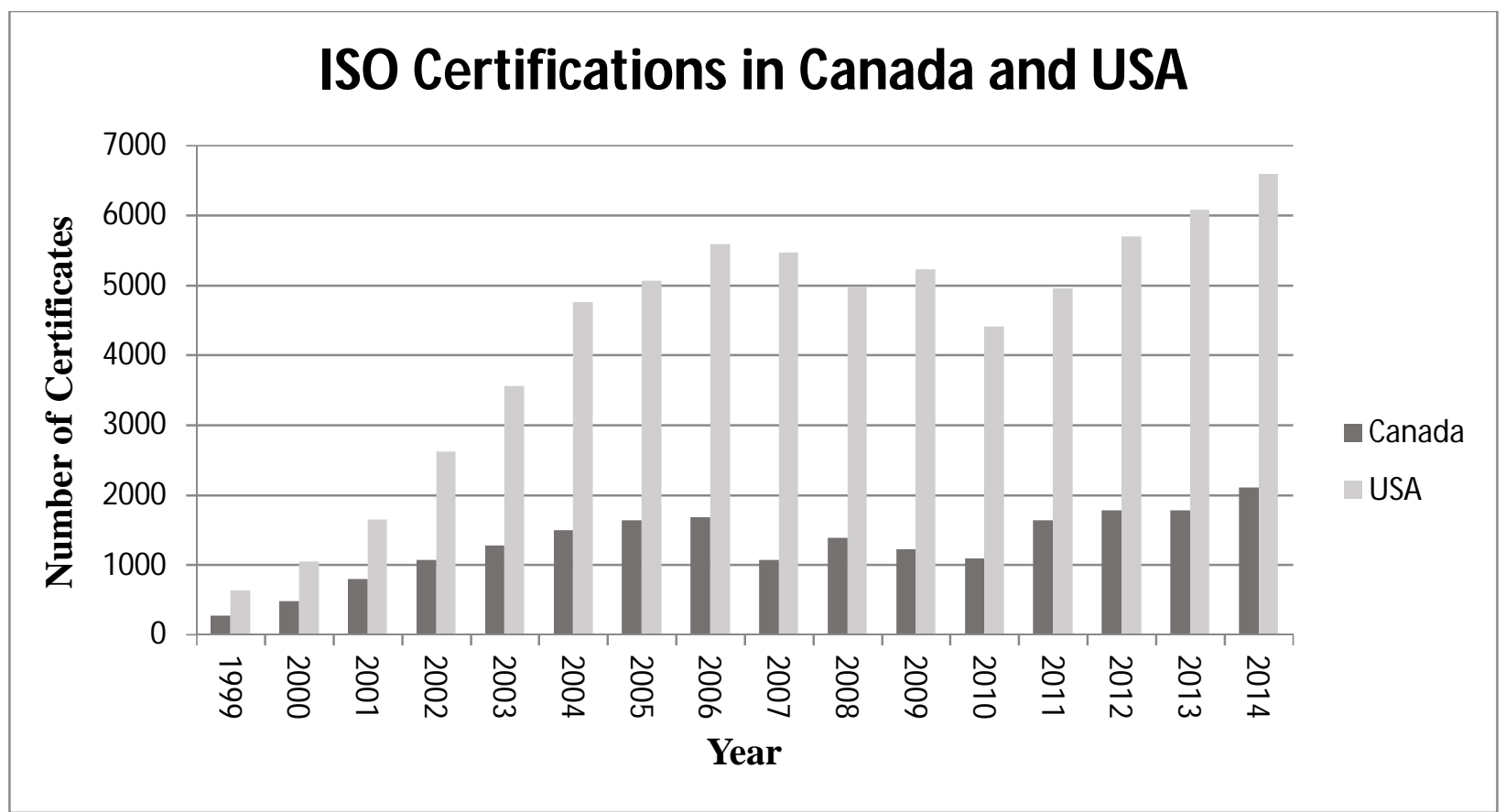

Figure 2.3 Total number of certifications in Canada and USA (Data obtained from ISO Survey, 2014) 
With respect to the number of certificates that have been withdrawn, the 2014 ISO survey only has data from 2006 to 2011. Within this period a total of 66,210 certificates were withdrawn worldwide. Within the same period, 1,207,805 certificates were awarded worldwide, indicating that the adoption rate of the standard surpassed its withdrawal rate by a considerable amount.

\subsubsection{Environmental Management Systems Software}

FitzGerald (1992), in investigating the trends with respect to the application of computer information systems to the field of environmental management, provided an overview of the evolution of such computer applications and the challenges users had with such applications. A summary of some of his findings is discussed as follows. The application of computer systems in the form of environmental information systems (EIS) to environmental management dates back as far as the 70s. The need is said to have arisen mainly due to the emergence of environmental regulations such as the Clean Air Act and other regulations that required companies to report on data such as ground water monitoring and chemical safety. As the number of regulations increased over the years, so did the amount of reporting required. This brought about the need for more complex information management systems as well as the eventual evolution of such systems. Besides regulations, the need for environmental information systems was also brought about due to the pressure mounted on companies to publicly disclose information on their environmental issues such as the handling of hazardous materials. Environmental information systems not only evolved due to emerging and changing regulations but also due to the evolution of computer systems. Before 1980, the systems were operated on corporate mainframes or large minicomputers, but with the advent of personal computers this changed and so did the design of the software. However, this new development did come with a few drawbacks because databases now had to be developed separately, which lead to users having to utilize different types of specialized software. This decentralization coupled with the fact that the environmental information systems could not be integrated with other individual software applications and other corporate information systems meant that data had to be entered several times, which made data capture more cumbersome and costly. The inability to integrate the system also made data sharing between environmental staff and other staff members difficult because, for example, software for air sampling or water monitoring were on different platforms from those used by other employees. The lack of integration coupled with the lack of consensus (regarding 
information requirements) amongst employees of different fields led to poor communication between employees that used environmental software and those that used other management information systems because most of them did not have any experience with both systems nor have a good understanding of each other's fields. These limitations brought about inefficiencies and increases in cost and thus environmental staff found it difficult to make a business case for the inclusion of environmental information systems into the corporate budget (FitzGerald, 1992).

Scholars have suggested that organizations are managing their corporate social responsibility (CSR) data (including environmental data) in five different ways, namely; by not tracking their data and having no systems in place to do so; by using readily obtainable software products such as Microsoft Excel; by developing the software in-house via their information technology department or via the help of consultants; by integrating existing corporate software platforms such as Oracle or SAP with CSR add-ons; and by buying specialized software solutions from one of the many vendors on the market today (Alnes et al., 2014).

The current specialized software for environmental management and other areas have been improved compared with what it was prior to the 1990s and most have overcome the limitations mentioned earlier. These improvements coupled with other factors have led to the tremendous growth in the environmental software market in the last five years especially in the area of manufacturing, and energy and utilities. They are being used not only to track data but also to manage processes, to generate reports required for meeting regulations like the Clean Air Act, and to collect and report on data for greenhouse gases (Leif, 2014) and corporate social responsibility (environmental, social and economic metrics reporting) (Gidwani, 2015; Leif, 2014). Besides environmental management and CSR, specialized software is also being applied in areas such as health and safety management (Gidwani, 2015; Leif, 2014), product safety, and risk assessments and analysis (Leif, 2014). With the expansion of organizations worldwide, companies now require software that will enable them monitor their environment, health and safety performance at different geographical locations and thus provide visibility on a global level (Leif, 2014) thus making software a necessity. 
The demand for more specialized EMS-related software is growing because there is a perceived need to enhance compliance efficiency, potential software users are becoming more aware of sustainability issues, and the software assists organizations in managing the risks of their daily operations (Leif, 2014). Also, regulations are becoming more complex (Ismail, 2012; Leif, 2014; Www.ihs.com), and organizations are focusing more on improving performance (Alnes et al., 2014; Leif, 2014). In addition, it could be said that given the considerable information and data generated in the process of maintaining one's environmental programs, especially for large organizations with multiple facilities in different regions (Ismail, 2012; www.enviance.com), many organizations have started using software tools to assist them in managing their individual environmental programs more efficiently (Ismail, 2012) as well as to enable them to implement and maintain a robust environmental management system (Leavoy \& Waggott, n.d.). A study carried out by Alnes et al. (2014) supports the aforementioned reasons for why organizations are starting to use customized software, and goes further to show that organizations see such software as being beneficial because the tracking and reporting of CSR data enables them to satisfy their internal and external stakeholders (regulators, consumers, investors, suppliers, retailers and the public) and to improve their internal processes and corporate image (Alnes et al., 2014).

Despite the increase in use of customized software, a number of companies are still collecting data manually using readily available software such as Microsoft Excel. Such software products are said to be inefficient for this purpose and reduce the quality of the data being collected (Alnes et al., 2014; Gidwani, 2015; Leif, 2014; Rapacioli, Thimmiah, Osborn, \& Richardson, 2011). According to Rapacioli et al. (2011), a study conducted by Accenture discovered that the majority of their respondents used Excel to collect data for sustainability metrics with a little over half using it for data analysis. However, Microsoft Excel was outperformed as a tool for data management when compared with specialized software (Alnes et al., 2014). This is mainly so because Excel and other similar software are not as robust as the specialized solutions on the market, which have specific environmental or sustainability performance management features and allow for data to be automatically collected and distributed within the organization (Rapacioli et al., 2011). The ability to collect and distribute data is seen as one of the strongest features of specialized software on the market today. 
Although there exists a good number of specialized software products on the market today, unfortunately there is still no one-stop customized software solution that meets all the needs of companies (Alnes et al., 2014; Leif, 2014) such as compliance, environmental management, health and safety for workers, and the mitigation of the daily risks associated with undertaking complex operations. As such, the market is still considered as being segmented and not yet mature enough (Leif, 2014). This may be due to the fact that not too many companies exist that make software that cover a wide variety of management systems.

Since there is no one-stop customized software solution, organizations have to take into consideration certain factors before buying such products. First and foremost, the organization needs to evaluate their current and future plans and how the software will fit into that plan (Alnes, et al., 2014; Leif, 2014). They will need to evaluate the vision and current competencies of the vendors, and seek products that offer a complete risk management approach rather than just compliance. Their choice of a vendor will also depend on the scope of the project to be undertaken, the vendor's industry experience (i.e., industry sector), the vendor's ability to provide support especially on a global level, and the method through which the software is deployed (e.g., software-as-a-service (SaaS) also known as cloud or on-premises). Software-as-a-service is a "delivery model for software in which you pay for software on a pay-per-use basis instead of buying the software outright" (Haag \& Cummings, 2008, p. 405). With respect to the software, potential users need to consider the functional coverage of the software, which includes areas such as environmental management, health management, safety management, product safety and risk assessments and analysis (Leif, 2014). Technical capabilities to consider include the software's ability to handle events, workflows and alerts (Alnes et al., 2014; Leif, 2014), regulatory content, documentation, and reporting and analytics; its ability to be used in different languages; its ability to be used on mobile devices; its hosting capabilities (SaaS, on-premises, etc.); whether or not it can be upgraded for use throughout the entire organization (Leif, 2014); its ability to be integrated with other corporate systems such as enterprise resource planning (ERP) systems or human resources systems (Alnes et al., 2014; Leif, 2014) ); and its ability to automatically acquire data (e.g., electricity data from utility providers) from third parties, which avoids the need to enter data manually thereby saving time and preventing input errors: in the long run it makes the reporting process more efficient (Alnes et al., 2014). 
Software vendors must also take certain factors into consideration when designing specialized software. A few of these factors include the user interface and how the user will interact with the information they intend to collect; the organizational culture of its users; the type of data, its format and characteristics which include things like variability, reliability and periodicity; the type of problems buyers deal with and how they managed current and past problems; and their knowledge and capabilities with respect to using similar software (Argent \& Grayson, 2001). Also, the software solution needs to be customizable in order to fit the different needs of the different clients and to fit the requirements of the different frameworks like ISO 14001 and the Global Reporting Initiative (Alnes et al., 2014). It is also important that the vendors work hand in hand with users in order to develop software that has features that meet the customer's needs (Alnes et al., 2014; Argent \& Grayson, 2001).

A few of the vendors that offer customized software solutions include Enviance, Intelex Technologies Inc., IHS, Enablon, SAP, KMI, EtQ, Gensuite, Medgate, 3E Company, UL Workplace Health and Safety, SiteHawk, Rivo Software, CMO Compliance (Leif, 2014) and Tennaxia (Gidwani, 2015). The vendors mentioned here manufacture software that cover quality, environment, health and safety, and corporate social responsibility. Those that lead the way with respect to environment, health and safety include Intelex Technologies Inc., SAP, IHS and Enablon while others like EtQ and Enviance have a smaller footprint in this area (Leif, 2014).

Many of the current environmental management systems software vendors advertise their products as having the potential to assist organizations with their environmental management systems/standards via their different features. Some of the functions/benefits of such products are outlined as follows:

1. They provide a centralized database system that enables employees to easily and quickly access the required information irrespective of their location (Enviance, n.d.a; Enviance, 2010b; Intelex, 2014; Ismail, 2012; Leavoy \& Waggott, n.d.). The database may include historical records of all environmental activities, which may be required for audit purposes (Intelex, 2014). 
2. They facilitate collaboration, communication, and sharing of information amongst different departments (Intelex, 2014; Ismail, 2012; www.enviance.com) as well as amongst different organizations (Enviance, n.d.b).

3. They facilitate the monitoring of compliance and conformance across different facilities, geographical locations and product lines (Intelex, 2014; Ismail, 2012) and thus provide global visibility for companies (Intelex, 2014). Organizations are better able to comply with regulations because the software facilitates the process of report generation (Gidwani, 2015).

4. Large amounts of environmental data can be collected (Ismail, 2012; www.enviance.com) and analyzed (Alnes et al., 2014; Ismail, 2012) more efficiently and made more understandable to decision makers through dashboards and other reporting tools (Enviance, 2010a; Intelex, 2014; Ismail, 2012; www.enviance.com). The environmental data can also be provided in real-time (Ismail, 2012; Leavoy \& Waggott, n.d.). Dashboards enable trends to be viewed at a glance so problem areas can be addressed quickly (Rapacioli et al., 2011). The analyzed data gives the company a competitive advantage because it enables them to make good decisions with respect to allocating resources efficiently and possibly lowering cost (Alnes et al., 2014), and identify future opportunities (Alnes et al., 2014; Argent \& Grayson, 2001).

5. They enhance tracking and follow-up procedures thereby enabling organizations to reduce environmental incidents and to control risks better (Intelex, 2014; Ismail, 2012; Leavoy \& Waggott, n.d.) especially on a global level (Leif, 2014).

6. They provide real time alerts/notifications regarding issues such as outstanding corrective actions or permit requirements (Enviance, 2010b; Intelex, 2014; Ismail, 2012; Leavoy \& Waggott, n.d.).

7. The software ensures that environmental data is accurate, comparable and traceable (www.ihs.com).

8. They ensure that the continuity (Enviance, 2010b; www.ihs.com) and reliability of environmental knowledge is maintained (www.ihs.com).

9. The software assists with the tracking of the employee training process by streamlining and automating the actions undertaken by managers and supervisors thereby ensuring that employees obtain the proper training (Intelex Technologies Inc., n.d.). 
10. The software also reduces the time required to collect and store data, generate reports, conduct audits and investigate inspections compared to other software packages (Intelex, 2014; Leavoy \& Waggott, n.d.). It also saves time by eliminating silos of data brought about by un-integrated software (Enviance, 2010b; Leavoy \& Waggott, n.d.), in which data from different spreadsheets, notes and files have to be accessed (Enviance, 2010b). A reduction in time for report writing and documentation is brought about via the software's document and document control features (Intelex, 2014). The audit process is also made easier because the auditors do not have to sift through piles of paperwork in order to obtain the information they need (Intelex, 2014). In fact, auditors found the data quality to be inconsistent for those that used only Microsoft Excel (Alnes et al., 2014).

11. The software helps facilitate the return on investment (ROI) of an organization's environmental management system via cost savings and cost avoidance by firstly, enhancing the company's ability to track and report activities such as water and energy usage on a real-time basis, which enables the organization to curb any excesses, thus cutting costs (Alnes et al., 2014; Leavoy \& Waggott, n.d.), and secondly, through real time tracking and managing of for instance permit requirements, violations that come with heavy fines can be avoided (Leavoy \& Waggott, n.d.).

12. On the whole the software can assist organizations in implementing and maintaining their ISO 14001 certification because they possess features that assist with some of the elements of the standard such as audit management, permit management, operational control, nonconformances, monitoring and measurement, legal and other requirements, inspection management, objectives and targets, environmental incidents, aspects and impacts, documentation and document control, management review and communications management (http://www.intelex.com/products/environment) some of which cover the functions mentioned above.

13. Overall it is suggested that organizations that utilize specialized software solutions should see an improvement in their environmental performance (Gidwani, 2015).

It is based on some of these benefits/functions outlined above as well as those outlined in the literature (e.g., Global Environment and Technology Foundation, 2004) that research question Q3 was formulated: 
Q3: Do environmental management system software products have the necessary features that enable them to assist organizations in implementing and maintaining the ISO 14001 management system standard?

While organizations are still using software such as Microsoft Excel to track their data (Gidwani, 2015; Rapacioli et al., 2011) it has been predicted that adoption rates for more specialized software are likely to increase in the future (Gidwani, 2015; Ismail, 2012), as a study conducted by ReScore Group suggests that a sizeable number of companies do have or plan to purchase specialized software solutions (Gidwani, 2015). One reason for the lack of use of specialized software solutions may be due to the fact that environmental managers and their counterparts are unable to show the value of the software to top management mainly because they themselves are not quite convinced that the software can actually be of use to them. Another reason may be the fact that although there are over 20 vendors competing in this market, not all the software solutions have the complete packages that suit the user's needs (Gidwani, 2015). Also, some organizations that do not track or manage their data or processes using specialized software say they do not have the resources and are of the opinion that there is no return on investment, which makes it an unwanted expense. Finally, some organizations may have already invested in a software system long ago and may not want to invest in a new system even though it may be better (Alnes et al., 2014). In addition, the cost of specialized software may also discourage organizations from using such products. The total cost over three years for an environment management software based on the size of the organization is said to be as follows: small $(\$ 76,000)$, medium $(\$ 300,000)$, and large $(\$ 800,000)$ (Leavoy \& Waggott, n.d.). This includes the initial cost of the software and its implementation and maintenance fees per year.

With respect to the design/features of EMS-based software and other specialized software products, some limitations have been highlighted by a few studies. For example, EMS-based software products are said to be too prescriptive, unable to be adapted to the unique needs of the organization, have a complex user interface, and are not capable of addressing all of the requirements of the standard (Global Environment and Technology Foundation, 2004). Also, not all specialized software products can be integrated with other corporate management systems that already exist within an organization (Gidwani, 2015). Finally, there may also be 
misconceptions and lack of knowledge by users with respect to the capabilities of specialized software (Alnes et al., 2014).

In light of the aforementioned benefits/technical capabilities and limitations of software features/design, a line of enquiry undertaken as part of this research involved inclusion of the following survey questions:

1. What would you say is the most helpful feature of the software in terms of its ability to assist you in meeting the requirements of the ISO 14001 standard? Please could you briefly explain why you found this feature most helpful?

2. In your opinion what is the least helpful feature of the software in terms of its ability to assist you in meeting the requirements of the ISO 14001 standard? Please could you briefly explain why you found this feature least helpful?

In terms of the size of organizations and the use of specialized software, it was observed by one commentator that large companies tend to use them more compared to small companies (Alnes et al., 2014). This may be due to the fact that they are better resourced, have a more complex system and are likely to have more than one facility in different geographical regions. With respect to worldwide usage of specialized software, organizations in Europe are seen to take the lead mainly due to pressure from government regulators and investors to report their data, unlike in the United States of America where reporting of for example CSR data is not mandated by government: the main pressure to report their data is from other external stakeholders (Alnes et al., 2014). Nevertheless, companies in the United States of America are beginning to realize that the use of specialized software is a good means to promote sustainable business practices and are beginning to catch on (Alnes et al., 2014). This is not surprising because specialized software is becoming more important for tracking and reporting on environment, social and governance activities and they can help organizations improve their performance in these areas especially if it is integrated with other systems (Gidwani, 2015). In fact, in the study by Gidwani (2015), organizations saw better performances in areas such as the environment (environmental policy and reporting, resource management, and energy and climate change) and employee welfare (diversity and labor rights, compensation and benefits, training, and health and safety) for which specialized software solutions were utilized. 
Recognizing the above points pertaining to the challenges that users of EMS-based/specialized software may encounter, the following additional questions were included in the survey:

1. In terms of the software's ability to assist you in meeting the requirements of the ISO 14001 standard, please briefly elaborate on any changes/improvements you think would assist you in making the software more functional for you and your organization?

2. In your opinion, how easy or difficult was it to implement the software for the ISO 14001 standard?

Finally, EMS-based software is said to have the ability to pay for itself as mentioned earlier and as such it was of interest to verify this claim by asking the questions below:

In your opinion, has the software paid for itself in terms of your ability to meet the requirements of the ISO 14001 standard. If yes, can you provide a rough estimate of how long it took for the software to pay for itself?

\section{Part 2}

\subsection{Literature Review on Organizational Learning and the Learning Organization}

The concepts of organizational learning (OL) and the learning organization (LO) are sometimes said to be similar and related (Esterby-Smith \& Lyles, 2011a; Tsang, 1997); however, there does exist a difference between both concepts. From an academic point of view, organizational learning is said to be "the study of the learning processes of and within organizations" (EsterbySmith \& Lyles, 2011a, p. 3). On the other hand, the learning organization is referred to as an entity that has the ability to learn effectively (Esterby-Smith \& Lyles, 2011a). However, both concepts are related by the fact that "a learning organization is one which is good at organizational learning" (Tsang, 1997, p. 75). DiBella and Nevis (1998) also make a distinction between both concepts as follows: "the learning organization is a system-level concept with particular characteristics or a metaphor for the ideal organization" (p. 6). It is a "particular type or form of organization in and of itself" (p. 6). On the other hand, organizational learning is a "term used to describe certain types of activities or processes that may occur at any one of several levels of analysis or as part of an organizational change process" (p. 6). 
According to Easterby-Smith and Lyles (2011a), the first references to organizational learning were made in the book by Cyert and March (1963) and the publication by Cangelosi and Dill (1965), however it was in the publication by the latter that the term 'organizational learning' was actually used. They mention that other foundational works included those by Argyris and Schön (1978), Hedberg (1981), Shrivastava (1983), Daft and Weick (1984), and Fiol and Lyles (1985). It was not until the 1990s that the study of organizational learning became more widely known, largely due to works by Huber (1991), March (1991), Simon (1991), and Epple, Argote, and Devadas (1991): they essentially set the 1990s research agenda for organizational learning.

The concept of the learning organization reached a certain prominence in the late 1980s with scholars such as Garratt (1987), Pedler, Boydell, and Burgoyne (1989), and de Geus (1988) making early contributions, with the publication by the latter creating the most attention. However, it was the book by Senge (1990) that popularized the term because it appealed to academics and practitioners alike (Easterby-Smith \& Lyles, 2011a).

The diversity of definitions for a learning organization and organizational learning may be due to the diverse origins of both concepts especially with respect to organizational learning (Robey et al., 2000) and the contributions from scholars in different disciplines such as management science, sociology, psychology, economics, political science, and anthropology (Easterby-Smith \& Lyles, 2011a). For this study, the following definitions seem to be particularly relevant: "A learning organization is an organization skilled at creating, acquiring, and transferring knowledge, and at modifying its behavior to reflect new knowledge and insights" (Garvin, 1993, p. 80); and "Organizational learning is the set of actions (knowledge acquisition, information distribution, information interpretation, and organizational memory) within the organization that intentionally and unintentionally influence positive organizational change" (Templeton, Lewis, $\&$ Snyder, 2002, p. 189). Since this research is focused on looking at the processes of learning in organizations, reference will be made more often to organizational learning.

In order to provide a broader view on the concepts of organizational learning and the learning organization, and to provide a connection between organizational learning, and ISO 14001 and EMS-based software (as discussed later in Part Three of this chapter), the next few subsections 
will be used to discuss different types of organizational learning, levels of organizational learning, contributions of a few scholars to the field of organizational learning, benefits of organizational learning, and factors that may impede organizational learning.

\subsubsection{Types of Learning}

The literature on organizational learning distinguishes between three types of learning as originally proposed by Bateson (1972), namely, Type 1, Type II, and Type III learning (Dierkes, Marz, \& Teele, 2001). They were further built upon by Argyris and Schön (1978) who referred to them as single-loop learning, double-loop learning and deutero-learning respectively. Singleloop learning involves the detection and correction of errors that do not affect the overall policies and goals of the organization (Argyris \& Schön, 1978). When single-loop learning occurs, changes may take place but they do not alter the organization's underlying norms; rather, continuity is fostered and the organization continues to follow its policies and objectives (Dierke et al., 2001). Usually, an immediate effect is seen with respect to a certain activity or area of the company, which may lead to a specific behavioral result or level of performance (Fiol \& Lyles, 1985). Other authors refer to this type of learning as adaptive learning (Senge, 2006; Slater \& Narver, 1995), experienced based learning (Burström, 2002), exploitation (Kane \& Alavi, 2007; March, 1991; Roome \& Wijen, 2005), lower-level learning (Fiol \& Lyles, 1985), and tactical learning (Dodgson, 1991).

Double-loop learning occurs "when error is detected and corrected in ways that involve the modification of an organization's underlying norms, policies, and objectives" (Argyris \& Schön, 1978 , p. 3). With this type of learning, changes in the environment cannot be dealt with by the organization by using existing strategies: the organization must make changes that will most likely conflict with its existing norms and policies. As a result, the organization questions its "existing theory of action, reevaluates and modifies its existing priorities, or even sets new priorities. The outcome is new or modified norms, policies, and objectives" (Dierkes et al., 2001, p. 283). Double-loop learning may arise due to a crisis that results from the introduction of a new organizational strategy, or a significant change in the organization's market, and it is said to have a long term effect on the organization (Fiol \& Lyles, 1985). Unlike single-loop learning, its main effect is not a behavioral outcome, but an establishment of new frames of reference. In fact, 
some amount of unlearning may take place (Fiol \& Lyles, 1985). Double-loop learning is also said to be similar to generative learning (Senge, 2006; Slater \& Narver, 1995), explorative learning (Kane \& Alavi, 2007; March, 1991; Roome \& Wijen, 2005), higher-level learning (Fiol \& Lyles, 1985), and strategic learning (Dodgson, 1991).

With respect to deutero-learning or Type III learning, the learning approach (to include singleloop and double-loop learning) of the organization is scrutinized via reflection and inquiry. In the process, an organization is able to determine the factors that facilitated or hindered learning and to improve on such learning approaches (Dierkes, et al., 2001). It is through deutero-learning that organizations learn how to learn, that is, they learn how to undertake single-loop and double-loop learning (Dodgson, 1993).

Although the classification of organizational learning into three types has been widely adopted by scholars of organizational learning, the categorization does have its critics. According to Dierkes et al. (2001), the three types of learning are at times difficult to distinguish from each other in real life situations and are said to overlap in certain conditions. Also, they focus mainly on error detection and correction as a means to learn and neglect the fact that learning can be "triggered by opportunities, creative initiatives, and the development or acquisition of new knowledge" (Dierkes et al., 2001, p. 283).

\subsubsection{Levels of Learning}

Organizational learning is said to occur at different levels within the organization. Most authors agree that it occurs on three levels, namely, individual, group and organizational, while a few others add a fourth level, interorganizational (Pawlowsky, 2001).

Individual learning is regarded by some authors as the most important for organizational learning because individuals are regarded as the agents of learning and they act on the organization's behalf (Friedman, 2001; Senge, 2006); they are responsible for information processing and decision making (Senge, 2006); and learning takes place in human heads (Crossan et al., 1995). It is through individuals that the learning process is put into motion: in fact, the individual is said to be the beginning and often the end of the organizational learning process (Friedman, 2001). 
For some scholars, the individual level is seen as the critical level of learning because organizations only learn when their employees learn, and when they take on new employees who have knowledge that does not currently exist in the organization (Crossan et al., 1995). However, others argue that individual learning alone is not sufficient for organizational learning (Friedman, 2001).

Group learning is said by some authors to be an extension of individual learning (Crossan et al., 1995). It comes into play because groups form the learning pathway between the individual and the organization as a whole (Pawlowsky, 2001). Although Senge (2006) stresses the role of the individual as an agent of organizational learning, he does point out that, "teams and not individuals, are the fundamental learning unit in modern organizations. This is where the rubber meets the road, unless teams can learn, the organization cannot learn" (p. 10). It is at this level that information sharing (Crossan et al., 1995; Pawlowsky, 2001) and interpretation, which are important processes that make organizational learning complete takes place (Crossan et al., 1995). Individuals have to work in groups (which forces them to share their knowledge) in order for their tacit knowledge to be converted to explicit knowledge and to develop new knowledge (Friedman, 2001). Furthermore, according to Roloff, Woolley, and Edmondson (2011), group or team learning is favored more over individual learning because with group learning, the learning process is said to occur faster and the organization is better able to deal with higher demands of productivity. They define team learning as "the processes and outcomes that involve positive change as the result of investments in developing shared knowledge and skills" (p. 252). They make mention of two types of group designs, namely, 'within group' and 'across group'. The latter is when individuals are simultaneously placed in multiple teams within the organization. Such multiple team memberships are said to enhance organizational learning because information has more paths through which it can flow, and the experiences of employees can be shared across the different departments. The across group design also ensures that more sources of information are available to other members of the organization.

The organization is also said to play its own role in organizational learning (Duncan \& Weiss, 1979; Fiol \& Lyles, 1985; Hedberg, 1981; Huber, 1991; Levitt \& March, 1988; Shrivastava, 1983; Stata 1989). "Learning by individuals and groups becomes organizational when inferences 
drawn from their experiences are encoded into routines (e.g., rules, standard operating procedures, policies, structures) that guide behaviour" (Friedman, 2001, p. 399). The organizational routines can then be passed on to new members (Fiol \& Lyles, 1985). Organizations are said to have learning systems because they are able to develop and maintain behaviours, mental maps, norms and values, all of which remain with the organization when employees leave (Fiol \& Lyles, 1985). If such organizational experiences are not ingrained or institutionalized, then only individuals would be said to have learned and not the organization (Argyris \& Schön, 1978). Also, it is at this level that the knowledge obtained from individuals is used for decision making (Crossan et al., 1995), and that the individual mental models are shared and jointly altered to develop shared mental models for the organization (Friedman, 2001).

Learning at the interorganizational level has to do with networking and the acquisition of information or knowledge external to the organization. It has however, not received as much attention as the three levels discussed above (Pawlowsky, 2001). Learning at this level takes place via partnerships, joint ventures, and other affiliations (Crossan et al., 1995).

\subsubsection{Further Scholarly contributions on Organizational Learning}

This study uses Huber's (1991) concept of organizational learning to explore the linkages between organizational learning and the ISO 14001 standard, and organizational learning and environmental management systems software. The contributions of other authors to the fields of organizational learning and the learning organization are also presented in order to better understand this relationship. These linkages will be discussed in Part Three of this chapter.

\subsubsection{The Constructs/Processes of Organizational Learning}

On examining the literature, Huber (1991) observed that there was a lack of a comprehensive examination of the concept of organizational learning and that there were too many diverse views on the subject. As such, he evaluated the literature to create a better understanding of

organizational learning. In so doing, he came up with the concept that organizational learning comprises four constructs/processes, namely information acquisition, information distribution, information interpretation and organizational memory. He further broke these constructs down with the exception of information distribution into subconstructs/subprocesses, of which, some 
have their own subconstructs/subprocesses. The constructs/processes and their subconstructs/subprocesses are depicted in Table 2.3. His definition of a learning organization is as follows: "an entity learns, if, through its processing of information, the range of its potential behaviors is changed" (p. 89). It is important to note that although Huber uses information and knowledge interchangeably he does attempt to make a distinction between both of them by stating that

I have, however, tried to use information when referring to data that give meaning by reducing ambiguity, equivocality, or uncertainty, or when referring to data which indicate that conditions are not as presupposed, and have tried to use knowledge when referring to more complex products of learning, such as interpretations of information, beliefs about cause-effect relationships, or, more generally, "know-how". (p. 89)

Table 2.3 Constructs and processes of organizational learning by Huber (1991)

\begin{tabular}{|c|c|c|}
\hline Constructs and Processes & $\begin{array}{l}\text { Subconstructs and } \\
\text { Subprocesses }\end{array}$ & $\begin{array}{l}\text { Subconstructs and } \\
\text { Subprocesses }\end{array}$ \\
\hline \multirow{5}{*}{ Knowledge Acquisition } & Congenital Learning & \\
\hline & Experiential Learning & $\begin{array}{ll}\text { - } & \text { Organizational } \\
\text { Experiments } \\
\text { - } & \text { Organizational Self- } \\
& \text { appraisal } \\
\text { - } & \text { Experimenting } \\
& \text { Organizations } \\
\text { - } & \text { Unintentional or } \\
& \text { Unsystematic Learning } \\
\text { - } & \text { Experience-based } \\
& \text { Learning Curves } \\
\end{array}$ \\
\hline & Vicarious Learning & \\
\hline & Grafting & \\
\hline & Searching and Noticing & $\begin{array}{ll}\text { - } & \text { Scanning } \\
\text { - } & \text { Focused Search } \\
\text { - } & \text { Performance Monitoring } \\
\end{array}$ \\
\hline Information Distribution & & \\
\hline
\end{tabular}


Table 2.3 Continued

\begin{tabular}{|c|c|c|}
\hline Constructs and Processes & $\begin{array}{l}\text { Subconstructs and } \\
\text { Subprocesses }\end{array}$ & $\begin{array}{l}\text { Subconstructs and } \\
\text { Subprocesses }\end{array}$ \\
\hline \multirow{4}{*}{ Information Interpretation } & Cognitive Maps and Framing & \\
\hline & Media Richness & \\
\hline & Information Overload & \\
\hline & Unlearning & \\
\hline \multirow{2}{*}{ Organizational Memory } & $\begin{array}{l}\text { Storing and Retrieving } \\
\text { Information }\end{array}$ & \\
\hline & $\begin{array}{l}\text { Computer-based } \\
\text { Organizational Memory }\end{array}$ & \\
\hline
\end{tabular}

Huber's four constructs are discussed briefly below.

\section{Knowledge Acquisition}

This is the process through which organizations intentionally and unintentionally search for and obtain useful information. The information can be obtained directly from the experience of the organization, from the experience of other organizations, and from the memory of the organization. The five processes involved in knowledge or information acquisition include congenital learning, experiential learning, vicarious learning, grafting, and searching and noticing. They are described in Appendix C.

\section{Information Dissemination or Distribution}

This construct involves the formal or informal sharing of information throughout the organization. It is said to be important because it allows for the various viewpoints within the organization to be brought together and triggers the process of information interpretation. Learning is more likely to take place when information is widely and timely distributed throughout the organization. As suggested by Huber (1991), internal employee transfer is one means by which nonroutine information is shared within the organization. Communication, which may be facilitated by technology (Argote, 1999; Nonaka, 1996; Romme \& Dillen, 1997; Roome \& Wijen, 2005) and the distribution of documents (Argote, 1999; Romme \& Dillen, 1997; Roome \& Wijen, 2005) are some other ways in which information or knowledge may be shared within an organization. 


\section{Information Interpretation}

This is the process through which members of an organization come to an agreement as to the meaning of the information that was acquired. Shared interpretation facilitates understanding and enables members of the organization to act upon information in unison. A thorough understanding of the information acquired and distributed can result in an increase in or decrease in collaboration amongst employees leading to a positive or negative change in behavior of members, nevertheless, organizational learning is said to take place (Huber, 1991). Shared interpretation also plays a role in the acquisition and interpretation of new information (Slater \& Narver, 1995; Tippins \& Sohi, 2003) because the new information is assessed based on the interpreted information that exists in the organization's memory (Tippins \& Sohi, 2003). Based on Huber's model, information interpretation has four subconstructs/subprocesses namely, cognitive maps and framing, media richness, information overload, and unlearning. They are also described in Appendix C.

\section{Organizational Memory}

This construct has to do with the storage of information by the organization via repositories to include humans. However, the latter are said to be poor sources of memory for the organization for the following reasons: employee turnover leading to loss of knowledge; those that require information do not always know where it is stored by their fellow employees; and on many occasions information is not stored because employees do not think it will be useful in the future. Organizational memory has two subprocesses namely, storing and retrieving information and computer-based organizational memory. They are both explained in Appendix C.

According to some authors, organizational memory can be declarative (which entails storing knowledge regarding for example, the organization's market situation) or procedural (which entails the storage of knowledge with respect to processes and procedures). Declarative memory has to do with general knowledge, while procedural memory has to do with specialized skills or routines (Tippins \& Sohi, 2003). Organizational memory is said to play an important role in organizational learning because it influences information acquisition (Huber, 1991; Moorman \& Miner, 1997; Slater \& Narver, 1995; Tippins \& Sohi, 2003), information distribution (Huber, 1991) and information interpretation (Huber, 1991; Moorman \& Miner, 1997; Tippins \& Sohi, 
2003). As suggested by other scholars, an organization's memory may be in the form of documents (Levitt \& March, 1988; Roome \& Wijen, 2005), embedded in employee's memory (Argote, 1999; Nelson \& Winter, 1982; Roome \& Wijen, 2005; Simon, 1991), be part of the organizational or physical structure (Argote, 1999; Levitt \& March, 1988; Roome \& Wijen, 2005), in the form of technology (Argote, 1999; Levitt \& March, 1988; Roome \& Wijen, 2005), and as routines (Argote, 1999; Cohen \& Bacdayan, 1996; Levitt \& March, 1988; Nelson \& Winter, 1982; Roome \& Wijen, 2005).

Some authors argue that information distribution and information interpretation are the processes that differentiate organizational learning from individual learning (Slater \& Narver, 1995) while others state that it is organizational memory that brings about this distinction (Goodman \& Darr, 1998).

\subsubsection{The Five Disciplines of a Learning Organization}

As mentioned earlier, it was Senge's book in 1990 that led to the popularization of the term "Learning Organization", thereby prompting organizations to start seeing themselves more as learning organizations (Easterby-Smith \& Lyles, 2011a).

For Senge (2006), a learning organization "is a place where people are continually discovering how they create their reality. And how they can change it" (p. 12). It is "an organization that is continually expanding its capacity to create its future" (p. 14). He proposed five disciplines that organizations need to master or improve on in order to become a learning organization. The disciplines are personal mastery, mental models, building a shared vision, team learning, and systems thinking. Figure 2.4 depicts the five disciplines, they are briefly described in Appendix C. 


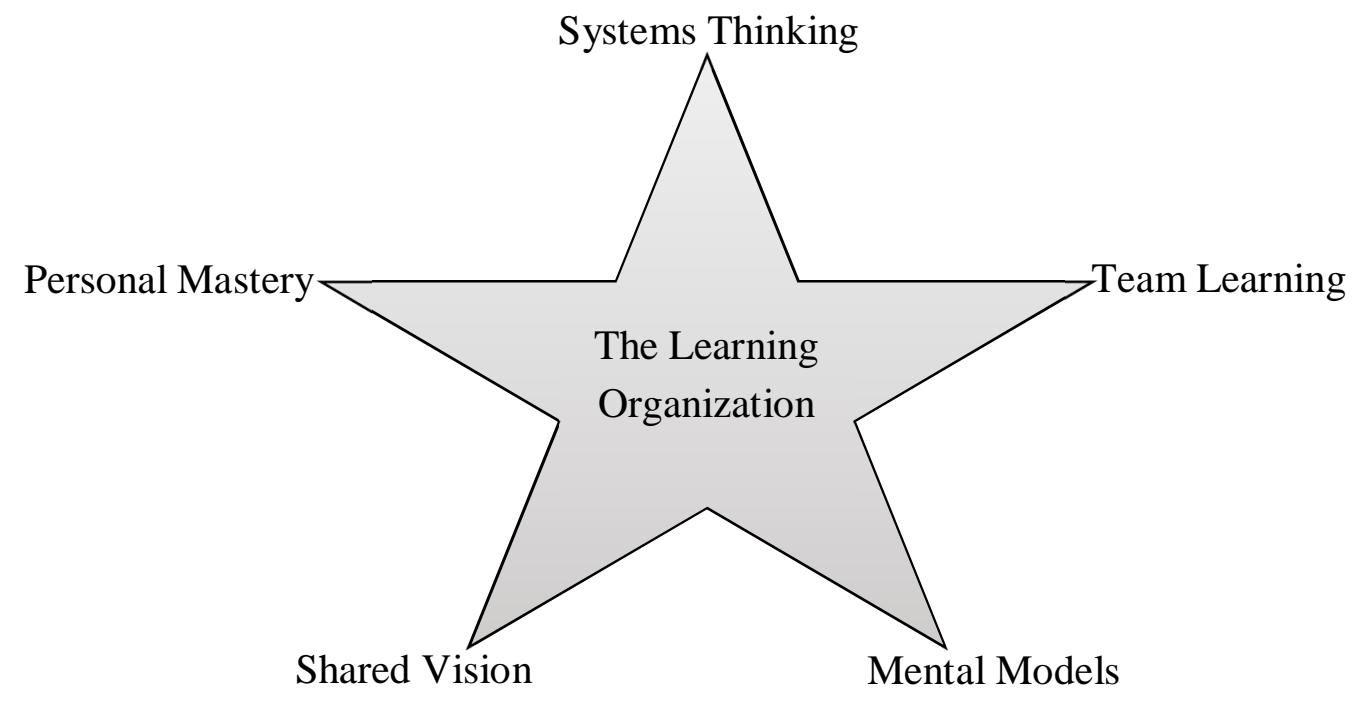

Figure 2.4 Senge's (2006) five disciplines of organizational learning

\subsubsection{The Building Blocks of a Learning Organization}

Like Senge (2006), Garvin (1993) focuses on the concept of the learning organization. He says that although a lot of scholars have studied the concept of the learning organization and the knowledge-creating company, most did not focus on the practical side, but rather they employed philosophy and metaphors. As such, he put forward a more practical approach using examples on how organizations had acquired learning skills and how they applied those techniques to improve performance. He is of the opinion that there should be some form of change for one to say that learning occurred and for some form of improvement to be seen by saying that "without accompanying changes in the way that work gets done, only the potential for improvement exists" (p. 80). Organizations that classify themselves as learning organizations are able to do so because they make the learning process occur intentionally and not by accident. He goes further to suggest five activities (building blocks) that learning organizations are skilled at and that if companies create "systems and processes that support these activities and integrate them into the fabric of daily operations, companies can manage their learning more effectively" (p. 81). The five activities or building blocks are systematic problem solving, experimentation with new approaches, learning from past experience, learning from the experiences and best practices of others, and transferring knowledge quickly and efficiently throughout the organization. Although Garvin is a scholar of the learning organization, his concept does somewhat overlap with the concept put forward by Huber (1991). For instance, experimentation with new approaches, 
learning from past experience, and learning from experiences of others can be likened to Huber's (1991) process of information acquisition, while transferring knowledge can be likened to information distribution. The five building blocks are shown in Figure 2.5, and are briefly discussed in Appendix C.

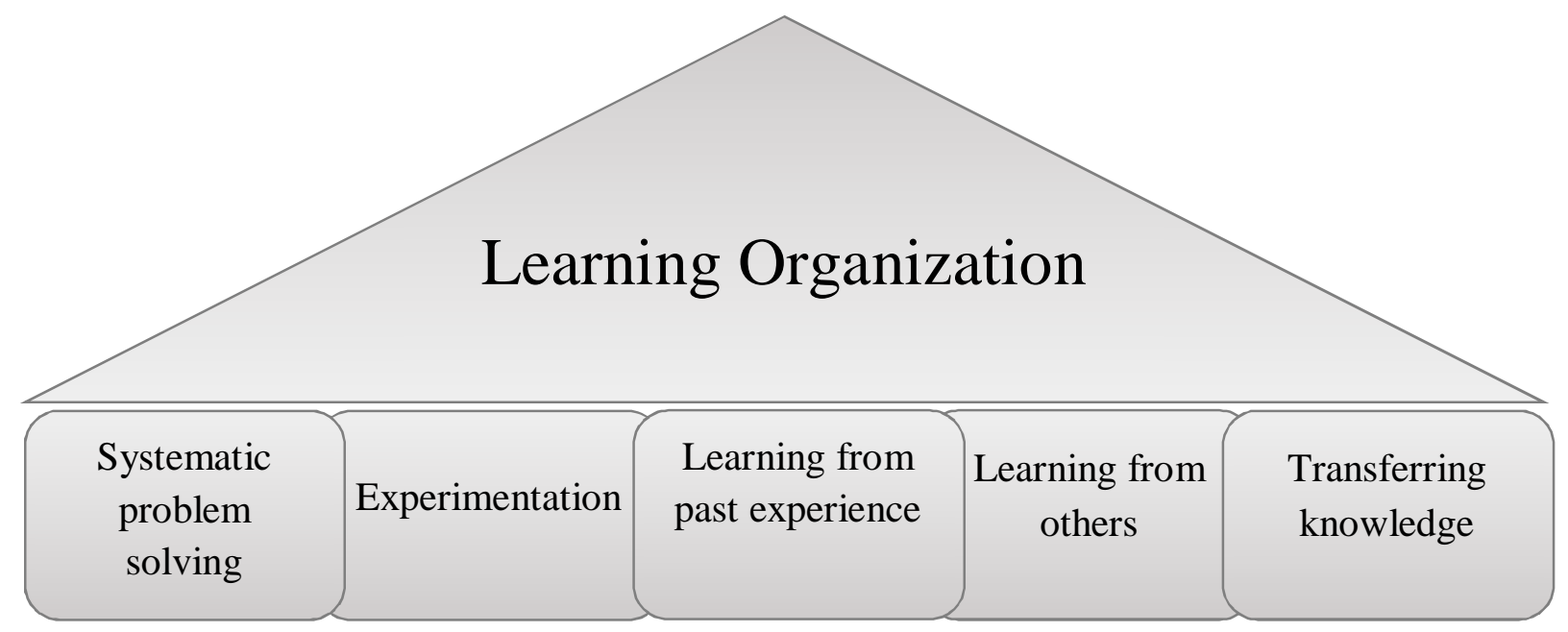

Figure 2.5 The building blocks of the learning organization by Garvin (1993)

\subsubsection{The Learning Cycle, and the Learning Orientations and Facilitating Factors}

The approach by DiBella and Nevis (1998) builds on the academic management literature. For them, they define organizational learning as "the capacity or processes within an organization to maintain or improve performance based on experience" (p. 28). Like Huber (1991), they identify with the information processing paradigm but proposed three information processes rather than four. The three processes are knowledge creation or acquisition, knowledge dissemination, and knowledge use. All three form what they call the organizational learning cycle, and they are all required for organizational learning to take place. They went further to propose what they refer to as learning orientations (LOr) and facilitating factors (FF), which are elements that assist in enhancing the learning cycle (i.e., the three processes) and thus enhance learning. Figure 2.6 shows the learning cycle, and the link between the learning orientations and the facilitating factors and the three processes. Only three elements out of seventeen are said to apply to all three processes, hence their position in the centre of the figure. The three processes are briefly described in Appendix C. 
The learning orientations are said to "reflect how learning takes place and the content of learning" as well as "represent the practices by which knowledge is acquired, disseminated, or used" (p. 39). They are based on the culture and fundamental competencies of the organization and can be described as paired approaches that fall on a continuum within which each approach is regarded as an extreme point. Organizations are said to favor one approach over the other or use a combination of both. Table 2.4 below shows the learning orientations and their learning approaches as they appear on the continuum.

Table 2.4 The seven learning orientations and their learning approaches on a continuum (Adapted from DiBella and Nevis (1998))

\begin{tabular}{|c|c|}
\hline Learning Orientation & Learning Approach \\
\hline Knowledge Source & Internal ------------------------------- External \\
\hline Content-Process Focus & Content ------------------------------ Process \\
\hline Knowledge Reserve & Personal ------------------------------ Public \\
\hline Dissemination Mode & Formal ------------------------------- Informal \\
\hline Learning Scope & Incremental ------------------------------Transformative \\
\hline Value-Chain Focus & Design-Make ----------------------------- Market-Deliver \\
\hline Learning Focus & Individual ------------------------------ Group \\
\hline
\end{tabular}

A brief description of each learning orientation is presented in Appendix C.

The ten facilitating factors are said to be an overlap and extension of the works of Senge (1990) and other scholars like Garvin (1993). "The factors are based on 'best practices' and common processes" (p. 24). They suggest that the more these factors are present the more likely an organization will learn: in other words, they promote learning. However, the presence of the facilitating factors is not a guarantee that learning will take place but in their absence the learning processes in organizations will be limited. They likened them to lubricants that help make an engine function properly. The ten facilitating factors are also briefly described in Appendix C. 


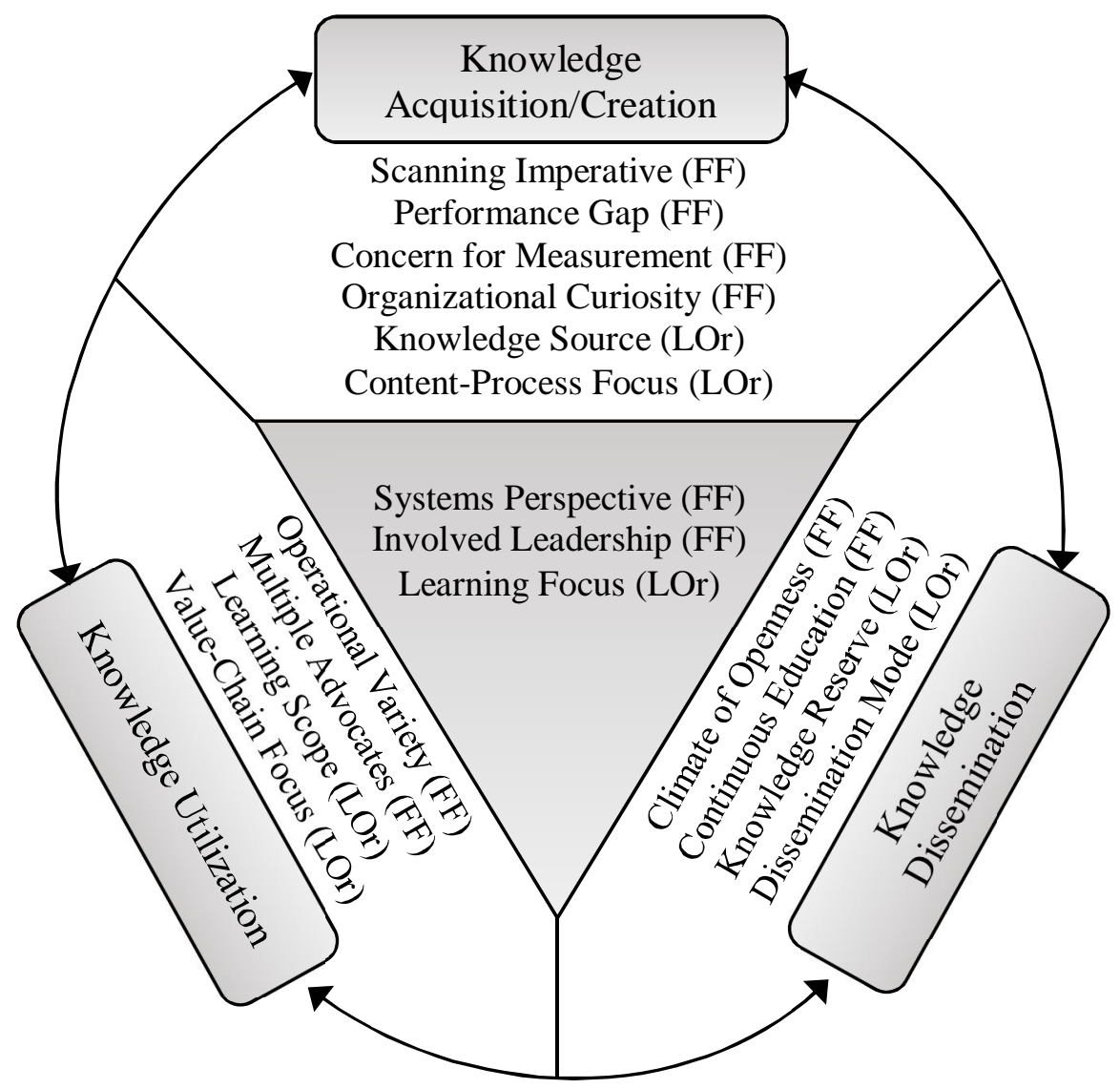

Figure 2.6 Elements of the integrated approach and their relation to the learning cycle (Adapted from DiBella and Nevis (1998))

\subsubsection{The Three stages of Organizational Learning}

Daft and Weick (1984) also made contributions to the information processing paradigm by proposing three stages that make up the learning process, namely scanning, interpretation, and learning. However, they place more emphasis on the interpretation of information in their model. They see interpretation as "a critical element that distinguishes human organizations from lower level systems (p. 285)". Organizations are said to be complex systems that acquire information from their environment, sort, and then analyse the acquired information for which interpretation plays an important role. For their interpretation model, they assume that (1.) Organizations operate as unrestricted social systems that undertake information processing activities. They must be able to process information with respect to "trends, events, competitors, markets, and technological developments" (p. 285). (2.) Organizations like individuals carry out the process of 
interpretation with the main difference being that sharing takes place on an organizational level be it data or insights. (3.) Top management is mainly responsible for the interpretation of information even though other employees may be engaged in scanning or information processing activities. (4.) The organizational interpretation process is a systematic one and does not occur by chance.

All three stages are said to be connected to each other by a feedback loop. Information from the learning stage may serve as new data for the scanning and interpretation stages. It is important to note that the learning cycle as proposed by Daft and Weick (1984) is a simplified approach that does not consider in detail the complications that can be brought about by the convictions, goals, politics, and viewpoints that exist within organizations. Figure 2.7 shows the three stages of the learning cycle and how they are connected. The three stages of the learning process are described in Appendix C.

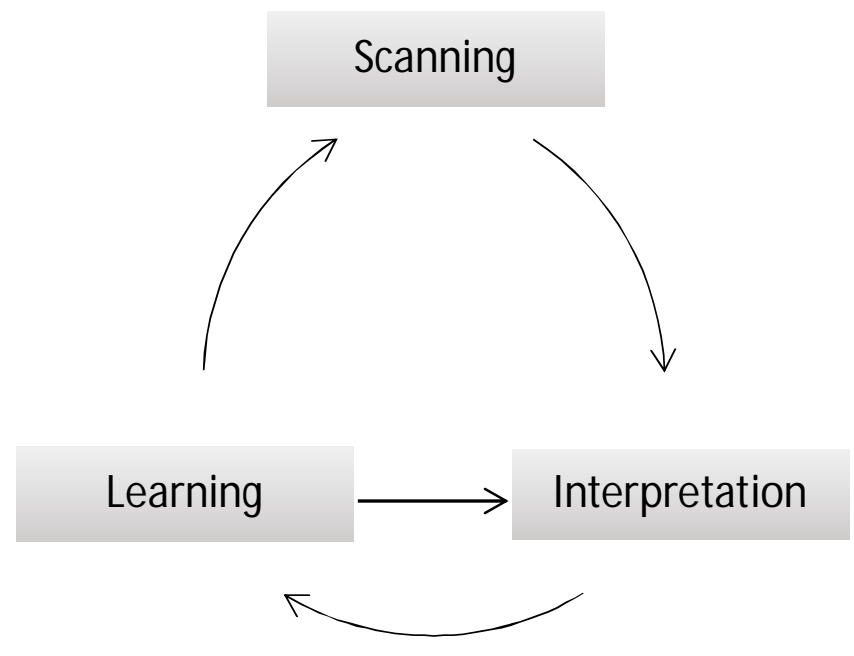

Figure 2.7 The three stages of organizational learning as proposed by Daft and Weick (1984)

\subsubsection{Knowledge Creation as Organizational Learning}

Nonaka, Toyama, and Byosiere (2001) contribute to the study of organizational learning by focusing on knowledge and its creation in organizations. For them, the ability to generate and use knowledge is what gives the organization a competitive advantage. They stress that the creation 
of knowledge forms part of learning and that it has been overlooked by most organizational learning scholars: this they say is one of the limitations of studies on organizational learning. The organization is considered to be a unit that continuously generates knowledge and not just an information processing machine. They proposed a three layered model of knowledge creation that includes knowledge conversion (socialization, externalization, combination, and internalization), $B a$, and knowledge assets. All three layers must interact with each other to bring about knowledge creation. Figure 2.8 shows the three layers of the knowledge creation process.

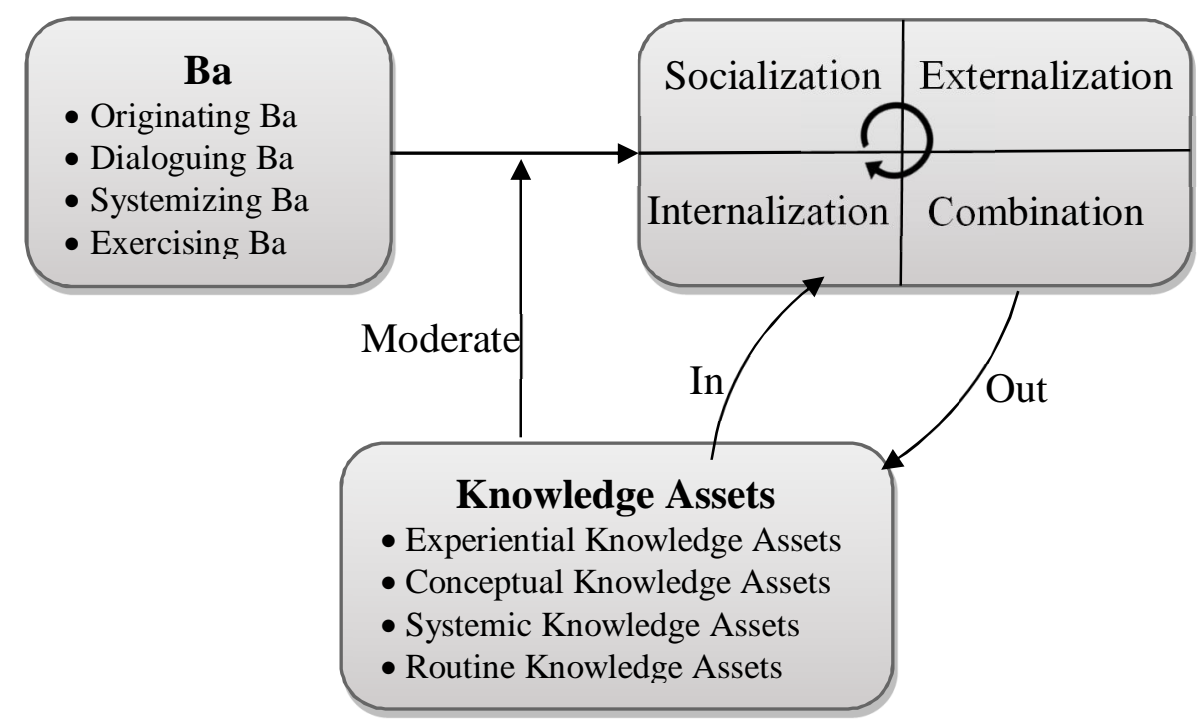

Figure 2.8 The three layers of the knowledge creation process (Adapted from Nonaka,
Toyama, et al. (2001))

\section{Knowledge Conversion}

The knowledge conversion process has to do primarily with the conversion of tacit knowledge into explicit knowledge and vice versa. They define explicit and tacit knowledge as follows: "explicit knowledge can be expressed in formal and systematic language and can be shared in the form of data, scientific formulae, specifications, manuals, and so forth. It can be easily processed, transmitted, and stored" (p. 494), while tacit knowledge "is highly personal and hard to formalize". "It is deeply rooted in action, procedures, routines, commitment, ideals, values, and emotions" (p. 494). It has a technical and cognitive component to it. Both are complementary and their relationship and how they interact with each other is fundamental to understanding the process of knowledge creation. Their interaction is referred to as knowledge 
conversion, which is regarded as a social process involving people. Knowledge conversion is made up of four modes, namely, socialization, externalization, combination, and internalization and are otherwise known as 'The SECI process'. They are briefly discussed in Appendix C.

Table 2.5 Summary of the SECI process

\begin{tabular}{|l|l|}
\hline Modes of conversion & Knowledge conversion \\
\hline Socialization & Tacit knowledge to tacit knowledge \\
\hline Externalization & Tacit knowledge to explicit knowledge \\
\hline Combination & $\begin{array}{l}\text { Explicit knowledge to more complex explicit } \\
\text { knowledge }\end{array}$ \\
\hline Internalization & Explicit knowledge to tacit knowledge \\
\hline
\end{tabular}

According to Nonaka, Toyama, et al. (2001), although individuals because of the tacit knowledge they hold play a major role in the knowledge creation process, the other levels in the organization, that is, group, organizational and inter-organizational, are also involved in the SECI process. Organizations are also said to distribute knowledge to their environment in the form of technology, products, services, and values. Likewise, they also receive knowledge from customers, suppliers and competitors and use it to generate new knowledge.

\section{Ba}

$B a$ in layman's term means 'place', it is the cornerstone of the four conversion processes mentioned above. It is defined as "a context in which knowledge is shared, created, and utilized, in recognition of the fact that knowledge needs a context in order to exist" (p. 499). Ba can be in the form of a physical space, for example, an office space; a virtual space, for example, email or teleconference; a mental space, for example, a shared experience, ideas, ideals; or a fusion of the aforementioned spaces. $B a$ is important because it is where interactions occur, and the interaction between individuals or individuals and their environment is important for the knowledge creation process. $\mathrm{Ba}$ facilitates the acquisition and combination of knowledge and thus provides a means to consolidate the knowledge assets of the organization. Four types of $B a$ are said to exist, each assisting with one of the modes of knowledge conversion mentioned above. They are originating $B a$, dialoguing $B a$, systemizing $B a$ and exercising $B a$, and they all interact with one another. A description of each $B a$ is presented in Appendix C. After the knowledge has been created in each 
$B a$, it is then shared within the organization and eventually becomes part of the organization's memory.

\section{Knowledge Assets}

These are said to be the "inputs and outputs of the knowledge-creation process" (p. 501) and they play an important role in the knowledge creation process of an organization. They also affect how $B a$ works. Nonaka, Toyama, et al. (2001) define assets as "firm-specific resources that are indispensable to the creation of values for the firm" (p. 501). Based on this definition, they see knowledge as an asset. They proposed four types of knowledge assets, viz, experiential knowledge assets, conceptual knowledge assets, systemic knowledge assets, and routine knowledge assets. They are discussed in Appendix C.

\subsubsection{Benefits of Organizational Learning}

Irrespective of the different views on both concepts, many authors seem to be of the opinion that a major benefit of organizational learning or being a learning organization is the improvement in performance (DiBella et al., 1996; Fiol \& Lyles, 1985; Nonaka, 1991; Slater \& Narver, 1995) and ultimately an enhancement of the organization's competitive advantage (Grant, 1996; Lei, Hitt, \& Bettis, 1996; Simonin, 1997; Tippins \& Sohi, 2003). The latter may be achieved because learning organizations will be in a better position to: enhance and maintain innovation, and respond to change (McHugh, Groves, \& Alker, 1998); better deal with customer needs through knowledge acquisition; improve quality of output; and improve the pace of change that brings about learning within the organization (Pedler, Burgogyne, \& Boydell, 1997). Using financial performance as an example, organizational learning is said to have the ability to lead to profitability and return on investment (Day, 1994a; Slater \& Narver, 1995) because organizations are in a better position to learn about their customers, competitors and regulators, which enables them to detect and act upon events and trends in today's ever changing and fast paced market (Day, 1994b).

It is based on the premise that organizational learning may lead to an improvement in performance as mentioned above that the following survey questions pertaining to the standard and EMS-based software were asked: 
1. If you are of the opinion that the standard leads to improved acquisition of useful information, could you comment on how this improvement affected organizational learning that influenced performance within your organization?

2. If you are of the opinion that the software leads to improved acquisition of useful information, could you comment on how this improvement affected organizational learning that influenced performance within your organization?

The same questions above were asked regarding information dissemination, information interpretation and organizational memory.

It is worth pointing out that the possible effect that organizational learning may have on performance was not measured; instead, the opinions of respondents were sought as to whether performance had been enhanced by an improvement in learning.

\subsubsection{Factors that impede Organizational Learning}

Most of the articles on organizational learning tend to focus more on the positive side of it and give the impression that the learning process is relatively smooth. However, this is not usually the case as pointed out by Antal et al. (2001). They state that "organizational learning is neither an effortless nor an automatic process, for the media continues to report regularly on troubled and failing organizations" (p. 865). They therefore attempted to highlight the barriers to learning that may exist in organizations by reviewing the literature on organizational learning. Based on their research, they discovered that barriers can be grouped into interrupted learning processes, psychological and cultural barriers, and barriers associated with organizational structure and leadership. The three categories are briefly discussed here.

\section{Interrupted Learning Processes}

This category is based on the model developed by March and Olsen (1975) and consists of four types of interruptions; namely, role constrained learning, audience learning, learning under ambiguity, and superstitious learning. It is based on the linkages that exist "between individual beliefs, individual action, organizational action, and environmental response" (Antal et al., 2001, p. 865). 
1.) Role constrained learning occurs when there is a break in the link between individual belief and individual action due to one's inability to put what they have learned into action. This usually happens when an employee is restricted by their job function in the organization.

2.) Audience learning occurs when the connection between individual action and organizational action is broken. For this barrier, an employee is unable to convince other employees to alter the behavioural rules that exist in the organization even after altering his/her own behaviour.

3.) Superstitious learning occurs when employees make wrong assumptions regarding the effect that the activities of their organization may have on the environment.

4.) Learning under ambiguity occurs when employees cannot recognize the changes that are taking place in the environment.

In addition to these four interruptions, Antal et al. (2001) highlighted two others that were proposed by Kim (1993), namely, situational learning and fragmented learning. Situational learning occurs when knowledge that has been learned is forgotten or is not stored, while fragmented learning occurs when learning is limited to only one employee or department in the organization and not the entire organization. It is said to occur mostly in highly decentralized organizations where the ability to network is usually limited. Finally, Hedberg (1981), added to the model of March and Olsen (1975) by introducing the term unlearning (Antal et al., 2001). If organizations do not unlearn then this could become a barrier to learning because unlearning allows for new knowledge to be acquired and for outdated knowledge to be discarded, and for old behaviours to be changed. Also, "the inability to stop certain skilled behaviours impedes the performance of new behaviours, and the inability to discard established mental models hinders the development and application of new ideas in an organization" (Antal et al., 2001, p. 866).

\section{Psychological and Cultural Barriers}

For this category, Antal et al. (2001) highlighted defensive routines, anxiety, success and failure, and short-sightedness as some of the barriers of organizational learning that were mentioned in the literature. 
1.) Defensive routines: as put forward by Argyris and Schön (1978) is developed by employees as a means to safeguard themselves from criticism that could affect their job in the organization. It usually occurs in organizations that have a culture of blame and lack of trust. Defensive routines have negative impacts because "they block the ability to learn to see or do things differently" (Antal et al., 2001, p. 867).

2.) Anxiety: according to Antal et al. (2001), the role of anxiety as a barrier to learning has been investigated by Schein (1993). Mechanisms within organizations that generate anxiety are said to block learning. Organizations that penalize employees who put their learning into practice and in the process depart from the rules of the organization, tend to promote anxiety that blocks learning.

3.) Success and failure: although both are said to be beneficial to learning, they do play their role in inhibiting learning. Despite the benefits of positive feedback from success, it can become a barrier to learning under certain circumstances. For instance, employees may fail to pick up on signals that indicate that something is going wrong because continuous success makes them become complacent. Also, success may lead to overconfidence which could prevent employees from discerning future risks. Crises is said to be required once in a while in order to prevent organizations from becoming complacent. Finally, continuous success may prevent members of the organization from seeking out new ideas and ways of doing things but rather continue to overuse the existing know-hows. While it is expected that organizations should learn from failure, there is also the danger that they could fall into what is called a failure-trap. This occurs when several concepts are tried out one after the other, and then discarded before any lessons could be learned from them. Similarly, "frequent failures can generate anxiety great enough to paralyze an organization so that it cannot learn" (p. 868).

4.) Short-sightedness: as a barrier to learning has been studied by Levinthal and March (1993). This occurs when companies focus more on short term outcomes and not long term outcomes and thus fail to look at the broader picture. In other words, they focus their learning on the present, which could be limited. 


\section{Organizational Structure and Leadership}

Antal et al. (2001) suggest that some structures favour learning while others do not. They highlight the work of Fiol and Lyles (1985) in which the latter argue that centralized and hierarchical structures inhibit learning because "a centralized, mechanistic structure tends to reinforce past behaviours, whereas an organic, more decentralized structure tends to allow shifts of beliefs and actions" (Fiol \& Lyles, 1985, p. 805). Other authors such as Moxen and Strachan (2000) are in agreement with this. However, Antal et al. (2001) also state that no empirical studies have proven that centralized structures inhibit learning and state that decentralized structures could also inhibit learning. This is so because decentralized structures can lead to fragmented learning as discussed earlier, which can lead to problems facing the organization as a whole to be left unsolved. Nonaka, Toyama, et al. (2001) agree with this and state that both structures do not take into consideration the dynamic nature of organizational knowledge creation. They instead proposed a middle-up-down structure, in which middle managers play a vital role. It entails putting in place "wide scope cooperative relationships and interactions between top, middle, and lower managers" (Nonaka, Toyama, et al., 2001, p. 505). With respect to leadership, Antal et al. (2001) observed that the absence of effective leadership or the absence of several effective leaders can inhibit learning. Organizational learning can also be impeded when leaders do not create an environment conducive for learning (Antal et al., 2001). This is in line with the facilitating factors of multiple advocates and leadership put forward by DiBella and Nevis (1998), which are both needed to enhance learning. Senge (2006) also talks about leadership as being important for the learning organization.

Senge (2006) does highlight a few barriers to organizational learning but refers to them as learning disabilities and mentions seven, of which he says, affects learning in everyday organizations. Some of them are similar to the barriers outlined by Antal et al. (2001). For instance, Senge (2006) mentions 'The myth of the management team' as a learning disability which can be likened to the defensive routines discussed above. Secondly, Senge's (2006) 'I am my position' can be related to role constrained learning because he says that employees tend to focus more on their job positions and overlook how it relates to the entire organization. Also, they see themselves as having no influence on other parts of the organization. Third, his 
'Fixation on events' disability can be likened to short-sightedness in which employees focus on short term events, this he says limits generative learning.

The other learning disabilities as described by Senge (2006) include 'The enemy is out there', which is blaming others for our failures and thus not tackling the right problems and learning from them; 'The illusion of taking charge' in which one is being reactive but thinks they are being proactive; the 'Parable of the boiled frog,' which is when we fail to detect and adapt to risks that are slowly developing within the organization; and the 'Delusion of learning from experience,' which occurs because the outcome of some of our actions take years to manifest and as such, one may not be able to detect problems that may arise in the future and make corrections in the present. As he stated, "we learn best from experience but we never directly experience the consequences of many of our most important decisions" (p. 23).

\section{Part 3}

\subsection{The ISO 14001 Standard, EMS-based Software, and Organizational Learning: Making} the connections

\subsubsection{The ISO 14001:2004 Environmental Management Systems Standard and Organizational Learning}

Only a few articles discuss a possible relationship between environmental management systems and/or standards (ISO 14001) and organizational learning. So far, most of them are theoretical developments of this relationship. Some of these articles show an explicit link between environmental management systems/standards and organizational learning (Burström, 2002; Epstein \& Roy, 1997; Reverdy, 2007; Rölker-Denker, 2011; Strachan, 1997) while others are a bit more implicit (Boiral, 2002; Darnall et al., 2008; Henriques \& Sadorsky, 2008; Huang \& Shih, 2009; Kloot, 1997; Petts et al., 1998; Veleva \& Ellenbecker, 2001). Although this research will focus on determining whether or not the implementation and maintenance of the ISO 14001:2004 standard has the ability to influence the four constructs/components of organizational learning as put forward by Huber (1991) and discussed in section 2.2.3 and Appendix $\mathrm{C}$, instances on how the standard may influence these constructs, as well as a general overview on how the standard may enhance organizational learning as suggested in the literature and based on the works of other organizational learning scholars, are presented in this section. 


\subsubsection{The Requirements of ISO 14001:2004 as facilitators of Organizational Learning}

Epstein \& Roy (1997) suggested that the ISO 14001 standard through its requirements (namely, environmental policy, planning, implementation and operation, checking, and management review), can contribute to organizational learning. A discussion on how the implementation and maintenance of the requirements of the standard and the standard in general may assist with organizational learning based on their work and the works of others is presented below.

\section{Environmental Policy}

The environmental policy is said to encourage organizational learning because it is a document that portrays the values, mission, commitment, vision (Epstein \& Roy, 1997), and "leadership by example" (ISO 14004:2004) of the organization as it pertains to environmental issues. The standard requires that the environmental policy be documented and communicated throughout the organization, and as such, it may assist with the development of a shared vision amongst employees and in turn inspire and motivate employees to participate more in environmental initiatives (Epstein \& Roy, 1997). The building of or presence of a shared vision is said to be crucial for a learning organization (Epstein \& Roy, 1997; Kloot, 1997; Lipshitz et al., 1996; Popper \& Lipshitz, 1995; Senge, 2006, Slater \& Narver, 1995), and is one of the five disciplines of a learning organization as described by Senge (2006). However, Senge (2006) does emphasize that the vision must be genuine and not simply a vision statement that is based on the compelling personality of a leader. With a genuine vision, employees may excel and learn out of their own will, which in turn will lead to a greater commitment and enrollment in preference to compliance (Senge, 2006). Furthermore, "a robust vision enables the organization to learn and adapt" (Slater \& Narver, 1995, p. 70). According to Senge (2006), a shared vision is of importance because it is required for generative learning to occur; it makes employees see the organization as their own; it builds trust; it creates a sense of oneness; it ensures that the learning process stays on course; it provides an underlying goal; it exposes our ways of thinking; it fosters risk taking and experimentation; it generates creative tension; and encourages commitment to long term goals, all of which are required in order to have a learning organization (Senge, 2006). Furthermore, a shared vision aligns the energies of employees with the goals of the organization (Senge, 2006; Slater \& Narver, 1995), enables the organization to determine the type of knowledge it should acquire (Epstein \& Roy, 1997; Slater \& Narver, 1995), and helps guide the planning activities of 
the organization (Slater \& Narver, 1995). In describing the role of the ISO 14001 standard in fostering a shared or joint vision in an organization, Burström (2002) cited Burström (2000) regarding the findings of a case study on the impact of the implementation of the environmental management system on a municipal organization and stated that by working with an environmental management system, employees were able to "put aside, or rather tone down, their traditional implicit and explicit positions in the municipal (environmental) policy sphere, and arrive at a valid overall definition of the municipal environmental situation" (p. 315-316 ). Also, based on results of a case study done by Reverdy (2007), the implementation of the ISO 14001 standard brought about a shared vision between the environmental department and other departments, and encouraged other departments to come on board as it pertains to environmental issues.

In building a shared vision through its policy, the standard may encourage active participation of employees, especially those close to the organization's activities that may have an impact on the environment (Boiral, 2002; Petts et al., 1998). Active participation is said to be an important condition for organizational learning because it may create a climate of openness that encourages employees to share their knowledge (information dissemination), which may in turn lead to the conversion of such employee's tacit knowledge to explicit knowledge (Boiral, 2002), thus promoting the process of externalization as put forward by Nonaka, Toyama, et al. (2001). Also, by building a shared vision, the standard may prevent the occurrence of audience learning because it may lead to a change in the environmental culture of the entire organization.

Finally, the policy by facilitating the building of common goals, visions, values and beliefs may lead to the creation of $b a$ in the form of a mental space. Creating common goals is one way that ba (mental space) can be built (Nonaka, Toyama, \& Konno, 2000).

\section{Planning}

As part of the planning requirement of the ISO 14001:2004 standard, organizations must identify their significant environmental aspects and impacts, and legal and other requirements as well as define objectives and targets, and develop environmental programs. As such, procedures and 
systems must be put in place to acquire and track information thereby keeping the organization up to date regarding new developments, best practices, and legal requirements.

\section{1.) Environmental aspects and impacts}

The environmental aspects and impacts requirement of the standard stipulates that the organization should determine the inputs and outputs of its present and past activities, its products and services, and so on, that may have a positive or negative effect on the environment (ISO 14001:2004). The data to be collected could be qualitative or quantitative in nature and may include information regarding the organization's processes and technologies; methods of transportation; environmental aspects as determined from regulations and by industry groups; and issues raised by stakeholders (ISO 14004:2004). As stated in the ISO 14004:2004 guideline, sources of such data may include general documents, operations manuals, codes of practice, past audit reports, national and international standards, data from monitoring processes, views of interested parties, reports on emergency situations or accidents, and a host of others (ISO 14004:2004). Based on the aforementioned, the identification of environmental aspects will therefore require the collection of information (ISO 14004:2004) from inside and outside the organization, and therefore entails Huber's (1991) process of information acquisition (experiential learning, vicarious learning, and searching to be more precise), or Daft and Weick's (1984) scanning process, or DiBella and Nevis' (1998) process of knowledge creation/acquisition, or learning from others, a building block put forward by Garvin (1993). With respect to the approach by DiBella and Nevis (1998), the organization's internal and external learning approaches with regards to its knowledge source orientation may be facilitated by the implementation of this requirement. After the environmental aspects have been identified, the standard requires that the organization determine which aspects are most significant and what their potential significant impacts may be. In order to determine and understand its potential significant impacts, an organization can choose to use flowcharts, cause-and-effect diagrams, and life cycle assessment (ISO 14004:2004), which all involve systematic problem solving, a building block of the learning organization (Garvin, 1993). Since technical analysis may be required in order to determine the significant environmental aspects and impacts (ISO 14004:2004), the process of information interpretation as described by Huber (1991) and Daft and Weick (1984) may be facilitated. In fact, even if technical analysis is not required, the data 
collected will have to be interpreted in order to make sense of the information and for there to be a common understanding between all those involved in the process. Once the significant aspects and impacts are determined, the knowledge gained can then be used to determine objectives and targets, training needs, methods of communication, operational controls, and monitoring and measurement procedures (ISO 14004:2004), hence, ensuring that the knowledge is utilized or that learning takes place. Knowledge utilization and learning form a part of the required cycle/stages of organizational learning based on the concepts of DiBella and Nevis (1998) and Daft and Weick (1984) respectively.

Also, the standard requires that the information on aspects and impacts be stored for future reference (ISO 14001:2004), thus forming part of the organization's memory. In the same vein, and based on the approach by DiBella and Nevis (1998), the fulfillment of this requirement may prompt the organization to enhance both its individual and public learning approaches with respect to its knowledge reserve learning orientation. With respect to the concept of knowledge creation by Nonaka, Toyama, et al. (2001), and the source and type of data to be collected, this requirement may strongly facilitate the process of combination because information is collected primarily from sources for which the knowledge is explicit, after which it is combined to form more explicit knowledge. It may to a lesser extent facilitate the processes of socialization (e.g., when tacit knowledge is obtained via interviews or meetings with interested parties and consultants), and externalization (e.g., when the tacit knowledge obtained is then made explicit via documentation).

The identification of the significant environmental aspects and impacts may promote teamwork and shared problem solving because it may involve the participation of employees who know the activities, products and services of the company very well (ISO 14004:2004). This shared problem solving (Leonard-Barton, 1995) and thus team learning is important for organizational learning (Crossan et al., 1995; Lipshitz et al., 1996; Pawlowsky, 2001; Senge, 2006) especially because it is one of the disciplines of a learning organization (Senge, 2006). Working or learning as a team is said to facilitate dialogue and discussion, which is necessary for learning to take place (Senge, 2006). Furthermore, teamwork is suggested to facilitate the sharing of information (Crossan et al., 1995; Pawlowsky, 2001) as well as the interpretation of information (Crossan et 
al., 1995; Jimenez-Jimenez \& Sanz-Valle, 2011; Kloot, 1997; Lopez, Peón, \& Ordás, 2004). Also, working as a team can create a climate of openness because it brings about trust as well as the sharing and questioning of employee's mental models. A climate of openness is one of the facilitating factors mentioned by DiBella and Nevis (1998). By prompting people to work together as a group, this requirement may also help develop the 'learning focus' of the organization with respect to both the individual and group learning approaches as described by DiBella and Nevis (1998). Working as a team can also facilitate the processes of socialization, externalization, combination, and internalization, and can lead to the creation of the four types of $B a$ (i.e., originating $b a$, dialoguing $b a$, systemizing $b a$, and exercising $b a$ ). As an example, Nonaka et al. (2000) mention the formation of a task force as a means to intentionally create $B a$.

Finally, the identification of aspects and impacts may trigger systems thinking, which is crucial for a learning organization (DiBella \& Nevis, 1998; Senge, 2006) because it prompts the scrutiny of the entire organization and its external environment in order to determine what effect its activities, products and services, be it on their own or through their interaction, may have on the environment. This requirement may also facilitate systems thinking because it may bring about the interaction amongst different units and groups within the organization. Systems thinking is a facilitating factor that is said to support all three processes (knowledge creation/acquisition, knowledge transfer, and knowledge utilization) of the learning cycle as described by DiBella and Nevis (1998).

\section{2.) Legal and other requirements}

This requirement also prompts the organization to collect new information especially information from its external environment (ISO 14001:2004). It serves to provide the organization with knowledge on applicable environmental laws or codes of practice thus enabling it to maintain or improve on its environmental performance (Whitelaw, 2004). Some recommended external sources of information include government bodies, published materials, industry groups, and consultants (ISO 14004:2004). Based on the above, this requirement may therefore facilitate the process of information acquisition, especially vicarious learning (a construct put forward by Huber (1991)) or scanning (as described by Daft \& Weick (1984)), and encourage the organization to learn from others, a building block put forward by Garvin (1993). 
Based on the approach by DiBella and Nevis (1998), it may also help enhance the organization's external learning approach with regards to its knowledge source orientation. The process of combination is most likely to be supported when identifying legal and other requirements because most of the information being collected is in the explicit form. However, socialization and externalization may be facilitated to a lesser degree in the case where, for example, information is sought through face-to-face interactions with consultants. It is recommended that the legal and other requirements be documented so that they can be easily tracked and updated (ISO 14004:2004). As such, if done, this requirement may also help enhance Huber's (1991) construct of organizational memory.

Finally, it may prevent or reduce learning under ambiguity because it may aid with the scanning of the environment and hence ensure that the organization is aware of the changes in its environment with respect to its legal obligations.

\section{3.) Objectives and targets}

The establishment and review of objectives and targets also entails acquiring information from inside and outside the organization's environment. Information required include the significant environmental aspects; the identified legal and other requirements; the concerns of stakeholders; the results of the environmental review; technological options; and financial and operational considerations (ISO 14001:2004; ISO 14004:2004). The objectives and targets are developed mainly by top management, but their establishment can also include other levels and functions in the organization that may play a role in the implementation and maintenance of the standard (ISO 14004:2004). As such, team work may be required for the establishment of this requirement and thus the promotion of learning as discussed earlier. Annex A of ISO 14001:2004 suggests that objectives and targets should take into account short term and long term issues, thus preventing short sightedness, which is said to be a barrier to learning (Antal et al., 2001; Senge, 2006). It also recommends that the organization in establishing its objectives and targets should search for the best-available technology when taking into account its technological options, thereby encouraging the organization to create new knowledge and be innovative. Since objectives and targets are to be measurable, they can act as facilitators of learning with respect to DiBella and Nevis' (1998) 'concern for measurement' in which metrics are said to be a good 
means to obtain feedback and thus enhance learning. The environmental objectives and targets are also to be documented (ISO 14001:2004).

\section{4.) Environmental programs}

With respect to the environmental programs, they define the procedures, goals, and responsibilities of the environmental management system, and requires shared responsibility cutting across different levels and functions of the organization in order to achieve the established objectives and targets (Epstein \& Roy, 1997; ISO 14001:2004). Hence, like the identification of aspects and impacts and the establishment of objectives and targets, the development and implementation of the environmental programs encourages shared problem solving and team learning amongst a diverse expertise of individuals with a common goal and thus may facilitate learning in this regard (Epstein \& Roy, 1997). Thus the implementation of this requirement may help facilitate learning by encouraging team work. The documented environmental programs are to be distributed to other functions in the organization that play a role in the environmental management system. As such, they may serve as a means to formally distribute information within the organization and as an internal knowledge source or a means for other employees to acquire information. It could therefore assist with the internalization of environmental knowledge by other employees outside of the environmental department. The environmental programs also become part of the organization's memory, as well as the organization's systemic (e.g., environmental manuals and other documentation) and routine knowledge assets (e.g., routine work practice). Knowledge assets play an important role in the knowledge creation process as described by Nonaka, Toyama, et al. (2001). The documentation process of the environmental programs also facilitates the processes of knowledge externalization and combination.

Although it is not explicitly mentioned in the literature linking environmental management systems and organizational learning, planning systems in general facilitate the acquisition of knowledge while the development of routines, procedures, and reports facilitate all four constructs of organizational learning (Kloot, 1997) and therefore function as learning mechanisms. Furthermore, planning is seen as learning because it helps scrutinize and change the mental models of employees, especially top management (Senge, 2006; Slater \& Narver, 1995). 


\section{Implementation and Operation}

Resources, roles, responsibility and authority, training and awareness, documentation and document control, and communication, all form a part of this requirement and some are suggested to play a role in organizational learning (Epstein \& Roy, 1997).

\section{1.) Resources, roles, responsibility and authority}

The ISO 14001:2004 standard requires that top management designate a representative to oversee the implementation and maintenance of the environmental management system and to ensure that it meets the requirements of the standard. The individual would serve as a leader and advocate for the organization with respect to environmental issues, and as mentioned by Senge (2006), DiBella and Nevis (1998), and Antal et al., (2001), an involved leader is important for learning to take place. Also, leaders are seen as champions of learning and unlearning (Slater \& Narver, 1995). Furthermore, in some organizations more than one individual can be designated as a representative (ISO 14001:2004, Annex A), thus providing multiple advocates for the promotion of the environmental values and goals of the organization. The presence of multiple advocates is said to be a facilitating factor for organizational learning (DiBella \& Nevis, 1998). In fact, as revealed by DiBella et al. (1996), the quality program at a company they studied was seen to move forward swiftly as soon as multiple advocates were brought on board. Besides requiring (a) designated champion(s), the standard via the ISO 14004 guideline strongly recommends that the commitment of top management be obtained thus encouraging the involvement of more leaders with respect to the environmental management system. Involved leadership is said to be a facilitator of learning and is important because it plays a major role with the processes of knowledge creation/acquisition, knowledge transfer and knowledge utilization (DiBella \& Nevis, 1998). The designated representative may also have the responsibility of interacting with interested parties on environmental issues (ISO 14004:2004), thus acquiring information or tacit knowledge that may be of use to the organization.

The environmental roles and responsibilities are not confined to the environmental department alone but can include other functions in the organization (ISO 14001:2004, Annex A), for example, purchasing, engineering, and quality (ISO 14004:2004). As such, a shared vision along with team learning and joint problem solving is likely to develop, which may promote learning in 
the organization as mentioned earlier. Besides human resources, the standard suggests that the organization identify other resources such as organizational infrastructure (e.g., communication lines, buildings, etc.), information systems, and technology, which will aid in the establishment of the environmental management system (ISO 14001:2004, Annex A; ISO 14004:2004). The acquisition of some of these resources may facilitate learning in the organization. For example, information systems may aid with the distribution and storage of information and facilitate the participation of employees in systemizing $b a$. The standard through its ISO 14004:2004 guideline recommends that organizations, especially small or medium sized enterprises (SME) that may have limited resources, engage in collaborative strategies by sharing technology and knowledge with larger organizations; sharing know-how and facilities with other SMEs; seeking training programs for employees from standardization organizations, trade groups, and so forth; and engaging universities in order to promote innovation. As a result, the standard may encourage vicarious learning, especially at the inter-organizational level. Finally, in order to implement the standard, organizations, especially SMEs may need to recruit new staff to oversee the process. The employment of new staff is said to lead to the acquisition of new knowledge by the organization (Esterby-Smith, 1997; DiBella et al., 1996) and is referred to as grafting by Huber (1991).

On another note, the fact that the standard through this requirement may support learning is supported by the fact that one of the said benefits of implementing the standard is its ability to assist organizations to efficiently and effectively define and assign roles and responsibilities within an organization (Proto \& Supino, 2000; Psomas et al., 2011).

\section{2.) Training and awareness}

The ISO 14001:2004 standard requires that training and awareness be provided to persons who work for and on behalf of the organization. This requirement is of importance because "awareness, knowledge, understanding and competence may be obtained or improved through training, education or work experience (ISO 14001:2004, Annex A, p. 14). Furthermore, one of the main responsibilities of top management is to build awareness and to motivate employees in order to build shared environmental values. The latter is of importance because "it is the commitment of individual people, in the context of shared environmental values that transforms 
an environmental management system from paperwork into an effective process" (ISO 14004: 2004, p. 21). Training and awareness therefore helps to enhance the skills of employees with and without environmental responsibilities and leads to the development of personal mastery. The latter is "an essential cornerstone of the learning organization" (Senge, 2006, p. 7), and has to do with the personal proficiency of members of an organization.

Other authors are in agreement with the notion that training can contribute to organizational learning. For example, Burström (2002) suggests that the training provided by an environmental management system can "contribute to individual and organizational learning in the organization, among other things helping to create new views of the world" (p. 314). Petts et al. (1998) see training as a means to develop knowledge and skills which form elements of a learning organization. They also mention the use of a competency based training that was used to improve the environmental knowledge of employees and to promote awareness with respect to environmental issues. Garvin (1993) states that "education and training programs are powerful tools for transferring knowledge" (p. 88).

Boiral (2002) states that training programs can be used to develop team spirit and to share knowledge as it pertains to solving environmental problems. DiBella and Nevis (1998) see training as a means for the formal dissemination of information, and as a means for providing continuous education (a facilitating factor) for all employees. Also, based on the concept of knowledge creation by Nonaka, Toyama, et al. (2001), training may facilitate the process of internalization. Huang and Shih (2009) are in agreement with this and refer to the conversion process as environmental knowledge internalization (EKI), in which learning is facilitated through the conversion of explicit environmental knowledge to tacit environmental knowledge. They also state that training can enhance environmental knowledge creation (EKC). Training is also one means to create exercising $b a$, which is important for the knowledge creation process (Nonaka, Toyama, et al., 2001).

Training also facilitates the development of the organization's memory (DiBella \& Nevis, 1998; Kloot, 1997), the interpretation of information, and the development of "shared" mental models, thereby enhancing the organization's ability to learn (Kloot, 1997). Mental models do affect our 
individual behavior and as such can affect learning in an organization, especially with regards to change. The standard via its ISO 14004:2004 guideline recommends as part of this requirement that employees and those that work on behalf of the organization are to be encouraged to make suggestions with respect to its environmental affairs thereby encouraging active participation of its members (ISO 14004:2004). As mentioned earlier, active participation has been found to facilitate organizational learning. The standard through its training requirement may also support the learning focus of the organization with respect to the individual and group learning approaches as described by DiBella and Nevis (1998). The training requirement may also help develop the organization's experiential and routine knowledge assets. Based on the above discussion, the standard through its training and awareness requirement may be able to facilitate Huber's (1991) four constructs of organizational learning.

On another note, one of the benefits of the standard is said to be its ability to build awareness and understanding amongst employees as it relates to environmental issues (Chavan, 2005; Psomas et al., 2011; Rondinelli \& Vastag, 2000; Schylander \& Martinuzzi, 2007). The training requirement may play a major role in this regard and in turn learning as discussed earlier.

\section{3.) Documentation and document control}

The documentation and document control requirement of the standard is also suggested to play a role with respect to organizational learning (Epstein \& Roy, 1997). One main purpose of documentation "is to provide necessary information to employees and other interested parties as appropriate" (ISO 14004:2004, p. 24). It also serves to provide direction as to where to retrieve more information with respect to the environmental management system (ISO 14001:2004). As such, it could facilitate the distribution of environmental information within the organization (Boiral, 2002; DiBella \& Nevis, 1998; Epstein \& Roy, 1997; Garvin, 1993), and serve as the organization's memory from which employees can acquire information (Boiral, 2002; Epstein \& Roy, 1997). Huang and Shih (2009) are of similar opinion and state that documentation aids with what they refer to as environmental knowledge sharing (EKS) because knowledge and information can be sent to others using documents, and environmental knowledge accumulation (EKA) because the documents can be used to amass knowledge or information from within and outside the organization. For them, the dissemination of information is also important because it 
serves as a facilitator for the development of new technology and green products (Huang \& Shih, 2009). With respect to DiBella and Nevis' (1998) learning orientations, the standard's documentation requirement can be said to enhance the organization's public knowledge reserve and public dissemination mode, and serves as an internal source of knowledge for the organization. Based on the aforementioned, documentation may therefore facilitate Huber's (1991) constructs of information distribution and organizational memory. It may also aid with the processes of externalization, combination, and internalization as described by Nonaka, Toyama, et al. (2001).

As mentioned by Huang and Shih (2009), it is through documentation that tacit knowledge can be made explicit, hence externalization, and that environmental knowledge internalization (EKI) may occur when handbooks or manuals are developed in order to provide employees with the knowledge they need to carry out their daily jobs. Also, the documentation of, for example, an audit report may facilitate the process of combination because explicit knowledge from various sources are combined to form more explicit knowledge to produce the report.

The documentation of environmental information/knowledge can also be used to provide customized training and empowerment, especially for new employees, who can consult them when in need of information or knowledge on environmental practices, and to prevent loss of knowledge through high turnover rates in organizations (Boiral, 2002). Also, it is mainly through the documentation requirement that most of the other requirements of the standard, such as the environmental aspects and impacts, the environmental programs, and the internal audit results may become knowledge assets for the organization, especially with regards to systemic and routine knowledge assets. Furthermore, it may ensure that knowledge that was acquired or created is utilized and that learning occurred. For example, the documented significant environmental aspects and impacts are used to put measures in place to prevent any effect the organization's activities may have on the environment. Finally, since the documentation process involves the combination of explicit knowledge, which may be undertaken by more than one person, it may facilitate the creation of systemizing $b a$ in which information technology plays a major role. 
The document control requirement ensures that documents are frequently reviewed and revised as needed; that up-to-date documents are available where needed, thereby ensuring that employees have the right information; and that outdated documents are not being used or are discarded (ISO 14004:2004) thus facilitating unlearning. The latter allows for new information or knowledge to be acquired or learned (Antal et al., 2001; Huber, 1991) and for new interpretations to be developed (Huber, 1991).

Documentation and document control may also play a role in ensuring that situational learning (i.e., when knowledge is not stored) and fragmented learning (i.e., when only one individual or department learns) as described in Part Two of this chapter do not occur in an organization.

\section{4.) Communication}

Internal communication as required by the standard is to be undertaken at the different levels and functions of the organization (ISO 14001:2004) because it facilitates problem solving and collaboration, and also helps raise awareness and encourage dialogue among employees as it pertains to the organization's environmental affairs (ISO 14004:2004). A few media that can be used for internal communication include internal newsletters, minutes of meetings, postings on bulletin-boards, websites (ISO 14001:2004, Annex A; ISO 14004:2004), meetings, suggestion boxes, email, and joint committees (ISO 14004:2004). The organization can choose to communicate with external parties with respect to its environmental management system using media such as newsletters, websites, annual reports, community meetings (ISO 14001:2004, Annex A; ISO 14004:2004), focus groups, informal deliberations, press releases, e-mail, and telephone hotlines (ISO 14004: 2004).

As with internal communication, external communication with interested parties can encourage understanding, facilitate enrollment, and promote dialogue with respect to the organization's environmental management system (ISO 14004:2004). Dialogue is said to be an important factor for the learning organization because it helps members to share and expose their mental models and possibly change their way of thinking (Senge, 2006). Petts et al. (1998) are in agreement with this and are of the opinion that communication can bring about change within an organization. Based on the aforementioned, the communication requirement may prevent 
audience learning from occurring. Effective communication (internal and external) as required by the ISO 14001 standard enables the flow and exchange of ideas necessary for learning (Burström, 2002; Epstein \& Roy, 1997) and ensures that more than one person in the organization learns (Epstein \& Roy, 1997). Burström (2002) states that the implementation of an environmental management system standard has the ability to enhance communication within an organization and thus positively affect organizational learning. This is so because communication enables members of an organization to share information and in the process develop a shared understanding and consensus (Burström, 2002; Slater \& Narver, 1995). Furthermore, communication could play a role in information interpretation because it may prompt the organization to use media that is rich in content, and media richness, which is one of the subprocesses put forward by Huber (1991) determines how information is interpreted.

Based on the aforementioned, and the methods that can be used for communication, one may infer that the communication requirement could assist with the acquisition, dissemination, interpretation and storage of information. Furthermore, communication could create a climate of openness and trust and therefore lead to the dissemination of information be it formally or informally (DiBella \& Nevis, 1998). Also, depending on the type of media (e.g., meetings and joint committees) to be used, it may facilitate the creation of some or all types of $b a$, and assist with the processes of socialization (via face-face meetings or focus groups), externalization (via minutes of meetings), combination (via communication networks), and internalization (via newsletters, websites, etc.).

The ISO 14004:2004 guideline also recommends that a means to obtain feedback from all employees as well as to deal with employee suggestions and concerns should be put in place as part of the organization's communication procedure, thus encouraging active participation of employees.

Finally, the building of environmental awareness and understanding amongst employees, a benefit of the standard (Chavan, 2005; Psomas et al., 2011; Rondinelli \& Vastag, 2000; Schylander \& Martinuzzi, 2007) may also be as a result of the standard's communication requirement. 


\section{5.) Operational controls}

The organization is required to identify what operational controls are needed and where they are to be put in place in order to handle its environmental aspects and impacts, achieve its objectives and targets (ISO 14001:2004), make sure it is in compliance with its applicable legal and other requirements, and to prevent or reduce environmental risks (ISO 14004:2004). The identification of operational controls entails evaluating all the operational areas that are associated with the organization's significant environmental aspects (ISO 14001:2004, Annex A) and includes looking at other departments such as engineering, research and development, and marketing; daily operations like manufacturing; and the distribution of products (ISO 14004:2004).

As a result, not only will the organization be prompted to acquire information from its internal and external environment and interpret the information, but it will also be prompted to adopt a systems approach in order to achieve this requirement, which is required for an organization to learn effectively. Also, knowledge already gained through other requirements such as the identification of environmental aspects and impacts may be used for the development of operational controls thereby ensuring that knowledge was utilized and that the learning stage as described by Daft and Weick (1984) or the learning cycle as described by DiBella and Nevis (1998) is complete.

Some examples of operational controls include documents (ISO 14001:2004), which could be "in the form of instructions, signs, forms, videos, photos..." (ISO 14004:2004, p. 26); contract agreements; and physical controls (ISO 14004:2004). Whatever controls are put in place must be communicated to employees and persons that work on behalf of the organization such as contractors (ISO 14001:2004; ISO 14004:2004), thus facilitating the distribution of information. Also, the documents serve as memory for the organization. It is recommended that training be provided to persons that work in areas where controls are needed (ISO 14004:2004) thereby improving the understanding and knowledge of such individuals. In identifying operational controls, new knowledge may be created, the four processes of knowledge conversion may be promoted, and the established operational controls may become knowledge assets for the organization. 


\section{6.) Emergency preparedness and response}

The standard requires that the organization identify all potential emergency situations and accidents and establish preventative measures as well as measures to mitigate such situations should they occur. In order to do so, the organization has to acquire information from within and outside its environment, for example, the type of hazards present on site, the proper methods to deal with emergency situations, the emergency situations that could occur at neighbouring facilities, to mention a few (ISO 14001:2004, Annex A). The information acquired will have to be interpreted and distributed within the organization. The emergency procedures will have to be documented, thus serving as memory or knowledge assets for the organization from which employees can obtain information should the need arise. The standard also requires that the emergency procedures be tested (ISO 14001:2004) thereby encouraging learning-by-doing, and thus facilitating the internalization of environmental knowledge. The processes of externalization and combination may also be facilitated via documentation. This requirement may also facilitate learning through the training of employees that are involved with emergency response; the assessment of past accidents, which enables the organization to put corrective and preventive measures in place; and the collaboration with other organizations that are in the same community.

\section{Checking}

The checking requirement of the ISO 14001:2004 standard serves as a learning mechanism because it provides a means of feedback and evaluation through monitoring and measurement activities (Burström, 2002; Epstein \& Roy, 1997), the internal audit, and the corrective and preventive actions requirement (Epstein \& Roy, 1997). The checking requirement prompts the organization to learn from its own experience (Epstein \& Roy, 1997): and learning from past experience is seen as important for a learning organization (DiBella \& Nevis, 1998; EasterSmith, 1997; Garvin, 1993; Huber, 1991; Senge, 2006) and can be likened to Huber's (1991) subprocess of experiential learning (organizational experiments to be precise). Epstein and Roy (1997) likened the checking requirement to the single-loop learning episode (see Figure 2.9) as described by Argyris and Schön (1978). As stated in Part Two of this chapter, single-loop learning involves the detection and correction of errors that do not affect the overall policies and goals of the organization. 


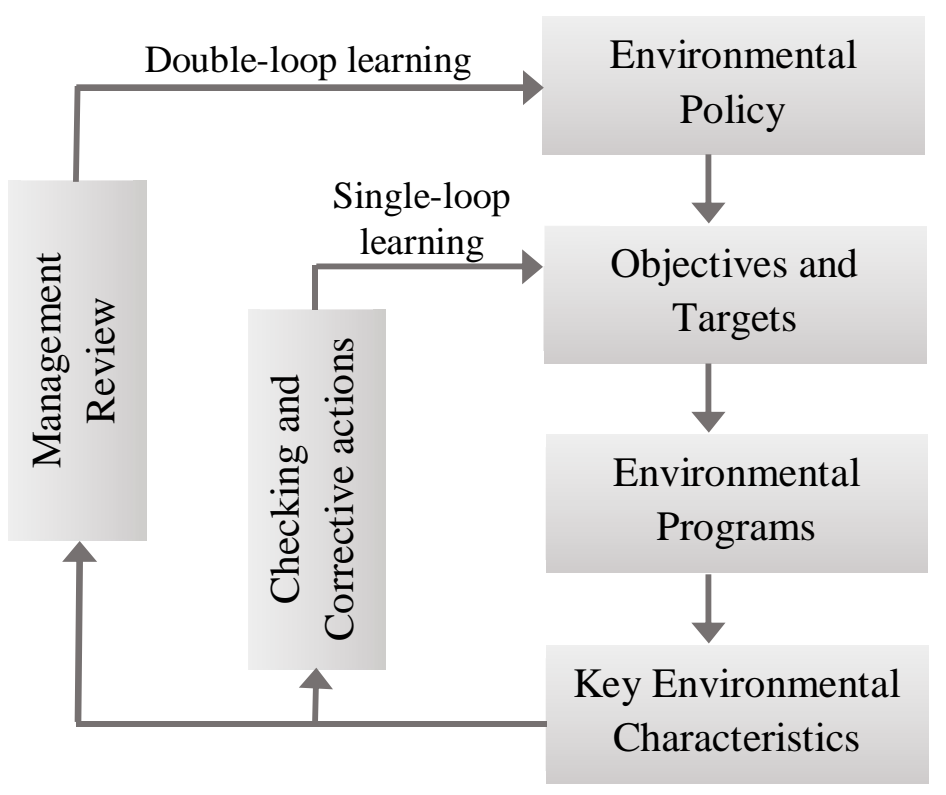

\section{Figure 2.9 Single-loop and double-loop learning episodes of ISO 14001 (Adapted from Epstein and Roy (1997))}

\section{1.) Monitoring and measurement}

Monitoring and measurement entails the collection and analysis of data (ISO 14001:2004, Annex A), which could be qualitative or quantitative in nature (ISO 14004:2004). As such, it could therefore facilitate the processes of information acquisition and interpretation. It may assist with the interpretation of information because the analysis of data provides meaning to the information collected. The knowledge acquired and interpreted can then be utilized for other areas of the environmental management system such as the assessment of operational controls, the evaluation of the objectives and targets, the implementation of corrective and preventive actions, and to monitor and assess the overall performance of the environmental management system (ISO 14001:2004, Annex A; ISO 14004:2004). For example, data on emissions and discharges can be used to ensure that the organization is meeting its legal and other requirements or its objectives and targets, thus prompting the evaluation of the success or failure of its environmental management system (ISO 14004:2004).

The monitoring and measurement requirement may also promote learning by acting as a facilitating factor, because it provides feedback, which enables the organization to determine if 
there are gaps in its performance, and it prompts the organization to develop metrics or use already established metrics for its measurements. Both attributes are similar to the facilitating factors 'performance gap' and 'concern for measurement' respectively, which support learning as put forward by DiBella and Nevis (1998). This requirement may also aid in the conversion of the acquired explicit knowledge to more explicit knowledge (combination) and explicit knowledge to tacit knowledge (internalization). Boiral (2002) suggests that the more closely employees work with equipment used for monitoring purposes, the more likely they will obtain (internalize) implicit knowledge, which can then be used to tackle environmental issues such as pollution prevention. The information obtained from this requirement is also to be documented (ISO 14001:2004).

\section{2.) Internal Audit}

The internal audit helps the organization determine if its environmental management system meets the requirements of the standard, and serves as a source of information for management (ISO 14001:2004). It serves as a means to detect any nonconformities with respect to the environmental management system; to provide feedback to correct and prevent any nonconformities that were identified; and in general, to determine elements of the environmental management system that might need to be improved (ISO 14004:2004). As such, conducting internal audits may facilitate single-loop learning or incremental learning, and act as a facilitating factor with regards to 'performance gap'.

The audit facilitates the collection and storage of environmental information useful to the organization and therefore serves as an internal knowledge source and a public knowledge reserve from which the employees can refer to in the future. Also, since the information collected will have to be analysed and interpreted, the audit can be said to aid with information interpretation. It also serves as an input for the management review process (ISO 14001:2004) thereby ensuring that the information obtained is utilized by the organization for the improvement of its environmental performance. In doing so, it also promotes the distribution and sharing of information. The internal audit may also assist with the processes of socialization (e.g., through interviews in which tacit knowledge is shared), externalization (e.g., when tacit knowledge collected is made explicit through documentation), combination (e.g., when explicit 
knowledge gathered from different areas of the organization is combined in the form of a report thus creating more complex explicit knowledge), and internalization (e.g., when the lessons learned from the audit process is passed on to other employees in order to take corrective and preventive actions).

\section{3.) Nonconformity, corrective action and preventive action}

Under the ISO 14001:2004 standard's nonconformity, corrective action and preventive action requirement, the organization is to identify and rectify nonconformities, find out what caused them, establish corrective and preventive measures in order to ensure that they do not recur, determine whether the corrective and preventive measures are working as planned, and keep a record of the feedback obtained from the corrective and preventive measures (ISO 14001:2004). This requirement may therefore serve as a means to detect errors in the system and to provide feedback where necessary, thus serving as a mechanism for learning. Also, when undertaking this requirement, information will have to be acquired, interpreted and distributed to those whose job activities are affected.

Nonconformities can be determined through the use of internal audits or by making the identification process part of the daily work duties of employees (ISO 14004:2004), which may encourage active participation. As discussed earlier, the internal audit may serve as a learning mechanism for the organization, and active participation is seen as an important condition for organizational learning. Also, potential nonconformities may be determined using techniques like trend analysis and hazard operability studies (HAZOP), or by using the results from corrective measures that were implemented in one area to predict possible problems in other areas where similar operations are undertaken (ISO 14004:2004). As such, systematic problem solving, which is essential for a learning organization (Garvin, 1993) may be encouraged.

The search for and establishment of preventive measures may also lead to the harnessing of tacit knowledge and the questioning of what is already in place (Boiral, 2002). By raising questions about what is on ground and the possible need for change, it may therefore facilitate single-loop learning or double-loop learning depending on what kind of changes will be required in order to put such preventive measures in place. It may also lead to the creation of new knowledge (Boiral, 
2002) because alternative approaches to carrying out certain activities may be learned. The documentation of the procedures for this requirement becomes part of the organization's memory as well as the organization's systemic and routine knowledge assets. As mentioned in Part One of this chapter, preventive action is no longer referred to in the latest version of the standard, however it will still be captured in the new clauses, context of the organization and actions to address risks and opportunities (BSI Group, 2015). As such, the possible role of preventive actions in facilitating learning as discussed above can still be taken into consideration.

\section{4.) Evaluation of compliance}

In order for the organization to evaluate its compliance to its applicable legal and other requirements, it can use any or a combination of the following: audits, facility tours, inspections, test results, interviews, and document reviews (ISO 14004:2004). As a result, information has to be collected, interpreted, and transferred within the organization, and knowledge may be converted as well as be utilized. The organization is also required to keep records of the findings of the evaluation (ISO 14001:2004). According to Garvin (1993), conducting facility tours is one way in which knowledge can be transferred within an organization. Interviews may facilitate the process of socialization, and serve as a means to collect and transfer information.

\section{5.) Control of records}

Records serve as evidence that the organization is conforming to the environmental management system and to the standard (ISO 14001:2004). Records include audit reports, process monitoring records, records of incidents, results of the management review, data on environmental performance, to mention a few (ISO 14001:2004; ISO 14004:2004). Records, therefore are a good means to enhance the organization's memory and therefore support the organization's learning orientations with respect to internal knowledge source and public knowledge reserve. They may also become knowledge assets for the organization, especially systemic knowledge assets. Although the control of records is no longer a requirement of its own in the new version of the standard, it is still captured under the clause, documented information (BSI Group, 2015; ISO 14001:2015), as such, it is still relevant in terms of its possible contribution to promoting learning. 


\section{Management Review}

The management review process is said to involve double-loop learning (Epstein \& Roy, 1997). Double-loop learning occurs "when error is detected and corrected in ways that involve the modification of an organization's underlying norms, policies, and objectives" (Argyris \& Schön, 1978, p. 3). This requirement as it relates to double-loop learning is depicted in Figure 2.9 above. It is important to note that double-loop learning is said to play a vital role in determining whether an organization succeeds or fails (Argyris, 1977; Senge, 2006); however, both types of learning are crucial for a learning organization (Senge, 2006). The feedback from the management review process and some of the other requirements of the standard such as the internal audit process is used to evaluate the performance of the environmental management system as well as the overall strategies and policies that are being used to implement and maintain the environmental management system (Epstein \& Roy, 1997). This requirement therefore enables the organization to learn from its own experience, which is a skill required of a learning organization (Garvin, 1993) and therefore facilitates experiential learning. The management review not only seeks to find errors, but also seeks to determine opportunities for improvement (ISO 14001:2004). It serves as an important learning mechanism because it allows for knowledge to be acquired and disseminated and enables the company to adjust to the new knowledge (Epstein \& Roy, 1997). Also, it is required that the records of the review be maintained (ISO 14001:2004) thus serving as memory for the organization from which lessons learned can be used for future purposes. The standard through this requirement may support the organization's learning orientation with respect to its learning scope (transformative), its learning focus (individual and group), and it may act as a facilitating factor with respect to 'performance gap'.

Because the review process will most likely entail discussion and dialogue, which are essential for learning (DiBella \& Nevis, 1998; Senge, 2006), organizational learning may be enhanced among the participants. Also, the discussion and dialogue may facilitate the interpretation of the new information that was obtained. The outputs from the review process serve as a source of knowledge that can be applied to other areas of the environmental management system thus ensuring that the process of knowledge utilization or learning takes place. Besides top management, environmental staff and members from different units in the organization can 
participate in the management review process (ISO 14004:2004), thereby allowing for a diverse group of individuals with different backgrounds to provide different perspectives.

Since the management review process brings about the interaction of employees, the processes of socialization, externalization, combination and internalization are likely to take place. Internalization of knowledge may also be encouraged when the results of the review are shared with other employees in order to implement corrective and preventive actions. Furthermore, the fact that it encourages the interaction of individuals (especially face-to-face) means that it could lead to the formation of $b a$, especially originating $b a$ and dialoguing $b a$ as described by Nonaka, Toyama, et al. (2001).

On another note, an organization's ability to learn or create knowledge is also dependent on the four dimensions of its core capabilities as outlined by Leonard-Barton (1995), namely: skills and knowledge of employees, physical technical systems (e.g., databases, software programs and various equipment), managerial systems (e.g., training programs, reward and incentive programs that reward learning), and values and norms. By building these four dimensions, an organization will be in a better position to learn (Epstein \& Roy, 1997). The ISO 14001 environmental management system standard directly (e.g., through training and instilling values and norms in the organization) and indirectly (by encouraging implementation of reward and incentive programs) has the capability to contribute to the development of these dimensions and thus enhance learning. The role of reward programs and incentives in promoting learning is also supported by Garvin (1993).

Again, environmental performance evaluation, which entails the use of environmental indicators, though not explicitly required by the ISO 14001:2004 standard can also serve as a learning mechanism because it is said to provide feedback to the organization via assessment and review of their activities (Burström, 2002; Veleva \& Ellenbecker, 2001). The environmental indicators utilized for this process therefore help facilitate experience-based learning (Burström, 2002) or single-loop learning. Knowledge may also be created from the use of such indicators. The environmental indicators as recommended by the ISO 14001:2004 standard enable an organization to determine whether it is meeting certain requirements of the standard such as its 
objectives and targets, and whether its environmental performance is improving on the whole (ISO 14004:2004). A few examples of environmental indicators include the number of environmental accidents or incidents that occurred, the amount of raw materials being used, and the amount of emissions produced (ISO 14004:2004). The use of environmental indicators can be said to be a facilitator of learning with respect to the facilitating factors, 'performance gap' and 'concern for measurement', as put forward by DiBella and Nevis (1998). In the latest version of the standard, the use of indicators has been added as part of the requirement, 'environmental objectives and planning to achieve them,' as such, the role of the standard in enhancing learning through the use of indicators may become more pronounced.

The ISO 14001 standard follows the Plan, Do, Check, Act (PDCA) model or cycle (ISO 14004:2004). The PDCA model is regarded as one of the techniques for systematic problem solving (Garvin, 1993), hence, the standard may promote learning through the use of this model.

Finally, a systems approach is said to be important in order for learning to be effective (DiBella \& Nevis, 1998; Easterby-Smith, 1997; Petts et al., 1998; Senge, 2006). In general, the implementation and maintenance of an environmental management system may encourage a systems approach by making employees aware of the fact that environmental issues are tied to almost every aspect of life and by enabling the different units in an organization recognize that they are dependent on one another, especially when it comes to tackling environmental problems (Burström, 2002). Active participation, communication, and a shared responsibility are said to play an important role in facilitating a systems approach (Petts et al., 1998), and are encouraged by the implementation of the standard.

\subsubsection{Other ways in which the Standard may facilitate Organizational Learning}

The ISO 14001 standard may contribute to organizational learning in other ways as well. First, organizational learning is seen to be associated with "planned" organizational change (Argyris, 1977; Burström, 2002; Kloot, 1997; Senge, 2006). Since the ISO 14001 environmental management systems standard can bring about transformative change within the organization or amongst some members of the organization it could contribute to learning (Burström, 2002). 
Such changes may also prompt an organization to unlearn old ways of doing things thus providing room to learn new things (Burström, 2002) as well as prevent audience learning.

Second, continuous experimentation is said to be required for a learning organization (Burström, 2002; DiBella \& Nevis, 1998; Garvin, 1993; Huber, 1991; Leonard-Barton, 1995; Senge, 2006). The implementation and maintenance of an environmental management systems standard such as ISO 14001 in itself can be considered to be an experiment that leads to the continuous development and implementation of new policies, processes, procedures, and technology as it relates to environmental issues (Burström, 2002). It could be likened to a 'demonstration project' as described by Garvin (1993) because its implementation may lead to changes in the entire organization which in turn may lead to the development of new capabilities. In the same vein, the standard may assist the organization in developing its transformative learning approach and encourage organizational curiosity, a facilitating factor that can promote learning. Furthermore, at its initial stage of implementation, the standard could be regarded as a new project, and according to Epstein and Roy (1997), new projects can lead to the development of new capabilities on the whole. Also, experimentation is one way in which explicit knowledge is internalized (Nonaka, Toyama, et al., 2001), hence, the standard may facilitate the knowledge conversion process in this regard.

Third, the implementation and maintenance of the standard may encourage the creation of environmental committees and the holding of regular meetings. Such meetings are said to facilitate the sharing of information (DiBella \& Nevis, 1998; DiBella et al., 1996; Huang \& Shih, 2009), as well as the acquisition and creation of useful environmental knowledge that can be used for decision making, and to tackle new challenges (Huang \& Shih, 2009). Besides formal meetings, informal meetings are also found to assist with the dissemination of information (DiBella \& Nevis, 1998). The implementation of the standard may encourage informal meetings between employees who have responsibilities with respect to the environmental management system and thus, also assist with the transfer of knowledge.

Fourth, the ISO 14001 standard may also help promote innovation with respect to environmental issues. In fact, the aforementioned is touted as one of the benefits of the standard (Montabon et 
al., 2000; Psomas et al., 2011; Radonjič \& Tominc, 2006). Huang and Shih (2009) reveal from their case study on how the combination of the experience obtained from the production department and the environmental management system (which was certified to ISO 14001) was used to create new technologies that helped the company reduce its impact on the environment (Huang \& Shih, 2009). Again, the implementation of the standard may also prompt organizations to develop green products or make their current products green, which requires some form of innovation. Furthermore, the implementation of green initiatives (to include clean technologies) in organizations is said to involve learning because in order to establish such initiatives, one will need to acquire or create knew knowledge and to learn new practices (Boiral, 2002).

Fifth, the standard may also help enhance an organization's learning orientation with respect to its 'content - process' by providing knowledge for both process improvement and product development. Its implementation and maintenance, and the continuous improvement process may lead to the improvement of, for example, an organization's manufacturing processes with respect to how it affects the environment. The standard as mentioned earlier may also play a role in product development as it pertains to green products. In the same vein, the standard may also facilitate the 'design-and-make' learning approach of an organization's 'value - chain' learning orientation. The 'design-and-make' approach entails research and development, and engineering and manufacturing (DiBella \& Nevis, 1998).

Sixth, the standard may act as a facilitating factor with respect to 'scanning imperative' because it may facilitate the acquisition of information from the organization's external environment through the engagement of external stakeholders, the use of consultants, and the environmental review process. The latter though not a requirement is strongly recommended especially for organizations that do not have an environmental management system. The review if done, is usually the first stage for the implementation of the standard and entails the evaluation of the organization's status in relation to the environment (ISO 14004:2004). In terms of gaining knowledge from stakeholders, Darnall et al. (2008) suggested that the engagement of government regulators (external stakeholders) can lead to the acquisition of environmental knowledge by organizations that have built a relationship with such stakeholders. Also, based on the findings of a case study conducted by Roome and Wijen (2005), the engagement of both 
internal (e.g., employees across the entire organization) and external (e.g., regulators, NGOs, trade associations) stakeholders as encouraged by the ISO 14001:2004 standard may contribute to organizational learning because it assists with the acquisition of information or knowledge useful to the organization from such stakeholders. For instance, in their study they mention that one of the companies they understudied was a member of a chemical trade association (external stakeholder), and as a result, the company was able to obtain information on best practices for pollution prevention and emission control through several of the working groups of the said association. The engagement of interested parties (stakeholders) is now a requirement in the new version of the standard (BSI Group, 2015; ISO 14001:2015), as such, the role of the standard in facilitating learning in this regard may become more prominent.

Eighth, DiBella and Nevis (1998) are of the opinion that certification can assist organizations to learn because it prompts organizations to examine their past experiences and to learn from the successes of those experiences. The certification process of the ISO 14001 standard may also promote learning in this regard.

Ninth, over time, the use of the standard may lead to what Huang and Shih (2009) refer to as environmental knowledge accumulation (EKA), which they say is gained primarily through experience and experimentation. The accumulated knowledge serves as a great resource for the development of new ideas and practices.

Tenth, the ISO 14001 standard asks for the integration of environmental issues into the overall decision making process of an organization, and organizations appear to be doing so with the aid of the standard (Darnall, Seol, \& Sarkis, 2009). Kloot (1997), in describing the relationship between management control systems (MCS) and organizational learning suggested that the use of MCS in decision making facilitates all of Huber's (1991) constructs with the exception of organizational memory and therefore could play a role in enhancing learning in an organization. Based on the foregoing, the ISO 14001 standard could also have the same effect on the learning process. The standard's role in this regard may become more prominent now that leadership is a clause on its own. As part of this clause, top management is to integrate environmental issues into the business processes of the organization (BSI Group, 2015). 
Finally, Total Quality Management (TQM) is said to have the ability to facilitate planned learning. The latter is said to entail organizational level learning because it helps to encode employee experiences into standard operating procedures, organizational systems, and routines, which can then be passed on to other members (Visser, 2007). Furthermore, the TQM program "is intended as the institutionalization of a process of deliberation, reflection, and collaboration with regard to error detection and correction" (Visser, 2007, p. 664). Based on the aforementioned, and the similar role that the ISO 14001 standard may play in the organization, it may also have the ability to influence planned learning.

\subsubsection{The ISO 14001 standard and Huber's (1991) Constructs}

As discussed in section 2.3.1.1, the ISO 14001 standard through some of its requirements may have the ability to influence the processes of information acquisition, information interpretation, information distribution and organizational memory and invariably influence organizational learning within organizations. For instance, the identification of environmental aspects and their associated impacts, the training requirement, and the audit process may facilitate all four constructs of organizational learning, and documentation may enhance the organizations memory and assist with the acquisition and distribution of information/knowledge. The requirements of the standard as they relate to the four constructs of organizational learning are depicted in Figure 2.10 below.

Flowing from the above discussion of the potential for certain ISO 14001 requirements to influence Huber's (1991) four constructs of organizational learning the following research question was formulated:

Q1: Does the ISO 14001 environmental management systems standard have the ability to facilitate the acquisition, distribution, interpretation, and storage of useful environmental information and therefore contribute to organizational learning.

Note that in the research undertaken here, actual changes or improvements in organizational learning is not measured. Rather, what is attempted is to collect and examine the perceptions of respondents within organizations concerning whether knowledge acquisition, distribution, 
interpretation and storage within the organization was facilitated as a result of the organization adhering to the various requirements of the standard.

\begin{tabular}{|c|c|c|c|}
\hline $\begin{array}{l}\text { Information } \\
\text { Acquisition }\end{array}$ & $\begin{array}{l}\text { Information } \\
\text { Distribution }\end{array}$ & $\begin{array}{l}\text { Information } \\
\text { Interpretation }\end{array}$ & $\begin{array}{l}\text { Organizational } \\
\text { Memory }\end{array}$ \\
\hline $\begin{array}{l}\text { - Environmental } \\
\text { aspects and } \\
\text { impacts } \\
\text { - Legal and other } \\
\text { requirements } \\
\text { - Objectives and } \\
\text { targets } \\
\text { - Environmental } \\
\text { programs } \\
\text { - Training and } \\
\text { awareness } \\
\text { - Documentation } \\
\text { and control of } \\
\text { documents } \\
\text { - Communication } \\
\text { - Operational } \\
\text { controls } \\
\text { - Emergency } \\
\text { preparedness } \\
\text { - Monitoring and } \\
\text { measurement } \\
\text { - Internal audit } \\
\text { - Corrective and } \\
\text { preventive } \\
\text { action } \\
\text { - Evaluation of } \\
\text { compliance } \\
\text { - Control of } \\
\text { records } \\
\text { - Management } \\
\text { review }\end{array}$ & $\begin{array}{l}\text { - Environmental } \\
\text { aspects and } \\
\text { impacts } \\
\text { - Objectives and } \\
\text { targets } \\
\text { - Environmental } \\
\text { programs } \\
\text { - Training and } \\
\text { awareness } \\
\text { - Documentation } \\
\text { and control of } \\
\text { documents } \\
\text { - Communication } \\
\text { - Operational } \\
\text { controls } \\
\text { - Emergency } \\
\text { preparedness } \\
\text { - Internal audit } \\
\text { - Corrective and } \\
\text { preventive } \\
\text { action } \\
\text { - Evaluation of } \\
\text { compliance } \\
\text { - Management } \\
\text { review }\end{array}$ & $\begin{array}{l}\text { - Environmental } \\
\text { aspects and } \\
\text { impacts } \\
\text { - Objectives and } \\
\text { targets } \\
\text { - Environmental } \\
\text { programs } \\
\text { - Training and } \\
\text { awareness } \\
\text { - Communication } \\
\text { - Operational } \\
\text { controls } \\
\text { - Emergency } \\
\text { preparedness } \\
\text { - Monitoring and } \\
\text { measurement } \\
\text { - Internal audit } \\
\text { - Corrective and } \\
\text { preventive } \\
\text { action } \\
\text { - Evaluation of } \\
\text { compliance } \\
\text { - Management } \\
\text { review }\end{array}$ & $\begin{array}{l}\text { - Environmental } \\
\text { aspects and } \\
\text { impacts } \\
\text { - Objectives and } \\
\text { targets } \\
\text { - Environmental } \\
\text { programs } \\
\text { - Training and } \\
\text { awareness } \\
\text { - Documentation } \\
\text { and control of } \\
\text { documents } \\
\text { - Communication } \\
\text { - Operational } \\
\text { controls } \\
\text { - Emergency } \\
\text { preparedness } \\
\text { - Monitoring and } \\
\text { measurement } \\
\text { - Internal audit } \\
\text { - Corrective and } \\
\text { preventive } \\
\text { action } \\
\text { - Evaluation of } \\
\text { compliance } \\
\text { - Control of } \\
\text { records } \\
\text { - Management } \\
\text { review }\end{array}$ \\
\hline
\end{tabular}

Figure 2.10 Requirements of the ISO 14001:2004 standard as they relate to Huber's (1991) four constructs of organizational learning

\subsubsection{The ISO 14001 standard as a barrier to Organizational Learning}

So far, the review has focused mainly on articles that show a positive relationship between the ISO 14001 standard and organizational learning. However, a few scholars did provide some 
critical comments concerning the relation between ISO 14001 and organizational learning. Although Burström (2002) emphasizes the positives, he does mention that the policies, routines and organizational structure brought about by environmental management systems standards such as ISO 14001 can also hinder learning in organizations, especially long-term learning. This is because such standards are said to lead to the establishment of formal structures that basically dictate what rules, procedures, and actions to follow, and therefore do not create any activities for learning. Strachan (1997) suggests that such formal structures normally lead to single-loop learning alone and are therefore unlikely to encourage any change in the overall strategies and policies of the organization; in other words, they inhibit double-loop learning. Some scholars suggested that organizational learning (double-loop learning) is more likely to take place in an organization that has a decentralized structure, a participative leadership and management structure, and employee participation (Fiol \& Lyles, 1985; Kloot, 1997; Slater \& Narver, 1995; Strachan, 1997); however, environmental management systems standards such as the ISO 14001 standard are said to facilitate a centralized and formalized management structure without much employee involvement, and as such, according to some commentators, the standard may not enhance double-loop learning (Moxen \& Strachan, 2000; Strachan, 1997). Esterby-Smith (1997) also mentions how much of the literature on organizational learning suggest that formal structures are said to hinder learning but he however stresses that such structures (and the challenges with them) most often cannot be avoided and should be seen as part of the life of the organization rather than as a negative. Also, although Boiral (2002) and Reverdy (2007) mention the fact that the ISO 14001 standard may lead to an increase in bureaucracy, Reverdy (2007) argues that the standard should be seen as a means to "develop new organizational resources that support coordination in order to develop integrated solutions and continuous improvement" ( $\mathrm{p}$. 6). Resources include knowledge, formal documents, formal roles, technical/control devices, and management tools which besides controlling behavior help with the creation and dissemination of knowledge (Reverdy, 2007).

Finally, drawing on the concept of fragmented learning as described by Antal et al. (2001), the standard may hinder organizational learning. This may be the case because the standard allows for only a unit or department or facility of an organization to attain registration. In doing so, the argument goes, only members of that unit may learn and not the entire organization. Also, for the 
organizations that have a mature and successful EMS, compliance with ISO 14001 may cause the organization to become complacent and thus fail to identify future risks. This is based on the suggestion that continuous success may lead to potential problems going unnoticed or organizations not seeking out opportunities for improvement (Antal et al., 2001; DiBella \& Nevis, 1998).

\subsubsection{Environmental Management Systems Software and Organizational Learning}

\subsubsection{Information Technology as a facilitator of Organizational Learning}

Literature on the linkages between environmental management systems software and organizational learning have not been found to date; however, articles do exist that show a relationship between information technology (IT), of which software is a part, and organizational learning. Information technology is said to be "a generic term for the convergence of computers, hardware, software, telecommunications, Internet, electronics and the resulting technologies" (Ruiz-Mercader et al., 2006, pg. 17). Also, software is said to be "the set of instructions your [computer] hardware executes to carry out a specific task for you such as creating a graph (spreadsheet software, for example) and surfing the Web (Internet Explorer, for example)" (Haag \& Cummings, 2008, p. 38). In order to make a connection between environmental management systems software and organizational learning, the literature discussing the relationship between information technology and organizational learning will be referenced.

A number of authors have tried to show a positive relationship between organizational learning and information technology (as discussed below). Some have also suggested that when organizational learning is enhanced by using information technology, performance also improves. However, empirical work to confirm this is said to be lacking (Tippins \& Sohi, 2003). Some articles have also directly or indirectly linked information technology to Huber's (1991) four constructs of organizational learning (e.g., Goodman \& Darr, 1998; Hayes, 2011; Pentland, 1995; Robey et al., 2000; Slater \& Narver, 1995; Tippins \& Sohi, 2003).

Robey et al. (2000) point out that information technology can facilitate Huber's (1991) four constructs of information acquisition, information dissemination, information interpretation, and organizational memory, and thus contribute to organizational learning. However, they lay 
particular emphasis on IT's role in supporting organizational memory as well as its role in facilitating communication and discourse. They state that although organizational memory, and communication and dialogue between employees, which are necessary for learning to take place, can be enhanced and facilitated without information technology, the latter enables these conditions to be undertaken more efficiently. Through what they refer to as "organizational memory information systems" information technology has the ability to support organizational learning because such systems allow for the "capture, representation, storage and retrieval of structured data, diagrams, models, text, and images in electronic databases" (p. 140). Such systems not only facilitate the storage of information but also provide a means for structured data to be accessed and collected, and for the data to be scrutinized, hence facilitating information interpretation. Robey et al. (2000) are also of the opinion that communication facilitates the creation of new interpretations of acquired information and for this reason, IT's role in enhancing communication and thus learning should not be overlooked. Some cited examples of information technology that support organizational learning include groupware and wide-band communication networks, which enable employees to have access to the organization's memory thereby assisting with the acquisition and distribution of information; data warehouses and databases of best practices, which are said to make up aspects of organizational memory; and group support systems and collaborative tools designed to assist with communication and discourse. Lotus Notes is one of such applications that is used frequently to facilitate collaboration.

Tippins and Sohi (2003) state that software is part of what is referred to as IT objects (computer hardware, software and support personnel) and that these objects assist with the "acquisition, processing, storage, dissemination, and use of information" (p. 749). They are in agreement with other authors that the use of information technology can facilitate the quick and efficient access to useful information as well as the quick distribution of the information acquired, and therefore can ensure that employees are always up to date with the latest information. They mention that due to the connectivity/communication brought about by information technology, the process of information interpretation can be facilitated because employees are able to participate more in the information management process, and can therefore better share their own interpretations thereby enabling them to arrive at a consensus regarding the information they acquired. They are 
also in agreement with the fact that information technology provides a mechanism for the storage of information relevant to the organization thereby enhancing organizational memory. However, this information they say must be readily available to employees and should be in a format that enables them to make the same interpretations. A discretionary database is an example of information technology that they state can influence organizational learning because it allows for the storage of information and ensures that the acquired and stored information can be easily and quickly accessed by both the original recipient and other recipients.

Goodman and Darr (1998) point out that organizational-level learning takes place when: there is an exchange of problems and their solutions, and the outcomes from such exchanges are made known to other employees; the problems and solutions, and the outcomes can be stored; and the members of the organization are able to share their interpretations regarding the problems and solutions, and subsequently store their experiences in the organization's memory. They argue that information technology in the form of computer-aided systems (CAS) has features that support these processes and thus have the ability to facilitate learning. They refer to CAS as "collections of technology, people, and organizational arrangements" (p. 418). In their study they came to the conclusion that the CAS (Electronic Library System) of interest could be classified as a "computer-aided organizational learning system" because it enhanced communication, facilitated the search for solutions, provided a means for employees to share their solutions to problems, and allowed for the creation and updating of the organization's memory. Like Robey et al. (2000) and Cross and Baird (2000), they make mention of Lotus Notes as an example of information technology that could facilitate learning because it plays a similar role to the electronic library system in their study. Communication technologies such as email that assist with the sharing of unstructured or tacit knowledge were other examples of information technology that they mentioned may facilitate learning.

Kane and Alavi (2007) carried out a study to investigate whether what they referred to as ITenabled learning mechanisms have any effect on single-loop and double-loop learning, which in their article they refer to as exploitation and exploration respectively. They came to the conclusion that information technology tools such as knowledge repositories and portals (KRP), and virtual team rooms (TR) (TRs are a merger between communication technology and KRP), 
facilitate single-loop learning, while tools such as electronic communities of practice (ECOP) in which communication technologies such as email and instant messaging are used to facilitate the interaction between employees at different locations who have similar interests and know-how, facilitate double-loop learning. They emphasize however, that the effect that such tools have on the two types of learning depends on factors such as: whether they are used alone or together, the learning capabilities of the individuals that make use of them, and the environmental conditions that the organization is facing (e.g., organizational turnover and environmental turbulence). Environmental turbulence as mentioned in their article refers to the rate at which knowledge requirements change within the industry in which the organization operates, for example, the knowledge requirements and the means through which such knowledge is acquired is said to change frequently in the biotechnology industry.

Pawlowsky et al. (2001), while discussing practices and tools that may assist with organizational learning, provide some examples of information technology that may assist with organizational learning, especially with the distribution of knowledge throughout the organization. Some of the technical infrastructure mentioned include "networks, intranet, local area networks (LANs), and specialized groupware-based knowledge-management tools, such as Lotus Notes, grapeVINE..." (p. 783). Such infrastructure is said to facilitate the distribution and filtering of knowledge. They elaborate on the use of grapeVINE as a means to acquire information stored in databases such as those of Lotus Notes and on local area networks, and its ability to send automatic alerts to users whenever there is new information available that is of interest to them based on their already established knowledge search profiles. In other words, users do not always have to constantly search through the database on their own. grapeVINE also enables users to see others who are using similar information, thereby helping to link individuals who have common interests. Besides grapeVINE, other groupware-based software such as Wincite are able to assist with the tracking of information (e.g., market conditions and activities of competitors), organizing the information, and disseminating the information. Based on the features of theses software products, they conclude that they "are ideal for identifying, disseminating, and sharing knowledge in organizations" (p. 784). 
Hayes (2011) discusses the use of information technology for knowledge management and how information technology in the form of shared databases and knowledge warehouses can be used to leverage knowledge. He is of the opinion that information technology can be used to facilitate knowledge management especially as it has to do with the "articulation, storage, transfer, creation, and retrieval of knowledge" (p. 84). He mentions two types of information technology applications that can be applied to knowledge management, namely interactive and integrative applications. Interactive applications enable employees to interact with each other notwithstanding their location and thus helps them obtain and share each other's opinions. Such applications as mentioned by Hayes (2011) usually include email, discussion forums, social networking tools, blogs, wikis, desktop conferencing, information provision, and real time interactions (p. 85). On the other hand, he states that integrative applications enable the acquired information to be stored and easily accessed and includes databases, e-bulletin boards, document management, knowledge repositories, expert systems, and best practice reports (p. 85). He states that groupware and intranet platforms (which are interactive applications) have been the main subject of discussion with respect to articles on information technology and organizational learning. Like other authors, he mentions the use of Lotus Notes as a means to share information. He also talks about a software platform called E2.0 that can be used to facilitate teamwork as well as "offer new ways to document, distribute, and retrieve knowledge within organizations" (p. 85).

Nonaka, Reinmoller, et al. (2001) mention the importance of using information technology to manage knowledge because knowledge enhances the competitive advantage of an organization. They are in agreement with other authors who are of the opinion that information technology in various forms can support learning. For instance, the use of intranet and data warehousing to acquire, link, share, and use information; the use of email and intranet to enhance the distribution and exchange of information; the use of groupware such as Lotus Notes to enhance teamwork as well as the transfer and exchange of information; and the use of specific software that provides databases from which employees can access saved information. However, they say that the majority of them are only being used to facilitate information processing and management, and not as a means to trigger or facilitate knowledge creation, which is what they say is required ( $\mathrm{p}$. 
828). They also say that most of them focus mainly on combination and the transfer of already available explicit knowledge and not tacit knowledge (p. 829).

In terms of using information technology to support knowledge creation and thus organizational learning, they suggest the use of information technology to facilitate the SECI model, that is, socialization, externalization, combination and internalization. For this, they mention the use of two complementary technologies, namely, conversion-support tools (CSTools) and actionreflection triggering (ART) systems that can be used to facilitate the knowledge creation process. For the process of socialization, the use of information technology is somewhat limited because this conversion process is supported mainly by physical face-to-face interaction, which is the best medium to exchange tacit knowledge since emotions such as ease or discomfort can be brought to bear. However, they do mention that video conferencing, because of its ability to mimic originating $b a$ and to bring about a virtual face-to-face interaction, may assist with this conversion process. Also, CSTools can help employees determine which other employees have the knowledge they require and thus aid socialization in this regard.

With respect to externalization in which tacit knowledge is externalized into concepts or diagrams through dialogue, groupware like Lotus Notes are said to be useful because they bring groups of people together to work on a common task, which is said to support externalization. However, they mention that most groupware focus on sharing and utilizing only explicit knowledge (mainly combination). They are of the opinion that CSTools offer people a virtual space (dialoguing $b a$ ) where they can engage in dialogue, and may therefore assist with the process of externalization (p. 832). With regards to combination (which requires a group of people to indirectly interact with one another), information technology is said to play a great role for this process because it is more capable of handling explicit knowledge, and it enables several people to be a part of the process. Examples of CSTools that could facilitate combination are groupware products that allow for the development of documents as a group such as Quilt by Bellcore that allows for the collaborative development of documents via email (p. 832). Internalization (which is aided by interactions that are personal and indirect, otherwise known as exercising $b a$ ), may be facilitated by information technology such as the internet and intranet, which are said to function as virtual exercising $b a$. Also, CSTools like expert systems, digitalized 
manuals, and networking technologies are said to be some examples of CSTools that help with internalization because they enable employees to learn at their own pace and enable them to communicate more effectively with others. They mention the use of "on-line manuals, videos, Frequently Asked Questions (FAQ) lists, on-line group discussions, ... and computer-supported cooperative work, ..." (p. 833) as some sources of explicit knowledge, which could in turn lead to the internalization of explicit knowledge when such sources are consulted by employees.

In order for the continuous and dynamic creation of knowledge to take place, the four processes of knowledge conversion must "shift into each other, creating a spiral movement" (p. 833). This is where the action-reflection triggering (ART) system comes into play. CSTools facilitate the conversion process, while the ART systems facilitate the shifting from one conversion process to the other. In other words, they trigger the nonstop shifting from socialization, to externalization, to combination, to internalization, and back to socialization. The ART systems function mainly by signalling a sense of urgency or crisis, which in turn prompts human beings to take action or to stop and reflect. Applications of ART systems can be found in scheduled queries that remind users to take action or in pop up interfaces that prompts the user to input data interactively.

Like Nonaka, Reinmoller, et al. (2001), Ruiz-Mercader et al. (2006) are of the opinion that information technology can enhance organizational learning because it can be used to convert tacit knowledge to explicit knowledge as well as to further convert explicit knowledge into more complex explicit knowledge. Furthermore, they also state that information technology plays a major role in the "creation, codification, storage, communication, analysis, diffusion and systematization of information and knowledge" (p. 21). They are also in agreement with the opinion that information technology can facilitate communication amongst people, which in turn can lead to new knowledge being created.

Real et al. (2006) also agree that the thoughtful application of information technology can be of benefit to organizational learning. They make reference to IT infrastructure, which they define as "the shared IT capabilities that enable the flow of knowledge in an organization to be supported" (p. 508). For them, information technology infrastructure (e.g., software and hardware) can assist with knowledge and learning activities, such as: "business intelligence, technologies for 
collaborating and distributing knowledge, knowledge discovery, localization and use, knowledge generation and storage, and support hardware for these technologies" (p. 508). Real et al. (2006) also mention that activities that could improve learning in an organization such as the sharing of information, communication, reflection, and the training of employees can be enhanced by using information technology (p. 509). They are also of the opinion that information technology may play a role in the knowledge creation process and are in agreement with Nonaka, Reinmoller, et al. (2001) and Nonaka, Toyama, et al. (2001) that information technology can facilitate the knowledge conversion process by acting as $b a$ (p. 514). They are also in agreement with Robey et al. (2000) that information technology plays a role with organizational learning because it provides a means for "storing, accessing, and revising some of the elements of organizational memory" (p. 514).

Huang and Shih (2009) discuss the use of environmental knowledge management (EKM) systems to enhance learning in organizations. They follow the definition of environmental knowledge management systems by Finster, Eagan, and Hussey (2001) who define such a system as consisting of "the tools, mechanisms, processes, structures, people, policies, strategies, data, and information that enable the creation, capture, accumulation, storage, retrieval, use, and transfer of knowledge that improve an organization's overall impact on the environment" (Finster et al., 2001, p. 123). Huang and Shih (2009) point out that through the use of the EKM system employees are able to search for environmental information stored in the database thereby enabling them to accumulate knowledge that they may require in order to carry out new tasks, thus facilitating the conversion of explicit knowledge to tacit knowledge (internalization). The system also enables employees to search for the appropriate E-learning courses they need for their personal development (p. 40).

They also make mention of the use of emails as a means to transfer environmental information and knowledge to those who need it, the use of electronic bulletin boards to share information with all the employees of an organization, and how information or knowledge stored in the form of manuals can be shared using the organization's intranet (p. 41). They described how as a means to accumulate and share knowledge the organization they understudied would upload the feedback from regular inspections and audits into their information system and then use the 
information/knowledge for training purposes (p. 41). They are also in agreement that information technology can be used to facilitate the conversion of tacit knowledge to explicit knowledge, thus assisting with the externalization of knowledge (p. 41).

Moynihan and Landuyt (2009) argue that an effective information system, which is a part of information technology is one that assists with the acquisition, storage and distribution of information and can therefore be classified as an organizational learning mechanism (OLM) (p. 1099). Hence, such systems can be said to play a role in enhancing organizational learning. In their study they observed that information systems have the ability to enhance organizational learning.

A few authors on organizational learning do briefly mention the likely positive role that information technology can play in enhancing organizational learning. For instance, Nonaka, Toyama, et al. (2001) mention the role that information technology (e.g., groupware) may play in facilitating systemizing $b a$ (a virtual world) (p. 500), and the role of computerized communication networks and databases in enhancing the process of combination (p. 497). Garvin (1993) suggests the use of computer data banks to keep records of successes and failures, thus assisting organizations in learning from their past experience (p. 86).

Huber (1991) mentions the use of computer based applications to assist with the storage and retrieval of information that was collected, which he suggests will facilitate organizational memory (Computer-based organizational memory to be precise) (p. 106). DiBella and Nevis (1998) suggest the use of computerized management information systems and the use of email as a means to disseminate information and knowledge within the organization (p. 33). Sadler (2001) mentions the use of computer discs as a means to store and retrieve information thus assisting with the internal acquisition of information, and organizational memory (p. 417). Epstein and Roy (1997) suggest that organizations should use software and databases to make the knowledge they have acquired formal and structured (p. 24).

Burström (2002) emphasizes the fact that an effective environmental management information system can foster communication and joint vision in an organization and thus promote learning 
(p. 316). Pentland (1995) states that implementing a new information technology system in general is a learning process because implementation "often requires changes in individual skills, cognitions, and expectations, as well as changes in formal roles and structures" (p. 1). He also states that computer-based information systems may assist with the distribution and storage of information within the organization (p. 3). Slater and Narver (1995) are of the opinion that information technology can serve as a means for communication and to exchange information, and that information on activities such as technology development can be posted on bulletin boards that were created using information technology. They also point out that due to the availability of information technology in the form of email and shared databases, organizations do not have to rely heavily on middle managers as channels for information flow. This they argue will improve the way organizations detect and respond to changes in their environment, improve the process of information sharing, and reduce the time between decision making and taking action (p. 70). In a nutshell, they state that information technology "has many potential elements, such as shared databases, communication networks, and decision support systems..., that may facilitate information dissemination and organizational memory..." (p. 72). Boiral (2002) suggests that information technology may help reduce the bureaucratic problems associated with the ISO 14001 standard, especially as it has to do with the large amount of paperwork that may be involved because information technology makes it easier to collect, accumulate and use information (p. 310).

\subsubsection{EMS-based Software as a facilitator of Organizational Learning}

With respect to the relationship between information technology and organizational learning discussed above, and the features and benefits offered by environmental management systems software, one can also suggest that EMS-based software may enhance organizational learning by facilitating its constructs or otherwise. First, by providing a centralized database system that contains environmental information that enables employees to easily and quickly access the required information irrespective of their location (Enviance, n.d.a; Enviance, 2010b; Intelex, 2014; Ismail, 2012; Leavoy \& Waggott, n.d.), they may assist in facilitating the acquisition and storage of information/knowledge or in developing the organization's internal knowledge source and public knowledge reserve. By enhancing the organization's memory, they in turn also contribute to the distribution and interpretation of information because according to Huber 
(1991), organizational memory influences the three other constructs of organizational learning. The provision of a database also allows for explicit knowledge to be internalized by employees who access information from it in order to perform their tasks or make decisions. As such, EMSbased software may also function as a conversion-support tool (CSTools) based on the functions of such tools as described by Nonaka, Reinmoller, et al. (2001). By facilitating the storage of information, they may also prevent situational learning from occurring.

Second, by facilitating collaboration, communication, and sharing of information amongst different departments (Intelex, 2014; Ismail, 2012; www.enviance.com) as well as amongst different organizations (Enviance, n.d.b), EMS-based software may facilitate the processes of information interpretation and information distribution and help build a learning organization by encouraging diverse people to work with one another, a strategy outlined by Senge (2006). In doing so, they may also prevent fragmented learning from occurring. Some of the information that may be shared within the organization using such software includes best practices, regulatory text, and various reports (www.enablon.com). By facilitating collaboration, they may also function as a virtual place $(b a)$ for the interaction of employees and lead to the externalization of tacit knowledge. Such software products may also contribute to the development of individual memory and the sharing of information via collaborative work.

Third, by facilitating the monitoring of compliance and conformance across different facilities, geographical locations, and product lines (Intelex, 2014; Ismail, 2012, www.enablon.com) the software may help provide feedback to the organization and thus enable an organization to learn from its own experience. They also serve as a means to obtain feedback by helping to enhance the tracking of activities such as environmental incidents, and energy and water usage, and ensure follow-up procedures are put in place with respect to the incidents/accidents or corrective measures (Intelex, 2014; Ismail, 2012; Leavoy \& Waggott, n.d.). As such, they can be said to facilitate single-loop learning or incremental learning through this feature.

Fourth, large amounts of environmental data can be collected (Ismail, 2012; www.enviance.com) and analyzed (Alnes et al., 2014; Ismail, 2012) more efficiently and made more understandable to decision makers through dashboards and other reporting tools (Enviance, 2010a; Intelex, 
2014; Ismail, 2012; www.enviance.com), thus facilitating information acquisition, distribution, and interpretation. Since the environmental information can be provided to decision makers in real-time on dashboards (Ismail, 2012; Leavoy \& Waggott, n.d.), the use of EMS-based software may reduce the time delay between decision and action, ensure that the information is utilized, and that learning takes place. Again, the dashboards may provide rich information to its users thus facilitating the process of information interpretation. The analyzed data not only allows for the organization to learn by detecting and correcting errors but also by enabling the organization to identify future opportunities, which according to Dierkes et al. (2001) can trigger learning.

Fifth, EMS-based software are said to provide real time alerts/notifications regarding issues such as outstanding corrective actions or permit requirements (Enviance, 2010b; Intelex, 2014; Ismail, 2012; Leavoy \& Waggott, n.d.; www.enablon.com; www.ihs.com) and therefore may act in similar fashion to the action-reflection triggering (ART) systems as described by Nonaka, Reinmoller, et al. (2001) in terms of facilitating the shifting from one conversion process to the next.

Sixth, by assisting with the tracking of the employee training process and in turn ensuring that employees obtain the proper training (Intelex Technologies Inc., n.d.), they may help facilitate the development of individual skills of employees as it pertains to the organization's environmental affairs.

Seventh, through their documentation and document control feature (Intelex, 2014), which enables the generation and storage of documents, EMS-based software may promote the distribution and storage of information. They may also facilitate the process of internalization and combination via this feature.

Finally, as stated by Pentland (1995), the installation of a new information technology system may facilitate learning, as such, the initial implementation of an EMS-based software may also contribute to learning. 
The above examination of EMS-based software suggest that it may have features that could facilitate Huber's (1991) constructs of organizational learning. For instance, the dashboard and reporting tools may assist with the acquisition and interpretation of information; the database feature may assist with all four constructs of organizational learning; the documentation feature may assist with the storage and distribution of information/knowledge; and by facilitating collaboration, the software may also promote all four constructs of organizational learning, especially at the individual and group levels of learning. As such, the research question outlined below was developed:

Q2: Do environmental management systems software packages have the ability to facilitate the acquisition, distribution, interpretation, and storage of useful environmental information and therefore contribute to organizational learning.

It should again be emphasized that in the research undertaken here, actual changes or improvements in organizational learning associated with EMS-based software is not measured. Rather, what is attempted is to collect and examine the perceptions of respondents within organizations concerning whether knowledge acquisition, distribution, interpretation and storage within the organization was facilitated as a result of the organization using EMS-based software.

\subsubsection{Information Technology as a barrier to Organizational Learning}

So far, the discussion has been on the positive effects that information technology may have on organizational learning. Some authors however do suggest that information technology could have a negative effect on learning. For instance, Gill (1995) reported on instances of how too much reliance on information technology may inhibit an organization's ability to learn. He mentions two case studies in which information technology (computer and communication networks in particular) led to a short term increase in the overall performance of the organizations to include financial performance but led to the organizations failing in the long term. In both cases, the major problem was the substitution of employees, especially middle managers with information technology. Although this appeared to work in a stable environment, it however became a detriment when the environment in which the organizations operated changed and became volatile. In the new environment, the organizations were unable to undertake unstructured scanning and interpretation of information that would have enabled them 
to adapt to whatever changes were taking place and for which computers were unable to do. Rather than restructuring, it was business as usual for them. In other words, there was little or no human interaction between members of both organizations and individuals in their external environment. He recommends that even though information technology can play a great role in enhancing performance, organizations still need employees whose jobs entails scanning and interpreting information from the external environment, and that organizations need to consider the human-system partnership when using information technology. In summary, he mentions that both organizations eventually failed because the customary means for obtaining and disseminating structured and unstructured information from the environment, that is humans, was substituted for media that supported mainly the acquisition and dissemination of structured information; and the job functions that required decision making and evaluation to be undertaken by employees were automated (p. 56).

Although Robey et al. (2000) have a more positive view with respect to the use of information technology to support organizational learning, they do mention a few instances in which information technology may inhibit learning. First, they state that organizations may become too reliant on the organizational memory systems that were established using information technology and in the process lose sight of the individual memory of knowledgeable members of the organization (p. 144). Second, as more and more information is accumulated, the likelihood that revisions will be made to the stored information will decrease. Pawlowsky et al. (2001) are of similar opinion and state that continuous revising of the stored information can be demanding when using certain types of information technology (p. 784). The accumulation of more information than employees can process could lead to information overload and thus hinder the process of information interpretation (Huber, 1991). Third, by using information technology to perform tasks that were previously carried out by employees, organizational learning could be inhibited because employees may forget how to undertake duties that they once used to do (Robey et al., 2000). Finally, Robey et al. (2000) are in agreement with Gill (1995) with respect to replacing employees with information technology and the effect it may have on organizational learning with regards to the organization's inability to scan and interpret information from its immediate environment. 


\subsection{Concluding Remarks}

In this chapter, an overview of environmental management systems and the ISO 14001 environmental management systems standard, EMS-based software and specialized software in general, organizational learning and the learning organization, the link between organizational learning and the ISO 14001:2004 standard, and EMS-based software was presented. In section 2.1.2 of Part 1, the requirements of the standard were briefly mentioned (with a full discussion provided in appendix C) and a discussion on the benefits, limitations, challenges, success factors, and adoption rates of the standard was provided. The discussion on the requirements provides background information that can be used to put forward the argument regarding the link between the standard and organizational learning, while the discussions on the limitations, challenges and success factors as it pertains to the standard provides the support for the research objective to determine the functionality of the standard and the improvements that could be made to the standard if necessary. Based on the information presented, it could be inferred that despite the limitations of the standard, its benefits appear to outweigh its limitations because its adoption rate worldwide has been on the increase since its inception. This is in light of the relatively low number of certificates that have been withdrawn compared to those that have been awarded as mentioned in section 2.1.2.7. The changes to ISO 14001:2004 were also briefly highlighted in section 2.1.2. While the changes made to the standard were not drastic, the few changes may lead to an improvement in terms of the standard's ability to assist organizations in accomplishing their environmental goals. For instance, the introduction of the leadership clause should ensure that environmental issues are integrated into the overall business strategies of an organization.

In section 2.1.3 of Part 1, a brief historical perspective as well as the features/benefits and limitations of specialized/EMS-based software were presented. The discussions in this section relate to this research study by highlighting the fact that although EMS-based software and other specialized software are of benefit to organizations, they still have some shortcomings in terms of satisfying the needs of the users. This study intends to gain an understanding as to what those shortcomings are while at the same time highlighting their strengths. Also, based on their features as presented in the literature and discussed in this chapter, EMS-based software may have the ability to assist organizations with some or all of the elements of an EMS (mainly ISO 
14001). In order to confirm if this is the case, the research question Q3 outlined earlier and in the next chapter was developed.

In Part 2 of this chapter, the concept of organizational learning and the learning organization was presented. The perspectives of different authors in the field were discussed. Although differences could be perceived amongst the different views, there did appear to be some convergence in terms of the approach of some of the authors. Providing the different approaches enables this research study to use a broader approach (from a theoretical standpoint) in terms of making a connection between the ISO 14001 standard and organizational learning. The types of learning, learning levels, benefits of organizational learning and the factors that could impede organizational learning were also provided. By discussing the types of learning, the research study can further substantiate whether the standard can facilitate learning by enhancing the different types of learning. Also, the standard can be seen as a means to improve learning at the different levels of the organization (e.g., the training of staff, which is at the individual learning level) and as such, an overview of the different learning levels within an organization was provided. Based on the literature, the standard may serve as a barrier to learning. Also, the implementation of the standard may prevent some of the barriers to learning from occurring. As such, it was also of value to provide some background information as to the factors that can impede organizational learning. Finally, the benefits of organizational learning were briefly discussed because it is one of the main reasons for investigating whether the standard and EMSbased software have the ability to facilitate learning in an organization.

In section 2.3.1 of Part 3, the perspectives of the different authors as discussed in Part 2 (and section C.3 in Appendix C) as well as those from other authors were drawn on in order to draw a possible connection between ISO 14001:2004 and organizational learning. Also, it was based on the connections using Huber's (1991) constructs that research question Q1 (presented earlier and in the next chapter) was formulated. From a theoretical standpoint, one may conclude that the standard does have the ability to facilitate organizational learning. Based on the theoretical analysis presented in this section, this study does bring to the forefront some ways in which the standard may facilitate learning. First, although some scholars (e.g., Burström, 2002; Epstein \& Roy, 1997) do discuss possible ways that the standard may facilitate certain learning mechanisms 
to include Huber's (1991) constructs, they do not explicitly make a connection between the requirements of the standard and Huber's (1991) four constructs, nor do they explicitly make a connection between the requirements of the standard and the concepts of other organizational learning scholars as discussed in this thesis.

Second, Epstein and Roy (1997) discuss how some of the requirements such as the environmental policy, planning (objectives and targets, and environmental programs), implementation and operation (training and awareness, documentation and control), checking (corrective action, monitoring and measurement, and audit); and management review facilitate learning, however this study goes a step further by highlighting in greater detail how all the requirements of the standard may facilitate organizational learning via Huber's (1991) constructs and otherwise.

Third, this study highlights the fact that other elements of the standard may promote learning. For instance, the certification process of the standard may bring about learning experiences for organizations, as the certification process on the whole is said to enable organizations to learn from their experiences (DiBella \& Nevis, 1998). Also, the PDCA (Plan, Do, Check, Act) model that is used by the standard is said to be a building block of a learning organization because it entails systematic problem solving (Garvin, 1993). As such, the standard may contribute to learning in organizations in this regard. Furthermore, the standard recommends the use of other techniques for systematic problem solving such as HAZOP, trend analysis, and risk assessment.

Fourth, the study highlights the standard's possible role in preventing some of the barriers, and acting as a barrier to organizational learning. For example, the standard may assist in preventing audience learning, superstitious learning, situational learning, learning under ambiguity, and short-sightedness. It may prevent audience learning because it may change the culture of the organization and therefore bring other employees on board regarding environmental issues. It may prevent superstitious learning because it could, through for example, the environmental aspect and impacts requirements ensure that employees have an idea of how the organization affects their immediate environment with respect to environmental issues. It may prevent learning under ambiguity because it may aid with the scanning of the environment and therefore 
keep the organization up to date with for example changing regulations. It may prevent situational learning because it may ensure that information is stored and not forgotten through its documentation requirement. It may prevent short-sightedness because it asks for short and long term goals to be developed through for example its objectives and targets requirements, however, one has to keep in mind the delusion of learning from experience as described by Senge (2006). On the other hand, it may bring about fragmented learning because if only one department or facility is registered, the entire organization may not learn. It may also bring about complacency through continuous success, and a failure of employees to see future risks, especially for those with a mature EMS.

Fifth, although Burström (2002) does mention the possible role an environmental management system may play in facilitating a systems approach, this study explicitly discusses how some of the requirements such as the identification of environmental aspects may bring about a systems approach with respect to environmental management.

Sixth, the study also highlights the possibility of the standard to influence organizational level learning (planned learning) due to its similarities with TQM, and interorganizational level learning through some of its requirement (e.g., the requirement to obtain resources and the emergency preparedness and response requirement). For instance, the standard recommends that organizations, especially SMEs seek collaboration with other organizations.

Seventh, its role in providing leadership and multiple champions, which are both required to promote learning (Dibella \& Nevis, 1998; Senge, 2006) was also brought to the forefront. This may be made possible through its requirement to assign roles and responsibilities.

Finally, its possible role in influencing decision making because it helps with the integration of environmental issues into the overall decision making process of the organization is highlighted in this study. Decision making is said to facilitate three of the constructs of organizational learning (Kloot, 1997). 
In section 2.3.2 of Part 3, a connection between EMS-based software and organizational learning was presented based on the literature linking information technology and organizational learning (with an emphasis on Huber's (1991) constructs) and the functions of such software products. Based on the arguments put forward using Huber's (1991) constructs, research question Q2 (presented in the next chapter) was also formulated. As is the case with the link between the standard and organizational learning, one could also infer from a theoretical standpoint that EMS-based software may have the ability to enhance organizational learning.

Although EMS-based software like other readily available software packages have features that may facilitate learning, a few of its features seem to particularly stand out. For instance, many EMS-based software packages have a dashboard that enables information to be quickly and efficiently acquired and transferred amongst members of the organization, and that presents data that has been analysed and interpreted so that employees can make sense of the information. In addition, the dashboard provides the information in real time, thus allowing for decisions to be made as soon as possible. Also, EMS-based software enables organizations to track and follow up on information especially regarding corrective and preventive actions and therefore may facilitate single-loop learning. This is further facilitated by the presence of the alert and notification feature that ensures such tasks are not overlooked. The ability to assist with the generation of reports is also a bonus for EMS-based software because information can be stored in the organization's memory. Finally, EMS-based software may act as a knowledge conversion tool in that it may assist with the processes of externalization, combination, and internalization.

The methodology for this research study is presented in the next chapter. 


\section{Chapter 3: Methodology}

\subsection{Research Method}

The strategy of inquiry or research method adopted in this thesis is the survey research method, which is a quantitative, non-experimental method. The survey instrument used was a questionnaire, which allowed for a potentially large sample size to be surveyed with the aim of generalizing where possible from a sample to a population (Creswell, 2003). A cross sectional study has been undertaken, meaning that it was conducted at a single point in time (Trochim, 2001).

\subsubsection{Appropriateness of the Method}

This strategy of inquiry was appropriate for this research for the following reasons: first, it allowed for the estimation of an outcome and its significance (Yin, 2003) via statistical analysis, and enabled the determination of a relationship if any, between variables; second, it allowed for the possibility of a large sample frame that covered a wide geographic area (Canada and USA) to be assessed; third, it allowed for the questionnaire to be sent by regular mail or email, thus making the survey a more cost effective one; fourth, it enabled the data collection process to be standardized and thus the same for all respondents, thereby ensuring that the information collected was easily comparable: this allowed for statistical analysis to be undertaken (Fowler, 2002); and fifth, since the questionnaires were self-administered, thereby offering anonymity to respondents, it is possible that more frank and honest responses may be collected than research enquiries based on face to face encounters (e.g., semi-structured interviews).

\subsubsection{Limitations of the Method}

Notwithstanding the aforementioned strengths of the survey research method, it also has weaknesses. Where possible, attempts were made to minimize the weaknesses. A major weakness of this method is the low response rate that is usually associated with questionnaires, which introduces non-response bias into the sampling process (Fowler, 2002). Non-response is an important issue with respect to data collection and the survey research method on the whole. It can lead to error in the outcome of the study because the sample frame may not be entirely representative of the target population. With this in mind, a few measures were put in place in an 
attempt to increase the response rates to the questionnaire as follows: the layout was made as clear as possible so that it could be completed with ease; terms were defined when necessary; repeated contacts were made with non respondents; the respondents were given the option of choosing their preferred mode of data collection (for example, email or regular mail) and more than one mode of data collection was used (Fowler, 2002); and as a form of inducement, the respondents were informed that a report summarizing the findings of the survey, which presumably should be of interest to them, would be sent to them (Alreck \& Settle, 1995, Tippins \& Sohi, 2003). Second, the survey research method does not provide the ultimate answers concerning a particular issue or question (Alreck \& Settle, 1995) and it does not necessarily lead to theory building as it often fails to provide in-depth analysis of the phenomenon being studied (Woodside \& Wilson, 2003). However, it should be seen as a means to gather evidence in support of existing or proposed theories (Alreck \& Settle, 1995). Finally, the survey method is also criticized for its inability to measure causality; however, it could provide support for relationships that exists within a theory (Alreck \& Settle, 1995), which is part of what this research aimed to achieve.

\subsection{Research Design}

\subsubsection{Research Questions}

As stated in Chapter 2, in order to fulfill the objectives of this research, the study attempted to answer the following research questions:

With respect to whether environmental management systems standards and EMS-based software have the capability to enhance organizational learning, the following major research questions are applicable:

Q1: Does the ISO 14001 environmental management systems standard have the ability to facilitate the acquisition, distribution, interpretation, and storage of useful environmental information and therefore contribute to organizational learning?

Q2: Do environmental management systems software packages have the ability to facilitate the acquisition, distribution, interpretation, and storage of useful environmental information and therefore contribute to organizational learning? 
With respect to the ability of EMS-based software to assist organizations with the implementation and maintenance of the standard, the study sought to answer the question below:

\section{1.) Q3: Do environmental management system software products have the necessary} features that enable them to assist organizations in implementing and maintaining the ISO 14001 management system standard? In other words, do such software actually assist organizations with tasks such as documentation, data compilation and analysis, auditing, training management, and data storage, which are some of the many tasks a good quality software package should be able to carry out (Global Environment and Technology Foundation, 2004; Ismail, 2012; Leavoy \& Waggott, n.d.)?

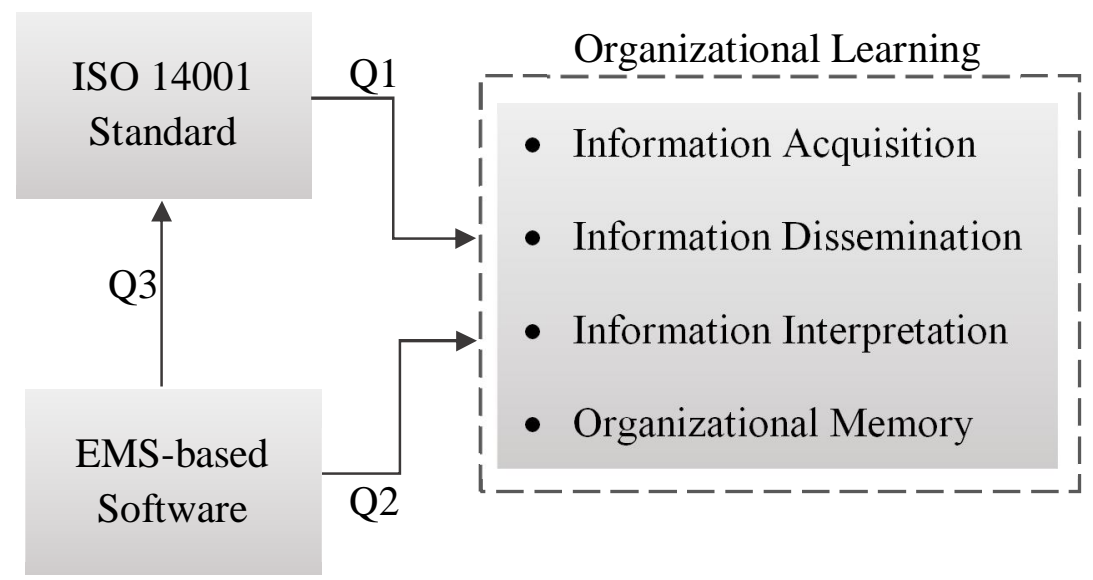

\section{Figure 3.1 Research question diagram}

As a secondary objective, this research sought answers to the following questions.

With respect to whether the ISO 14001 environmental management systems standard and EMSbased software has the ability to enhance organizational learning and in turn performance the following questions were presented:

1.) If you are of the opinion that the standard leads to improved acquisition of useful information, could you comment on how this improvement affected organizational learning that influenced performance within your organization?

2.) If you are of the opinion that the software leads to improved acquisition of useful information, could you comment on how this improvement affected organizational learning that influenced performance within your organization? 
The same questions above were asked with respect to information dissemination, information interpretation and organizational memory.

With respect to the functionality of the standard and EMS-based software the following questions were asked:

1.) What would you say is the most helpful feature/requirement of the ISO 14001 standard? Please could you briefly explain why you found this feature/requirement most helpful?

2.) What would you say is the least helpful feature/requirement of the ISO 14001 standard? Please could you briefly explain why you found this feature/requirement least helpful?

3.) What would you say is the most helpful feature of the software in terms of its ability to assist you in meeting the requirements of the ISO 14001 standard? Please could you briefly explain why you found this feature most helpful?

4.) In your opinion what is the least helpful feature of the software in terms of its ability to assist you in meeting the requirements of the ISO 14001 standard? Please could you briefly explain why you found this feature least helpful?

5.) In terms of the software's ability to assist you in meeting the requirements of the ISO 14001 standard, please briefly elaborate on any changes/improvements you think would assist you in making the software more functional for you and your organization?

6.) In your opinion, how easy or difficult was it to implement the software for the ISO 14001 standard?

7.) In your opinion, has the software paid for itself in terms of your ability to meet the requirements of the ISO 14001 standard. If yes, can you provide a rough estimate of how long it took for the software to pay for itself ?

It is worth emphasizing that in the research undertaken here, actual changes or improvements in organizational learning are not measured. Rather, what is attempted is to collect and examine the perceptions of respondents within organizations concerning whether knowledge acquisition, distribution, interpretation and storage within the organization was facilitated as a result of the organization adhering to the various requirements of the standard, or as a result of using EMS software. 


\subsubsection{Sample Frame}

Organizations in North America (Canada and USA) that are registered to the ISO 14001 standard as well as organizations that use environmental management systems software were the main focus of the survey. The organizations that used environmental management systems software were clients of some of the major EMS-based/customized software developers. Although not a condition for selecting the sample frame, the survey did include organizations from various industries and sectors, and of different sizes (i.e., small, medium and large).

A list of ISO 14001 certified companies operating in North America was obtained drawing on the following sources: the Canadian General Standards Board (http://www.tpsgcpwgsc.gc.ca/ongc-cgsb/programme-program/management/iso/sme-ems/iso-eng.html), QMI SAI Global (http://www.qmi.com/), the Independent Association of Accredited Registrars (http://iaardirectory.jadianonline.com/ Directory), and NSF International Strategic Registration (http://www.nsf.org/). A number of registrars were also contacted in order to obtain their client list. The Registrar Company Inc. (TRC) (http://www.theregistrarco.com) provided their client list for this research. With respect to the companies that used EMS-based software, some of the companies and their contact information were obtained directly or indirectly (client list on website) from EMS-based software vendors. The entire list of organizations that was compiled for this study was then crosschecked to ensure there were no double entries.

\subsubsection{Sample Size and Sampling Method}

Non probability sampling as opposed to probability sampling was used to select the sample frame from the target population (ISO 14001:2004 certified organizations and organizations that use EMS-based software) because it was not possible to obtain a comprehensive list of both populations. Most of the companies that used EMS-based software were either registered to the standard or used the standard as a guide to implement their environmental management system.

A total of 899 companies were contacted for this research out of which 163 were known users of EMS-based software products. However, out of the 163, only 76 were known to have their EMS certified to the standard. As for the remaining 87, they either used the ISO 14001 standard as a guide for their environmental management system or it was not possible to determine whether 
they were registered or not. Thus, 812 organizations that had their EMS certified to ISO 14001:2004 formed a part of the sample frame for this research. Based on the data published in the ISO survey 2014, 7,477 organizations in North America (Canada and USA) were ISO 14001 certified in 2012. This population is classified as a small population because it is less than 100,000 (Rea \& Parker, 2005). With respect to research question Q1, the sample size of 812 was seen to be appropriate because it was greater than the minimum recommended sample size of 100 and above the recommended maximum of ten percent $(10 \%)$ of the entire population for surveys (Alreck \& Settle, 1995). Furthermore, this sample size was also higher than that required when calculations for the sample size were done using a statistical equation outlined in Rea and Parker (2005). The equation as outlined in Rea and Parker (2005) is as below:

$n=\frac{Z_{a}^{2}(0.25)(N)}{Z_{a}^{2}(0.25)+(N-1) M E_{p}^{2}}$

Where

$n$ = sample size

$Z_{a}=\mathrm{Z}$ score for various levels of confidence (It is set at 1.96 for the $95 \%$ confidence level and

2.575 for the $99 \%$ confidence level)

$N=$ total population

$M E_{p}=$ margin of error in terms of proportions

Note: equation 3.1 above is for small populations $(\mathrm{N}<100,000)$

Based on the calculations using equation 3.1, for a population of 7,477, sample sizes of approximately 550 and 362 would be satisfactory at a margin of error of $4 \%$ and $5 \%$ respectively using a confidence level of $95 \%$. The margin of error used for the calculation is within the recommended range of three to five percent $(3 \%-5 \%)$ and is less than ten percent $(10 \%)$ for surveys (Rea \& Parker, 2005). Similar calculations for the sample size were not done with respect to research question Q2 because the total number of companies that use EMS-based software was not obtainable. However, the sample size of 163 was greater than the minimum recommended sample size of 100 as stated by Alreck and Settle (1995) and thus found to be suitable for the survey. 
Although the calculations do not apply to non probability sampling, they were carried out in order to show the representativeness of the sample size if probability sampling had been undertaken.

\subsubsection{Survey Respondents}

The key respondents were employees who oversaw the environmental affairs for the organization and therefore were seen to have the requisite knowledge regarding environmental management systems standards and were most likely to use environmental management systems software. A few of the positions included the Director of Environment, Health and Safety, Environmental Managers, Environmental Coordinators, and Environmental Engineers. The survey involved one respondent per organization.

\subsubsection{Data Collection}

Data collection was undertaken using a self-administered questionnaire comprising of closedended statements and open-ended questions. The primary means of distribution of the questionnaire to the organizations was by email as this helped to reduce the time required to send and receive the questionnaire as well as to reduce the cost of administering the survey. The email addresses of participants were obtained from the organization's website, via phone calls made to the organizations, and directly from a vendor of EMS-based software. A paper version of the questionnaire was also sent by regular mail to 47 of the 899 organizations, 35 of which no contact information (email address and telephone number) was available and 11 of which their email addresses failed. One potential participant requested to have the questionnaire sent by snail mail after being contacted via telephone. Phone calls were also made in order to solicit participation of non respondents who had initially been contacted by email only. A minimum of two reminders was sent to non respondents via email. The survey was distributed intermittently between January, 2013 and December, 2014. 


\subsubsection{Survey Design}

\subsubsection{Measures for Organizational Learning}

Measures to indirectly evaluate the organizational learning capability of the ISO 14001 standard and EMS-based software were formulated for this study based on the literature/studies (as discussed in Chapter 2) on: the relationship between organizational learning and environmental management systems standards (with an emphasis on the relationship between the requirements of the ISO 14001 management systems standard and Huber's (1991) constructs of organizational learning); the relationship between information technology and organizational learning (with an emphasis on the relationship between software (IT) and Huber's constructs of organizational learning); and the measurement of the constructs of organizational learning. The constructs of organizational learning have been used in a number of empirical studies (for example, JerezGomez, Cespedes-Lorente, \& Valle-Cabrera, 2005; Jimenez-Jimenez \& Sanz-Valle, 2011; Lopez et al., 2004; Tippins \& Sohi, 2003; Templeton et al., 2002) as a measure for organizational learning and were thus found to be appropriate for this study. It was based on the aforementioned discussion that the closed-ended statements in section $\mathrm{A}$ and section $\mathrm{B}$ of the questionnaire were formulated. It is important to note that while this study employs the use of Huber's (1991) constructs, it does not measure organizational learning per se. It rather obtains the opinions of participants as to whether the standard and software may have had an influence on the four constructs of organizational learning.

\subsubsection{Survey Questions and Framework}

In framing the questions, the following general guidelines as outlined by Trochim (2001) were considered: the question content, the response format to be used for collecting the data, and the question wording. With regards to the question content, issues such as the necessity of a question, the need for several questions, and whether the question is biased were considered. For the response format, structured (closed-ended) and unstructured (open-ended) response formats were both used. For this study, structured questions and statements were used so as to have a standardized format thereby allowing for responses to be easily analyzed and compared. Unstructured questions were used in order to allow respondents to elaborate freely on certain issues, and as follow-up questions to some of the structured statements. With respect to question/statement wording, issues such as the difficulty or clarity of the question/statement, the 
directness of the wording, and the personal level of the questions/statements were taken into consideration.

The questionnaire (fillable Microsoft word document) was organized into four sections (A through D) consisting of open-ended questions and closed-ended statements/questions. Section A consisted of open and closed-ended questions/statements. The closed-ended statements were developed in order to assist in understanding whether the ISO 14001:2004 standard is capable of facilitating the four constructs of organizational learning and thus capable of assisting employees and their organizations in learning. In other words, they were intended to assist in answering research question Q1. The closed-ended statements in this section were as follows:

1. I find that the standard assists me in my ability to acquire useful environmental information that applies to the organization.

2. The standard assists me in my ability to disseminate (distribute) useful environmental information within the organization and beyond, in the form of policies, procedures, best practices, etc.

3. The standard assists me and my colleagues in our ability to analyze and interpret useful environmental information that applies to the organization.

4. The standard assists me in archiving (storing) relevant environmental data and information about the organization for current and future referencing.

Each statement/item above represented each of the four constructs of organizational learning. Since organizational learning was not being measured per se, the use of one item/statement as opposed to multiple items (as is the case in studies that measured organizational learning) to represent each of the four constructs was found to be suitable.

Using a five-point Likert scale, respondents were asked to indicate the extent to which they agree or disagree with the closed-ended statements above. One (1) was used to represent "strongly disagree", two (2) for "moderately disagree", three (3) for "undecided", four (4) for "moderately agree" and five (5) for "strongly agree". 
For each of the four closed-ended statements, a follow-up open-ended question was presented. The open-ended questions were asked in order to assist in understanding whether the facilitation of the four constructs of organizational learning had any effect on learning in the organization and whether an improvement in learning if any, may have also enhanced the performance of the organization. They were also added as a means to add richness to the results of the study as well as to enhance the reliability and validity of the study (Krosnick \& Presser, 2010). An example of an open-ended question is as below:

1. If you are of the opinion that the standard leads to improved acquisition of useful information, could you comment on how this improvement affected organizational learning that influenced performance within your organization?

Examples were presented along with each question/statement (open and closed-ended) in order to give the respondent a better understanding of the questions and statements. The ability of organizational learning to improve performance was not directly measured; instead, the opinions of respondents were sought with respect to whether aspects of the standard had a perceived influence on the four constructs of organizational learning and in turn performance.

Section B consisted of open-ended questions and closed-ended statements intended to assist in understanding whether environmental management systems software is capable of enhancing the four constructs of organizational learning and thus capable of assisting employees and their organizations in learning, and to determine if an improvement in learning translated into an improvement in performance. In other words, they were intended to answer research question Q2 and the follow-up open-ended questions similar to those in section A. The closed-ended statements were designed in a similar fashion as those in section A and respondents were also asked to respond using the five-point Likert scale described in section A above.

Section $\mathrm{C}$ consisted of questions and statements that were intended to assist in understanding whether environmental management systems software has the necessary features or characteristics to assist employees and their organizations with the implementation and maintenance of the ISO 14001:2004 environmental management systems standard and to examine the functionality of EMS-based software. The questions in this section were formulated 
based on the available literature/studies on EMS-based software. Some examples of the closedended statements in this section included:

1. I find that the software provides helpful templates that assist me in my ability to develop documents outlining procedures, policies, and so forth as part of the ISO 14001 management systems standard's requirement.

2. The software includes information that assists auditors in their ability to verify conformance to the audit criteria in the ISO 14001 standard.

3. The software has a tool that assists me in my ability to manage training records as part of the ISO 14001 management systems standard's requirements.

4. The software allows for the integration of several management systems/standards.

5. The software has tools that assist me in my ability to prepare reports in the format required by environmental regulators and other government agencies.

6. The software provides a central library system for documents generated as part of the ISO 14001 management systems standard's requirements.

Respondents were asked to provide a "Yes" or "No" when responding to these statements. The majority of the closed-ended statements in this section were developed based on the study by the Global Environment and Technology Foundation (2004). The statements above were developed in order to answer research question Q3.

The open-ended questions concerning the functionality of the software in terms of what users found most and least helpful, suggested improvements for the software, the ease or difficulty in implementing the software, and whether the software has the ability to pay for itself were presented in this section

Finally, section D consisted of closed-ended and open-ended questions pertaining to the participants and their organization. For example, respondents were asked to provide their job position, time spent at the organization, size of the organization, and length of time the organization has been registered to ISO 14001. The entire questionnaire can be viewed in Appendix A. 
The survey questions were reviewed by an arms-length peer review panel and the Accelerate Research Review Committee as part of the Mitacs-Accelerate program. The review contributed to the development of the questionnaire used for the study.

\subsubsection{Data Analysis}

The data was coded, after which, statistical analysis (descriptive and inferential) was performed on the data collected by the survey. Descriptive statistics (e.g., mean, standard deviation, frequencies) was used to evaluate the responses of the participants (based on their responses to the closed-ended statements in section A and section B of the questionnaire) in order to better understand whether the ISO 14001:2004 standard and EMS-based software might have the ability to facilitate the four constructs of organizational learning and thus enhance organizational learning. The research also sought to observe the difference in responses if any, between groups, in this case private and public sector and possibly small, medium and large businesses and as such, an independent t-test for the independent samples for the first group (public and private sector) and a one-way independent analysis of variance (ANOVA) for the second group (small, medium and large organizations) were found to be appropriate (Field, 2009; Salkind, 2009) and were thus undertaken. Cronbach's Alpha was used to verify the reliability or internal consistency of the measurement items for the constructs of organizational learning with respect to the closedended statements in sections A and B. It is one of the most common statistical techniques for estimating the reliability in cross sectional research data (Alwin, 2010; Salkind, 2009). In order to determine whether EMS-based software has the ability to assist organizations in implementing and maintaining the ISO 14001:2004 standard (based on the responses to the closed-ended statements in section $\mathrm{C}$ of the questionnaire), descriptive statistics and inferential statistics (chisquare and loglinear analysis) were performed on the data. Correlation and regression (linear and ordinal) analysis were also conducted on the data in order to determine if other relationships existed amongst the different variables. For instance, a linear and ordinal regression were conducted in order to determine if the number of years an organization is registered to the standard has any relationship with the responses to the four constructs of organizational learning. The statistical software IBM SPSS was used to analyze the data obtained using the closed-ended statements while QSR NVivo was used for the text/inductive analysis of the data obtained using the open-ended questions. 
The QSR NVivo software enabled importation of the questionnaires (in PDF format) into a predefined folder in the software called "source". The questionnaire then served as a source from which one could extract or code the data. Topic coding was then done by creating "nodes" that represented each open-ended question on the questionnaire and then placing all the responses to each question under the respective nodes/questions. For example, the question in section A regarding the most helpful feature of the ISO 14001 standard was used as a "node". This allowed for all the responses to this question to be extracted one at a time from all the questionnaires in the "source" folder and placed (coded) under this node. This enabled one to read and reread and interpret all the responses to the same question in the same location as well as to carry out queries such as 'text search' and 'word frequency' in order to obtain the common themes. In doing so, one was able to conduct analytical coding for which the common themes observed were then used to create new nodes under the original nodes. In the long run, all the responses that represented a common theme appeared under the same node. Opening a node gives you access to all the related responses to a question stored in one location and shows you the source of each response, that is, the questionnaire/respondent. The software also has a function called "classification" which enabled one to input the descriptive data collected using section D of the questionnaire such as gender of respondents, size of the organization, occupation of respondents, and so on. This allowed one to observe the spread of the data and to, if necessary, filter the data, and compare the respondent's comments based on the descriptive data. Although the software facilitates the analysis of qualitative data, it must be pointed out that the determination of the common themes and thus the findings of the study is mostly based on the judgement and knowledge of the researcher with respect to the research objectives.

The potential for nonresponse bias was examined using the wave analysis technique, which entails comparing early respondents with late respondents based on key estimates (Atif, Richards, \& Bilgin, 2012; Lineback \& Thompson, 2010). Late respondents are those who responded to the survey after contacting them on several occasions and are therefore used to represent non respondents (Lineback \& Thompson, 2010). An independent t-test for the independent samples was used to compare both groups. 


\subsubsection{Limitations of the Design}

First, due to the fact that the collection of the total number of organizations (ISO 14001:2004 certified organizations and organizations that use EMS-based software) was not possible and was therefore not determined, and that random sampling to choose the sample frame was therefore not done, the sample frame for this study may or may not be representative of the target population. This is one of the known disadvantages of non probability sampling. Nevertheless, non probability sampling has been said to be a useful sampling technique for studies involving special populations for which a list of the total population cannot be obtained (Baker et al., 2013; Couper \& Bosnjak, 2010; Rea \& Parker, 2005; Schreuder, Gregoire, \& Weyer, 2001).

Second, as mentioned earlier, only one respondent per organization was surveyed for this study. This could result in a limited report of the phenomena being studied (Woodside \& Wilson, 2003). Nevertheless, surveying one respondent per organization has been undertaken and deemed appropriate in previous studies on organizational learning (Jerez-Gomez et al., 2005; Templeton et al., 2002) and was therefore considered to be appropriate for this research.

Finally, since the research was cross sectional in nature, it was not possible to make assessments over a period of time. In other words, the study was limited to determining whether the ISO 14001:2004 standard and EMS-based software were capable of enhancing learning and not whether they actually brought about learning over a period of time within the organizations. A longitudinal study would be more appropriate in determining whether learning occurred over a long period of time.

\subsubsection{Reliability and Validity as applied to the Survey Research Method}

Reliability in research design implies that a research study can be repeated successfully by the originator and by other researchers using the same procedures and conditions used by the original researcher with the outcome being the same as the original study (Alreck \& Settle, 1995; Alwin, 2010; De Vaus, 2006; Salkind, 2009). Validity in research design implies that the research study will achieve what it was designed to achieve (Alreck \& Settle, 1995; Alwin, 2010; De Vaus, 2006; Salkind, 2009). They both play an important role in any research design because 
they ensure that the data that is collected can be used to answer research questions as credibly as possible (De Vaus, 2006). As such, they must be established or enhanced as much as possible.

With regards to the survey research method, threats to reliability and validity can occur in certain stages of the process such as the sampling process, the development of the research instrument (questionnaire), and the data collection process (Alreck \& Settle, 1995). Attempts to enhance the reliability and validity in these stages of the survey process were carried out in a number of ways as discussed below.

\subsubsection{Reliability}

With respect to the sampling process, an appropriate sample size was used in an attempt to ensure that the sample was representative of the population from which it was drawn and thus to improve reliability. With respect to the design of the questionnaire, efforts were made to ensure that the questions were clear and understandable, and that straightforward and identical instructions were provided for all the questionnaires. Other strategies for enhancing reliability with a focus on questionnaire design included adequate wording, ensuring that terms had the same meaning for all participants and ensuring that terms were defined properly and as needed (Fowler, 2002; Salkind, 2009).

\subsubsection{Validity}

In order to enhance the internal validity of this research a few measures were employed. First, the information that was provided in the questionnaire was presented clearly and consistently so that it could be understood by all the respondents. Second, follow-up open-ended questions to some closed-ended statements were used in order to ensure that the respondents put some thought into their responses when answering the closed-ended statements (Fowler, 2002). Third, efforts were made to reduce or eliminate all forms of bias that could be introduced by the researcher or the respondents as bias tends to lower the validity of data (Alreck and Settle, 1995). For instance, attempts to avoid accessibility bias was done by choosing employees of the organizations surveyed who had the requisite knowledge on the subject being studied and not those that were readily accessible. Finally, the validity of the study may have been enhanced due to the fact that a self-administered data collection procedure was used and that there was a 
commitment to confidentiality and anonymity. This may be the case because respondents are said to provide honest responses when they are assured that their answers will be kept confidential and anonymous (Fowler, 2002).

\subsection{Ethics}

No serious ethical issues were anticipated for this research study. However, since the research involved human subjects, an ethical review of the research procedures was conducted by the Research Ethics Board of Ryerson University. The evidence of approval by the board is presented in Appendix A.

In order to conduct the research in an ethical manner, respondents were informed among other things of the organization conducting the research, the purpose of the research, the degree of confidentiality, and the fact that their participation was voluntary.

In order to maintain confidentiality, the following procedures were followed:

- Data collected was secured at all times. Data stored electronically on laptops, USB drives or any other electronic devices were encrypted.

- Names of respondents or organizations were not included on the questionnaires. Instead, an identifier (e.g., coded ID number) was used so that the respondent could still be contacted should there be any queries regarding their responses.

- The links between responses and respondents were minimized, in other words completed questionnaires were stored separate from the files with respondent's information (name and company).

- Only the student researcher and his supervisor had access to the raw data.

- Information that can lead to the identification of a respondent and their organization will not be included in any papers or articles to be made public.

With respect to informed consent, a consent agreement was sent to each of the respondents for their signature along with the questionnaire. Signed consent agreements were returned by those who participated in the study. 
To conclude this chapter, it can be said that the research methodology (despite the limitations of the design and the survey research method (questionnaire) on the whole), is appropriate for this research study. The survey research method allows for feedback from a suitable sample frame that consists of a diverse group of organizations in terms of industry sector and size to be obtained, which is what this study sought to do. Also, despite the fact that there was no comprehensive list of organizations that are registered to the standard or that use EMS-based software, the use of non probability sampling still allowed for the target populations to be surveyed. In the next chapter, the results and discussion of the survey data is presented in order to reach conclusions as to the ability of the ISO 14001:2004 standard and EMS-based software to enhance organizational learning, the ability of EMS-based software to assist organizations with the implementation and maintenance of the standard, and the functionality of both the standard and EMS-based software. 


\section{Chapter 4: Results and Discussion}

In this chapter, the results with respect to the response to the survey are presented, and background information concerning the respondents and the organizations is provided. This is then followed by the presentation and discussion of the results regarding respondent's perceptions of the ability of the ISO 14001 standard and EMS-based software to facilitate the four constructs of organizational learning as well as the perceived ability of the standard and software to enhance performance by facilitating learning. Next, presentation and discussion of the functionality of software (that is, its ability to assist organizations with the implementation and maintenance of the ISO 14001 standard), its most and least helpful features, whether its implementation is found to be easy or difficult, suggested improvements, its ability to pay for itself, and the reasons why some organizations do not use EMS-based software is provided. Finally, the results with respect to the perceived functionality of the standard-- that is, the requirements/features that respondents found most and least helpful -- is presented and discussed.

\subsection{Survey Response and Nonresponse Bias}

As discussed in Chapter 3, a questionnaire was sent to a total of 899 organizations between January 2012 and December 2014 out of which 76 responded. The questionnaire was sent mainly via email, however a few were sent using snail mail when no contact information (email address and/or telephone number) was available or the email transmission failed. No response was received from those who were sent the questionnaire by snail mail. Based on the total number of organizations (899) and the number of participants that responded (76), the response rate was approximately 8.5 percent. The low response to the survey might have been due to the length of the questionnaire as well as the fact that a lot of the non respondents when contacted, mentioned that they did not have much time on their hands. The comparatively small number of participants does pose limitations on the study in terms of being able to draw strong conclusions and to generalize the results, nevertheless, the findings of the study do provide useful preliminary insights for future research. 
Nonresponse bias was determined by dividing the respondents into two groups and comparing their responses to the four closed-ended statements in section A, that is, their opinion was solicited as to whether the standard has the perceived ability to facilitate information acquisition, information distribution, information interpretation, and organizational memory and therefore to facilitate organizational learning. As stated in Chapter 3, one closed-ended statement represented each construct of organizational learning, hence the four statements. The comparison was done using an independent $t$-test. The two groups included those that responded when the questionnaire was sent to them for the first time (early respondents) and those that respondent after reminders were sent out (late respondents/non respondents). This resulted in 27 early respondents and 49 late respondents/non respondents. The results indicate that there was no significant difference in how participants responded to each of the four statements. However, for the statement regarding information acquisition, the t-statistic for 'equal variances not assumed' was used. The results were the same when the total scores of the four statements per respondent was used for the analysis. Nonresponse bias was also examined using two different groups from those used above. Since the time period ( 2 weeks) for the first reminder was close to the first wave, they were both combined to form the early respondents, while those that were sent more than two reminders were considered as late or non respondents. This assumption was suitable based on the study by Atif et al. (2012). This resulted in 44 early respondents and 32 late respondents/non respondents. As with the first analysis, the results also indicate that there were no significant differences in the participant's responses with respect to each of the four statements. Again, similar results were obtained when the total scores were used. Based on the foregoing analyses one may conclude that nonresponse bias may not be a major issue for this research study.

\subsection{Background of the Respondents}

Respondents were requested to provide background information about themselves such as their job title and length of time spent in that position, their gender, their age, and their academic qualification. With respect to their job titles, the majority of the respondents fell within the fields of environment, health and safety, and quality management. The Job titles in such fields ranged from Vice President, to Director, to Senior Manager, to Manager, to Coordinator, and to Engineer. To see the full list please see Table B.1 in Appendix B. The time respondents had been 
in those positions ranged from 6 months to 20 years, with the majority of them having spent 2 years and above in their respective positions. See Figure B.1 in Appendix B. Four (4) respondents did not provide information with respect to the length of time spent in their current position. Based on the job title and time in position of the respondents it can be concluded that the respondents had enough knowledge and experience with environmental management systems and ISO 14001 at their organization and thus helps with the reliability and validity of the survey. The majority of the respondents fell within the age range of $50-59$ (29 respondents), followed by 40 - 49 (20 respondents) and then 30 - 39 (17 respondents). Fifty-six (56) were males and 19 were females. One respondent did not provide an answer. Respondent's academic qualifications ranged from a high school diploma to a doctorate degree with the majority having a bachelor's degree (31 respondents), followed by a master's degree (27 respondents). Three respondents did not provide a response to this question.

\subsection{Background of the Organizations}

The 76 organizations were registered to the ISO 14001:2004 standard. Also, out of the 76 organizations, 22 disclosed that they used software to assist them with managing their environmental management system/ISO 14001, however, only 12 used EMS-based software. As a result of the very small sample size, no assertions are being made in this study concerning the representativeness of the responses in the sample. Nevertheless, the 12 respondents provided useful insights with respect to the use of EMS-based software to facilitate the implementation and maintenance of an environmental management system that is in line with ISO 14001:2004.

Based on the North American Industry Classification System (NAICS), the organizations that participated in this study belonged to the following sectors: manufacturing (31-33), utilities (22), transportation and warehousing (48-49), agriculture, forestry, fishing and hunting (11), mining, quarrying, and oil and gas extraction (21), educational services (61), administrative and support, waste management and remedial services (56), public administration (91), and professional, scientific and technical services (54), with most of them belonging to the manufacturing sector $(62 \%)$. The lists of the industry sectors of the organizations based on the raw data and the NAICS codes are presented in Table B.2 and Table B.3 respectively in Appendix B. In terms of the size of the organizations, 16 were small, 25 were medium, and 34 were large. One respondent 
did not disclose the size of the respondent's organization. Also, $49(64 \%)$ of the organizations were in the private sector, while 27 (36\%) were in the public sector. The minimum age of all the organizations was 4 years while the maximum age was 146. Most of the organizations fell within the 20 - 29 year range, followed by the $100-109$ year range, and then by both the $50-59$ and 30 - 39 year ranges as shown in Figure 4.1 below. The average age of all the organizations was about 58 years. Based on the ages of the organizations and their average age, one may conclude that they are mature enough and would have gone through the learning process, and may be more likely to be learning organizations, especially when considering the developmental perspective put forward by DiBella and Nevis (1998). In terms of the length of time the organizations were registered to ISO 14001:2004, the minimum number of years was 2 years, while the highest number of years was 17 years as shown in Figure 4.2 with the average number of years of registration being 9 years. Based on the number of years registered, one may also conclude that the majority of the organizations that participated in the survey had a mature environmental management system and had enough experience with ISO 14001:2004. This should contribute to the strength of the findings of the study notwithstanding the fact that the study may have failed to capture a larger number of organizations that were early adopters of the standard.

With respect to the twelve organizations that used EMS-based software, they were found to belong to the following sectors: manufacturing (31-33), utilities (22), agriculture, forestry, fishing and hunting (11), educational services (61), administrative and support, waste management and remedial services (56), and public administration (91). Although the majority (4) belonged to the manufacturing sector, the cross section of sectors does indicate that the software is used by a diversity of organizations. The results also indicate that organizations from both the private and public sectors use EMS-based software. In fact, a slightly larger number of public organizations were found to use the software. It therefore highlights the fact that EMSbased software is now being designed to meet the needs of public organizations, which was not the case a few years ago (Global Environment \& Technology Foundation, 2004). Also, only one organization out of the twelve was a small organization with the rest being medium and large organizations. The latter were in the majority (7). However, the small organization had stopped using EMS-based software before this survey had been conducted. One of the reasons appeared to be the cost of the software. This may be an indication that at this time EMS-based software 
may be too expensive for small organizations. Indeed, large organizations that should have more resources also found it to be an expensive investment as discovered by this study.

The 12 organizations used EMS-based software that was developed by five different companies, which will be referred to in this study as software Company A, B, C, D, and E respectively. Seven (7) respondents used Company A's software, 2 respondents used Company B's software, and Companies C, D and E's software was used by 1 respondent each. Some participants in this study used two different software packages belonging to Company A, namely, an integrated management (IM) software and an environmental management (EM) software. They will be referred to in this study as IM software and EM software respectively. Company B and D's software was an environmental management software. Company C's software was an information management system that supported an organization's environmental management system, while Company E's software was an integrated solution that incorporated environmental management. One half of the organizations had an integrated management system. The presence of the latter could have been the reason why some of the organizations chose to use an EMSbased software. In fact, 3 out of the 6 organizations used EMS-based software programs that were specifically designed to work as part of an integrated management system.

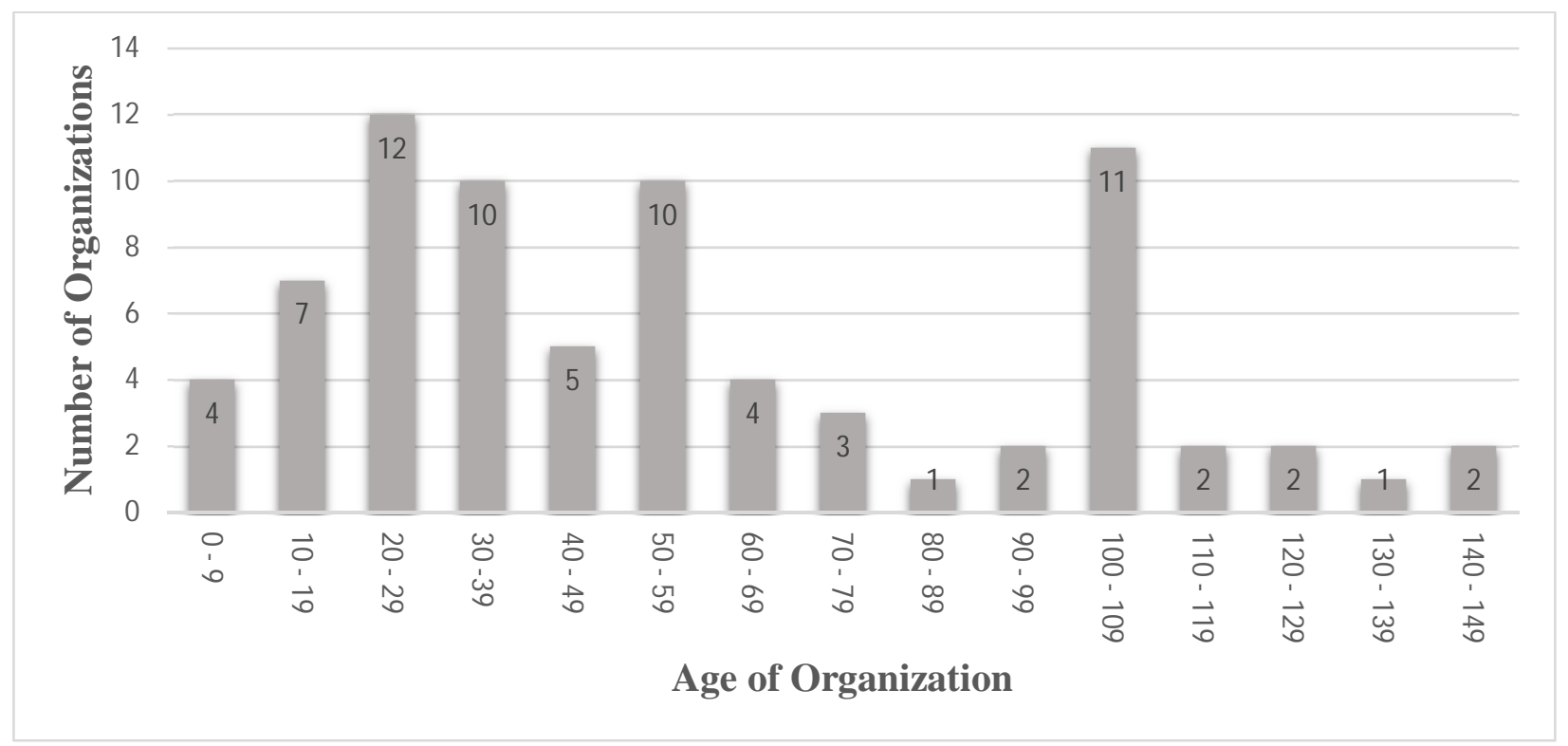

Figure 4.1 Age of organizations that participated in this study 


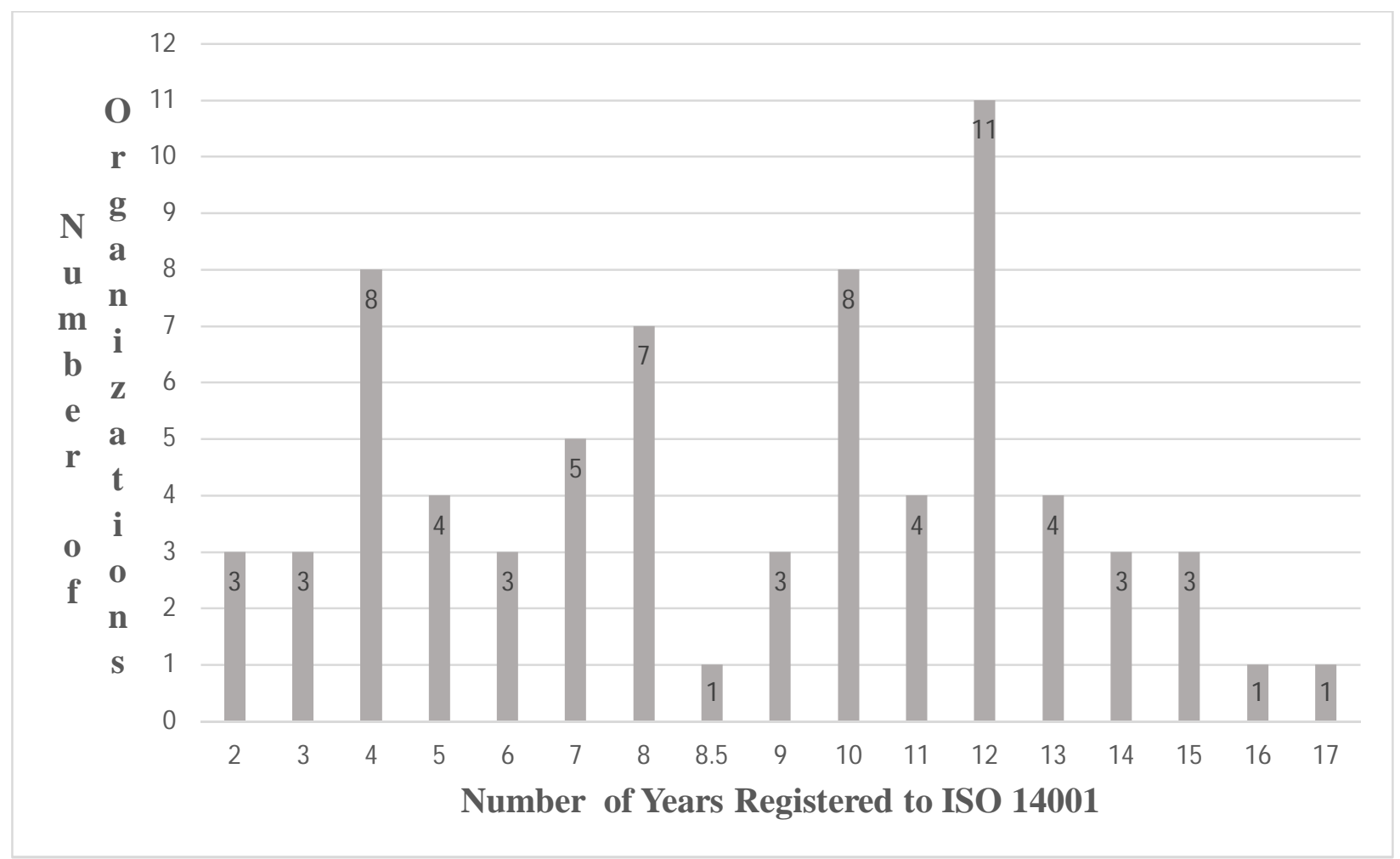

Figure 4.2 Number of years that participating organizations were registered to ISO 14001:2004

In order to have a better idea of what other voluntary standards organizations are using and how this may play into the implementation and maintenance of ISO 14001, respondents were asked to list other standards that they were certified to or using as a guide. A list of these management systems/standards is presented in Table B.4 in Appendix B. Fifty-seven (57) organizations were registered to/used either one or a combination of other standards, while 17 organizations only had ISO 14001:2004 (2 respondents did not provide a response for this question). Thirty-three (33) respondents were using ISO 9001 (a standard for quality management systems), 15 were using OHSAS 18001 (a standard for occupational health and safety), and 9 were using ISO/TS 16949 (a quality management system standard tailored to the automotive and relevant service part industry). The high number of users of these standards is not surprising given the fact that most of the organizations were in the manufacturing sector and that ISO 9001 in particular has been around much longer than all the other standards. 
In terms of which management systems/standards were integrated, 42 (56 percent) of the organizations had their management systems integrated, while 33 organizations (44 percent) did not have an integrated system (one organization did not provide a response). Of the organizations that had an integrated system, 38 had their environmental management system (mainly ISO 14001) integrated with other management systems. Out of this number, 30 (79 percent) had their environmental management system (mainly ISO 14001) integrated with their quality management system (mainly ISO 9001), and 20 (53 percent) had their environmental management system (mainly ISO 14001) integrated with their occupational health and safety management system (mainly OHSAS 18001).

Although a slightly greater number of organizations had their management systems integrated, the results also show that a fair amount did not. A reason for the integration could be due to the ability to combine the documentation process (Schylander \& Martinuzzi, 2007) as well as the audit process (Karapetrovic, 2002; Schylander \& Martinuzzi, 2007), which would in turn save time and money. Another reason for integration of management systems/standard, especially environment and quality may be because of some of their similarities. In fact, it is said that ISO 14001 was intentionally created to be similar to ISO 9001 with respect to some of its requirements (Poksinska et al., 2002). Integrating both of them would reduce or eliminate double work and redundancy (Jørgensen \& Simonsen, 2002). Also, the establishment of the international standard, ISO 19011 which serves as a guide for quality and environmental management systems audits could be another motivation for organizations to integrate both management systems (Schylander \& Martinuzzi, 2007). Finally, integrating quality, environment, and health and safety is also seen as good practice because conducting work procedures and handling materials safely also helps protect the environment (Zwetsloot, 1995). On the other hand, organizations may shy away from integrating their management systems because integrated systems may bring increased bureaucracy, complexity, and be more resourceintensive (Schylander \& Martinuzzi, 2007). 


\subsection{ISO 14001 and Organizational Learning}

\subsubsection{ISO 14001 as a facilitator of the four constructs of Organizational Learning}

All 76 respondents provided responses to the four closed-ended statements in section A, which were designed to answer research question Q1; that is, to gain a better understanding as to whether the ISO 14001 standard has the capability to facilitate information acquisition, information interpretation, information dissemination, and organizational memory and in turn facilitate organizational learning. A five-point Likert scale (with 1, "strongly disagree"; 2 , "moderately disagree"; 3, "undecided"; 4, "moderately agree"; 5, "strongly agree") was used. A factor (principal component) analysis using the responses to the four closed-ended statements in section A revealed the existence of only one factor, indicating that the four statements may be representative of only organizational learning as it pertains to this study.

Cronbach's alpha was calculated in order to determine the reliability of the questionnaire with respect to the four closed-ended statements, and to determine whether or not the four constructs of organizational learning can be used together to evaluate the organizational learning capability of the standard. The Cronbach's alpha analysis $(\alpha=.723)$ indicated that the questionnaire was reliable with respect to research question Q1 because this value is within the suitable range of $\alpha$ $=.7-.8$ (Field, 2009). The analysis also showed that there was a significant correlation between the score of each statement and the total score for the four statements and so the four statements combined may be used to determine whether the ISO 14001 standard could enhance organizational learning.

Table 4.1 below shows the number of responses to each of the four statements based on the complete Likert scale. The data indicates that the majority of the respondents moderately agreed with the fact that the standard may have the ability to facilitate the four constructs of organizational learning. It also shows that more respondents strongly agreed with respect to the standard's ability to influence information dissemination and organizational memory. 
Table 4.1 Summary of responses regarding the ISO 14001 standard's ability to influence the four constructs based on individual scores

\begin{tabular}{|l|c|c|c|c|c|}
\hline \multicolumn{1}{|c|}{ Statement } & $\begin{array}{c}\text { Strongly } \\
\text { Agree }\end{array}$ & $\begin{array}{c}\text { Moderately } \\
\text { Agree }\end{array}$ & Undecided & $\begin{array}{c}\text { Moderately } \\
\text { Disagree }\end{array}$ & $\begin{array}{c}\text { Strongly } \\
\text { disagree }\end{array}$ \\
\hline $\begin{array}{l}\text { I find that the standard } \\
\text { assists me in my ability to } \\
\text { acquire useful } \\
\text { environmental information } \\
\text { that applies to the } \\
\text { organization }\end{array}$ & 14 & 39 & 11 & 11 & 1 \\
\hline $\begin{array}{l}\text { The standard assists me in } \\
\text { my ability to disseminate } \\
\text { (distribute) useful } \\
\text { environmental information } \\
\text { within the organization and } \\
\text { beyond, in the form of } \\
\text { policies, procedures, best } \\
\text { practices, etc. }\end{array}$ & 23 & 39 & 9 & 4 & 1 \\
\hline $\begin{array}{l}\text { The standard assists me and } \\
\text { my colleagues in our ability } \\
\text { to analyze and interpret } \\
\text { useful environmental } \\
\text { information that applies to } \\
\text { the organization }\end{array}$ & 12 & 37 & 18 & 6 & 3 \\
\hline $\begin{array}{l}\text { The standard assists me in } \\
\text { archiving (storing) relevant } \\
\text { environmental data and } \\
\text { information about the } \\
\text { organization for current and } \\
\text { future referencing }\end{array}$ & 23 & 34 & 7 & 9 & 3 \\
\hline
\end{tabular}

Based on the total scores of the four statements per respondent, it was determined that the majority of the respondents (87\%) were of the opinion that the ISO 14001:2004 standard has the capability to contribute to organizational learning. On assessing the four statements separately, the number of respondents that felt that the standard assisted them with the four constructs is as follows: information acquisition (70\%), information dissemination (82\%), information interpretation (65\%), and organizational memory (75\%). The percentages mentioned above were obtained after amalgamating groups 1 and 2, and groups 4 and 5 of the Likert scale into "disagree" and "agree" respectively, and are presented in Table 4.2 below. Based on the foregoing it can be seen that more participants felt that the standard influenced information distribution than the other constructs. This suggests that information distribution may play a 
greater role with respect to organizational learning in general or in relation to the standard alone. This contrasts with some findings described in the literature, where organizational memory is said to play a major role with respect to organizational learning because it influences the other three constructs (Robey et al. (2000).

Table 4.2 Summary statistics regarding the ISO 14001 standard's ability to influence the four constructs based on amalgamated scores

\begin{tabular}{|c|c|c|c|c|}
\hline Statement & Agree & Undecided & Disagree & $\begin{array}{c}\text { Percentage } \\
\text { agreed }\end{array}$ \\
\hline $\begin{array}{l}\text { I find that the standard assists me in my } \\
\text { ability to acquire useful environmental } \\
\text { information that applies to the organization }\end{array}$ & 53 & 11 & 12 & 70 \\
\hline $\begin{array}{l}\text { The standard assists me in my ability to } \\
\text { disseminate (distribute) useful environmental } \\
\text { information within the organization and } \\
\text { beyond, in the form of policies, procedures, } \\
\text { best practices, etc. }\end{array}$ & 62 & 9 & 5 & 82 \\
\hline $\begin{array}{l}\text { The standard assists me and my colleagues in } \\
\text { our ability to analyze and interpret useful } \\
\text { environmental information that applies to the } \\
\text { organization }\end{array}$ & 49 & 18 & 9 & 65 \\
\hline $\begin{array}{l}\text { The standard assists me in archiving (storing) } \\
\text { relevant environmental data and information } \\
\text { about the organization for current and future } \\
\text { referencing }\end{array}$ & 57 & 7 & 12 & 75 \\
\hline
\end{tabular}

The findings may also imply that the length of time the organization was registered to the standard may have a role to play with respect to the ability of the standard to influence the four constructs of organizational learning. With respect to this assumption, a correlation analysis was undertaken to determine whether there was a relationship between the four constructs of organizational learning and the number of years the organizations were registered to the standard. A correlation analysis was also done between the total scores for each construct per respondent and the number of years the organization was registered to the standard. With respect to the former, a spearman's rank correlation indicated that there was a weak, negative, and non significant correlation as follows: information acquisition $(r=-.168, \mathrm{p}>0.05)$; information distribution $(r=-.092, \mathrm{p}>0.05)$; information interpretation $(\mathrm{r}=-.184, \mathrm{p}>0.05)$; and organizational memory $(\mathrm{r}=-.003, \mathrm{p}>0.05)$. There was also a weak, negative, and non significant 
relationship between the total scores and the number of years registered to the standard $(\mathrm{r}=$ $.132, \mathrm{p}>0.05)$. Though tentative, the results may suggest that the standard may have a greater influence on the constructs and thus learning during its early stages of adoption. Based on the following, a linear regression analysis was also carried out. However, the length of time the organizations were registered to the standard was found not to be a good predictor of how participants responded to the four statements. The reason could be the fact that the majority of the organizations that participated in the study had a mature EMS. Future research could therefore examine at what stage of the standard's implementation are the constructs influenced the most -- early stages, or at a more mature stage?

The mean value for each statement (that is, without amalgamating the scores) as shown in Table 4.3 below, aligns with the percentages provided in Table 4.2 above in that the majority of the respondents felt that the standard had the ability to influence information distribution compared to the other three constructs. However, based on the standard deviations most of the responses fell between a neutral position and a strongly agree position with respect to the four constructs and so any inferences drawn from this summary should be approached with caution.

Table 4.3 Summary statistics regarding the ISO 14001 standard's ability to influence the four constructs based on mean values

\begin{tabular}{|c|c|c|c|}
\hline Statement & $\begin{array}{l}\text { Mean } \\
\text { Value }\end{array}$ & $\begin{array}{l}\text { Standard } \\
\text { Deviation }\end{array}$ & $\mathbf{n}$ \\
\hline $\begin{array}{l}\text { I find that the standard assists me in my ability to acquire useful } \\
\text { environmental information that applies to the organization }\end{array}$ & 3.71 & 0.977 & 76 \\
\hline $\begin{array}{l}\text { The standard assists me in my ability to disseminate (distribute) } \\
\text { useful environmental information within the organization and } \\
\text { beyond, in the form of policies, procedures, best practices, etc. }\end{array}$ & 4.04 & 0.871 & 76 \\
\hline $\begin{array}{l}\text { The standard assists me and my colleagues in our ability to } \\
\text { analyze and interpret useful environmental information that } \\
\text { applies to the organization. }\end{array}$ & 3.64 & 0.976 & 76 \\
\hline $\begin{array}{l}\text { The standard assists me in archiving (storing) relevant } \\
\text { environmental data and information about the organization for } \\
\text { current and future referencing. }\end{array}$ & 3.86 & 1.104 & 76 \\
\hline
\end{tabular}

Note. $\mathrm{n}=$ Number of respondents.

Bearing in mind the low response rate, and the fact that the questions elicit respondent's perceptions of impact, rather than directly measure organizational impact, the results suggest that 
the ISO 14001:2004 standard may facilitate Huber's (1991) four constructs of organizational learning, and therefore there is some preliminary, qualified and limited support for the proposition that it contributes to organizational learning. The results support the proposition put forward by Epstein and Roy (1997) who suggested that the standard through some of its requirements (planning, implementation and operation, checking, management review) could facilitate the acquisition, transfer and storage of information. Although Epstein and Roy (1997) did not mention information interpretation directly they mentioned that the standard through its planning, and implementation and operation (specifically communication) requirements could facilitate the opening up of boundaries leading to shared problem solving and the exchange of ideas. Shared problem solving and the exchange of ideas are said to lead to the interpretation of information (Crossan et al., 1995; Jimenez-Jimenez \& Sanz-Valle, 2011; Kloot, 1997; Lopez, et al., 2004). The results are also in line with the views of Burström (2002) who indicated that an environmental management system (in line with ISO 14001) may facilitate learning through the acquisition of, and in turn dissemination of useful information amongst the members of an organization. Also, Burström (2002) is of the opinion that an EMS has the ability to facilitate learning via communication and the exchange of information. As mentioned above, both activities may assist with the interpretation of information. Reverdy (2007) also mentions the fact that the implementation of the standard could facilitate the acquisition and sharing of new knowledge between different departments in an organization.

\subsubsection{Private vs Public Sector opinions regarding ISO 14001 and Organizational Learning}

Although not a focus for this study, the survey provides some preliminary information concerning the question of whether there were any differences with respect to the responses provided by the respondents from private and public sector organizations. For this, an independent t-test was conducted using the total scores of each statement per respondent, and an independent t-test using each statement on its own. Based on the total scores, on average, more respondents from public organizations $(\mathrm{M}=16.11, \mathrm{SE}=0.56)$ felt that the standard could facilitate organizational learning when compared to respondents from private organizations $(\mathrm{M}=14.78$, $\mathrm{SE}=0.41$, however, this difference was not significant $\mathrm{t}(74)=-1.95, \mathrm{p}>0.05$. Please see Table 4.4 below for the summary. 
Table 4.4 Comparing the opinions of respondents from private and public sector organizations on the effect of ISO 14001 on the four constructs (using total scores of the four statements per respondent)

\begin{tabular}{|l|c|c|c|c|}
\hline & n & Mean & $\begin{array}{c}\text { Standard } \\
\text { Deviation }\end{array}$ & Standard Error \\
\hline Private & 49 & 14.78 & 2.845 & 0.406 \\
\hline Public & 27 & 16.11 & 2.887 & 0.556 \\
\hline
\end{tabular}

Note. $\mathrm{n}=$ Number of respondents.

With respect to the independent t-test using the statements individually, the same pattern was seen. Slightly more respondents in the public sector were of the opinion that the standard could facilitate all four constructs of organizational learning than those in the private sector. Again, these differences were not significant. See summary below in Table 4.5.

Table 4.5 Comparing the opinions of respondents from private and public sector organizations on the effect of ISO 14001 on the four constructs (using mean values for each statement)

\begin{tabular}{|l|l|l|l|l|}
\hline \multicolumn{1}{|c|}{ Constructs } & \multicolumn{1}{|c|}{$\begin{array}{c}\text { Private } \\
\text { and } \\
\text { Public }\end{array}$} & Mean & $\begin{array}{c}\text { Standard } \\
\text { Deviation }\end{array}$ & $\begin{array}{c}\text { Standard } \\
\text { Error of } \\
\text { Mean }\end{array}$ \\
\hline \multirow{2}{*}{$\begin{array}{l}\text { ISO 14001 and Information Acquisition } \\
(\mathrm{t} \text { 74 })=-1.69, \mathrm{p}>0.05)\end{array}$} & Private & 3.57 & 0.957 & 0.137 \\
\cline { 2 - 5 } $\begin{array}{l}\text { ISO 14001 and Information Dissemination } \\
(\mathrm{t} \text { (74) }=-1.08 . \mathrm{p}>0.05)\end{array}$ & Private & 3.96 & 0.865 & 0.124 \\
\cline { 2 - 5 } $\begin{array}{l}\text { ISO 14001 and Information Interpretation } \\
(\mathrm{t}(74)=-1.13, \mathrm{p}>0.05)\end{array}$ & Private & $\mathbf{3 . 1 9}$ & $\mathbf{0 . 8 7 9}$ & $\mathbf{0 . 1 6 9}$ \\
\cline { 2 - 5 } $\begin{array}{l}\text { ISO 14001 and Organizational Memory } \\
(\mathrm{t}(74)=-1.74, \mathrm{p}>0.05)\end{array}$ & Public & $\mathbf{3 . 8 1}$ & 0.980 & 0.140 \\
\cline { 2 - 5 } & Private & 3.69 & 1.140 & $\mathbf{0 . 1 8 5}$ \\
\hline \multirow{2}{*}{ Public } & $\mathbf{4 . 1 5}$ & $\mathbf{0 . 9 8 9}$ & $\mathbf{0 . 1 9 0}$ \\
\hline
\end{tabular}

Note. $\mathrm{n}=$ number of respondents; $\mathrm{n}=49$ for private sector and $\mathrm{n}=27$ for public sector.

\subsubsection{Size of Organization, and ISO 14001 and Organizational Learning}

It was also of interest to see if there were any differences in how organizations of different sizes, that is small, medium, and large, responded to the statements regarding the four constructs of organizational learning. In order to determine this, a one-way independent ANOVA was used. As with the private and public sector comparison, total scores as well as scores for individual statements were used for the analysis. A total of 75 respondents (16 small, 25 medium, and 34 large) provided an answer with respect to the size of their organization. One respondent did not 
provide a definite answer and so was not included in the analysis. Based on the total scores, the results of the analysis indicated that there were no differences in the opinion of the respondents with respect to the standard and organizational learning, $\mathrm{F}(2,72)=0.423, \mathrm{P}>0.05$ (See Table 4.6). Gabriel and Hochberg (both used for uneven sample sizes) post hoc tests were also carried out and they also showed that there were no significant differences between the groups (P > 0.05). Similar results were obtained when evaluating each statement on an individual basis.

Table 4.6 Assessing the opinions of respondents from organizations of different sizes on the effect of ISO 14001 on the four constructs (using total scores for the four statements per respondent)

\begin{tabular}{|l|c|c|c|c|}
\hline & n & Mean & $\begin{array}{c}\text { Standard } \\
\text { Deviation }\end{array}$ & Standard Error \\
\hline Small & 16 & 15.81 & 2.344 & 0.586 \\
\hline Medium & 25 & 15.16 & 2.853 & 0.571 \\
\hline Large & 34 & 15.00 & 3.247 & 0.557 \\
\hline
\end{tabular}

Note. $\mathrm{n}=$ Number or respondents.

The similarities in the mean values shown in Table 4.6 (despite the differences in the number of respondents) might have been due to a larger number of participants from the large organizations taking a "neutral" or "disagree" position compared to medium and small organizations. The same was the case when comparing medium and small organizations. In fact, all but one respondent from the small organizations that participated in this study agreed with the statement that the standard has the ability to influence the four constructs of organizational learning. Although not indicated by the results, the standard may be more effective as a learning mechanism within small organizations because of the smaller number of employees. Future research could potentially attempt to better understand whether the standard has different learning effects based on the size of the organization, especially since larger organizations (given their complex operations and processes and number of employees) may need to facilitate all four constructs more than small or medium sized organizations.

\subsubsection{Industry Sector opinions regarding ISO 14001 and Organizational Learning} It was also interesting to see how respondents from organizations of different industry sectors responded with respect to the standard's ability to facilitate learning. Based on the total scores, and bearing in mind the qualifications and limitations associated with the survey results noted 
earlier, more respondents from the manufacturing sector agreed that the standard has the ability to influence organizational learning. The same trend was seen when considering responses to the four individual statements that represented the four constructs. The summary of the results with respect to the total scores is shown in Table B.5 in Appendix B. The pattern of the findings may reflect the fact that the majority of the participants of this study belonged to the manufacturing sector and not that it is representative of the opinions of those from that sector. That being said, future research could be conducted to better understand the differential effect of the standard on various industrial sectors.

\subsubsection{ISO 14001:2004 as a facilitator of Organizational Learning and in turn Environmental Performance}

For each closed-ended statement regarding the four constructs of organizational learning as provided in section A of the questionnaire, respondents were asked to provide answers to a follow-up open-ended question. The questions were designed to elicit the respondent's elaborated response (depending on how they responded to the closed statements) on how the standard assisted in facilitating the constructs of organizational learning (e.g., information acquisition), and how such an improvement influenced learning and in turn performance. The question that was asked is: If you are of the opinion that the standard leads to improved acquisition of useful information, could you comment on how this improvement affected organizational learning that influenced performance within your organization? The same question was asked regarding the other three constructs of organizational learning.

While bearing in mind the preliminary and tentative nature of the results due to the low response numbers, the feedback suggests that the standard by facilitating the four constructs of organizational learning brought about certain learning mechanisms/conditions. The latter as obtained from the responses of participants are summarized in Table 4.7 and are discussed below. The participant's responses with respect to each construct are outlined in Appendix B. 
Table 4.7 Learning mechanisms/conditions that were brought about by the standard's ability to facilitate the four constructs of organizational learning

\begin{tabular}{|c|c|}
\hline Constructs & Learning Mechanisms/Conditions \\
\hline Information acquisition & $\begin{array}{l}\text { - Improved knowledge, awareness and understanding of } \\
\text { employees } \\
\text { - Training programs } \\
\text { - Up-to-date information } \\
\text { - Structured and systems approach to environmental management } \\
\text { - Accountability }\end{array}$ \\
\hline Information dissemination & $\begin{array}{l}\text { - Improved knowledge, awareness and understanding of } \\
\text { employees } \\
\text { - Communication } \\
\text { - Employee engagement and participation } \\
\text { - Accountability } \\
\text { - Up-to-date information }\end{array}$ \\
\hline Information interpretation & $\begin{array}{l}\text { - Improved knowledge, awareness and understanding of } \\
\text { employees } \\
\text { - Shared consensus }\end{array}$ \\
\hline Organizational memory & $\begin{array}{l}\text { - Up-to-date information } \\
\text { - Improved knowledge, awareness and understanding of } \\
\text { employees } \\
\text { - Archiving of historical data } \\
\text { - Tracking of trends and thus feedback } \\
\text { - Communication and sharing of information }\end{array}$ \\
\hline
\end{tabular}

\subsubsection{Learning Mechanisms/Conditions}

\section{Awareness, knowledge and understanding}

Bearing in mind the qualifications noted above, the perceptions of respondents suggests that the standard may improve the knowledge, awareness and understanding of employees within the organization. The organizations saw improvements in understanding with respect to best 
practices, legal and other requirements, and discovered ways to reduce or control the environmental impacts of their organization. The improvement in understanding of environmental issues also facilitated discussions amongst employees with respect to problem solving in the organization. Through the acquisition, distribution and storage of information, employees appear to have more information/knowledge at their disposal, and are able to use this information/knowledge to carry out their duties more effectively. Through the interpretation of information, employees are more likely to have a better understanding and shared consensus with respect to environmental issues. As discussed in chapter 2, a better understanding and a shared consensus can facilitate learning in organizations (Daft \& Weick, 1984; Huber, 1991).

Furthermore, an improvement in knowledge and awareness will assist in enhancing the skills of employees with and without environmental responsibilities and lead to the development of their personal mastery, which is an important aspect of organizational learning (Senge, 2006). Studies on the benefits of the standard have shown that there is an increase in the environmental awareness and understanding of employees to include top management (Chavan, 2005; Psomas et al., 2011; Rondinelli \& Vastag, 2000; Schylander \& Martinuzzi, 2007; Turk 2009) in areas such as environmental aspects and impacts, and regulations (Rondinelli \& Vastag, 2000). The improvement in awareness and understanding is said to be a reason for the improvement in areas such as energy consumption, and waste and recycling (Schylander and Martinuzzi (2007). This improvement in awareness and understanding as it relates to the benefit of the standard may be due to the ability of the standard to influence the four constructs of organizational learning.

Some of the requirements that were found to improve on these conditions include the internal and external audits, management review, training, the identification of aspects and impacts, documentation, and roles and responsibilities.

\section{Up-to-date information}

The tentative and preliminary results of the survey suggest that by facilitating the acquisition, dissemination and storage of information the standard may assist organizations in remaining up to date with respect to relevant information/knowledge. This was said to be made possible via the documentation, document control, records control, legal and other requirements and the audit 
requirements. Having up-to-date information is an important condition for learning because it ensures that employees have the current and relevant information to carry out their duties, make good decisions, and solve problems. It can also play a role in ensuring unlearning, a subconstruct of information interpretation (Huber, 1991), is taking place. Through unlearning, new information or knowledge is acquired or learned (Antal et al., 2001; Huber, 1991) and new interpretations are conceived (Huber, 1991). Furthermore, as mentioned by Tippins and Sohi (2003), the quick and efficient distribution of information ensures that employees are up to date. The standard's ability to facilitate the acquisition, dissemination and storage of information could be a reason why the standard is said to keep organizations up to date with respect to regulations, advances in technology, best practices and so on (Bansal \& Bognar, 2002; Psomas et al., 2011).

\section{Communication}

The survey results also suggest that there may be improvements in communication and thus improvements in the sharing of information. This was mainly via the standard's ability to influence information distribution and organizational memory. By looking for ways to distribute information, organizations may be prompted to evaluate and improve their methods of communication. Improvements in communication may in turn open boundaries and build trust within the organization, both of which are conditions that are needed for organizational learning to take place (DiBella \& Nevis, 1998).

By facilitating the improvement in organizational memory through documentation and records management, organizations will have a better means to distribute information and to communicate more effectively. Documentation was found by this study to be of importance for the distribution of information especially for large organizations. As mentioned in the literature, the development of an organization's memory especially in the form of documents can ensure that information is accessible and can be easily shared within the organization (Argote, 1999; Romme \& Dillen, 1997; Roome \& Wijen, 2005).

As mentioned by several authors, effective communication is an important learning mechanism or condition because it enables the flow and exchange of ideas (Burström, 2002; Epstein \& Roy, 
1997; Slater \& Narver, 1995), ensures that more than one person in the organization learns (Epstein \& Roy, 1997), facilitates a systems approach (Petts et al., 1998), and can lead to the development of new interpretations of acquired information (Huber, 1991; Robey et al., 2000; Tippins \& Sohi, 2003). Furthermore, the findings align with Burström's (2002) assertion that the implementation of an environmental management system standard could enhance communication within an organization and thus enhance organizational learning.

Based on the aforementioned, the improvement in communication may prevent audience learning and fragmented learning from occurring since more people will be involved in the learning process.

\section{Accountability}

The survey results suggest that the standard may assist in keeping employees and thus organizations accountable due to its influence on the acquisition and dissemination of information. According to one respondent, the management review requirement was said to keep senior management accountable because objectives and targets were set and responsibilities were assigned during the review. The data obtained through the objectives and target requirement and other requirements such as the monitoring and measurement requirement could be used to track and develop trends, and thus keep organizations on track or accountable with respect to their performance. Also, the requirement to assign roles and responsibilities may help with keeping employees accountable because it requires that various elements of the standard be assigned to key individuals across the organization and that they carry out their tasks as required. As discussed by Friedman, Lipshitz and Overmeer (2001), accountability is one of the conditions for promoting learning. They mention that accountability entails accounting for our actions and their outcomes as well as implementing solutions to problems and learning from successes and failures from past experience (p. 762). They also say it "means experimenting with new behaviors and taking responsibility for the outcomes in order to stimulate learning" (p. 762).

\section{Shared consensus}

The survey results provide preliminary support for the proposition that implementation of the standard may influence information interpretation and facilitate the development of a shared 
consensus, especially with respect to environmental terminology. A shared consensus is vital for learning to take place because it ensures that employees are working towards the same goal and vision, and it prevents the likelihood of conflicts occurring amongst employees. A shared consensus should also lead to better cooperation among members of the organization and an improvement in work processes. As discussed in Chapter 2, the process of information interpretation can bring about better understanding and shared consensus, which in turn facilitates learning (Daft \& Weick, 1984; Huber, 1991).

\section{Tracking of trends and provision of feedback}

The survey results provide preliminary and tentative support for the proposition that the standard assists with improving the tracking of trends and thus the provision of feedback by influencing organizational memory. This was said to be made possible through the documentation of objectives and targets, the management review requirement, and documentation on the whole. As mentioned by Epstein and Roy (1997), the management review as well as the audit requirement serve as a means to obtain feedback regarding the EMS. The fact that the outcomes of such requirements are documented, and thus serve as memory for the organization is all the reason why the information acquired can then be used as feedback. Other requirements not mentioned by respondents that could provide feedback include the non-conformance, corrective action and preventive action requirement and the monitoring and measurement requirement.

Feedback is an important aspect of learning because it is a good means to obtain information from past experience. It is also important for learning as it is said to play a major role in systems thinking because it results in shared problem solving (DiBella \& Nevis, 1998; Senge, 2006) and it enables the organization to determine whether the outcomes of their actions are successful or not (DiBella \& Nevis, 1998). Also, by obtaining feedback, errors in the system may be detected and corrected thereby bringing about single-loop or double-loop learning depending on what type of changes are required. Finally, the acquisition and evaluation of feedback is seen as part of the learning process with respect to what Huber (1991) refers to as organizational experiments (a subconstruct of information acquisition). Huber (1991) also recognizes the importance of feedback by emphasizing the role of media richness in providing feedback. 


\section{Archiving of historical data}

By influencing the storage of information, organizations using the standard were seen to improve the way they archived their historical data. This was said to be made possible through records management, and the documentation of information obtained from implementing the monitoring and measurement requirement. The archiving of historical data is important for learning because the information/knowledge can be used as a source of feedback or as reference for when new problems arise. Other requirements such as the audit process could play a role in this regard because the problems detected as well as their solutions are to be documented and therefore can be referenced in the future should the need arise. Historical data therefore provides a means for the organization to learn from its mistakes and past successes. As mentioned earlier, the historical data can be used to develop trends, which in turn could provide information showing opportunities for improvement.

\section{Training}

The survey results suggest that organizations were seen to improve their training programs, flowing from the standard's ability to facilitate the acquisition of new information/knowledge. As discussed in Chapter 2, information obtained from, for example, undertaking the identification of environmental aspects and impacts can be used to develop amongst other elements of the standard, the training programs for all employees. The development of training programs is seen as a mechanism to promote organizational learning (Kane \& Alavi, 2007). An improvement in training should improve learning not only because it can facilitate the four constructs of organizational learning but because it leads to the development of the skills and competencies of members of the organization. Training as part of the standard's requirement was seen as a means to improve the environmental knowledge and awareness of employees (Petts et al., 1998; Poksinska et al., 2003) and as a means to convert explicit environmental knowledge to implicit environmental knowledge (Huang \& Shih, 2009).

\section{Structured and systems approach}

The survey results provide preliminary and qualified support for the proposition that the standard facilitates a structured and systems approach to environmental management by facilitating the acquisition of information in particular. This was said to be made possible via the standard's 
planning requirement. The planning requirement (especially the requirement to identify environmental aspects) prompts the organization to examine all areas of its operation and their interconnectedness thus facilitating a systems approach as discussed in Chapter 2. The role of the standard in providing a systematic approach to environmental management was evidenced in the studies by Christensen and Rasmussen (1998), and Boiral and Sala (1998). Also, the standard/EMS could encourage a systems approach by making employees aware of the fact that environmental issues are tied to almost every aspect of life and by bringing about the collaboration of the different units in an organization, especially when it comes to tackling environmental problems (Burström, 2002). A systems approach is said to be important in order for learning to be effective (DiBella \& Nevis, 1998; Easterby-Smith, 1997; Petts et al., 1998; Senge, 2006). Furthermore, it is said to facilitate knowledge acquisition and transfer (DiBella \& Nevis, 1998), which are both constructs of organizational learning.

\section{Employee engagement and participation}

According to the survey results, employee engagement and participation including top management was seen to improve mainly through the standard's ability to influence information distribution and interpretation. This may be due to the fact that employees now have a better understanding of environmental issues as discussed earlier and are now empowered with knowledge and therefore feel more comfortable taking part in environmental activities. According to some respondents, employee engagement and participation was seen to improve through the distribution of information via their policies and procedures, the training programs for new and current employees, the information made available on the organization's public websites and social media, and the multi-departmental committees. As discussed in Chapter 2, employee participation or engagement is an important condition for learning in an organization (Boiral, 2002; Fiol \& Lyles, 1985; Kloot, 1997; Petts et al., 1998; Slater \& Narver, 1995; Strachan, 1997). Furthermore, organizational learning (double-loop learning) is more likely to take place in an organization in which there is employee participation amongst other things (DiBella \& Nevis, 1998; Fiol \& Lyles, 1985; Kloot, 1997; Nonaka, Toyama, et al., 2001; Slater $\&$ Narver, 1995; Strachan, 1997). The requirements for training and the identification of aspects were found to play a role with respect to employee engagement. 


\subsubsection{Performance Improvements}

Among the respondents who indicated their perception of an improvement in environmental performance and/or performance in general flowing from use of the standard, some participants were specific in stating how the four constructs brought about the learning conditions discussed above and the outcomes of those learning conditions in terms of performance improvements. Others mentioned improvements in performance as a direct result of an improvement in the four constructs of organizational learning. The findings are briefly discussed below.

First, the improvement in employee engagement was found by some respondents to assist the organization in achieving their objectives and targets, implementing corrective actions more effectively, improving their training programs, implementing work procedures, and implementing their environmental programs more effectively. Increased engagement of employees was also found by some respondents to assist organizations in better implementing sustainability programs such as recycling programs, better managing their resource consumption, and reducing their impact on the environment on the whole. In fact, the respondent for one organization indicated that the organization was able to reduce the negative impact of its paint production line as a result of greater employee engagement and participation.

Second, one respondent observed an improvement in the quality and quantity of the communication methods used in the organization, which facilitated the exchange of ideas and in turn led to an improvement in environmental performance.

Third, a perceived improvement in the knowledge, awareness and understanding of employees was said by one respondent to enable the organization to be more adaptable, especially as it pertains to responding to changes in regulations. Commentators have suggested that the ability to be adaptable to new knowledge is a skill necessary for a learning organization (Garvin, 1993). Improvements in terms of compliance, communication processes, and material consumption, and a reduction in or control of their impacts were also noticed by respondents. Organizations were also said by respondents to be in a better position to determine their resource needs. According to Schylander and Martinuzzi (2007), an improvement in the awareness and understanding of employees was said to bring about an improvement in areas such as energy consumption, and 
waste and recycling, thereby providing some evidence that an improvement in performance may be as a result of the learning capabilities of the standard.

Fourth, due to the facilitation in adoption of more of a systems approach to environmental management in one organization, an improvement in the level of conformance to the standard was said by one respondent to be made possible. This could be explained by the fact that with a systems approach, incidents of non-compliance may be more regularly detected, and this in turn could lead to an improvement in environmental performance.

Finally, due to a purported improvement in how an organization tracked data and the resulting feedback obtained, one respondent suggested there was an improvement in organizational ability to track consumption of natural resources, facilitating the ability to identify new opportunities for further improvement. Savings may have been made possible due to the feedback with respect to their energy consumption. An improvement in compliance was also observed.

The improvements in performance that were observed as a result of the standard's ability to directly facilitate the four constructs of organizational learning are briefly discussed below. Due to the perceived improvement in the acquisition of information, certain elements of the standard were seen to improve such matters as legal compliance, the environmental programs, procedures and work practices, emergency response procedures, and the use of environmental indicators. In terms of environmental performance, the standard in prompting the acquisition of information from stakeholders and through the identification of environmental aspects and impacts enabled a reduction in liquid and solid wastes, air emissions (e.g., carbon dioxide) and noise pollution. Arguably, such improvements would be expected to be forthcoming because employees will be in a better position to carry out their duties as a result of the information they acquired. Internal and external stakeholders can be a tremendous source of information for an organization and thus help enhance learning in the organization (Darnall et al., 2008; Roome \& Wijen, 2005). This observation provides support for the proposition that the standard may enhance learning by prompting organizations to seek information from a variety of sources, including external stakeholders. The establishment of recycling programs and the establishment of efficient solid waste management programs was observed to be as a result of an improvement in the 
organization's ability to interpret information. An improvement in understanding and employee engagement may have been the reason for this improvement.

Respondents comments suggest that the standard in facilitating the distribution of information, may enable an organization to make improvements in its image, which may lead to an improvement in financial performance. A respondent mentioned that an environmental section on their organization's website was specifically designed to help educate their sales staff and other visitors of the website on the environmental attributes of their products. The sales staff were therefore in a better position to carry out their duties and to promote the products and services of the organization. As mentioned earlier, the standard in facilitating the constructs of organizational learning could potentially lead to the improvement in the knowledge, awareness and understanding of employees, which should in turn enable them to do their jobs more effectively.

Improvements in organizational memory were said by respondents to assist in improving documentation, document control, records management, and training programs. Also, organizations were said to be better able to decide what information is to be stored and for how long. The latter change in organizational conduct cannot be particularly required or encouraged by the standard, but the standard was found by one respondent to motivate its organizations to put in place information retention times. With the improvement in documentation and records keeping, one respondent indicated that its organization saw improvements in their spill management programs, while another organization was said to have better control of the types of chemicals that were being used in its products (paints).

The survey results also suggest that some respondents were of the opinion that the standard improved the distribution of information within the organization, which aligns well with the argument put forward by Epstein and Roy (1997). This further buttresses the quantitative analysis of the survey results provided earlier in which information distribution was said to be the learning construct most influenced by the standard. Training and awareness, communication, management review, documentation, objectives and targets, and definition of roles and responsibilities especially for employees whose work has the potential to have an impact on the 
environment were seen by respondents as the requirements in the standard that facilitated the distribution of information.

The implementation of key performance indicators was found by one respondent to prompt organizations to share the feedback obtained with top management and other employees as needed. Also, the standard was said to prompt one organization to carry out "walk through" assessments and to establish a "management of change" process, both of which were said to help with the dissemination of information. This could be an indication that the standard may serve as a motivation to implement other processes that could lead to an improvement in learning and in turn performance. The same respondent mentioned that the standard prompted them to create certain job positions such as production department coordinators and environmental department liaison officers that helped with the dissemination of information. This is in line with the standard's roles and responsibility requirement which notes that more than one individual can be designated as a representative for the environmental management system (ISO 14001: 2004, Annex A). Also, the creation of new job positions in order to promote the environmental management system can be likened to using multiple advocates, which is a facilitating factor of learning as put forward by DiBella and Nevis (1998).

A few other avenues (some of which are not requirements of the standard) through which information/knowledge was found by respondents to be distributed within organizations include via the distribution of policies and procedures; the organization's intranet and internet sites, and environmental information system; sustainable development reports, newsletters, and environmental bulletin boards; regularly scheduled meetings; daily review/discussion of environmental performance with employees; documentation of metrics; training for new and current employees; the internal and external audits, which were said to stimulate learning and awareness; and communication on the whole. Many of these avenues to distribute information are similar to those already identified in the literature (Argote, 1999; DiBella \& Nevis, 1998; Roome \& Wijen, 2005) and as such further buttress the proposition that the standard may facilitate learning in a number of ways aside from its requirements.

The comments of respondents also align well with the discussions in Chapter 2 , in terms of the 
standard, especially in its initial stages of implementation, being able to facilitate learning because it can be considered to be a major project, with; the role that the certification process itself could potentially play in facilitating organizational learning. For instance, one respondent stated that "the greatest acquisition of useful information for the organization occurs in the development and implementation of the standard for initial certification, when you must undertake an organizational environmental audit in order to identify pertinent environmental aspects and define their objectives." Apart from assisting an organization with the acquisition of information, the certification process was also found by one respondent to facilitate the ongoing analysis and interpretation of information.

\section{Another respondent mentioned that}

the 18 elements of the standard and the overall framework of ISO 14001 provides us with a good initial framework that helps us to obtain the right kind of initial information for all 18 elements. However, the information is typically not to the detail that an organization would need to improve learning and influence performance within the organization. Having said that, we can point to the audit portion of the standard because it allows us to obtain useful feedback from our external auditors because they are able to give us insight as to how the various elements are implemented in other organizations.

The findings of the study as discussed above suggest that the adoption of the standard may influence the four constructs of organizational learning and in the process bring about an improved learning environment within the organization. Also, to some extent the survey findings appear to highlight the fact that organizations saw improvements in performance as a result of these learning mechanism/conditions. In this respect, the qualitative findings appear to support the quantitative results discussed in section 4.4.1 where it was suggested that the standard facilitated all four constructs of organizational learning. However as noted earlier, these findings are the perceptions of those that participated in the study. They are preliminary indications of possible conclusions that might emerge from a more detailed and in-depth research project. 


\subsubsection{Other Findings}

The qualitative comments of respondents also shed some potential light concerning why some disagreed or were undecided with respect to the standard's ability to facilitate the four constructs of organizational learning. One respondent felt that the initial stage of implementation of the standard led to the acquisition of information especially with respect to the identification of the environmental impacts of their activities, but that once the organization moved to the maintenance phase, which was the case with their organization, the standard did not assist much in terms of acquiring information. At that point, the goal was no longer to obtain more information, but rather to manage the information they already have. According to three respondents, other drivers such as regulations and company standards as well as the mandatory audits (outside of the standard) can facilitate learning in an organization in terms of information acquisition. Similar comments were made with respect to information distribution and organizational memory in terms of other drivers being at play. One respondent mentioned that their corporate Health, Safety and Environment management system assisted them with the dissemination of information, while others felt that other standards assisted with organizational memory because requirements such as documentation and record keeping were already driven or initiated by environmental regulations, company best practices, and standards such as ISO 9001 and ISO/TS16949. Another respondent who was undecided with respect to information interpretation was of the opinion that regular meetings outside of the management review can facilitate this construct. The results indicate that of all those that provided comments as to why they disagreed or were undecided, $80 \%$ used other standards. On this point, it is worth reiterating that out of the 76 survey respondents, 58 were employees at organizations that used other standards/management systems in addition to ISO 14001, while only 18 used ISO 14001 exclusively.

These qualitative findings suggest that other standards, such as ISO 9001 may not only help with the implementation of other similar standards as observed in the literature and this study, but they may also play a role in terms of promoting organizational learning. The assertion that environmental laws and regulations may facilitate learning or innovation has been presented in the literature (Hart, 1995; Porter \& Linde, 1995) and indeed some predate the publication of ISO 14001 in 1996. Drawing on the findings discussed above, an ordinal (proportional odds) 
regression was carried out using the data obtained from this study. Each of the four closed-ended statements were used as the outcome variable (dependent), while the number of those that used ISO 14001 and other standards and those that used only ISO 14001 were used as a categorical predictor variable. Those who used the ISO 14001 and other standards were coded as a "0", while those that used only ISO 14001 were coded as a "1", which meant that those that used only ISO 14001 served as the reference group. The length of time the companies were registered to the standard was also included in the model to see what effect it may have even though it was not correlated with each of the constructs. Although the model passed the goodness of fit test (with the exception of the pearson's goodness of fit for information interpretation) and the test of parallel lines (assumption of proportional odds), it did not appear to be a good predictor as the results for model fitting were non significant. Also, the two predictor variables appeared not to be related to the responses to the four closed-ended statements as their coefficients were all non significant. This could be due to the fact that all the organizations had ISO 14001. Future research could potentially be undertaken to compare the learning effects using organizations that use only the ISO 14001 standard with those that use only one other standard.

The results of this study also highlights issues concerning the distribution of environmental information within organizations: in some cases, the majority of the employees may only be recipients of basic environmental information while the employees who receive the wealth of the information are limited to those in the environmental department or on an environmental committee. In effect, the depth of knowledge provided to all employees is a decision made by each organization. The standard does require that all employees be made aware of the elements of the organization's environmental management system (ISO 14001:2004; ISO 14004:2004) but does not stipulate to what degree. The fact that it is possible for a single facility or department to have its EMS certified, and not the whole organization, may be considered a limitation of the ISO 14001 standard as currently applied. This "unit only" or "facility only" approach could lead to fragmented learning since only members of a particular unit or facility may be beneficiaries of organizational learning.

The results of the study also suggest that the standard on its own may not have the ability to facilitate organizational learning (information distribution in particular) throughout the 
organization and that it may just be one out of the many learning mechanisms present at the organization. This study was designed to shed light on whether the standard has the ability to contribute to organizational learning, while recognizing that the standard on its own may not result in a learning organization. Burström (2002) mentioned that an environmental management system (using ISO 14001) cannot on its own lead to the creation of a learning organization but that an environmental management system may still play a significant role in a learning organization (p. 318). Networking with other organizations in the same industry was said to be more beneficial for sharing information as mentioned by a respondent. This is in keeping with the observation of commentators that learning can take place on the interorganizational learning level (Crossan et al., 1995; Nonaka, Toyama, et al., 2001; Pawlowsky, 2001).

The improvement in organizational memory and the subsequent documents produced, were said to serve as evidence of due diligence that the organization was undertaking and meeting its obligations as promised. It was also said to serve as evidence during the audit process.

\section{Requirements that played a role in influencing learning}

In responding to the open-ended questions regarding organizational learning and performance, some respondents mentioned a few of the requirements that assisted them with the learning process, even though they were not required to do so. The requirements that were found to play a role included: audits (internal and external), legal and other requirements, environmental aspects, management review, training, documentation, control of documents, control of records, objectives and targets, communication, roles and responsibilities, and monitoring and measurement. Some requirements were mentioned more than others and therefore give a preliminary indication of which requirements may play a major role compared to others. This is not definitive as not all the respondents who provided a response mentioned a requirement. However, it does provide preliminary information which could be the starting point for further research in terms of determining which requirements influence learning the most. Since none of the requirements were found to assist with all four constructs, it is not possible to determine which requirement had an overall major influence on organizational learning. However, based on the responses of participants, it was possible to determine which requirements facilitated each of the constructs the most. A brief discussion is presented below. Figure 4.3 shows which 
requirements played a role in influencing the four constructs of organizational learning.

\begin{tabular}{|c|c|c|c|}
\hline $\begin{array}{l}\text { Information } \\
\text { Acquisition }\end{array}$ & $\begin{array}{l}\text { Information } \\
\text { Distribution }\end{array}$ & $\begin{array}{l}\text { Information } \\
\text { Interpretation }\end{array}$ & $\begin{array}{l}\text { Organizational } \\
\text { Memory }\end{array}$ \\
\hline $\begin{array}{l}\text { - Internal and } \\
\text { external audits } \\
\text { - Environmental } \\
\text { aspects and } \\
\text { impacts } \\
\text { - Legal and other } \\
\text { requirements } \\
\text { - Documentation } \\
\text { - Objectives and } \\
\text { targets }\end{array}$ & $\begin{array}{l}\text { - Documentation } \\
\text { - Training and } \\
\text { awareness } \\
\text { - Communication } \\
\text { - Management } \\
\text { review } \\
\text { - Policy } \\
\text { - Internal and } \\
\text { external audits } \\
\text { - Objectives and } \\
\text { targets } \\
\text { - Roles and } \\
\text { responsibilities }\end{array}$ & $\begin{array}{l}\text { - Training and } \\
\text { awareness } \\
\text { - Environmental } \\
\text { aspects and } \\
\text { impacts } \\
\text { - Management } \\
\text { review } \\
\text { - Objectives and } \\
\text { targets } \\
\text { - Communication } \\
\text { - Monitoring and } \\
\text { measurement } \\
\text { - Internal and } \\
\text { external audits }\end{array}$ & $\begin{array}{l}\text { - Documentation } \\
\text { - Control of } \\
\text { records } \\
\text { - Control of } \\
\text { documents } \\
\text { - Management } \\
\text { review } \\
\text { - Objectives and } \\
\text { targets } \\
\text { - Monitoring and } \\
\text { measurement }\end{array}$ \\
\hline
\end{tabular}

\section{Figure 4.3 Requirements of the ISO 14001:2004 standard that were found to facilitate Huber's (1991) four constructs of organizational learning}

\section{Audit (Internal and External)}

The audit process was seen to facilitate the acquisition, distribution and interpretation of information, with it playing a greater role with respect to information acquisition, followed by information distribution. Also, of all the requirements that assisted with information acquisition as shown in Figure 4.3, the audit process was found to have the most influence. The audit was seen as a means to help facilitate the exchange of ideas and to provide feedback to the organization, especially from an unbiased eye (external auditors). Information acquisition may have been influenced the most because the main aim of an audit is to evaluate the EMS, which would entail the acquisition of information pertaining to the organization's environmental activities.

\section{Training}

Training was found to help with the distribution and interpretation of information or knowledge. 
However, it played a larger role regarding the distribution of information. It also played the greatest role with respect to information interpretation when compared to other requirements as shown in Figure 4.3. This is not surprising, as training should assist employees in their ability to interpret and understand the information that is provided to them. The survey results suggest that training helped improve the knowledge, awareness and understanding of employees, fostered employee engagement, and helped clear up misconceptions regarding the EMS. Employees were said to have a better understanding of the organization`s regulatory requirements, and on how their jobs impacted the environment and how to control the impacts of their organization as a result of this requirement.

\section{Documentation}

The documentation requirement was found by respondents to facilitate the acquisition, distribution and storage of information, but seemed to play a larger role in facilitating the storage of information followed by information distribution. It was also found to play the greatest role with both information distribution and organizational memory when compared with other requirements as shown in Figure 4.3. This may be explained by the fact that documents play such an integral role in how information is transferred and stored. Through this requirement, survey results suggest that the awareness and participation of employees was improved; it tended to ensure that information was up to date, and that employees were able to carry out their duties in a consistent manner; and it assisted with the tracking of data and provision of feedback.

\section{Management review}

This requirement was found by respondents to assist with the distribution, interpretation and storage of information, but especially with information distribution, followed by information interpretation. The management review was said to help with the sharing of information within the organization, especially amongst senior management, it kept senior managers accountable, and it triggered the analysis and interpretation of information especially via the evaluation of the EMS. Since the review is documented, one can understand its role in enhancing the organization`s memory. The role that the management review may play in terms of learning may depend considerably on the particular organization applying the standard. ISO 14001 does not stipulate who exactly is to participate in management reviews apart from top management, nor 
does it stipulate how frequently reviews are to be held. As such, the standard's ability to facilitate organizational learning through this requirement may be somewhat limited.

\section{Environmental aspects and impacts}

This requirement was said by respondents to assist with the acquisition and interpretation of information but slightly more with information acquisition. It was found to provide a structured approach for the collection of information vital for the EMS, to influence the interpretation of information that brought about better understanding and cooperation amongst employees, and to provide information useful for the development of training programs.

\section{Document control}

Respondents found that this requirement assisted with organizational memory. It was said to assist in ensuring that the information that was stored was always revised and therefore up to date and accurate, and that out dated information was no longer being used.

\section{Records control}

Like document control, the control of records was found to facilitate organizational memory. Its role was mainly to provide records of historical events and serve as a retrieval system for the organization. It also served as proof of compliance.

\section{Communication}

This requirement was observed to play a role with only the distribution of information, which appears quite understandable. It was found to help improve the knowledge, awareness and understanding of employees, facilitated employee engagement, and led to the overall improvement in communication within the organization. Also, it was said to enable organizations to better share best practices and procedures.

\section{Legal and other requirements}

This requirement was found by respondents to play a role with information acquisition. In doing so, it enabled organizations to stay up to date with respect to environmental laws and regulations and enabled organizations to ensure compliance. The standard requires that organizations 
identify and review their legal and other requirements and to put in place measures to ensure they meet such requirements.

\section{Monitoring and measurement}

This requirement was observed to equally facilitate the interpretation and storage of information. It was found to enhance the knowledge and awareness of employees, provide feedback on the effectiveness of their processes, provide historical data for future reference, and lead to the engagement of more employees. It could be possible that in helping with the analysis and interpretation of data, the understanding of employees improved and thus their willingness to participate more in environmental initiatives.

\section{Objectives and targets}

This requirement was found to play a role with information acquisition, distribution and storage, but a slightly larger role with organizational memory. It was said to help in providing feedback with respect to the progress of the EMS, and led to employees having a common goal with respect to the organization's environmental goals. The fact that the requirement has to be documented and that the information plays a great role in achieving the goals of the EMS may have been the reason why it was found to influence organizational memory.

\section{Roles and responsibilities}

This was seen to assist with the distribution of information alone based on the fact that specific roles in the organization were created in order to facilitate the distribution of information. Also, assigning roles to other members of the organization (outside of the environmental department) may force such members and maybe members of their department to gain knowledge on environmental issues.

\section{Policy}

The policy was said to assist with the sharing of information, but more so in terms of the expectations and commitments of the organization as it relates to the EMS. Commitments included reducing waste, complying with laws and regulations, continuous improvement and 
pollution prevention. As such it may have served as a means to foster employee participation and engagement.

\subsection{Software and Organizational Learning}

As with the connection between organizational learning and the ISO 14001 standard, the survey also sought the opinion of respondents regarding whether EMS-based software has the ability to enhance organizational learning and in turn enhance performance. That being said it must be noted that organizational learning and performance were not measured.

\subsubsection{Software as a facilitator of the four constructs of Organizational Learning}

In all, 22 respondents provided responses to the four closed-ended statements in section $\mathrm{B}$, which was designed to answer research question Q2; that is, do environmental management systems software packages have the ability to facilitate the acquisition, distribution, interpretation, and storage of useful environmental information and therefore contribute to organizational learning? However out of the 22 organizations that responded, only 12 used EMS-based software. Although the number of respondents that used EMS-based software was very low, the results do provide some preliminary and tentative findings and could serve as a starting point for future research. As such, statistical analysis was carried out on the data obtained from the survey. Cronbach's alpha was calculated in order to determine the reliability of the questionnaire with respect to the four closed-ended statements in section $\mathrm{B}$, and to determine whether or not the four constructs of organizational learning could be used together as a means to evaluate the organizational learning capability of the software. Using only the responses from the users (12) of EMS-based software, the Cronbach alpha analysis $(\alpha=.891)$ indicated that the questionnaire was reliable because the value was between $\alpha=.7$ and $\alpha=.8$ (Field, 2009). However, due to the low number of responses one cannot conclude that the questionnaire was reliable with respect to section B. Furthermore, the analysis also showed that some of the statements were significantly correlated with each other which meant that some of the statements were redundant and under ideal situations some may have to be deleted. Information acquisition and information dissemination, and information acquisition and organizational memory were seen to be highly correlated. There were no significant correlations when the statement relating to information acquisition was not included in the analysis. Nevertheless, all four statements were drawn on for 
the analysis. The analysis also showed that there was a significant correlation between the score of each statement and the total score for the four statements and so, the four statements combined could be used as a means to evaluate the organizational learning capability of EMS-based software. Based on the total scores of the four statements per respondent, it was determined that the majority of the respondents $(83 \%)$ were of the opinion that EMS-based software has the capability to contribute to organizational learning. On assessing the four statements separately, the number of respondents that felt that the software assisted them with the four constructs was as follows: information acquisition (67\%), information dissemination (67\%), information interpretation (58\%), and organizational memory (75\%). As in section 4.4.1 the scales were amalgamated in order to determine the above percentages for each statement. See Table 4.8 below.

Table 4.8 Summary statistics regarding the ability of EMS-based software to facilitate the four constructs based on amalgamated scores

\begin{tabular}{|l|c|c|c|c|}
\hline \multicolumn{1}{|c|}{ Statement } & Agree & Undecided & Disagree & $\begin{array}{c}\text { Percentage } \\
\text { agreed }\end{array}$ \\
\hline $\begin{array}{l}\text { I find that the software assists me in my } \\
\text { ability to acquire or collect useful } \\
\text { environmental information that applies to the } \\
\text { organization in the form of documents, data, } \\
\text { diagrams, etc. }\end{array}$ & 8 & 1 & 3 & 67 \\
\hline $\begin{array}{l}\text { I find that the software assists me in my } \\
\text { ability to disseminate (distribute) useful } \\
\text { environmental information within the } \\
\text { organization and beyond }\end{array}$ & 8 & 1 & 3 & 67 \\
\hline $\begin{array}{l}\text { The software assists me in my ability to } \\
\text { analyze and interpret the useful environmental } \\
\text { information collected. }\end{array}$ & 7 & 1 & 4 & 58 \\
\hline $\begin{array}{l}\text { The software provides a mechanism that } \\
\text { assists me with the archiving (storage) of } \\
\text { relevant environmental data and information } \\
\text { about the organization. }\end{array}$ & 9 & 1 & 2 & 75 \\
\hline
\end{tabular}

The results are in line with authors discussed earlier in Chapter 2 Part 3 who were of the opinion that information technology can help facilitate organizational learning. However, on looking more closely at the survey results for each statement, EMS-based software was seen to contribute the most to organizational memory which may be because most EMS-based software have a 
centralized library for storage of information (Enviance, n.d.a; Enviance, 2010b; Intelex, 2014; Ismail, 2012; Leavoy and Waggott, n.d.) as well as because of their documentation and document control features. The results are also in agreement with Robey et al. (2000) who place more emphasis on the role of information technology in enhancing organizational memory. The software's ability to facilitate information acquisition and distribution as indicated by the results may also be because of the central library system, the presence of dashboards (Enviance, 2010a; Intelex, 2014; Ismail, 2012; Rapacioli et al., 2011; www.enviance.com), its ability to facilitate communication and collaboration, and the availability of tracking and follow-up systems (Intelex, 2014; Ismail, 2012; Leavoy \& Waggott, n.d.; Leif, 2014). The software's ability to moderately facilitate information interpretation could be due to some of them having statistical and graphical tools to analyze data, and their ability to provide information in a format that is understandable to its users through for example their dashboards.

Although this study focused on EMS-based software, it was also interesting to see how the respondents viewed the general effects of software on organizational learning. As such statistical analysis was also done using all 22 responses. Although the value of Cronbach's alpha $(\alpha=.838)$ fell within the required range, no conclusions can be made as to the reliability of the questionnaire with respect to section B because of the low number of responses. The analysis also showed that there was a significant correlation between the score for each statement and the total score for the four statements and so the four statements combined could be used to evaluate the organizational learning capability of software. Based on the total scores of the four statements per respondent, it was determined that the majority of the respondents $(76 \%)$ were of the opinion that software in general has the capability to contribute to organizational learning. On assessing the four statements separately, the number of respondents that felt that the standard assisted them with the four constructs is as follows: information acquisition (67\%), information dissemination (62\%), information interpretation (38\%), and organizational memory (71\%).

Looking at the results obtained here, the trend appears to be the same with EMS-based software with organizational memory having the highest score and information interpretation having the lowest. However, based on the results, the majority (38\%) of the respondents were in disagreement that the software they used could help with the interpretation of information. This could be due to the fact that non ISO 14001 specific software do not have some of the features 
that EMS-based software has such as features that facilitate collaboration and communication within the organization as well as dashboards that help present rich data.

Although the results do indicate that EMS-based software facilitated the four constructs of organizational, the low number of responses prevent the making of any sort of conclusive statements about the results. However, they do serve as a starting point for undertaking future research on this topic.

\subsubsection{Software as a facilitator of Organizational Learning and in turn Environmental Performance}

As with the ISO 14001 standard and organizational learning, for each closed-ended statement regarding the four constructs of organizational learning provided in section B of the questionnaire, respondents were required to provide answers to a follow-up open-ended question. The question of interest was: If you are of the opinion that the software leads to improved acquisition of useful information, could you comment on how this improvement affected organizational learning that influenced performance within your organization? The same question was asked regarding the other three constructs of organizational learning. The learning mechanisms/conditions that resulted from the facilitation of the four constructs are summarized in Table 4.9 and discussed briefly below. This is followed by a brief discussion on the improvement in performance that was observed.

Table 4.9 Learning mechanisms/conditions that were brought about by the ability of EMS-based software to facilitate the four constructs of organizational learning

\begin{tabular}{|l|l|}
\hline \multicolumn{1}{|c|}{ Constructs } & \multicolumn{1}{c|}{ Learning Mechanisms/Conditions } \\
\hline Information acquisition & - Tracking of information and feedback \\
& - Efficient and timely collection of information \\
& - up-to-date information \\
\hline Information dissemination & - Tracking of information and feedback \\
& - Timely distribution of information \\
& - Consistent information \\
\hline
\end{tabular}




\section{Table 4.9 Continued}

\begin{tabular}{|l|l|}
\hline \multicolumn{1}{|c|}{ Constructs } & \multicolumn{1}{|c|}{ Learning Mechanisms/Conditions } \\
\hline Information interpretation & $\bullet$ Training programs \\
& $\bullet$ Understanding and decision making \\
\hline Organizational memory & $\bullet$ Up-to-date information \\
& - Tracking of information and feedback \\
\hline
\end{tabular}

The results with respect to the learning mechanisms/conditions and each construct is presented in Appendix B.

\subsubsection{Learning Mechanisms/Conditions}

\section{Tracking of information and feedback}

This condition for learning was said to be facilitated through the ability of EMS-based software to facilitate the acquisition, distribution and storage of information and was made possible due to the presence of modules that helped with objectives and targets, and notifications. Information (e.g., results, feedback) acquired using the software could be used to prompt the responsible parties to take corrective actions as needed and to learn from the feedback obtained (hence facilitating single-loop or double-loop learning). Also, as discussed in section 4.4.2.1 feedback is an important condition for the learning process (DiBella \& Nevis, 1998; Huber, 1991; Senge, 2006). Although not mentioned by respondents, the presence of a dashboard may enable information to be tracked more efficiently by employees. Also, since the software allows for information to be stored, it may enable one to trend data and to obtain feedback from the analysis of the data. The information can then be used to solve problems or determine opportunities for improvement.

\section{Efficient and timely collection and distribution of information}

EMS-based software was found by respondents to not only help with the acquisition and subsequently the distribution of information, but the respondents also felt that the software assisted organizations to do so in an efficient and timely manner. With respect to information acquisition, no particular feature was mentioned by respondents; however, in the opinion of the author, the presence of the dashboard in many EMS-based software may be an example of a 
feature that could assist with the timely collection of information because the information is often provided in real time. The information can then be used for decision making. By assisting with the dissemination of information, employees should be able to obtain the information they need in a timely manner. This may enable them to have the knowledge required to carry out their duties more effectively and efficiently. The software's monitoring and measurement module, its document control module, its dashboard, and its reporting capabilities were found to improve the distribution of information. When information is readily and quickly available to those who need it, learning is said by commentators to be more likely to occur (Epstein \& Roy, 1997; Garvin, 1993; Huber, 1991).

\section{Up-to-date Information}

EMS-based software helped ensure that the information that was being utilized by employees was up to date by facilitating the acquisition and storage of information, and subsequently the revision or discarding of obsolete information. As discussed in section 4.4.2.1, keeping information up to date and discarding old information (unlearning) helps promote learning (Antal et al., 2001; Huber, 1991). According to respondents, the document control feature of EMSbased software was found to help make the revisions possible, especially since it had a notification system that alerted document owners of when revisions were due. By ensuring that information is up to date, the software may assist in ensuring that employees are obtaining the appropriate and current information in order to undertake their jobs properly.

\section{Consistency in information or knowledge disseminated}

EMS-based software was said by respondents to assist in ensuring that the information that was being distributed within the organization was consistent and therefore may ensure that the reliability of environmental knowledge is maintained. In doing so, the software may assist in ensuring that all the employees are on the same page and that they develop a shared interpretation and consensus regarding the information provided to them. The dissemination of information in the form of documents could be one way that information is shared in a consistent manner. 


\section{Improvement in training program}

EMS-based software was said to enable users to analyse and interpret information, and to use the interpreted information to understand and improve on their training needs. This may lead to an improvement in learning because as discussed in Chapter 2, training has the ability to facilitate the acquisition, dissemination, interpretation, and storage of information, and to enhance the knowledge and skills of employees.

\section{Improvement in understanding and decision making}

EMS-based software was found by respondents to improve the understanding of the information presented to employees, and therefore enabled them to make better decisions, especially for top management. This it did by facilitating the interpretation of information. This may be due to the fact that the software served as a means to share information rich in content, which according to Huber (1991) is important for information interpretation. This is speculation on the part of the author, but the dashboard feature that provides real time information to managers in a format that is understandable to them may have played a role in this regard. In doing so, the managers were likely to build a shared interpretation and consensus on the information provided to them. Graphs and charts and other statistical tools were also found to play a role in facilitating the interpretation of information and subsequently decision making. The use of such tools are said by commentators to facilitate learning because they allow for systematic problem solving (Garvin, 1993). As discussed earlier in Chapter 2 and section 4.4.2.1, an improvement in understanding is necessary for learning to take place.

\subsubsection{Performance Improvements}

Based on the findings of this study, the improvements in performance brought about by the EMS-based software's ability to influence learning were found by respondents to be internal processes related to the elements of the standard. It is perhaps to be expected that an improvement in such processes should translate into an improvement in environmental performance. EMS-based software was found by respondents to assist organizations in improving their legal compliance due to its ability to support the acquisition and distribution of information, which in turn facilitated the tracking of information and provision of feedback. An improvement in compliance was seen because organizations were able to better track information 
and obtain feedback regarding their legal obligations. An improvement in compliance may have also been made possible because the software assisted organizations in carrying out their legal due diligence and in facilitating the regulatory inspection process. This was made possible because a few EMS-based software products have an audit module that can facilitate the acquisition and storage of information, which can then be sourced directly by regulators, auditors, and other interested parties. Based on the foregoing, the software may serve as a means to establish transparency and accountability within the organization, which are conditions for promoting organizational learning (Friedman et al., 2001). Transparency helps encourage learning because it prevents self-deception (intentional or unintentional) and encourages honest disclosure by others, and in turn leads to the acquisition of valid information, which is said to be required for learning to be effective (Friedman et al., 2001). In general, EMS-based software products that have documentation features would enable documents to be stored in one location and for such documents to be readily accessible when needed.

Other areas that saw improvements include document management (to include revision and storage mechanisms) and training management. The ability of the software to assist with the monitoring of compliance (Ismail, 2012), document management (Leavoy a\& Waggott, n.d.), and training management (Intelex Technologies Inc., n.d.) could be related to its ability to support the constructs of organizational learning.

The findings of this study as discussed above provide some support for the proposition that EMS-based software may have the ability to influence organizational learning and in turn performance. However, due to the low responses, the findings are preliminary and tentative in nature. Again, one must point out that organizational learning and performance were not directly measured in this study, but rather the opinions of respondents on the topic at hand were obtained.

Although not strictly speaking a part of the objectives of this study, the comments of respondents concerning the learning effect of non-EMS-based software were seen in this study to have similar learning effects as EMS-based software. For instance, non-EMS-based software was found to assist with the tracking of information, ensure that information was kept up to date, help improve training programs, improve understanding and decision making, assist in ensuring that 
information was collected and distributed in a timely fashion, and facilitate the efficient exchange of ideas. Some software had statistical and graphing tools that enabled them to interpret data easily. As such, the EMS-based software and non-EMS-based software findings of this study align well with the literature that information technology to include software may have the ability to facilitate the learning process in an organization. Of interest was also the fact that a respondent who used non-EMS-based software stated that they saw improvements in how they analysed and interpreted information because the software had the capability to group similar topics together. This is similar to a software system described by Robey et al. (2000) that has the ability to catalog conclusions and decisions made by users, and then analyze the information in order to search for consensus or conflicts. Should a conflict be found, the software would automatically send a meeting notification to those who had different interpretations in order for them to have a discussion and dialogue over their conflicting ideas, and possibly come up with new and shared interpretations. Such a feature could be considered for EMS-based software.

Finally, the study does highlight a possible limitation of EMS-based software in facilitating learning. One respondent who used Company A's EM software agreed that the software could facilitate organizational memory, however, the respondent said that the software had its limitations in this regard because only those in the company that had the license for the software could access the information. This would imply that only a limited number of people in the organization will have access to the information, which may result in fragmented learning.

\subsection{Functionality of Software}

Respondents were asked to respond to a variety of statements in section $\mathrm{C}$ of the questionnaire in order to determine whether EMS-based software does help organizations with the implementation and maintenance of the ISO 14001 standard/environmental management system. The study also sought to identify what features users found most helpful or least helpful, what improvements they would like to see, how easy or difficult it was to implement the software, and whether or not they received a return on investment from using the software. 


\subsubsection{Capability of EMS-based Software to assist with the ISO 14001 Standard}

In order to answer research question Q3 (i.e., Do environmental management system software products have the necessary features that enable them to assist organizations in implementing and maintaining the ISO 14001 management system standard?), respondents were asked to answer questions 1 to 22 in section $\mathrm{C}$ of the questionnaire. However, due to the low response of users of EMS-based software, inferential statistics (chi square and loglinear analysis) was not undertaken. The number (11) of respondents that answered 'yes' or 'no' to the questions in section $\mathrm{C}$ is nevertheless presented as shown in Figure 4.4 below.

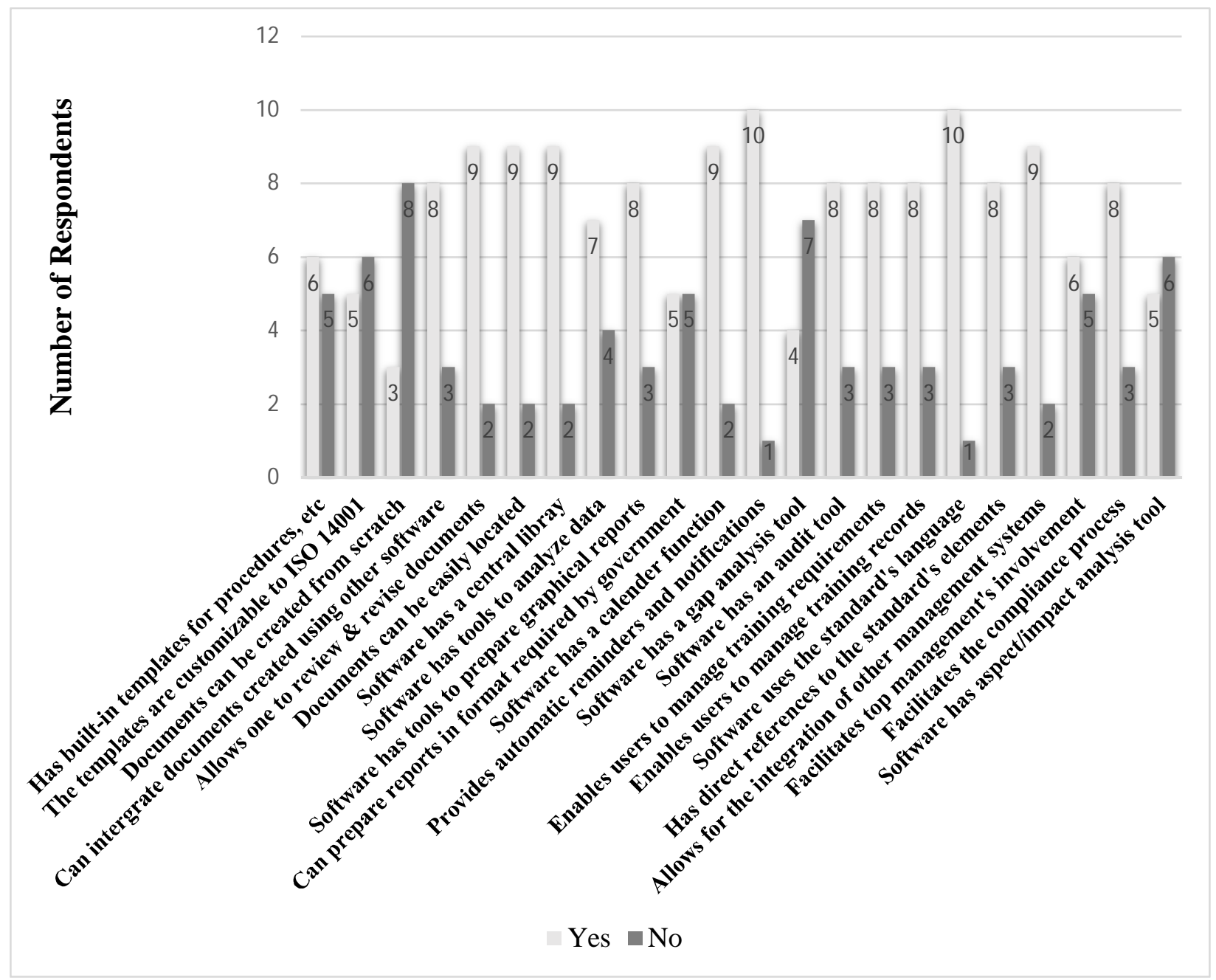

Figure 4.4 Features of EMS-based software that may assist with the implementation and maintenance of the ISO 14001 standard 
In terms of documentation and document control, those who responded stated that the software had the ability to assist with creating documents from scratch, allowed for documents created using software such as Microsoft Word and PDF to be integrated, allowed for documents to be reviewed and revised, enabled users to easily locate documents, and had a central library. With respect to data compilation and report generation, EMS-based software was seen to have the ability to analyze data and to prepare graphical reports. The majority of the respondents stated that EMS-based software had the ability to assist them with milestone/task management and tracking due to its calendar function and its ability to provide automatic reminders and notifications. The majority also agreed that EMS-based software had features that could assist them with gap analysis, the audit process, training management, the integration of different management systems, and with meeting their compliance requirements. Finally, the software was also said to have ISO 14001 context specific text by the majority of the respondents. Based on the foregoing, EMS-based software products do appear to have features that assist with some of the elements of the standard as discussed in the literature review in Chapter 2. However, one has to be cautious in making strong conclusions due to the very low number of responses obtained, and instead we will say that the study provided only tentative, non-conclusive information in terms of answering research question Q3.

\subsubsection{Most helpful Feature of Software}

In order to identify the most helpful or important feature of the software, respondents were asked the following questions: What would you say is the most helpful feature of the software in terms of its ability to assist you in meeting the requirements of the ISO 14001 standard? Please could you briefly explain why you found this feature most helpful? A total of eighteen (18) responses were obtained for these questions with eleven (11) of them coming from users of EMS-based software. The common threads observed from their responses are briefly discussed below.

\section{Document management}

Seven (7) of the respondents felt that the software's ability to assist them with documentation was of great value to them. Five (5) of the respondents were users of EMS-based software developed by Company A (2 respondents used the IM software and one used the EM Software), Company D, and Company E. The users of EMS-based software mentioned that the document 
control feature of the software helped them facilitate the documentation approvals process; provided automatic notifications for document reviews, thus keeping them up-to-date; and assisted them in fulfilling the other requirements of the standard because the standard requires that most of the other requirements be documented. In addition, a user of EMS-based software mentioned that their "program includes a large number of facilities. Document management would be difficult without software designed for document management. Procedures and data can also be easily viewed and shared across the company." This statement supports the fact that EMS-based software could buttress organizational learning by facilitating the sharing of information, especially in large organizations, and the role that documentation may play in facilitating learning. This feature of EMS-based software was found most helpful by respondents in medium and large organizations and thus may indicate that the software could be more relevant to such organizations in terms of managing and distributing information.

\section{Notification}

A respondent who used Company A's IM software mentioned that they found the notification feature most helpful because it enabled them to provide alerts and reminders to employees letting them know when their tasks were due. The notification system was said to be an important feature with respect to dealing with elements of the EMS such as implementing corrective actions and fulfilling permit requirements, a point identified by several commentators (Alnes et al., 2014; Enviance, 2010b; Intelex, 2014; Ismail, 2012; Leavoy \& Waggott, n.d.; www.enablon.com; www.ihs.com). The presence of a notification system also supports the learning capability of the software because it may function as an action-reflection triggering (ART) system as described by Nonaka, Reinmoller, et al. (2001) in terms of aiding with the shifting from one knowledge conversion process to the next.

\section{Tracking and monitoring}

Four (4) respondents mentioned the fact that the software's ability to assist them with the tracking and monitoring of information was very helpful to them; however, only two (2) users of EMS-based software provided a response. A respondent who used Company A's EM software said that it enabled the user to track and monitor areas of the environmental management system such as the corrective actions, audits, and training requirements. A user of Company $\mathrm{C}$ software 
found the environmental data collection and reporting function of the software most useful because it enabled the organization to track its environmental performance on the whole, and assisted them with the process of establishing, tracking, and reviewing their objectives and targets. Respondents who used non-EMS-based software mentioned that the software they used enabled them to track and monitor their key performance indicators, and that tracking of their performance in general kept them accountable.

In keeping with the observations of commentators, some respondents noted that the ability of specialized software to assist with tracking and follow up with respect to elements of the standard such as environmental incidents, and their environmental activities in general was seen as valuable to organizations that used them (Intelex, 2014; Ismail, 2012; Leavoy \& Waggott, n.d.; Alnes et al., 2014). This is arguably the case because it assists the organization in terms of its ability to monitor the progress of its environmental management system.

\section{Presence of an accessible and sortable repository}

Three (3) respondents, 2 of whom used EMS-based software, mentioned that they found the software's database feature most helpful. Two users of company B's software liked the centralized and sortable repository or database feature of the software because data could be stored and analyzed off line at a later date, and simply because it helped them save time. A respondent who used non-EMS-based software also mentioned that they found the database feature helpful, especially since it allowed for information to be accessed by employees and auditors. The presence of an accessible and sortable database may assist in supporting learning especially because it could enhance the organization's memory.

\section{Others}

Other respondents who used non-EMS-based software mentioned the ability of the software to be customizable to their needs, and the ability "to interact with the system from a broad array of mobile devices from any location" as some of the features they found helpful regarding the software they used.

On another note, one user of Company A's EM software mentioned that although the software 
had features that covered most if not all of the elements of the standard, they did not find any feature helpful because the software was poorly designed.

Although, the majority of the users of EMS-based software mentioned document management as the most helpful feature, the low response rate means that only tentative conclusions can be made in this regard. However, the study does provide some preliminary insights regarding some of the features that may be of importance, especially for potential users of software. The results also indicate how such features may support organizational learning.

\subsubsection{Least helpful Feature of Software.}

In order to identify the least helpful feature of the software, respondents were asked the following questions: What would you say is the least helpfulfeature of the software in terms of its ability to assist you in meeting the requirements of the ISO 14001 standard? Please could you briefly explain why you found this feature least helpful? Fifteen (15) responses were obtained for these questions although only 9 were from users of EMS-based software. The responses are summarized below.

\section{Company A}

A user of Company A's IM software said that the software's environmental policy module was not needed, while another felt that the inability to customize the software to their needs was an issue. A user of Company A's EM software felt that the measurement and monitoring module was not valuable especially for large organizations that would find it cumbersome to track all its measurement devices. The same respondent also mentioned that some of the fields in the module did not offer any valuable information. Another user of Company A's EM software mentioned that the software in general did not cater to the user's needs and work processes, and that it introduced more steps into the work process than was necessary, thereby making things more complicated. In fact, the respondent felt that the software failed to capture real-world management processes. Company A's EM software was also said to lack intuition, unable to be aligned with government business processes, difficult to configure, and lacking in quality assurance. Another respondent who used Company A's EM software mentioned that although they found some features to be more helpful than others, all the features of the software were 
important nevertheless. The respondent who used company C's software was of the same opinion.

\section{Company B}

One respondent who used Company B's software made mention that the software had features that did not apply to their organization's business operations and thus was not helpful to them. The customer requirements database was one of those features mentioned by the respondent.

\section{Company D}

The respondent who used Company D's software mentioned that the software was not compatible with other software products that they were using. The issue had to do with the software's "usability based on the various versions and types of operating systems used across the company. Maintaining the same versions for operating systems and search engines, and insuring their compatibility with the software, can be difficult."

\section{Company E}

A user of Company E's software made mention that the software's corrective and preventive actions feature though good, was not efficient or helpful should the time or resources required to prepare the information be unavailable.

\section{Non EMS-based software}

Respondents who used non-EMS-based software said that the software they used did not directly support ISO 14001 nor their compliance needs; lacked formatting options and thus had limited functionality in some areas; was too basic and was not customized to the standard; lacked the ability to change the name of a document approver in one step rather than having to do so document by document; and lacked the ability to allow for sufficient information to be built into the system in order to support the internal audit process. These limitations do indicate the reason why some EMS-based software products may be more suitable for assisting with the implementation and maintenance of the standard than non-EMS-based software. For instance, some EMS-based software products have an audit module that may help overcome the limitation mentioned regarding the internal audit process. One respondent who used non-EMS-based 
software found all the features of the software they used to be helpful.

The results presented above suggest that EMS-based software products have their limitations with respect to the functionality of certain features. One concern appeared to revolve around modules that did not function properly or that were not applicable to the organization's business operation. Other concerns included the lack of compatibility with other software packages and the inability to align it with other business applications. These concerns were among those that were highlighted in the literature on specialized software products (Gidwani, 2015; Global Environment and Technology Foundation, 2004). This study also highlights the fact that although both private and public organizations are using EMS-based software, it appears that not all software packages are at the moment capable of meeting the specific needs of public organizations. This may be the case because respondents who mentioned that the software was not compatible or customizable, especially to government business processes, belonged to the public sector. Further research could therefore try to understand why such software products are not compatible and how to make them more user friendly for public organizations. The lack of compatibility and inability to align the software with other business applications can be seen as a limitation with respect to organizational learning. This is so because if the software cannot be aligned with other business applications and is therefore limited to the environmental department, its ability to facilitate learning on an organizational wide level may be limited.

Due to the low number of responses, the results in this part are necessarily tentative, but do provide preliminary insights as to what the weaknesses of EMS-based software are, and this information is likely to be useful to both the vendors and potential users of the software.

\subsubsection{Ease or Difficulty with respect to the Implementation of the Software}

Respondents were asked to provide a response to the following question: In your opinion, how easy or difficult was it to implement the software for the ISO 14001 standard? Eighteen (18) responses were obtained for this question, with eleven (11) provided by users of EMS-based software. In terms of the implementation of Company A's software, one user of the IM software found implementation relatively easy, another said that it was difficult at first but that training made it easy to implement, while another mentioned that it was "difficult to justify the upfront 
expense and on-going maintenance costs.” Regarding the EM software, one respondent found implementation easy but this was mainly because they had already implemented their management system on paper. Another respondent found the implementation process difficult due to the limited ability to configure certain aspects of the software, which in turn made it somewhat difficult to align the software with their business processes, and due to the fact that the initial training provided was too general. The same respondent also mentioned that the configuration of the modules of the software was time consuming. A third user found it to be a painful and costly process.

With respect to Company B's software, one user said that its implementation was relatively easy because the software was fairly intuitive, while another user said that the implementation process was a bit complex at the initial stage. The respondent who used Company C's software said that the software was user friendly mainly because it was web based, however the respondent did mention that the migration of historical data was problematic. The respondent further mentioned that the adoption of the software by employees was an issue and that change management for employees may be required. For company D, the software was relatively easy to implement and was found to be fairly intuitive. As for company E, the respondent mentioned that the software was difficult to implement.

Based on the responses from respondents who used non-EMS-based software, the software packages they used were said to be relatively easy to implement with the exception of one that was said to be of medium difficulty. In one case it was said to be easy but time consuming.

The results indicate that the ease or difficulty in implementing the software varies and depends on the software product being used and whether training was provided. The ease of implementation may also depend on whether the software was implemented at the same time that the standard was being implemented or after its implementation. As stated by a respondent the implementation of the software was easier because the standard was already in place. Difficulty in implementation could also be affected by the computer savviness of employees and the culture within the organization. As mentioned by respondents, they had issues with both, with one organization having to institute management of change programs to get other employees on 
board. The computer literacy and culture of the organization are a few of the conditions users and vendors should consider before an organization purchases any specialized software (Argent \& Grayson, 2001).

\subsubsection{Suggestions for Improvement of the Functionality of Software}

Respondents were asked to provide a response to the following question: In terms of the software's ability to assist you in meeting the requirements of the ISO 14001 standard, please briefly elaborate on any changes/improvements you think would assist you in making the software more functional for you and your organization? Fifteen (15) responses were obtained for this question out of which nine (9) were from respondents who used EMS-based software.

Suggested improvements for Company A's IM software included provision of a web-based platform and the ability to customize the software. With respect to Company A's EM software, the provision of flexible pre-built templates for procedures that will enable users to make changes as they see fit, the ability to reduce the number of approval layers in the standard nonconformance module, and the ability to set data entering rules in order to limit human error were some of the suggested improvements mentioned. Also, the software should be able to incorporate the planning and management assessment elements of the standard as well as be workable and results-oriented. One respondent who used Company A's software was of the opinion that EMSbased software products currently available on the market are being designed by people who are not experienced enough, and that the design of such software should include input from experienced environmental managers and environmental practitioners.

Pertaining to Company B's software, one respondent recommended the provision of built-in reporting functions, which would eliminate the use of separate report generation software, while the second respondent had no concerns. In terms of Company C's software, the respondent suggested that the software should be improved so that it can assist users with impact assessment and management, be able to incorporate legal requirements, and enable them to effectively follow up with action plans. With respect to Company D's software, it was suggested that the dashboard needed to be improved in order to make it more accessible by management and other users. As for company E's software, it was suggested that it should be simplified in terms of its 
operation and use.

One EMS-based software user in providing suggestions for improvement stated that, Software should be designed to meet the practical needs of users first, then add integration, then add on the EMS elements. The ISO 14001 EMS elements are trivial. Software needs to provide easy tools for mobile data capture (e.g., iPads and formbuilding for inspections and maintenance) and mapping, configurable equipment lists, and connections to other structural IT programs (e.g., personnel management systems, location structure) A good system should come pre-built with major environmental programs (e.g., hazardous and solid waste management, oil pollution prevention (SPCC), air emissions compliance). It should also have configurable data upload tools, especially ones that can be employed by users.

Respondents who used non-EMS-based software but provided responses stated that they would want software to be customizable to the ISO 14001 standard; have table and graphing functions; enable them schedule, coordinate and document the internal audit process; and have the ability to be integrated with other corporate systems such as training modules.

The comments provided shed further light on the limitations of EMS-based software and provides insights to vendors of such software as to what improvements can be made to their products. The suggestions provided also highlight the fact that some EMS-based software products may be limited in terms of facilitating learning. First, the inability of users to conveniently make revisions to documents when they see fit means that information may not be always up to date and employees may end up using obsolete information. It also implies that unlearning and thus learning may not take place. Second, the fact that employees cannot effectively follow up with action plans means that single-loop learning may not take place effectively because even though errors might have been detected, they may end up not being corrected on time or at all. Finally, the lack of a workable dashboard may result in information 
not being acquired, distributed and interpreted in an effective and timely manner.

In summary, the results regarding the functionality of EMS-based software suggest that organizations can benefit from using EMS-based software as a means to improve their internal processes as it relates to the EMS/standard and other business processes. However, the results also suggest that organizations that are using EMS-based software may be having issues with them. This may be because they did not conduct a thorough research (especially with respect to the technical capabilities of software as discussed in Part 1 of Chapter 2) of products on the market before purchasing them. For example, determining beforehand whether such software can be customizable or are compatible with what they have on ground, and evaluating how such software products can cater to their needs, and if they can be integrated with other systems that are already in existence. The aforementioned points are also some of the suggestions provided to potential users when considering purchasing EMS-based software (Alnes et al., 2014; Argent \& Grayson, 2001; Leif, 2014). Also, the results appear to show that EMS-based software vendors may not be working closely with potential clients in order to fulfill their specific needs as suggested in the literature (Alnes et al., 2014; Argent \& Grayson, 2001), and to obtain feedback as to what users in general want out of such products.

\subsubsection{Return on Investment (ROI)}

Respondents were asked to provide a response to the following question: In your opinion, has the software paid for itself in terms of your ability to meet the requirements of the ISO 14001 standard. If yes, can you provide a rough estimate of how long it tookfor the software to pay for itself? Ten (10) respondents who used EMS-based software provided responses as to whether or not the software had paid for itself.

Two (2) users of Company A's IM software said that it had paid for itself but a time frame was not provided. As at the time of the survey, both respondents had been using the software for approximately seven years. Two users of Company A's EM software said that the software was yet to pay for itself after having used it for one year and three years respectively, while another user said that based on the number of man hours saved, the software paid off in one year. They had been using the software for 2 years as at the time of the survey. With respect to Company B's 
software, one user said it paid off in approximately 1 year while the other said it paid off in three years. They had been using the software for 15 years and 8 years respectively. Company D's software was said to pay off in a few months, the software had been used for 13 years. The user of Company C's software was unsure whether it had paid off after having used it for 4 years, while the respondent who used Company E's software said that it was yet to pay off after having used it for 8 years. The results discussed above are summarized in Table 4.10 below.

Table 4.10 Summary of return on investment of EMS-based software

\begin{tabular}{|l|c|c|c|}
\hline Company/Respondent & $\begin{array}{c}\text { ROI } \\
\text { achieved }\end{array}$ & $\begin{array}{c}\text { Time achieved } \\
\text { (years) }\end{array}$ & $\begin{array}{c}\text { Time using software } \\
\text { (years) }\end{array}$ \\
\hline Company A IM & Yes & N/A & 7 \\
\hline Company A IM & Yes & N/A & 7 \\
\hline Company A EM & No & N/A & 1 \\
\hline Company A EM & No & N/A & 2 \\
\hline Company A EM & Yes & 1 & 15 \\
\hline Company B & Yes & $\approx 1$ & 8 \\
\hline Company B & Yes & 3 & 4 \\
\hline Company C & unsure & N/A & 13 \\
\hline Company D & Yes & $<1$ & 8 \\
\hline Company E & No & N/A & \\
\hline
\end{tabular}

Note. $\mathrm{N} / \mathrm{A}=$ Not applicable

Although the results indicate that some of the organizations that used EMS-based software achieved a return on investment, the results are seen as inconclusive. Due to the limited number of responses received and the fact that a time frame to achieve the ROI was not provided in all cases, these findings in their present form are particularly problematic in terms of any possible follow up.

\subsubsection{Reasons for not using EMS-based Software}

In order to identify and better understand why some organisations do not use EMS-based software as mentioned by Alnes et al. (2014), the respondents for this study who did not use EMS-based software were asked to provide a reason why. Thirty-eight (38) responses were obtained and they are summarized below. 
1.) EMS-based software was not readily available at the time when they started using management systems standards.

2.) EMS-based software did not fit their needs as at the time when they were considering using software for their management systems. This was because their systems were either very unique or they used an integrated approach for which software was not capable of handling. One respondent mentioned looking for EMS-based software that could be integrated with Microsoft Sharepoint but was unable to find one.

3.) Their needs were met using other non ISO 14001 specific software like intranet networks, SAP, LiveLink, Microsoft office suites (especially Word and Excel), Microsoft Sharepoint, various databases, and software for preventative maintenance management. Some respondents already had such software in place before adopting the standard and as such, they continued to use them for the implementation and maintenance of ISO 14001.

4.) Red tape due to the lack of support and approval from other departments, especially the information technology department.

5.) Obtaining management buy-in was found to be very difficult. One respondent mentioned that management did not agree for the organization to use EMS-based software.

6.) Some organizations set up their software system for ISO 14001 and other management systems in-house. This they did because of the uniqueness of their operations, or because they had the resources (human) to do so, or because they were advised to do so by experts.

7.) They tried using EMS-based software but decided to stop using it because they did not have success implementing them; because of the future ongoing cost of the software; and because of organizational issues such as obtaining buy-in from employees, and the computer savviness of employees, which was lacking.

8.) They were of the opinion that EMS-based software is cumbersome, especially for large organizations, and that the use of other software such as Microsoft office and Microsoft Sharepoint were much easier and simplified.

9.) They were of the opinion that EMS-based software is too expensive and did not provide much value, especially when experienced staff who could use regular software for the same purpose were available; and the environmental impact of the organization was low or only one site was certified, and as such did not require much administrative work. 
10.) In terms of the size of the firm, small firms with low administrative needs would not need to use such software, while large firms may find using EMS-based software cumbersome and very expensive.

11.) They did not explore or did not know about EMS-based software and what value they may provide.

12.) They already had other standards in place long before ISO 14001 and were using other types of software to manage such standards. As such, when they adopted ISO 14001 they did not see the need to purchase a separate software but rather continued with what was already in place.

13.) Their organization's environmental burden on the whole was very low

14.) One respondent mentioned the fact that they were looking to stop the third party certification for the ISO 14001 standard because they no longer saw its value, and as such there was no need to invest in software.

15.) As at the time of the survey, a few respondents were actually considering purchasing EMSbased software and thus their reason for participating in this study.

The reasons provided above do highlight some of the limitations already discussed earlier such as the inability to integrate the software with other systems and the issue with organizational culture (to include top management). It also shows that other simplified software packages such as Microsoft Excel are still being used, as mentioned in Chapter 2. It also brings up the issue of cost which was found to be a problem by those that use EMS-based software, and the fact that this might be a major issue for small organizations, especially those with a small environmental footprint. The reasons provided above serve as food for thought for potential buyers of the software and support the conclusion that the viability, attractiveness and functionality of specialized EMS software products is a subject deserving of more research.

\subsection{Functionality of the Standard}

Respondents were asked for their opinion as to what features or requirements of the standard they found most helpful and least helpful and why. The aim of these questions was to gain a better understanding as to which requirements/elements are most critical for the successful implementation and maintenance of the standard as well as those that pose a challenge to 
organizations that use the standard. The questions were also asked in order to improve understanding as to what changes if any can be made to the standard in order to make it more user friendly for organizations. The complete results of the study are provided in appendix B. The results in terms of number of respondents per feature/requirement is broken down according to private and public sector, size of organization, and industry sector as shown in Table B.6 and Table B.7 in Appendix B. A discussion of some of the results is provided in sections 4.7.1 and 4.7.2 below.

\subsubsection{Most helpful Feature/Requirement of the ISO 14001:2004 Standard}

Respondents were asked to provide an answer to the following questions: What would you say is the most helpful feature/requirement of the ISO 14001 standard? Please could you briefly explain why you found this feature/requirement most helpful?

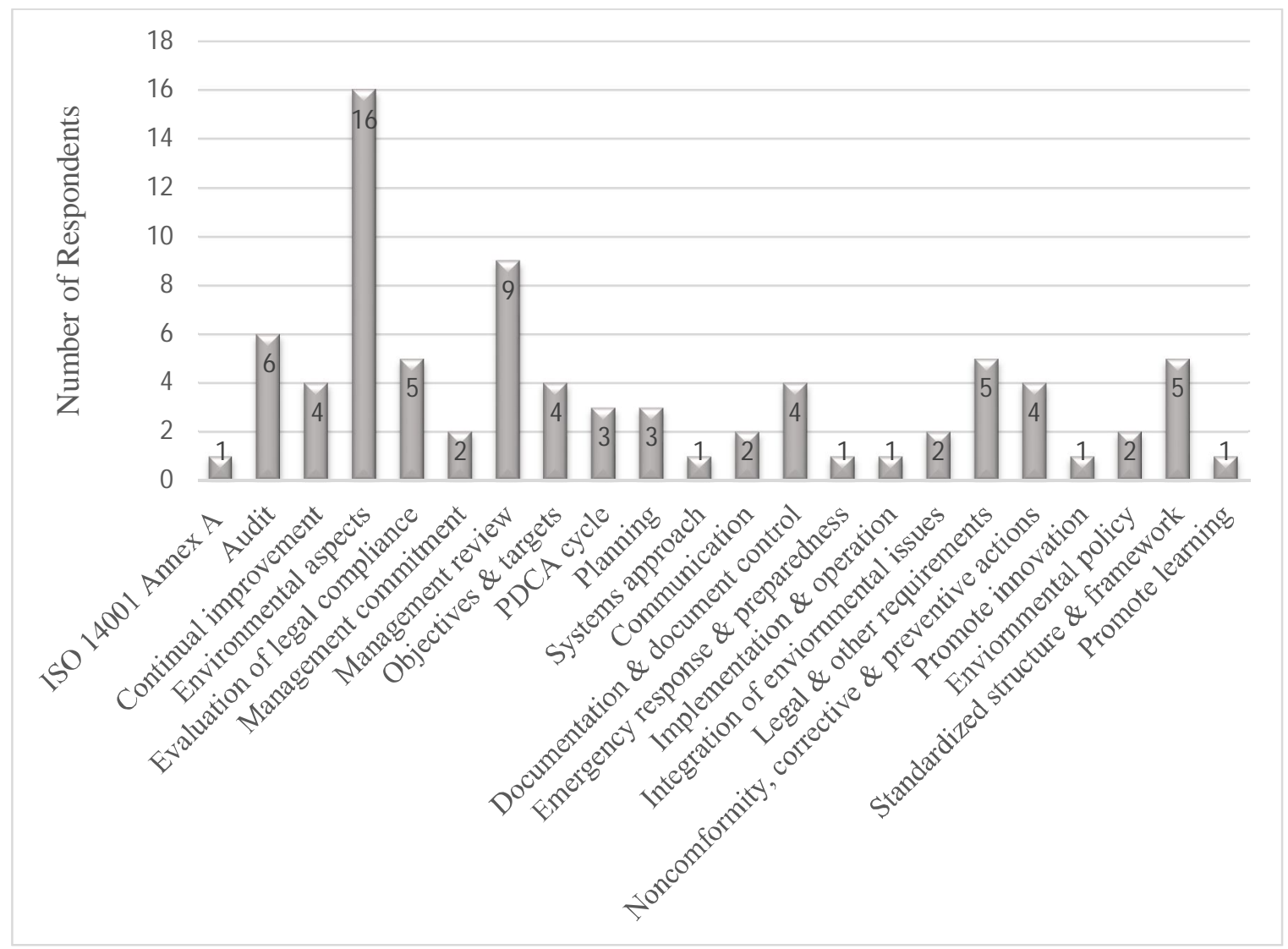

Figure 4.5 Requirements/features of the ISO 14001:2004 standard that were found to be most helpful 
As shown in Figure 4.5 above, the majority of the respondents found the requirements to identify environmental aspects most helpful followed by the management review and then the audit requirement. A discussion of the results is presented below.

\section{Environmental aspects}

The fact that the identification of environmental aspects was found by respondents to be the most helpful requirement of the standard was perhaps not surprising because of the fact that it is more or less the starting point of the implementation of the EMS, and also because an effective environmental management system cannot be built without the knowledge of an organization's environmental aspects and its potential environmental impacts. The requirement was found to be most helpful because the information obtained was used to develop the other requirements of the standard such as the training requirement. The findings of this study are in line with the observations of Poksinska et al. (2003) and Zutshi and Sohal (2004) in that the identification of environmental aspects was seen as an important requirement/factor for the success of an organization's environmental management system. This was the case (as is for this study) because it helped with the identification of the risks and potential impacts of the organization's activities (Poksinska et al., 2003). Interestingly, the responses provided by participants regarding this requirement indicate that it has the potential to influence organizational learning because according to respondents, it prompted them to adopt a systems approach in that they had to evaluate all areas of their organization, and it facilitated the collaboration amongst the different units within the organization. Collaboration as discussed in Chapter 2 facilitates Huber's (1991) four constructs of organizational learning. Also, the results of the study indicate that the information acquired by implementing this requirement was used to develop training programs, which in turn should assist in improving the knowledge and understanding of employees.

As showed in Table B.6 in Appendix B, the majority (11) of those that found this requirement most helpful belonged to the manufacturing sector, which is seen as a high polluting industrial sector (Darnall et al., 2008; Psomas et al., 2011). As such, they may see the identification of their organization's environmental aspects and their potential impacts as crucial to the successful implementation of the standard and in turn pollution prevention. Of course, this is bearing in 
mind that the survey results may be biased towards the manufacturing sector due to the low response rate. Also, the organizations were of all sizes with the majority (7) being large organizations. It may be an indication that SMEs are very much concerned about their environmental aspects and their potential impacts just as much as their large counterparts.

\section{Management review}

The management review was found by some respondents to be most helpful because it enabled organizations to systematically evaluate the implementation of the standard and their environmental performance on the whole. In other words, it enabled organizations to determine the successes and failures with respect to the standard's implementation and maintenance. Also, the management review as a means to obtain the commitment and participation of top management as mentioned by respondents implies that it may play a significant role in the success of the environmental management system. This is so because the commitment of top management is said to play a vital role in the success of an environmental management system (Chin \& Pun, 1999; Christensen \& Rasmussen, 1998; Poksinska et al., 2003; Zutshi \& Sohal, 2004). Management commitment is important because top management is said to be responsible for communicating the need for the EMS and for encouraging employees to come on board (Chin \& Pun, 1999). Also, they are responsible for developing the environmental policy and for setting the objectives and targets as it applies to the EMS (Poksinska et al., 2003).

Management commitment was found to be a helpful feature of the standard by a smaller number of the participants of this study. It was also seen to facilitate learning because according to respondents, it brought about a sense of ownership within the organization and led to multiple advocates coming on board. The presence of multiple advocates is a facilitating factor of organizational learning according to DiBella and Nevis (1998). A sense of ownership also plays a role in facilitating learning as mentioned in Chapter 2 (Senge, 2006). The results of the study also indicated that management commitment brought about improvements in environmental performance. The reason more respondents did not see management commitment as being very important for the EMS may be due to the fact that it is not a requirement and is only recommended by the 2004 version. However, with respect to the latest version (2015) of the standard, the leadership clause should bring management commitment to the forefront in terms 
of ensuring that the implementation and maintenance of the standard is a success.

The responses from participants reveal some learning conditions that were brought about by the management review process such as the engagement of top management and other employees; enabling the organization to seek out future opportunities; its ability to facilitate communication; and as a means to provide feedback. The findings support the notion by Epstein and Roy (1997) that the management review process can play a role in organizational learning because it serves as a means to disseminate information as well as a means for an organization to obtain feedback and therefore learn from its own experience.

According to one respondent (at a large organization), the management review served as a means for employees to have direct access to top management to include the Chief Executive Officer (CEO), which may not always be the case especially for large organizations. This would go a long way in ensuring that top management is engaged and that environmental issues are brought to the forefront of the organization with respect to its business decisions. The majority of the organizations that found this requirement useful were large organizations as seen in Table B.6.

\section{Audit}

The audit process (both internal and external) was found to be most helpful by respondents mainly because it enables organizations to attain and maintain legal compliance, to seek opportunities for improvement, and to continually evaluate the environmental management system thereby ensuring that the elements/requirements are being fulfilled. Of course, achieving legal compliance and the avoidance of costly fines that come with non compliance is of importance to organizations and thus a possible reason why some respondents found this requirement most helpful. In fact, respondents who found legal compliance as being most helpful to them said that the avoidance of cost from non compliance was one of the reasons they thought it was important. As with this study, the audit was also seen as important by other studies because it enabled organizations to stay on course with respect to the EMS (Potoski \& Prakash, 2005). Furthermore, the audit is seen as a means to obtain feedback, to uncover risks early before they become a major issue for the organization (Beeler, 1999; Darnall et al., 2009), and to preempt regulation (Darnall et al., 2009). In fact, the audit is regarded as "a cornerstone of the entire 
ISO system" (Ammenberg, Wik, \& Hjelm, 2001, p. 184).

The internal and external audits do offer organizations slightly different benefits as discussed in the literature. With respect to internal audits, they are said to be of benefit because they focus more on the improvement of the organization's internal processes (Darnall et al., 2009; Searcy et al., 2012). Furthermore, internal audits can be used to prepare the organization for the external audit (Searcy et al., 2012). Regarding external audits, they are seen as impartial, transparent and trustworthy because they are conducted by independent third party organizations and therefore provide evidence to external stakeholders regarding the organization's environmental stewardship. This may in the long run help enhance the image of the company (Darnall et al., 2009).

The responses also show that the audit process may influence organizational learning because it was said to provide opportunities for improvement and assist with the detection and correction of errors as it applies to the EMS. It may therefore bring about single-loop learning as mentioned by Epstein and Roy (1997). To add to this, "most auditors seemed to believe that standardized EMSs, used correctly, support new ideas concerning environmental issues and hence do not hinder the spread of new thinking" (Ammenberg et al., 2001, p. 190).

More respondents from private organizations found the audit requirement most helpful compared to their public counterparts (see Table B.6). This may be because they may come under stricter scrutiny and as such, see the audit as a means to ensure they remain compliant with laws and regulations.

Besides the requirements discussed above, other features and requirements of the standard were found to be helpful to some respondents (not the majority) for reasons outlined in Appendix B. A brief discussion of these features or requirements, especially as it pertains to organizational learning is presented below.

The requirement to evaluate compliance and the legal and other requirement were found to be of importance by the same number of respondents mainly because they both ensured that the 
organization remained compliant. Both requirements were said to save the organization money by avoiding cost from fines. As shown in Table B.6, mostly respondents from private organizations found legal compliance to be of importance. This could be due to the fact that private organizations may come under stricter scrutiny compared to their public counterparts. Based on the responses of participants, both requirements were also found to influence learning in one way or the other. The evaluation of compliance was found to assist with the discovery of new knowledge on how to address their legal obligations, and prompted the discovery of new opportunities by prompting the organization to undertake an audit. On the other hand, the legal and other requirement was found to assist organizations with the storage of information regarding their legal obligations and therefore may contribute to the organization's memory. Respondents found that having all their information on legal obligations in one location made it easier for the information to be acquired and to be put to use should the need arise.

As with the observation of Chin and Pun (1999), this study found the environmental policy to be helpful or important, but not the most important. Nevertheless, those that found it helpful mentioned the fact that it helped bring about a consensus within the organization with respect to environmental issues. This may have been due to the ability of the policy to foster a shared vision, which may facilitate learning as suggested by Epstein and Roy (1997). In terms of management attitudes, the environmental policy was seen as an important element of the ISO 14001 standard because the establishment of objectives and targets is based upon the policy (Chin \& Pun, 1999).

The communication requirement was found by respondents to be helpful because it led to an improvement in communication within the organization. As with this study, communication was found to be an important element of the standard, however, it was not seen as the most important factor for success of the standard (Chin \& Pun, 1999). Communication was reported as being a key success factor for the EMS because it served as a means to exchange ideas with internal and external stakeholders (Zutshi \& Sohal, 2004). Also, as discussed in Chapter 2, communication should lead to an improvement in the exchange of information and ideas as well as the interpretation and storage of information and thus facilitate learning. As such, should an organization witness an improvement in communication, organizational learning may therefore 
be enhanced. Those that found communication to be important belonged to large organizations (see Table B.6). This could have been a reason why they found it helpful as it may require more effort to exchange information within such organizations.

Similar to the study by Chin and Pun (1999), the findings of this study also indicate that emergency preparedness and response was helpful but not the most helpful, However, it was said by respondents to improve the knowledge and understanding, and therefore preparedness of employees with respect to emergency situations, and thus may have a role to play with respect to influencing learning in organizations.

The nonconformity, corrective action, and preventative action aspects of ISO 14001 were said by some respondents to be helpful because they provided feedback, and helped organizations to identify problem areas and their solutions. As such, they too may facilitate learning in this regard. They may also help to prevent situational learning (when information is not stored or forgotten) because as mentioned by a participant it prevented employees from forgetting about past incidents from which lessons can be learned.

The planning requirement on the whole was said to lead to the motivation of staff and the enrollment and participation of staff from other departments besides the environmental department, which are all conditions required for learning to take place. This is in line with the responses provided by other participants with respect to the requirements to identify environmental aspects and develop objectives and targets, which are both a part of the planning requirement, in that they may have similar influence on the learning process. For one of the respondents, planning was most helpful because the other requirements of the ISO 14001:2004 standard had already been covered due to the implementation of ISO 9001. The respondent adopted ISO 9001 four years before ISO 14001. It is an indication that ISO standards that have similar structures may support each other in terms of implementation.

Despite the challenges that organizations are said to have with documentation and document control, both requirements were found to be helpful to some (not the majority) of the participants of this study. Besides assisting organizations in ensuring that other requirements were being met 
because they had to be documented, they were also found to be helpful because they ensured that documents were continually revised. This in turn would ensure that unlearning takes place and that employees had up-to-date information. The requirements were also said to ensure that whatever information was distributed in the organization was consistent, thereby ensuring that all employees were on the same page. Despite the fact that larger organizations may find documentation in particular more burdensome, both requirements were found by this study to be important irrespective of the size of the organization.

Also, the continual improvement element of the standard was found to facilitate the collection of feedback, and may therefore enable the organization to learn from its past experience, while the objectives and target requirement and the accompanying environmental programs were said to facilitate collaboration amongst different departments.

The ability of the standard to facilitate the integration of environmental issues into the daily operation of the organization was seen as important by some participants. Some of their responses do indicate that in doing so organizational learning may be enhanced. First, the integration was found to assist in opening boundaries within the organization, which would enhance the sharing of information and knowledge. Second, the standard was said to facilitate the integration of environmental issues into a products life cycle, and may therefore influence learning when considering the content-process knowledge orientation (product development in particular) as put forward by DiBella and Nevis (1998). Based on the aforementioned, the inclusion of a requirement (as part of the leadership clause) to integrate environmental issues into the overall business processes of an organization in the latest version (ISO 14001:2015) of the standard may be a step in the right direction.

Based on the results from section B.2.1 in Appendix B, the PDCA cycle was said to assist with the process of information acquisition and may therefore contribute to organizational learning. In fact, it may facilitate all four constructs of organizational learning because it ensures that most, if not all the requirements of the standard are being put to work. The PDCA cycle was found to be most helpful by a few participants of this study. Its role as a learning mechanism has been mentioned earlier in this study and in the literature (Garvin, 1993). 
Other features that were mentioned that point to the standards ability to facilitate organizational learning include its ability to promote innovation, its ability to promote learning in general by facilitating the distribution and storage of information, and its systems approach. The standard's ability to promote learning and innovation is said to be some of its benefits (Montabon et al., 2000; Psomas et al., 2011; Radonjič \& Tominc, 2006) because it prompts the organization to create new technologies for pollution prevention (Boiral, 2002; Huang \& Shih, 2009). Innovation entails organizational learning because knowledge has to be acquired from inside and outside the organization as well as distributed in order for innovation to take place (Jimenez-Jimenez \& Sanz-Valle, 2011). Finally, as pointed out by a respondent, the standard may prevent the loss of knowledge due to employee turnover mainly because most of the requirements have to be documented. As such, information/knowledge regarding the EMS will remain with the organization irrespective of whether employees leave. Boiral (2002) does mention the use of the ISO 14001 standard to prevent the loss of knowledge through employee turnover. From this standpoint, the standard can be said to facilitate learning on an organizational level.

In summary, the study in attempting to answer the research question mentioned above, does highlight the fact that some requirements such as the identification of environmental aspects and the management review may be worth placing more focus on in order for the EMS to be successful. It also indicates that organizations found the different requirements of benefit to them because they lead to an improvement in internal processes, or to an improvement in the environmental performance of the organization, or provided financial benefits through for example cost avoidance. The responses as discussed above also support the findings of the study as discussed in section 4.4 that the requirements of the standard may have the ability to support organizational learning.

\subsubsection{Least helpful Feature/Requirement of the ISO 14001:2004 Standard}

Respondents were required to provide an answer to the following questions: What would you say is the least helpful feature/requirement of the ISO 14001 standard? Please could you briefly explain why you found this feature/requirement least helpful? The participant's responses to this question is presented in Appendix B. With respect to the requirements of the standard, most of the respondents felt that documentation and the external audit, followed by the environmental 
policy were least helpful or challenging to them for reasons discussed below. As seen in Figure 4.6, a good proportion of the respondents felt that the standard was limited in general in one way or the other with the majority (12) mentioning that they found all the requirements to be useful.

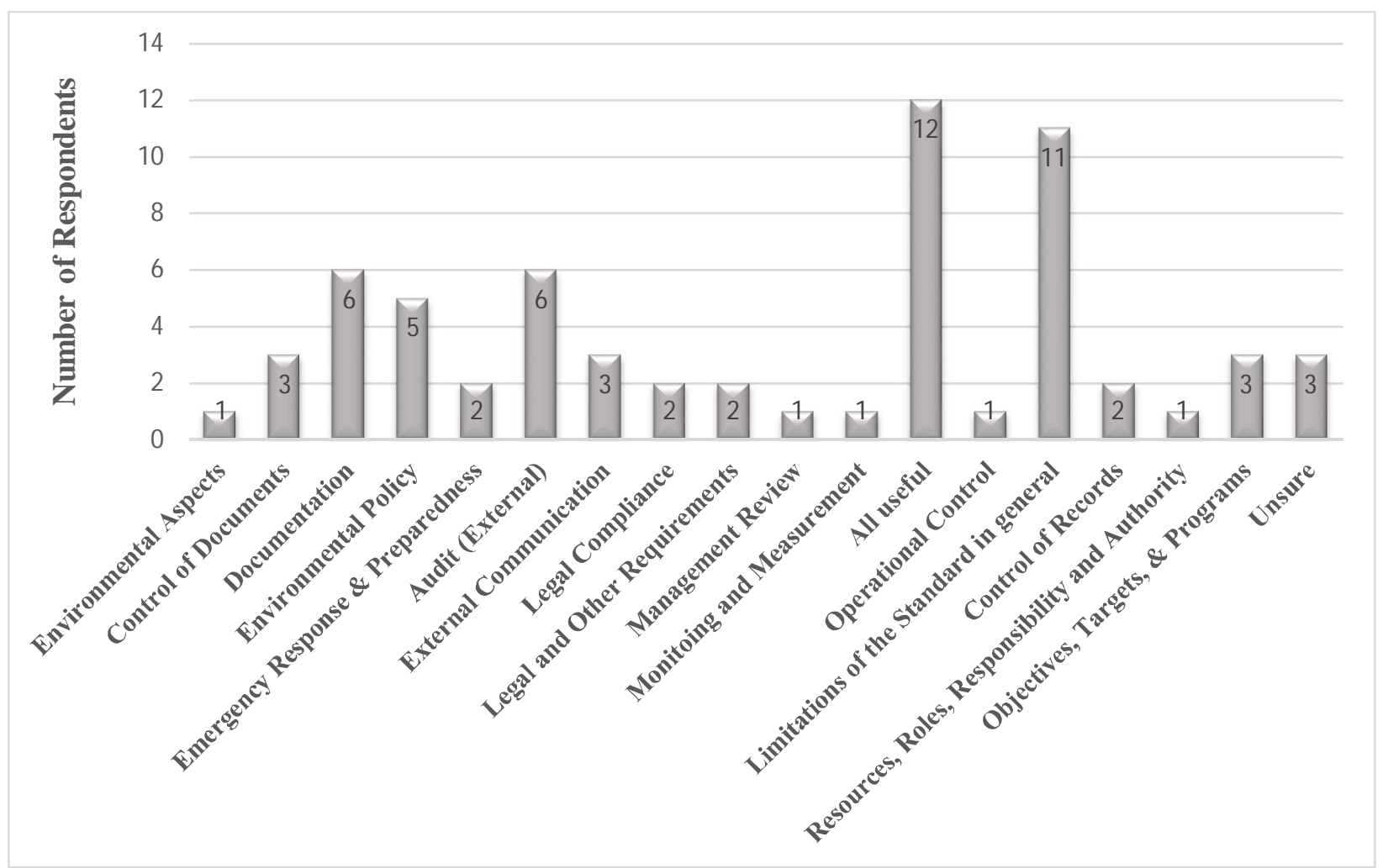

\section{Figure 4.6 Requirements/features of the ISO 14001:2004 standard that were found to be least helpful}

\section{Documentation}

As mentioned earlier, documentation along with the audits (mainly external) was found by the majority of the participants to be the least helpful features/requirements of the standard. The major concern had to do with the amount of extra paperwork required and thus the additional burden placed on the organization. This was also determined to be the case for organizations that adopted the ISO 14001 standard as reported by various authors (e.g., Ann et al., 2006; Poksinska et al., 2003; Psomas et al., 2011; Turk, 2009) and was one of the requirements that required the most effort to implement (Poksinska et al., 2003). Although the majority of those that found documentation to be a challenge were large organizations (as shown in Table B.7), the results do indicate that documentation could be an issue for small organizations as well. This could be the 
case because a respondent at a small organization did mention that they found extensive documentation unnecessary and a challenge for them, especially since the foot print of their organization was small. The results also indicate that whether or not documentation is seen as a challenge could be based on whether other standards were adopted before ISO 14001 and whether an integrated management system is in place. This assumption is based on the fact that the documentation requirement of the ISO 14001 was found to be redundant by one of the participants due to the fact that they already had ISO 9001 in place. The organization had been using ISO 9001 for 11 years and ISO 14001 for 3 years and had both systems integrated. The same was the case for the control of documents requirement as it was found to be unnecessary because it was already established using ISO 9001. The organization had been using ISO 14001 for 12 years and ISO 9001 for 15 years. Integration as suggested by another respondent and as discussed in the literature may be a great way to lessen the burden of documentation. The findings here are similar to those in section 4.7.1 with respect to ISO standards being able to provide complementary knowledge-based resources for one another and appeared to be a recurring theme amongst the participants of this study. However, one of the respondents who found documentation to be a challenge had ISO 9001 in place before ISO 14001 but did not have them integrated. This may be an indication that the integration of management systems and the ability to utilize the knowledge-based capabilities of standards such as ISO 9001 may go a long way in easing the burden of some of the requirements such as documentation. Also, the fact that some organizations still found documentation to be a challenge even though they adopted other standards prior to ISO 14001 may be an indication that the learning culture to include the amount of collaboration within the organization may play a great role in this regard.

The results also reveal that a respondent found documentation to be challenging due to the large number of employees that had to be trained, despite the fact that the organization used EMSbased software. They had been using the software for 13 years and had been registered for 12 years at the time of the study. The software was determined to have all the features for documentation as well as for training management based on the response obtained from the respondent. This observation does indicate that while EMS-based software might assist with the implementation of the standard it may not necessarily make the process less burdensome for its users. This finding regarding the documentation of training for employees could also be the 
reason why some organizations find employee training to be challenging (Poksinska et al., 2003; Psomas et al., 2011).

\section{Audit}

With respect to the ISO 14001 audit process, it was only the external audit that respondents had issues with. The first concern had to do with the audit exposing the organization too early to legal enforcement. This has been observed to be one of the limitations of the standard and a source of discouragement to organizations that may be considering certification (Bansal \& Bogner, 2002; Darnall et al., 2009; Kirkland \& Thompson, 1999). Early exposure of the organization to legal enforcement can lead to unwanted fines from regulatory violations. The second concern was the high cost of the external audit and certification thereafter. This has also been observed in the literature to be an issue for organizations (Darnall et al., 2009; Dogui et al., 2014; Hilary, 2004), and is said to be a barrier for the implementation of ISO 14001, especially for SME's (Hilary, 2004). The results of this study suggest that organizations of all sizes found it to be an expensive exercise. Although, it may be cheaper for small organizations, they may still find it to be an expensive exercise because of their limited resources.

The third concern of respondents had to do with the frequency of the audits and the contact time with the auditors, which were both found to be too long. Auditing too frequently could lead to fatigue on the part of the organization (Searcy et al., 2012) and further add to the already high cost of the audit. One solution to reduce audit fatigue may be to conduct the internal and external audits at the same time (Searcy et al., 2012). Also, registrars are said to reduce the contact time but more so to reduce cost, however, the less time used to conduct the audit the less effective the audit may be (Ammenberg et al., 2001; Burdick, 2001). The lengthy audit cycle has been reported as a barrier to the implementation of the standard (Hilary, 2004). A standardized formula to evaluate the number of contact days for the audit based on the different scenarios at each organization could be used in order to justify the length of the audit cycle, and to ensure the credibility of ISO 14001 on the whole (Burdick, 2001).

The final concern was regarding the external auditors handling the audit process as a paper exercise. In such cases, organizations may not gain much in terms of acquiring knowledge and 
improving their environmental performance. This appears to be a known issue with audits in general as it has been reported in the literature (e.g., Darnall et al., 2009). This issue could be linked to the fact that some external auditors are said to certify organizations knowing fully well that such organizations are only interested in greenwashing and not in protecting the environment (Dogui et al., 2014).

Aside from the issues discussed above, the external audit does have a few other drawbacks as discussed in the literature. First, there appears to be a lack of competent auditors (Ammenberg et al., 2001; Hilary, 2004), as such, the audit may not be conducted as effectively as it should. Second, external auditors are sometimes lenient, especially with SMEs because of their limited resources, and because they wish to remain competitive (Ammenberg et al., 2001; Dogui et al., 2014). However, this may diminish the credibility of the audit process and the standard as some SMEs may be greater polluters than their larger counterparts (Dogui et al., 2014). Third, due to the fact that the external auditors are being paid by the organizations that they are auditing, they may not be entirely independent of such organizations and thus may tend to be partial. Should this be the case, the credibility of the audit process could be diminished (Burdick, 2001; Dogui et al., 2014). One solution may be to prevent any direct monetary agreement between the auditor and auditee by introducing an intermediate body that will handle the financial aspects of the audit. However, this does come with its draw backs such as increased cost and bureaucracy to name a few (Dogui et al., 2014). Finally, the external audits were found to at times produce inconsistent results for the same facility (i.e., two different auditors providing different findings), and communication between the auditors and auditees tend to be lacking or poor (Searcy et al., 2012). The later point may have contributed to the issue of conflicting interpretations that organizations appear to be facing with respect to the standard.

Interestingly a respondent mentioned that the internal audit is just as valuable as the external audits and costs less. This could be due to some of its benefits as discussed earlier in section 4.7.1. Nevertheless, the internal audit does have its drawbacks. For instance, auditors are not always competent, proper planning is not always done before conducing the audit, they do not always lead to improvements in the organizations processes (Searcy et. al., 2012), and they are not always seen as transparent or trustworthy because they are most often done by the employees 
of the organization (Darnall et al., 2009).

Based on the results of this study, the issue with external auditing in Canada and USA could be as a result of the lack of guidelines or presence of weak or vague guidelines provided to registers by accreditation bodies in North America, which are eventually passed down to the organizations seeking ISO certification. According to the study by Burdick (2001) the guidelines provided to registrars in America were often absent, or weak, or vague when compared to their European counterparts. To conclude, the challenges organizations are said to face in fulfilling the audit requirement (Poksinska et al., 2003; Psomas et al., 2011) might be due to the reasons provided.

\section{Environmental policy}

Although the policy is supposed to play an important role for the success of the environmental management system, the results of this study indicate that this may only be the case at the initial stage of the implementation of the EMS/standard. Once the EMS becomes mature, it may be of no more value to the environmental management system. This could be the case especially if the organization determines that the system is working as required and that no major revisions of the policy, which may trigger the revision of other requirements such as the objectives and targets and programs are needed. Those that felt that the policy was least helpful were registered for 4 to 17 years. Also, the findings indicate that the policy was least helpful because it was said to be too generic and that it was not read by most employees. This could be the case, but the onus lies on the organization to ensure that the policy is tailored towards its vision and mission and that it is circulated and read by all its employees. The standard does provide a generic guideline for the development of the policy and requires that it be circulated to all employees. Bearing this in mind, and contrary to the findings in section 4.7.1 and as discussed in Chapter 2, the policy may not be able to facilitate a shared vision in the organization and therefore promote learning, especially if it is not promoted by top management and read by employees. It is an indication that the ability of some of the requirements of the standard to promote learning will depend on how they are implemented.

The results also indicate that organizations have issues with requirements other than those mentioned above. For instance, some requirements or features were found to be least helpful or 
not necessary because they should be a part of an organization's business operations (e.g., emergency preparedness and response, legal compliance, objectives, targets and programs, control of records, and legal and other requirements) or because they are already required by legislation (e.g., emergency preparedness and response, legal compliance, and legal and other requirements). For instance, emergency preparedness and response is required by federal and provincial legislation in Canada. While this might be true, it may not be applicable in all situations. For example, not every country may have emergency preparedness and response as part of its legislation. These are things the ISO may have taken into consideration when developing and revising the ISO 14001 standard.

Contrary to the findings of respondents in this study, monitoring and measurement was seen by commentators to be one of the critical factors required for the implementation of the standard when considering technical aspects of environmental management (Chin \& Pun, 1999). However, the main issue as raised by a participant had to do with the calibration and documentation thereafter of large numbers of equipment, especially since the organization in question was a large one. The same organization used EMS-based software for one year and was registered to the standard for 3 years. It further indicates that the software may not have lessened the burden for its users.

The requirement to obtain resources for the implementation of the standard was found to be least helpful by one respondent because it could not force top management to provide the necessary resources for the EMS. Obtaining sufficient resources was said to be one of the challenges faced by organizations that adopted the standard (Liyin et al., 2006). The introduction of the leadership clause in the ISO 14001:2015 version may help to ensure that the necessary resources are provided as appropriate. The organization was a medium-sized organization and so resources could be a particular issue facing smaller organizations.

The findings of this study do reveal that some organizations may fail to benefit from some of the learning capabilities associated with the standard's requirements. First, one respondent mentioned that they were more or less forced to establish environmental targets and programs just because the standard required it and not because it was of any value to them. They may 
therefore miss out on the learning potential of this requirement with respect to providing feedback as to the effectiveness of the standard. Second, it was felt by a respondent that it was not necessary to evaluate all the organizations activities, products and services just for the sake of compiling a list of all the environmental aspects, to include those that are known not to have an impact on the environment. However, in not doing so, the organization could fail to acquire all the necessary information required to implement the standard successfully and at the same time fail to uncover some underlying risks that could occur due to their activities. In other words, the ability of the environmental aspects requirement to influence learning may be overlooked. The organization in question was a small organization and so its environmental foot print may be small. On the other hand, it belonged to the chemical manufacturing industry and as such may have the potential to seriously impact the environment. Third, the management review was said to be least helpful by one respondent but only because it was not held frequently enough in order to address significant issues. The respondent mentioned that the review was held on a quarterly basis at their organization. This does seem reasonable as the recommended time frame for the management review is 3 to 6 months during the early stages and once a year when it is mature (Whitelaw, 2004). Of course as stated by Whitelaw (2004), the frequency will depend on whether the objectives are being met. If they are not, then it should be held more often. With respect to this respondent, it is possible that the organization's objectives and targets were not being met and that having the management review on a quarterly basis was not enough to address the observed shortcomings. It is possible that top management at the said organization did not see the value of the review as a means to obtain feedback and to learn, and hence did not feel it needed to be held more frequently. It may also be possible that they became complacent because they felt that the EMS was mature and functioning as required and as such, did not require much revising that would warrant meeting more often. Their EMS had been certified for about 10 years. The standard does not stipulate a time frame to conduct the management review, so at the end of the day, the frequency of the review depends on the organization. Maybe the International Organization for Standardization (ISO) should recommend a frequency for the management review that they feel will provide optimum results for the organization and to incorporate it into the standard in order make it uniform amongst all organizations. The study is serving to highlight some of the above noted potential learning issues associated with the standard. 
In general, other concerns that respondents had with the standard include the fact that it was time consuming to implement, it was not prescriptive enough with clear enough directions (e.g., other requirements, and operational control requirement), the standard did not have much use once the EMS was mature, and issues with interpreting the standard coupled with the conflicting interpretations between the auditors and auditees. The issue with the standard being too broad and not prescriptive enough has been found by scholars to be one of its limitations (Bansal \& Bognar, 2002), and is something the developers of the standard could look into. With respect to the standard becoming less useful over time, while possible, the continuous improvement approach should prevent this from happening. Furthermore, based on the literature and the results of this study, the audit was said to prevent stagnation by prompting the organization to look for opportunities for improvement, where possible. Finally, organizations may need to seek other ways to apply the standard to its fullest such as using it as a tool to facilitate organizational learning.

Regarding the issue of interpreting the standard, the requirements that respondents had issues with included environmental aspects, roles and responsibilities, objectives and targets, and the internal and external audit process. The interpretation of the requirements to identify environmental aspects and the setting of targets is said to be a known issue for organizations. One issue had to do with whether only environmental criteria is to be included in the evaluation of significant aspects and impacts as opposed to including other criteria such as quality or legal demands (Ammenberg et al., 2001). This could be a reason why organizations were said to find the identification of aspects challenging (Poksinska et al., 2003; Psomas et al., 2011). Another issue had to do with deciding on what targets to set and how many, as this is normally left to the judgement of the external auditors (Ammenberg et al., 2001). Based on the results of this study, it was interesting to see that all the organizations that had problems with interpretation had been registered for more than 5 years: in fact, the majority were 10 years and above. It would be expected that early adopters of the standard would be the ones having such an issue and not those that have been using the standard for such a long time.

The inability of organizations, especially those in the initial stages of implementation, to properly interpret and thus understand the standard was said by commentators to be one of the 
difficulties organizations faced with the implementation of ISO14001:2004 (Christensen \& Rasmussen, 1998). The issue of interpretation is said to stem from the broad or non-specific nature of the standard. Also, based on the study by (Ammenberg et al., 2001), research suggested that auditors believed that the interpretation of the standard varied depending on who was doing the auditing: in fact, auditors working at the same firm (registrar) were found to have different interpretations of the standard. As mentioned in Part 1 of Chapter 2, the issue of registrars having conflicting interpretations of the standard and the non-uniformity in which the standard may be presented by the different registrars worldwide has already been observed as a possible limitation of the standard (Bansal \& Bognar, 2002; Burdick, 2001; Morrison et al., 2000). Also, the standard on its own has been said to be difficult to interpret and translate (Kirkland \& Thompson, 1999; Schylander \& Martinuzzi, 2007), and hence the likely reason why some participants of this study also found this to be an issue. To make things more complicated, getting the external and internal auditors on the same page when it comes to interpreting the standard is said to be sometimes an uphill task (Ammenberg et al., 2001). Perhaps the new version will prove to be less of a problem in this regard.

The problem with interpreting and understanding the ISO 14001:2004 standard does raise the question as to whether organizations are using the ISO 14004 guideline. The latter does provide more detailed recommendations on how to implement the different requirements of the standard. One respondent of this study did find the provision of a guide to ISO 14001:2004 in the form of Annex A to be the most helpful feature. With the guide in place, organizations should be better able to understand how to implement and maintain the standard. Further research could look into the usefulness of Annex A and ISO 14004 as a means to assist organizations with the interpretation and implementation of the standard.

\subsection{Concluding Remarks}

This chapter discussed the results of the survey undertaken for this study. While fully recognizing and acknowledging the limitations associated with the survey in terms of the comparatively small number of respondents, the survey results nevertheless provided some useful information and insights with respect to the link between organizational learning and the ISO 14001:2004 standard, as well as the link between organizational learning and EMS-based 
software; the ability of EMS-based software to assist organizations with the standard; and the functionality of such software products and the standard. The empirical results presented in section 4.4.1 provide preliminary support for the idea that the standard through its requirements has the ability to promote learning by facilitating the four constructs of organizational learning. As such, the standard's requirements could be leveraged by organizations as a means to improve the knowledge of its employees or facilitate other learning processes with the end goal being to improve performance. It is however important to note that due to the low response rates, no conclusive observations are being made here. The responses to the follow up open-ended questions as discussed in section 4.4.2 do provide some support for the empirical results as well as provide interesting insights for future research.

The results presented in section 4.4.2 suggest that the ISO 14001 standard, by facilitating the adoption of the four constructs of organizational learning, can potentially lead to improvements in training programs; adoption in some organizations of approaches to ensure that relevant information and thus employees are always up-to-date; the facilitation of more structured systems approaches within the organization; improved knowledge, awareness and understanding of relevant environmental and management issues; improved communication practices; improved accountability; enhanced exchange of information and ideas; improved possibilities for shared consensus on relevant environmental and management issues; enhancements to practices for the storage of information/knowledge; facilitated feedback processes; and improved employee engagement. These learning mechanisms/conditions can all influence learning within an organization as discussed in Chapter 2 and could assist in leading to the improvement in the organization's performance as evidenced from the results of this study. For instance, the results indicate that organizations using the standard were in an enhanced position to implement sustainability programs; manage spills, noise issues, solid and liquid wastes, and resource consumption; and improve internal processes such as work procedures, document and records management, implementation of corrective actions, and ensuring conformance and compliance.

The results also show that the standard may facilitate learning indirectly by prompting or motivating the organization to implement learning mechanisms. It also highlights various mechanisms through which organizations can facilitate the distribution of information (e.g., 
through reports, meetings and environmental information systems), and that other standards such as ISO 9001 may be able to facilitate learning as well.

The results presented in this section also draw attention to the requirements of the standard that are likely to play a role in facilitating each of the four constructs and in what capacity. Thus, organizations can leverage attention to such requirements in order to enhance learning and performance. For instance, the management review and audit process were found to be good learning mechanisms because they provide feedback with respect to the success of the standard; this being the case, organizations could decide to have them done more frequently.

The empirical results set out in section 4.5.1 suggest that EMS-based software may also have the ability to promote learning and therefore serve as 'food for thought' for organizations that use or are planning to use such software products. It also provides some insights for developers of such software products in terms of designing them to ensure that they have the ability to facilitate learning. However, as is the case with the standard, it is not possible to make conclusive remarks due to the very low response rate. However, the results presented in section 4.5.2 do provide preliminary support for the findings.

The results in section 4.5.2 suggest that EMS-based software, by facilitating the four constructs of organizational learning, could bring about improvements in how information is tracked, ensure information is acquired and distributed quickly and consistently, ensure that information is up to date, improve understanding and decision making, facilitate the development of training programs, and provide a means to store and retrieve information, all of which influence learning and can enhance performance within the organization. EMS-based software was seen as helpful for improving performance in terms of training, work processes, the regulatory process and thus legal compliance, document management and a few others. The results also highlight the features of the software that are likely to play a role in facilitating learning. For example, the sortable database that enables users to store and retrieve useful information.

Section 4.6 provides insights as to the features of the software that may assist organizations with the implementation and maintenance of the standard and those that may play a key role in 
ensuring that the EMS/standard is a success. It also highlights the weaknesses of such software products and likely improvements that can be made in order to make them more user friendly. The aforementioned would be of importance to potential users (in terms of what to look out for) and developers of EMS-based software (in terms of improvements to be made). Also, some of the suggestions for improvement provided by respondents bring to light the fact that if implemented, they may facilitate the learning process. For example, the provision of or improvement in the software's dashboard could ensure that information is efficiently distributed or interpreted by its users. On the other hand, some of the limitations of EMS-based software do suggest that in their present state some programs may have limitations in terms of facilitating learning. For instance, the inability of certain software to be integrated with other business processes may imply that learning is limited to certain members of the organization. The results also suggest in a preliminary way that EMS-based software may at this time not be suitable for public organizations.

Finally, the results pertaining to the requirements/features of the standard that were found by respondents to be most and least helpful were presented in section 4.7. By drawing attention to the requirements/features that were perceived to be most helpful (e.g., environmental aspects, management review, internal audits, etc.) and the reasons why, the study provides insights as to which requirements/features organizations may need to focus their energies on in order for the implementation of the standard to be faster and more effective. The results also shed light on the issues that organizations may face with the requirements/features of the standard and therefore enables them (especially new adopters) to be in a better position to deal with such issues should they arise. It also stresses further some of the limitations of the standard which may need to be addressed by its developers, such as issues with interpretation and its inability to provide enough guidance for some users because of its broad nature. The results presented in section 4.7 also support the results in section 4.4.1 and 4.4.2 by reinforcing the point that several of the requirements may facilitate organizational learning. The results in section 4.7 also suggest some of the limitations of the standard in terms of facilitating organizational learning.

In the next chapter, the research summary and conclusions, limitations of the research study, recommendations for future research and the research implications are presented. 


\section{Chapter 5: Conclusions and Recommendations}

\subsection{Research Summary and Conclusion}

This research study had three main goals. The first main goal was to explore the organizational learning capability of the ISO 14001 standard. In other words, the goal was to explore whether the standard through some or all of its requirements has the capability to facilitate within organizations the four constructs (information acquisition, information dissemination, information interpretation, and organizational memory) of organizational learning put forward by Huber (1991), and in turn to enhance organizational learning. For this, the following research question was developed:

Q1: Does the ISO 14001 environmental management systems standard have the ability to facilitate the acquisition, distribution, interpretation, and storage of useful environmental information and therefore contribute to organizational learning?

The theoretical discussion and the quantitative and qualitative results of this research provided some evidence concerning the ability of the ISO 14001 standard to contribute to organizational learning as the majority of the survey respondents were of the opinion that the standard did assist their organizations with respect to the four constructs mentioned above. The research undertaken for this study suggests that the standard facilitated information distribution more than the other three constructs, followed by organizational memory, information acquisition, and then information interpretation. The explanation for why the standard seemed to have a greater effect for some constructs rather than others was not immediately apparent but could be dependent on factors such as the length of time the organization has been registered to the standard. The results support the literature linking environmental management systems (mainly ISO 14001) and organizational learning, and the use of the four constructs as a measure for organizational learning. It must be noted that in this research, organizational learning was not directly measured; instead, the perceptions of key respondents within selected organizations that used ISO 14001 was elicited to ascertain whether in their view elements of the standard had the ability to support the four identified constructs of organizational learning. 
Research undertaken for this study suggests that the ISO 14001 standard, by facilitating use of each of the aforementioned four learning constructs in organizations that adhere to its terms, could improve the learning conditions within implementing organizations, and this in turn could lead to enhancements in environmental performance and other related improvements. First, results of the survey conducted as part of this research suggests that organizations that facilitate the acquisition of information, as per the terms of ISO 14001, can assist with the following: improvement in the knowledge, awareness and understanding of employees; improvement in the development of effective training programs; lead to better accountability amongst employees; ensure that employees are up to date with the relevant information; and potentially lead to a more structured and systematic approach to environmental management. Second, the comments of the respondents suggest that adherence with the standard can facilitate the distribution of information and in turn assist with improvements in knowledge, awareness and understanding of staff and others who work on behalf of the organization, improvements in communication, the enhancement of employee engagement and participation, improvements in accountability, and in ensuring that employees are up to date with respect to their responsibilities and work procedures.

Third, in facilitating the interpretation of information, the standard was seen to have the ability to improve the knowledge, awareness and understanding, thus cooperation amongst employees, and facilitate the development of a shared consensus, especially with respect to environmental issues. Fourth, an improvement in the organization's memory, was seen by some respondents to enable organizations to have up-to-date information at all times, assist with improving the knowledge, awareness, and understanding of employee duties and responsibilities with respect to the environmental management system, assist with improving the archiving of historical data, assist with improving the tracking of trends and thus providing feedback, and assist with improving communication and sharing of information.

Research undertaken for this study suggests that the ability of the standard to influence the four constructs of organizational learning and to bring about the aforementioned learning mechanisms/conditions can enable organizations to improve their environmental performance and other internal processes in general. For instance, organizations may be in an enhanced position to implement sustainability programs; manage spills and noise issues; and improve 
internal processes such as work procedures, document and records management, and ensuring conformance and compliance. It should be stressed that the effect of organizational learning on performance was not directly measured, rather the participants were asked to provide their opinions as to what performance improvements they observed as a result of the standard's ability to influence learning.

The study also provides preliminary insights regarding the requirements of the standard that may play a major role with respect to influencing the four constructs of organizational learning. Of all the ISO 14001 requirements studied, those associated with the audit process were found to influence information acquisition the most, those pertaining to training were observed to influence information interpretation the most, while those pertaining to documentation were found to influence information distribution and organizational memory the most.

Organizational learning was not directly measured; instead, the perceptions of key respondents within selected organizations was elicited to ascertain whether in their view aspects of the standard had the ability to support the four constructs of organizational learning.

The second main goal of this research study was to explore the organizational learning capability of EMS-based software. As was the case with the research pertaining to the ISO 14001 standard, the focal point of attention was to explore the ability of EMS-based software to facilitate the four constructs of organizational learning, and thus better understand whether the software can enhance learning in organizations. For this, the following research question was developed:

Q2: Do environmental management systems software packages have the ability to facilitate the acquisition, distribution, interpretation, and storage of useful environmental information and therefore contribute to organizational learning?

However, the low response rate of software users in the survey conducted for this research detracts from the ability to make strong assertions concerning the organizational learning capability of EMS-based software. Nevertheless, based on the quantitative results obtained, the study does show preliminary evidence that EMS-based software may have the ability to enhance organizational learning because it was seen to facilitate the four constructs of organizational learning. Also, bearing in mind the aforementioned limitations of the study, the qualitative 
results suggested that EMS-based software could enhance organizational learning and performance. They also support the findings of the empirical analysis in that EMS-based software may have the ability to influence organizational learning via its constructs. In facilitating information acquisition, research suggests that EMS-based software may: assist organizations with the tracking of information and the provision of feedback; assist with ensuring that information could be collected in a timely and efficient manner; and assist with ensuring that information was always up to date. With respect to information dissemination, survey results of respondents suggested that organizations that used EMS-based software may see improvements in how they tracked information and obtained feedback, improvements in the consistency and uniformity of information transferred throughout the organization, and improvements in terms of providing the information to those who needed it on time. In facilitating the interpretation of information, survey results of respondents suggested that EMSbased software may improve the training programs of the organization, and improve understanding and decision making with respect to environmental affairs. Finally, with respect to the enhancement in organizational memory, survey results of respondents suggested that EMSbased software may assist organizations with the tracking of information and the provision of feedback, and assist with ensuring that information was always up to date.

Research undertaken for this study concerning the ability of EMS-based software to influence the four constructs of organizational learning and to bring about the aforementioned learning mechanisms/conditions suggests that it can assist in enabling organizations to improve mainly on their internal processes as it relates to the EMS. For example, organizations observed improvements in their regulatory process and thus compliance, and they were better able to handle document management and control processes.

The third main goal of this research was to answer the question:

Q3: Do environmental management system software products have the necessary features that enable them to assist organizations in implementing and maintaining the ISO 14001 management system standard? 
In other words, does EMS-based software have features that help organizations fulfill some or all of the requirements of the standard such as identification of environmental aspects, legal and other requirements, internal and external audits, documentation, etcetera? The low response rate of software users in the survey conducted for this research has the effect of making the observations tentative and preliminary in nature, concerning the ability of EMS-based software to assist organizations with the implementation and maintenance of the standard/EMS. Bearing these qualifications in mind, the research undertaken for this study suggests that EMS based software may have the ability to assist in some areas. First, it was seen by respondents to assist with some areas of document management such as the creation of documents from scratch, the integration of documents created using other software products such as Microsoft word and PDF, the review and revision of documents, providing easy access to documents, and the storage of documents. Second, it was found by respondents to assist with data compilation and report generation, because it had features that allowed for the analysis of data and for the preparation of graphical reports. Third, EMS-based software was seen by respondents to assist users with milestone and task management, and with the tracking of information. Finally, EMS-based software was found by respondents to have the ability to assist organizations with environmental gap analysis, the audit process, training management, the integration of different management systems, with meeting their compliance requirements, and by providing ISO 14001 context specific text.

A secondary goal of this research was to further gain an insight into the performance of EMSbased software products and the challenges users may have using such products. As such, respondents were asked questions regarding what the most and least helpful features of the software were and why, how easy or difficult it was to implement the software, what improvements they would like see made to EMS-based software, and whether or not they received a return on investment on the product. Bearing in mind the low response rate to the survey concerning use of EMS-based software, and hence the tentative nature of the conclusions, some feedback from software users could be of value to the organizations that manufacture such software products and to those considering using EMS-based software. A few participants of this study who used non-EMS-based software also provided feedback with respect to the software 
that they used. Though not the target of this research, their input was found to be of importance because their feedback could also be of value to EMS-based software vendors and users alike.

In terms of the features that software users found most helpful, those that stood out included the document control feature that helped with the management of documents, the notification feature that provided real time alerts for items that were due, the data collection and reporting feature that helped with the tracking and monitoring of information, and a database feature which served as an accessible and sortable repository for information. The presence of some of these features does support the findings of this study with respect to the learning capabilities of EMS-based software. For instance, the document management feature was found to assist organizations with the efficient distribution of information within the organization. The ability of the software to be customizable to the user's needs, and the ability to use the software on a variety of mobile devices from any location were some other features that were found helpful by respondents who used non-EMS-based software. With respect to the features of EMS-based software that were found to be least helpful or absent altogether, some include the inability to customize the software to one's needs; the presence of modules that did not provide much value either because they did not apply to the organization's operations or because they were poorly designed such as the measurement and monitoring module, the environmental policy module, the customer requirement database, and the corrective and preventive actions module; and their lack of compatibility with other non-EMS-based software, and business processes. However, there were cases for which users of EMS-based software were satisfied with all the features that were currently present. The findings also indicate that such deficiencies of EMS-based software may limit its ability to influence learning. For example, its lack of compatibility with other business processes may lead to information being available to only those in the environmental department. With respect to non-EMS-based software, issues that were raised included the inability of the software to directly support ISO 14001 or assist them in meeting their compliance needs; the lack of formatting options; being too basic; the inability to change the name of a document approver in one step rather than having to do so document by document; and the inability to allow for sufficient information to be built into the system in order to support the internal audit process. 
In terms of how easy or difficult it was to implement EMS-based software, the reactions of respondents were mixed, and of course depended on which software was being used. While some found the implementation easy, others had difficulty implementing them. Some found it easy either because the software was intuitive or because adequate training was provided. Others found it difficult because either the training was too broad or because the software could not be aligned with their business operations. A few others had issues with the start-up and ongoing maintenance cost that was incurred: this was found to be an issue for organizations of all sizes but could be more of an issue for small organizations. Finally, there was the issue of the computer savviness of employees and the culture of the organization.

Suggestions for improvement for some of the EMS-based software used by participants of this study included:

1.) The provision of a web-based platform to assist users of the software

2.) The ability to customize the software

3.) The provision of flexible pre-built templates for procedures that will enable users to make changes as they see fit,

4.) Making the software more user friendly in terms of the layers of approval for nonconformance

5.) The ability to set data entering rules in order to limit human error

6.) The incorporation of the planning and management assessment elements of the standard

7.) The provision of a built-in report generation feature that would prevent users from having to generate reports using different software

8.) An improvement in the dashboard which will give top management better accessibility

9.) Enable users to follow up on action plans and,

10.) Incorporate features that assist with legal requirements, and that enables one to assess and manage impacts.

To some extent, the suggestions provided further highlight the limitations of current EMS-based software. They also further highlight the fact that some EMS-based software products may be limited in terms of facilitating learning. For instance, the lack of a workable dashboard may result in information not being acquired, distributed and interpreted in an effective and timely 
manner. The findings therefore indicate that the suggestions if implemented may improve the ability of EMS-based software to enhance the acquisition, dissemination, interpretation and storage of information.

Some of the functions that users of non-EMS-based software products said would assist them in maintaining their environmental management system include: the ability of the software to be customizable to the ISO 14001 standard; the presence of table and graphing functions; the ability to enable users schedule, coordinate and document the internal audit process; and the ability of the software to be integrated with other corporate systems such as training modules.

Based on the findings of this study it could be argued that although EMS-based software products may be useful, they still have some way to go in fulfilling all the needs of its users. For instance, the need for EMS-based software to be capable of being integrated with other software products. The results suggest that although the EMS-based software is being used by public sector organizations, they are still not compatible with government business processes. As such, manufacturers of such products need to work hand in hand with software users in order to determine what their needs are and make the necessary adjustments. Also, those that wish to make use of EMS-based software need to do their research properly in order to decide on which software fits their specific needs. Furthermore, this study supports the opinion that vendors need to work more with independent researchers in order to validate the claims of their products as this will also shed light as to what issues the users of their products and similar products are encountering. Based on the feedback from some of the respondents, this study is also in line with the literature regarding the fact that some organizations still use non-specialized software such as Microsoft Excel or develop software in-house to manage the environmental management system/standard. Some of the reasons provided by participants as to why their organizations did not use EMS-based software are as follows: the software did not fit with their organizational processes; they already had specialized (for other management systems) or non-specialized software in use before adopting ISO 14001; they had difficulty obtaining management buy-in; the initial and ongoing maintenance cost of the software was too high; their environmental burden was low and as such, the EMS did not require much administrative work; and they were unaware that EMS-based software existed. 
Another secondary goal of this research was to gain an understanding of the experiences of users of the ISO 14001 standard in order to determine what changes could be made to the standard if necessary. As such, participants were asked to identify which requirement or feature of the standard they found most and least helpful and why. Environmental aspects came out on top as the most helpful requirement followed by the management review, and then the internal audit. The main reason why the environmental aspects requirement was seen as most helpful was because it was said to be the backbone of the environmental management system. The fulfillment of the other requirements of the standard and the environmental management system all depend on the identified significant environmental aspects and subsequently their potential significant impacts that are tied to the organization's activities, products and services.

As for the management review requirement, it was seen as helpful because it provided a means for the organization to evaluate its environmental management system in its entirety and to enroll the participation and commitment of top management amongst other reasons. The audit was of importance because it helped keep the organization on track in terms of its environmental management system and in meeting its legal obligations amongst others. The importance of these requirements with respect to the success of the standard have been reported in the literature. The responses provided also support the quantitative and qualitative results of this study regarding the requirements of the standard having the ability to support learning. In terms of the requirements that were found to be least helpful, documentation and the external audits came out on top, followed by the environmental policy. The results support the findings in the literature with respect to documentation and the audit process. The results showed that documentation came out on top because it was seen as being laborious and sometimes redundant, especially for organizations that had already established other management systems like ISO 9001 prior to adopting ISO 14001.

With respect to the external audits, concerns included its frequency (too often), its cost, and the potential to expose organizations to legal enforcement prematurely, especially when conducted in the early stages of the implementation of the standard. The standard does not stipulate when exactly the audit should be done and how often, and so the issues mentioned here with the exception of cost may have arisen from the directives given to the organizations by the third 
party auditors for the certification process. The environmental policy on the other hand was found to be almost always generic and not read by most of the employees, and as such did not provide much value to the organization. Despite these concerns, the majority of the participants were satisfied with the requirements and features of the standard. On the other hand, outside of the requirements of the standard, a good number of participants had general issues with the standard. Some of the issues included, problems interpreting the standard coupled with conflicting interpretations by registrars, the implementation and maintenance of the standard was found to be time consuming, the standard was found to become non-useful after a while, and some requirements were found to be redundant because other standards were being used or because of government regulations, for example legal and other requirements and emergency preparedness and response, with the latter already being stipulated by law. The standard was also said to be too broad and not prescriptive enough in some areas, and did not provide any control for the environmental department as they had to rely on other departments to fulfill some of the requirements. The findings of this study with respect to the standard being too general and not prescriptive enough and the problem of interpreting the standard is also in support of the literature in which the same issues were reported. The findings also indicate that some of the requirements of the standard may be limited in terms of their ability to support learning and may depend on how they are implemented by the organization. For instance, the results showed that most employees do not read the environmental policy and as such, it may not be able to foster a shared vision as suggested in the literature.

A secondary focus of this research study was also to better understand what other standards/management systems were being used by organizations in North America, and if the organizations had integrated such systems/standards. The results suggested that the quality management system (mainly ISO 9001) was the most widely used followed by the occupational health and safety management system (mainly OHSAS 18001). Other management systems/standards that were used by participating organizations included ISO 50001 (Energy Management), ISO/TS 16949 (quality management specific to automotive industry and service parts), ISO 17025 (for laboratories that carry out tests and/or calibrations), FSSC 22000 (food safety management system), International Safety Management (ISM) Code, Sustainable Forestry Initiative, and a few others. 
Based on the results, it appears that a good number of organizations in North America have yet to come on board in terms of integrating their management systems, as only a slight majority of those that participated had their systems integrated. Of those that had their systems integrated, an overwhelming number had their environmental management system integrated with their quality management system while a moderate number had their environmental management system integrated with their occupational health and safety management system. The results also suggested that organizations that had adopted other standards, especially ISO 9001 before the ISO 14001 standard found it easier to implement ISO 14001 and that those standards may have also contributed in one way or the other to the learning process of the organization before ISO 14001 was brought on. With respect to other facilitators of learning, the results also indicate that environmental regulations may also play a role in this regard.

\subsection{Research Limitations}

This research study was not without limitations. First, the research did not measure organizational learning directly, and instead focused on the perceptions of respondents within organizations concerning the use of the ISO 14001 standard and software to address the identified four learning constructs. Second, the fact that non probability sampling was used to obtain the sample frame, coupled with the low response rate obtained means that one has to be very careful when generalizing the results. Also, because only one respondent per organization was surveyed, an in depth picture on the subject matter as it pertains to the entire organization may not have been obtained. Again, since the Likert scale was used, the results obtained are more likely to be the subjective opinions of the representatives of the organizations. Finally, being a cross sectional study it was not possible to determine how the ISO 14001 standard and EMS-based software may influence learning over a long period of time.

\subsection{Recommendations for Future Research}

In some ways, the aforementioned limitations of the current study lead to identification of opportunities for possible future research on this topic. For instance, the use of a longitudinal approach as well as case studies would allow for a more in depth analysis as to how the standard and EMS-based software might affect learning on a long term basis, and choosing a specific 
EMS-based software product and investigating its capability via case studies might be a research area of interest.

Also, further research on how the ISO 14001 standard and EMS-based software may facilitate learning could be conducted using the concepts put forward by DiBella and Nevis, (1998), Nonaka, Toyama, et al. (2001), and Nonaka, Reinmoller, et al. (2001). For example, conducting case studies to determine whether the standard and software have the ability to enhance some or all of the learning orientations of an organization (e.g., knowledge reserve, dissemination mode, etc.) or act as facilitating factors (e.g., continuous education, performance gap, concern for measurement) and thus enhance learning, and whether the standard and software have the ability to assist with the knowledge creation process, be it assisting with the knowledge conversion process (SECI process), or acting as and/or creating $b a$, or assisting with the development of the organization's knowledge assets, or all three layers combined. Studies could also attempt to investigate whether the standard and EMS-based software can act as a barrier to learning as suggested in the literature. Again, further research could also be undertaken using longitudinal studies or case studies in order to determine whether there is any difference in the pace of learning (brought about by the standard or software) between private and public organizations because based on the literature, public organizations are said to be poor at learning.

Further research could also be conducted to investigate the standard's ability to influence learning based on the size of the organization and industry sector. With respect to the size of the organization, this is based on the assumption that the standard may be able to facilitate the four constructs more effectively in a small organization. Research could also try to determine at what stage of implementation does the standard influence the four constructs the most if at all. This is based on the assumption that it may do so at the initial stages of its implementation and the fact that the findings of this study indicate that the standard could become non-useful once it becomes mature. The requirements of the standard that may play a major role in influencing learning could also be investigated.

With respect to the functionality of EMS-based software, further research could try to understand why such products are not compatible with public sector organizations, and to provide a solution 
to whatever issues where discovered. Also, further research could attempt to understand what factors are likely to influence the adoption of EMS-based software. The adoption of EMS-based software could be dependent on the industry sector of the organization, whether the organization is privately or publicly owned, the size of the organization, whether or not the organization has an integrated management system, and the length of time the organization has been registered to the standard.

Finally, this study highlights the fact that no comprehensive database of organizations that have their EMS certified to the ISO 14001 standard in North America exists. The establishment of such a database could be championed by the developers of the standard. This will enable probability sampling to be undertaken.

\subsection{Research Implications}

First, by providing background information regarding environmental management systems and the widely adopted ISO 14001 standard, this research study provides information as to how such systems/standards can be of benefit to an organization and in the long run to the environment. By providing an overview of the success factors, challenges and limitations of the standard, organizations that are contemplating adopting the standard will be better equipped to do so. Such information may also be useful to organizations that have already adopted the standard.

Second, by providing an overview on the subject of organizational learning, the study also provides insights to practitioners with respect to promoting learning in an organization and why it is important to implement or enhance learning processes within an organization bearing in mind the fact that it could offer an organization a sustainable competitive advantage and increased financial performance. In all, organizations will be in a better position to know which strategies enhance learning and those to avoid in order not to hinder learning.

Third, the study provides a broader view (both from a theoretical and empirical point of view) on the role that the ISO 14001 standard can play within an organization with respect to learning and related issues. In other words, the study provides insights regarding the ability of the standard to facilitate learning and in turn improve performance. With this in mind, organizations can go 
beyond compliance and use the standard as a means to improve their internal capabilities and in turn enhance their competitive advantage. This could be through the development of new technologies, or the development of green products, or the improvement in internal processes. In all, this will enable the organization reduce its environmental impact and ultimately lead to the protection of the environment.

Fourth, the study provides further insights regarding the success factors and challenges as it pertains to the requirements/elements of the standard. This will be of use to the developers of the standard as well as to organizations that are in the initial stage of implementing the standard. Organizations that use the standard will be in a better position to focus their energies on the most important factors that will enable them to successfully implement and maintain the standard. The study also sheds some light on the benefits and trends with respect to the integration of environmental management systems and other management systems, which could be of benefit to organizations that have implemented more than one management system.

Fifth, the study has also provided some insight as to the capabilities of EMS-based software in terms of its ability to support the ISO 14001 standard, and the strengths and limitations that such software products may have as well as some suggestions for improvement in order to make them more user friendly for users of the standard. This contribution will of no doubt be of importance to users of such software products and to the manufacturers alike. Also, it could be said that the study served as a means to communicate the existence of EMS-based software to a range of respondents that currently do not use such software products. This research study also highlights the fact that EMS-based software has the potential to facilitate learning and thus can be viewed as a means to facilitate learning in an organization.

Finally, the study provided support for the existing limited research that is currently available regarding the ability of the ISO 14001 standard and EMS-based software to promote learning, and the role that EMS-based software could play in the field of environmental management. 


\section{Appendix A: Research Instrument and Ethical Approval}

\section{A.1 Questionnaire}

Management System Standards, Management Systems Software, and Organizational Learning: Making the Connections

Dear Participant,

Thank you for agreeing to participate in this survey. We estimate that it should take you about thirty minutes to complete the survey.

This survey (fillable form) is organized into four sections (A through D), which consist of openended and closed-ended questions.

In section A we ask questions intended to assist us in understanding whether environmental management systems standards are capable of assisting you and your organization in learning.

In section B we ask questions intended to assist us in understanding whether environmental management systems software is capable of assisting you and your organization in learning. If your organization does not use this type of software, then you can skip this section.

In section $\mathrm{C}$ we ask questions intended to assist us in understanding whether environmental management systems software has the necessary features or characteristics to assist you and your organization with the implementation and maintenance of environmental management systems standards. If your organization does not use this type of software, then you can skip this section.

In section D we ask questions with respect to you the participant (Table D1) and your organization.

Although the ISO 14001 environmental management system standard is the focal point of interest for this project, we have two questions that invite you to comment on your experience with other management systems standards (if applicable).

For this study the following respective definitions are relevant:

"A learning organization is an organization skilled at creating, acquiring, and transferring knowledge, and at modifying its behavior to reflect new knowledge and insights" (Garvin, 1993, p. 80).

"Organizational learning is the set of actions (knowledge acquisition, information distribution, information interpretation, and organizational memory) within the organization that intentionally and unintentionally influence positive organizational change" (Templeton, Lewis and Snyder, 2002, p. 189). 
We kindly request that the completed questionnaire be returned via email to the investigator two (2) weeks after you received it. If you prefer, the investigator can contact you and administer the survey by telephone. If you have any questions about this survey, please contact:

\author{
Randolph Ibe \\ PhD Candidate \\ Environmental Applied Science and Management \\ Ryerson University \\ 6479902609 \\ ribe@ryerson.ca
}

Please use the scale below when responding to questions in Section A and B.

\begin{tabular}{ccccc}
\hline 1 & 2 & 3 & 4 & 5 \\
Strongly Disagree & Moderately Disagree & Undecided & Moderately Agree & Strongly Agree \\
\hline
\end{tabular}

\title{
Section A
}

The following questions relate to the ISO 14001 environmental management systems standard and organizational learning. If your organization also uses standards other than ISO 14001, please ensure to answer questions $8 \& 9$ in section D. (Please check the appropriate box for each question using the scale provided)

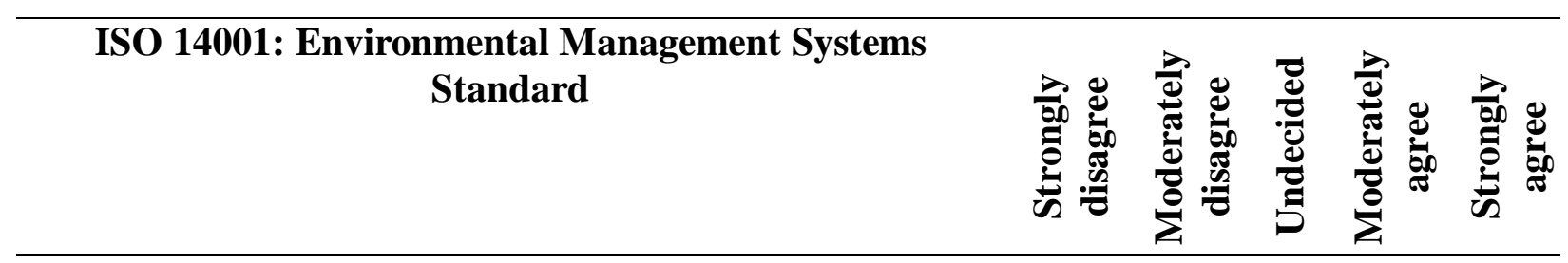

\section{Information Acquisition}

1a. I find that the standard assists me in my ability to acquire useful environmental information that applies to the organization. For example, the ISO 14001 requirement concerning internal audits is one way in which the standard has stimulated me and my organization to acquire useful environmental information.

1b. If you are of the opinion that the standard leads to improved acquisition of useful information, could you comment on how this improvement affected organizational learning that influenced performance within your organization? For example, I found that the feedback from internal audits helped me gain knowledge about or identify barriers to performance improvement of an environmental program, that were then removed. 


\section{Information Dissemination}

2a. The standard assists me in my ability to disseminate (distribute) useful environmental information within the organization and beyond, in the form of policies, procedures, best practices, etc. For example, the ISO 14001 requirement concerning internal and external communication is one way that the standard stimulated me and my organization to engage in information dissemination.

2b. If you are of the opinion that the standard leads to improved dissemination of useful information, could you comment on how this improvement affected organizational learning that influenced performance within your organization? For example, I found that an improvement in the distribution of environmental information through policies, newsletters, intranet sites, etc. lead to an improvement in environmental knowledge of employees and thus enhanced environmental performance.

Information Interpretation (Here "information interpretation" refers to when members of an organization develop a consensus on the meaning of information disseminated to them)

3a. The standard assists me and my colleagues in our ability to analyze and interpret useful environmental information that applies to the organization. For example, the ISO 14001 requirement concerning education and training is one way in which the standard stimulated me and my organization to engage in information interpretation.

3b. If you are of the opinion that the standard leads to improved analysis and interpretation of useful information, could you comment on how this improvement affected organizational learning that influenced performance within your organization? For example, I found that an improvement in information interpretation lead to a better understanding of environmental issues and enhanced cooperation among employees.

\section{Organizational Memory}

4a. The standard assists me in archiving (storing) relevant environmental data and information about the organization for current and future referencing. For example, the ISO 14001 requirement concerning documentation and document control is one way in which the standard stimulated me and my organization to store useful information.

4b. If you are of the opinion that the standard leads to improved storage of useful information, could you comment on how this improvement affected organizational learning that influenced performance within your organization? For example, I found that improved procedures for the storage of information helped to ensure that useful environmental information was retained on a long-term basis, thereby enhancing the ability of employees 
to inform themselves on environmental matters and act in a more consistent and efficient manner over the long term.

\section{Functionality of the Standard}

1(a.) What would you say is the most helpful feature/requirement of the ISO 14001 standard?

(b.) Please could you briefly explain why you found this feature/requirement most helpful?

2(a.) What would you say is the least helpful feature/requirement of the ISO 14001 standard?

(b.) Please could you briefly explain why you found this feature/requirement least helpful?

\section{Section B}

The following questions relate to management systems software and learning. If your organization does not use software for ISO 14001 please move on to section D. (Please check the appropriate box for each question using the scale provided)

\section{Software for ISO 14001}

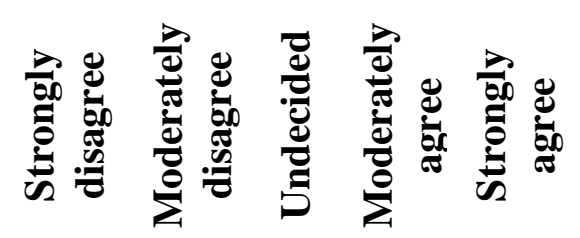

\section{Information Acquisition}

1a. I find that the software assists me in my ability to acquire or collect useful environmental information that applies to the organization in the form of documents, data, diagrams, etc.

1b. If you are of the opinion that the software leads to improved acquisition of useful information, could you comment on how this improvement affected organizational learning that influenced performance within your organization? For example, I found that managers are better equipped with information required to manage environmental risks or compliance given the fact that the software enabled such information to be collected quickly and more efficiently.

\section{Information Dissemination}

2a. I find that the software assists me in my ability to disseminate (distribute) useful environmental information within the organization and beyond. For instance, the software may have a communication tool for this task.

2b. If you are of the opinion that the software leads to improved dissemination of useful information, could you comment on how this improvement affected organizational learning that influenced performance within your organization? 


\section{Information Interpretation}

3a. The software assists me in my ability to analyze and interpret the useful environmental information collected. For instance, this could be done through the use of basic statistical and graphical

tools.

3b. If you are of the opinion that the software improved your ability to analyze and interpret the useful information, could you comment on how this improvement affected organizational learning that influenced performance within your organization?

\section{Organizational Memory}

4a. The software provides a mechanism that assists me with the archiving (storage) of relevant environmental data and information about the organization. For instance, the software could have a central library/database system that assists with this task

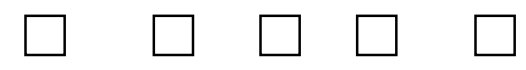

4b. If you are of the opinion that the software leads to improved storage of useful information, could you comment on how this improvement affected organizational learning that influenced performance within your organization?

\section{Section C}

The following questions relate to the ability of management systems software to assist you with the implementation and maintenance of the ISO 14001 management systems standard. If your organization does not use software for ISO 14001 please move on to section D. (Please select Yes or No from the drop down menu).

\section{ISO 14001: Environmental Management Systems Standard}

\section{Documentation and Document Control}

1. I find that the software provides helpful templates that assist me in my ability to develop documents outlining procedures, policies, etc as part of the ISO 14001

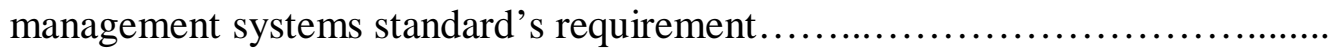

2. I find that the templates can be customized to fit with the documentation requirements of the ISO 14001 standard.

3. The software assists me in my ability to create ISO 14001 related documents from scratch, in other words, without the use of templates.

4. The software assists me in my ability to integrate existing ISO 14001 related documents that were created using different programs such as Microsoft word, PDF, etc

5. The software has a document management function that assists me in my ability to review ISO 14001 related documents

6. The software assists me in my ability to easily locate documents that were created as part of the ISO 14001 management systems standard's requirements...

7. The software provides a central library system for documents generated as part of the ISO 14001 management systems standard's requirements 


\section{Data compilation and report preparation}

8. The software has tools that assist me in my ability to analyze environmental data (note: the tools may be statistical in nature).

9. The software has tools that assist me in my ability to prepare graphical reports to determine for example, trends in environmental performance.....

10. The software has tools that assist me in my ability to prepare reports in the format required by environmental regulators and other government agencies......

Milestone /task management and tracking

11. The software has a calendar function that assists me and my colleagues in our ability to track environmental management system upcoming events (e.g., management tasks, deliverables, etc.).

12. The software has a management tool that delivers automated reminders or notifications (e.g., reminders of permit requirements, tasks and deadlines)

Gap analysis tool

13. The software has tools that assists me in my ability to assess the environmental management system against the requirements of the ISO 14001 standard........

Audit component/tools

14. The software includes information that assists auditors in their ability to verify conformance to the audit criteria in the ISO 14001 standard.

Training management

15. The software has a tool that assists me in my ability to manage training requirements as part of the ISO 14001 management systems standard's requirement.

16. The software has a tool that assists me in my ability to manage training records as part of the ISO 14001 management systems standard's requirement

Context specific text

17. The software uses the ISO 14001 management system standard's language.

18. The software has direct references to the ISO 14001 standard's relevant elements.

Integrated system capability

19. The software allows for the integration of several management systems/standards

Management involvement

20. I find that the software helps engage top management with the ISO 14001 management system standard through ease of access or reporting.

Compliance

21. The software assists me in my ability to meet the terms of the ISO 14001 standard.

Aspect/Impact analysis tool

22. The software has an aspect/impact analysis tool that assists me in my ability to identify, rank and prioritize the organization's significant environmental aspects and impacts as part of the ISO 14001 management systems standard's requirements..........................................................

1 (a.) What would you say is the most helpful feature of the software in terms of its ability to assist you in meeting the requirements of the ISO 14001 standard? 
(b.) Please could you briefly explain why you found this feature most helpful?

2 (a.) In your opinion what is the least helpful feature of the software in terms of its ability to assist you in meeting the requirements of the ISO 14001 standard?

(b.) Please could you briefly explain why you found this feature least helpful?

3. In terms of the software's ability to assist you in meeting the requirements of the ISO 14001 standard, please briefly elaborate on any changes/improvements you think would assist you in making the software more functional for you and your organization

4. In your opinion, how easy or difficult was it to implement the software for the ISO 14001standard?

5. In your opinion, has the software paid for itself in terms of your ability to meet the requirements of the ISO 14001 standard. If yes, can you provide a rough estimate of how long it took for the software to pay for itself?

\section{Section D}

Table D1

\begin{tabular}{|c|c|c|c|c|c|c|}
\hline 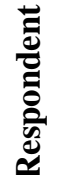 & Age & Gender & $\begin{array}{l}\text { Level of Education } \\
\text { (e.g., BSc., MSc., etc.) }\end{array}$ & $\begin{array}{l}\text { Years with } \\
\text { organization }\end{array}$ & Current position & $\begin{array}{l}\text { Length of time in } \\
\text { current position }\end{array}$ \\
\hline 1. & & & & & & \\
\hline
\end{tabular}

(We request your age and gender as they can reveal one's preference to use software and management system standards as well as to learn.)

1. How many years has your organization been in operation?

2. Industry sector

3. Private or Public sector

4. Size of the organization (Small, medium or large)

5. Number of years this organization has been registered to ISO 14001. Note: If the organization's certification has expired or the organization has never been registered to the standard but uses it as a guide to implement and maintain its environmental management system, please indicate whichever is the case, and the length of time it was registered to or used the standard

6. Name of management system software this organization currently uses for ISO 14001 
7. How long has this organization been using management systems software for ISO 14001 ?

8. (a) Does your organization use any other management system standards other than ISO 14001 ? If yes, which standards do you use and how long have you been using them?

(b) Do you use software to implement such standards? If yes, which software and how long have you been using them?

9. Do you have an integrated management system? If yes, which management systems are integrated?

10. Other comments

Thank you for your participation! 


\section{A.2 Proof of Ethical Approval}

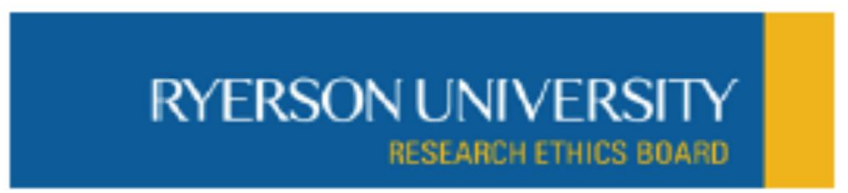

To: Randolph Onyema tbe

Environmental Applied Science and Management

Re: REB 2011-282: Management System Standards, Management Systems Software, and Organizational Learning \& Performance: Making the Connections

Date: October 7, 2011

\section{Dear Randolph Onyema Tbe,}

The review of your protocol REB File REB 2011-282 is now complete. The project has been approved for a one year period. Please note that before proceeding with your project, compliance with other required University approvals/certifications, institutional requirements, or governmental authorizations may be required.

This approval may be extended after one year upon request. Please be advised that if the project is not renewed, approval will expire and no more research involving humans may take place. If this is a funded project, access to research finds may also be affected.

Please note that RBB approval policies require that you adhere strictly to the protocol as last reviewed by the REB and that any modifications nust be approved by the Board before they can be implemented. Adverse or unexpected events must be reported to the REB as soon as possible with an indication from the Principal Investigator as to how, in the view of the Principal Investigator, these events affect the continuation of the protocol.

Finally, if research subjects are in the care of a health facility, at a school, or other institution or community organization, it is the responsibility of the Principal Investigator to ensure that the ethical guidelines and approvals of those facilities or institutions are obtained and filed with the REB prior to the initiation of any research.

Please quote your REB file mumber (RBB 2011-282) on future correspondence.

Congratulations and best of luck in conducting your research.

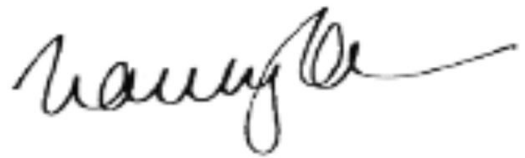

Nancy Walton, Ph.D.

Chair, Research Ethics Board 


\section{Appendix B: Survey Data and Results}

\section{B.1 Survey Data}

\section{Table B.1 List of job titles of participants for this study}

\begin{tabular}{|c|c|}
\hline \multicolumn{2}{|c|}{ Job Title/Positions of Participants } \\
\hline AVP Environmental Affairs & Quality and Safety Administrator \\
\hline Chief Sustainability Officer & Quality \& Compliance Manager \\
\hline Compliance Manager & Quality Engineer \\
\hline Compliance Officer & Quality Manager \\
\hline Coordinator in Environmental Accounting & Quality/Environment/Technical \\
\hline Coordinator, Environment \& Licenses & Regulatory Compliance Coordinator \\
\hline Corporate Safety Director & Safety, EMS-ISO Administrator \\
\hline Director of Environmental Services & Safety \& Environmental Program Manager \\
\hline Director of Quality & Sales \\
\hline Director, Environment & Senior Advisor Environmental Strategy \\
\hline Director, Health and Safety & Senior Environmental Specialist \\
\hline Director, Quality \& EHS & Senior Strategist \\
\hline Director, Quality and Environment & Senior Analyst HSE Reporting \\
\hline ISO Engineer & Senior Manager Sustainability \\
\hline EHS Administrator & Special Projects Manager \\
\hline EHS Coordinator & Senior Quality Engineer/EMS Team Leader \\
\hline EHS Director & Superintendent, Analytical Services \\
\hline EHS Engineer & Manager, Quality and Environment \\
\hline EHS Leader & Technical Services Superintendent \\
\hline EHS Manager & ISO/Safety Assistant Manager \\
\hline EMS Coordinator & Vice President - EHS \\
\hline Environmental Coordinator & Vice President, Marine Operations \\
\hline Environmental Leader & Manufacturing/Project Engineering \\
\hline Environmental Manager & Project Manager \\
\hline Environmental Program Officer & QEHS Manager \\
\hline Environmental Superintendent & Manager, Environmental Control \\
\hline Group IMS Coordinator & Manager, Environmental Programs \\
\hline Head, Safety \& Technology & Manager, Forestry and Environment \\
\hline HSE Specialist & Team Coordinator - Sustainability Mgmt. \\
\hline $\begin{array}{l}\text { Director, Regulatory Compliance \& } \\
\text { Environment/Safety \& Planning, performance } \\
\text { \& Learning }\end{array}$ & \\
\hline
\end{tabular}


Table B.2 Industry sector based on raw data and number of organizations

\begin{tabular}{|l|c|}
\hline \multicolumn{1}{|c|}{ Industry Sector } & Number of Organizations \\
\hline Aerospace & 3 \\
\hline Aluminium Rolling and Recycling & 1 \\
\hline Aviation & 1 \\
\hline Chemical & 3 \\
\hline Utilities (Electricity and gas) & 5 \\
\hline Engineering Consulting and Testing & 1 \\
\hline Fisheries & 1 \\
\hline Food (Meat Processing) & 1 \\
\hline Forestry & 5 \\
\hline Higher Education & 1 \\
\hline Iron and Steel & 5 \\
\hline Manufacturing (various) & 28 \\
\hline Marine Industrial & 1 \\
\hline Maritime (Engineering and Transportation) & 1 \\
\hline Military Defense & 1 \\
\hline Mining & 1 \\
\hline Municipal Government & 2 \\
\hline Nanotechnology & 1 \\
\hline Nuclear & 2 \\
\hline Oil and Gas & 1 \\
\hline Public Transit & 2 \\
\hline Pulp and Paper & 3 \\
\hline Solid Waste Management (Landfill \& Compost) & 1 \\
\hline Transportation & 3 \\
\hline Waste Treatment and Disposal & 1 \\
\hline Water and Wastewater Treatment & 1 \\
\hline
\end{tabular}

Table B.3 NAICS industry sector and number of organizations

\begin{tabular}{|l|c|}
\hline \multicolumn{1}{|c|}{ Industry Sector } & Number of Organizations \\
\hline Manufacturing (31-33) & 47 \\
\hline Utilities (22) & 9 \\
\hline Transportation and Warehousing (48-49) & 7 \\
\hline Mining, Quarrying, and Oil and Gas Extraction (21) & 6 \\
\hline Agriculture, Forestry, Fishing and Hunting (11) & 1 \\
\hline Educational Services (61) & 2 \\
\hline $\begin{array}{l}\text { Administrative and Support, Waste Management and Remedial } \\
\text { Services (56) }\end{array}$ & 1 \\
\hline Public Administration (91) & 1 \\
\hline Professional, Scientific and Technical Services (54) & 1 \\
\hline
\end{tabular}


Table B.4 Other management systems/standards used by participating organizations

\begin{tabular}{|l|c|}
\hline \multicolumn{1}{|c|}{ Management System/Standard/Voluntary Program } & $\begin{array}{c}\text { Number of } \\
\text { Organizations }\end{array}$ \\
\hline ISO 9001 (Quality Management Systems Standard) & 33 \\
\hline OHSAS 18001 (Occupational Health and Safety Management System) & 15 \\
\hline ISO 50001 (Energy Management System Standard) & 1 \\
\hline FSSC 22000 (Food Safety Management System) & 1 \\
\hline Corporate Standard & 1 \\
\hline Drinking Water Quality Management System (DWQMS) & 1 \\
\hline IOWA Environmental Management System & 1 \\
\hline OHS Certificate of Recognition & 1 \\
\hline ISO/TS 16949 (Automotive Quality Management System) & 9 \\
\hline International Safety Management (ISM) Code & 1 \\
\hline ISO 17025 (Testing and Calibration Laboratory Standard) & 3 \\
\hline Operating Management System Standard & 1 \\
\hline CNSC S-296 (Environmental Protection Policies, Programs and & 1 \\
Procedures at Class I Nuclear Facilities and Uranium Mines and Mills) & 1 \\
\hline CSA Z299.3 (Quality Assurance Program) & 1 \\
\hline AS9100 (Aerospace Quality Management System) & 1 \\
\hline Sustainable Forestry Initiative & 1 \\
\hline SAFE Companies Certification & 1 \\
\hline
\end{tabular}

Note. CNSC = Canadian Nuclear Safety Commission; CSA = Canadian Standards Association; OHS = Occupational Health and Safety

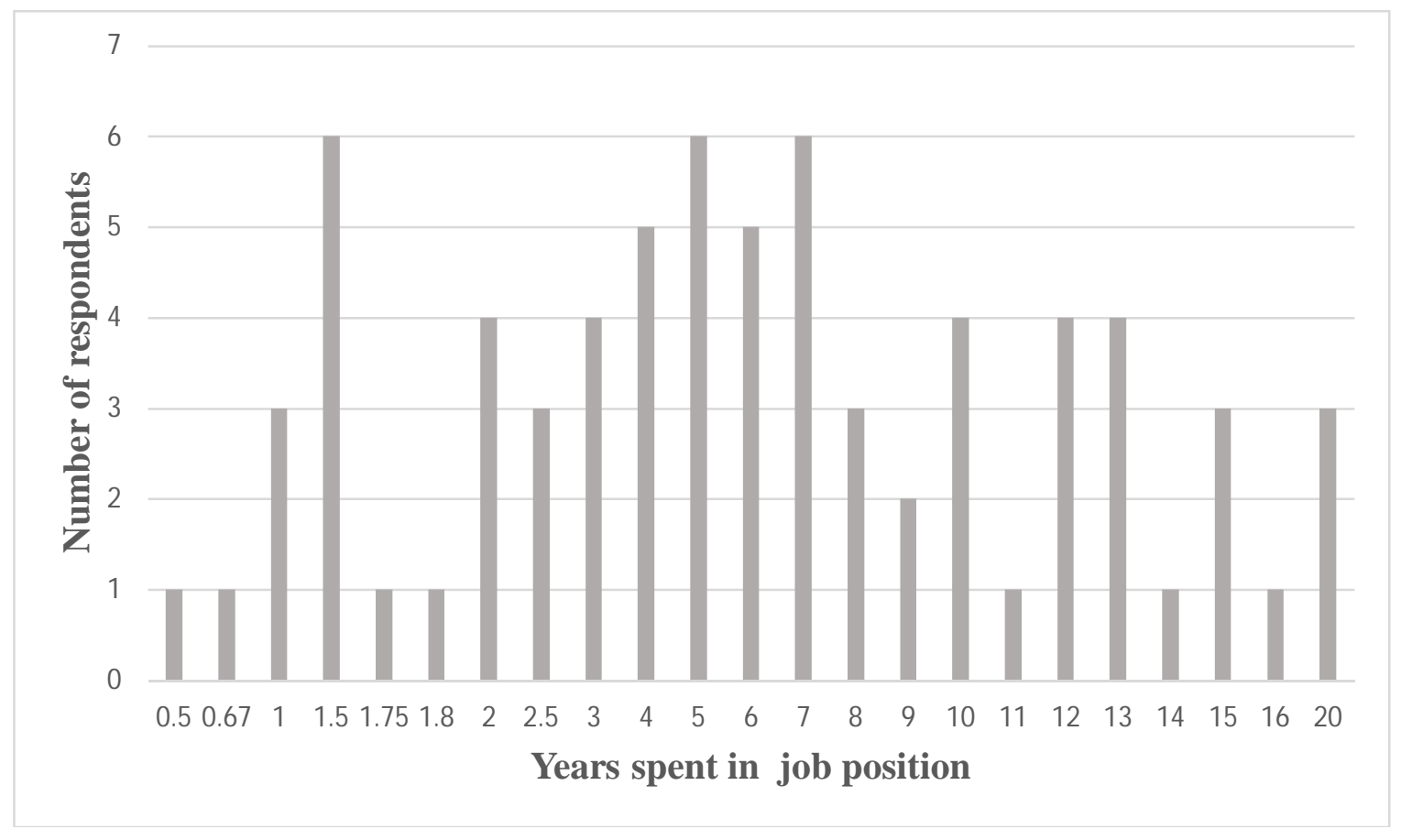

Figure B.1 Number of years spent by the respondents in their respective positions 
Table B.5 Summary statistics regarding the ability of ISO 14001:2004 standard to influence organizational learning based on industry sector using total scores

\begin{tabular}{|c|c|c|c|c|c|c|c|c|c|}
\hline & \multicolumn{9}{|c|}{ Industry Sector } \\
\hline & 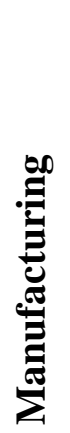 & 串 & 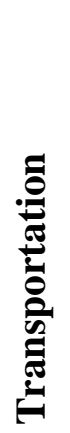 & 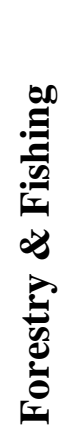 & 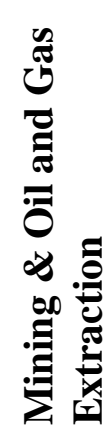 & 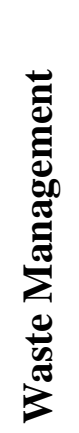 & 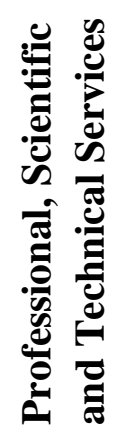 & 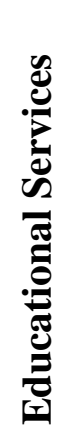 & 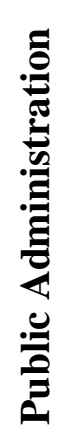 \\
\hline Agree & 41 & 9 & 6 & 4 & 1 & 2 & 1 & 1 & 1 \\
\hline Undecided & 2 & 0 & 0 & 2 & 1 & 0 & 0 & 0 & 0 \\
\hline Disagree & 4 & 0 & 1 & 0 & 0 & 0 & 0 & 0 & 0 \\
\hline Total & 47 & 9 & 7 & 6 & 2 & 2 & 1 & 1 & 1 \\
\hline
\end{tabular}


Table B.6 Summary of descriptive data of the requirements/features of the standard that were found most helpful by respondents

\begin{tabular}{|c|c|c|c|c|c|c|c|c|c|c|c|c|c|c|}
\hline \multirow[b]{2}{*}{$\begin{array}{l}\text { Requirements/ } \\
\text { Features }\end{array}$} & \multicolumn{2}{|c|}{$\begin{array}{c}\text { Private } \\
\text { and Pubic }\end{array}$} & \multicolumn{3}{|c|}{$\begin{array}{c}\text { Size of } \\
\text { Organization }\end{array}$} & \multicolumn{9}{|c|}{ Industry Sector (NAICS) } \\
\hline & 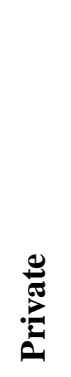 & 弟 & 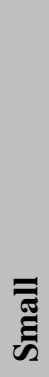 & ${ }^{\Xi}$ & 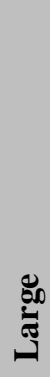 & 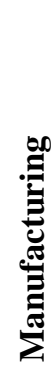 & 曷 & 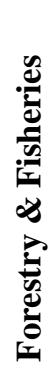 & 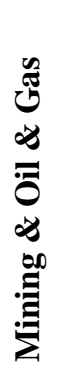 & 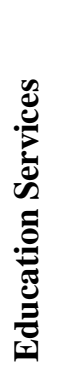 & 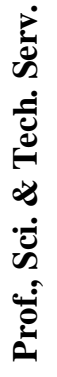 & 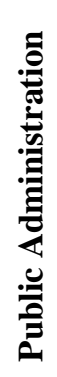 & 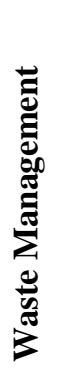 & 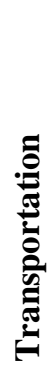 \\
\hline $\begin{array}{l}\text { Environmental } \\
\text { Aspects }\end{array}$ & 10 & 6 & 4 & 5 & 7 & 11 & 2 & - & - & - & - & - & 1 & 2 \\
\hline $\begin{array}{l}\text { Management } \\
\text { Review }\end{array}$ & 5 & 4 & 1 & 3 & 5 & 7 & 1 & - & - & - & 1 & - & - & - \\
\hline Audit & 4 & 2 & 1 & 4 & 1 & 5 & - & - & - & - & - & - & - & 1 \\
\hline $\begin{array}{l}\text { Emergency } \\
\text { Preparedness }\end{array}$ & 1 & - & - & 1 & - & 1 & - & - & - & - & - & - & - & - \\
\hline $\begin{array}{l}\text { Promote } \\
\text { Innovation }\end{array}$ & 1 & - & 1 & - & - & 1 & - & - & - & - & - & - & - & - \\
\hline $\begin{array}{l}\text { Promote } \\
\text { Learning }\end{array}$ & 1 & - & - & - & 1 & - & 1 & - & - & - & - & - & - & - \\
\hline $\begin{array}{l}\text { Systems } \\
\text { Approach }\end{array}$ & 1 & - & 1 & - & - & 1 & - & - & - & - & - & - & - & - \\
\hline $\begin{array}{l}\text { Legal and other } \\
\text { Requirements }\end{array}$ & 1 & 4 & 2 & 1 & 2 & 3 & - & - & - & - & - & 1 & 1 & - \\
\hline $\begin{array}{l}\text { Evaluation of } \\
\text { Compliance }\end{array}$ & 4 & 1 & 1 & 3 & 1 & 4 & - & - & - & - & - & - & - & 1 \\
\hline Nonconformity & 3 & 1 & - & 1 & 3 & 1 & 1 & 2 & - & - & - & - & - & - \\
\hline $\begin{array}{l}\text { Management } \\
\text { Commitment }\end{array}$ & 1 & 1 & - & 1 & 1 & 1 & - & - & 1 & - & - & - & - & - \\
\hline $\begin{array}{l}\text { Documentation } \\
\text { \& Control }\end{array}$ & 2 & 2 & 1 & 2 & 1 & 2 & - & 1 & - & - & - & - & - & 1 \\
\hline $\begin{array}{l}\text { Continual } \\
\text { Improvement }\end{array}$ & 2 & 2 & 1 & - & 3 & 2 & 1 & - & - & - & - & - & - & 1 \\
\hline $\begin{array}{l}\text { Objectives \& } \\
\text { Targets }\end{array}$ & 3 & 1 & - & 1 & 3 & 3 & - & - & 1 & - & - & - & - & - \\
\hline Planning & 2 & 1 & 1 & 1 & 1 & - & - & 1 & - & 1 & - & - & 1 & - \\
\hline Communication & 1 & 1 & - & - & 2 & 1 & - & - & - & - & - & - & - & 1 \\
\hline Implementation & 1 & - & 1 & - & - & 1 & - & - & - & - & - & - & - & - \\
\hline Policy & 1 & 1 & - & 1 & 1 & 1 & - & - & - & - & - & - & - & 1 \\
\hline $\begin{array}{l}\text { Integration of } \\
\text { Env. issues }\end{array}$ & 1 & 1 & 1 & - & 1 & 1 & - & 1 & - & - & - & - & - & - \\
\hline PDCA Cycle & 2 & 1 & 1 & 1 & 1 & 1 & 1 & 1 & - & - & - & - & - & - \\
\hline Annex A & 1 & - & - & 1 & - & 1 & - & - & - & - & - & - & - & - \\
\hline $\begin{array}{l}\text { Standardized } \\
\text { framework }\end{array}$ & 3 & 2 & - & 2 & 3 & 2 & 2 & - & - & - & - & - & - & 1 \\
\hline
\end{tabular}


Table B.7 Summary of descriptive data of the requirements/features of the standard that were found least helpful by respondents

\begin{tabular}{|c|c|c|c|c|c|c|c|c|c|c|c|c|c|c|}
\hline \multirow[b]{2}{*}{$\begin{array}{l}\text { Requirements/ } \\
\text { Features }\end{array}$} & \multicolumn{2}{|c|}{$\begin{array}{c}\text { Private } \\
\text { and Pubic }\end{array}$} & \multicolumn{3}{|c|}{$\begin{array}{c}\text { Size of } \\
\text { Organization } \\
\end{array}$} & \multicolumn{9}{|c|}{ Industry Sector (NAICS) } \\
\hline & 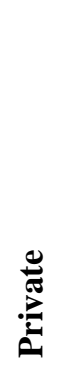 & 弟 & $\begin{array}{l}\overline{\overline{\varpi ్}} \\
\text { ซี }\end{array}$ & 䍖 & 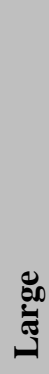 & 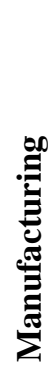 & 总 & 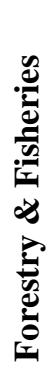 & 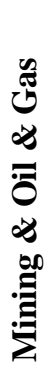 & 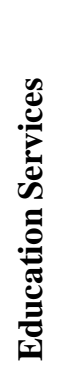 & 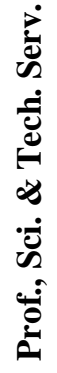 & 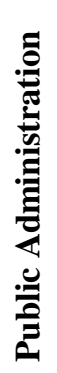 & 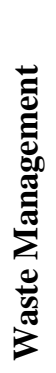 & 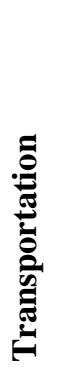 \\
\hline Documentation & 3 & 3 & 1 & 2 & 3 & 5 & - & - & - & - & - & - & - & 1 \\
\hline Policy & 4 & 1 & - & 1 & 4 & 4 & 1 & - & - & - & & - & - & - \\
\hline External Audit & 5 & 1 & 1 & 2 & 3 & 4 & 1 & - & - & 1 & - & - & - & - \\
\hline $\begin{array}{l}\text { Legal \& other } \\
\text { Requirements }\end{array}$ & 1 & 1 & - & 1 & 1 & 1 & - & 1 & - & - & - & - & - & - \\
\hline $\begin{array}{l}\text { Evaluation of } \\
\text { Compliance }\end{array}$ & 1 & 1 & 1 & - & 1 & 1 & - & - & 1 & - & - & - & - & - \\
\hline $\begin{array}{l}\text { Control of } \\
\text { Documents }\end{array}$ & 2 & 1 & & 2 & 1 & 2 & - & 1 & - & - & - & - & - & - \\
\hline $\begin{array}{l}\text { Operational } \\
\text { Control }\end{array}$ & 1 & - & 1 & - & - & - & - & - & - & - & - & - & 1 & - \\
\hline $\begin{array}{l}\text { Control of } \\
\text { Records } \\
\end{array}$ & 2 & - & - & 2 & - & 1 & - & 1 & - & - & - & - & - & - \\
\hline $\begin{array}{l}\text { Management } \\
\text { Review }\end{array}$ & 1 & - & - & - & 1 & 1 & - & - & - & - & - & - & - & - \\
\hline $\begin{array}{l}\text { Environmental } \\
\text { Aspects }\end{array}$ & 1 & - & 1 & - & - & 1 & - & - & - & - & - & - & - & - \\
\hline $\begin{array}{l}\text { Objectives \& } \\
\text { Targets }\end{array}$ & 3 & - & 1 & - & 2 & - & 1 & 1 & - & - & - & - & - & 1 \\
\hline $\begin{array}{l}\text { External } \\
\text { Communication }\end{array}$ & - & 3 & 1 & 2 & - & 2 & - & - & - & - & 1 & - & - & - \\
\hline $\begin{array}{l}\text { Monitoring \& } \\
\text { Measurement }\end{array}$ & - & 1 & - & - & 1 & - & - & 1 & - & - & - & - & - & - \\
\hline $\begin{array}{l}\text { Emergency } \\
\text { Preparedness }\end{array}$ & 1 & 1 & - & - & 2 & 1 & 1 & - & - & - & - & - & - & - \\
\hline Resources & 1 & - & - & 1 & - & 1 & - & - & - & - & - & - & - & - \\
\hline
\end{tabular}

Note . Prof., Sci. \& Tech. Serv. = Professional, Scientific and Technical Services

\section{B.2 Results}

\section{B.2.1 ISO 14001:2004 as a facilitator of Organizational Learning and in turn}

\section{Environmental Performance}

\section{B.2.1.1 ISO 14001:2004 and Information Acquisition}

In all, 49 respondents provided responses with respect to the following question: If you are of the opinion that the standard leads to improved acquisition of useful information, could you 
comment on how this improvement affected organizational learning that influenced performance within your organization? The main themes, especially as it concerns learning mechanisms/conditions are outlined below. The results regarding the improvements in performance are also presented.

\section{Improvement in knowledge, awareness, and understanding of employees}

The standard, by facilitating and improving the acquisition of information enabled the organizations to improve on the environmental knowledge, awareness, and understanding of its employees regarding elements of the environmental management system such as their environmental aspects and impacts as well as on environmental knowledge on the whole. According to two respondents, the acquisition of information and the subsequent improvement in awareness and knowledge was made possible through the measurement of key parameters and the internal and external audits. The internal and external audits were said to help identify problem areas and their possible solutions as well as opportunities for improvement and continuous learning. According to another respondent, the standard has helped us to improved [sic] the environmental awareness and the knowledge of environmental aspects at each level of the organisation. The completion of an exhaustive risk assessment, the enforcement of formal procedures and the review of the applicable regulations, all required by the standard, have lead [to] the acquisition of environmental information.

\section{Improvement in training}

The information that was acquired enabled organizations to understand their training needs and thus improve on their training strategies, and to develop appropriate training for employees. One respondent said that the information acquired was used to determine the appropriate training for their plant level production personnel. 


\section{Ensured that they were up-to-date with relevant information}

The standard by facilitating the continuous acquisition of information was said to enable organizations to remain up to date on areas within and outside of the environmental management system such as best manufacturing practices and techniques, and federal, state and local laws. This was said to be achievable through for example the legal and other requirements, and the audit requirements of the standard. One respondent stated that

in addition to the example provided (internal audits), there are several other ways that ISO 14001 requirements support the acquisition of useful information. The external audits provide useful information that is brought to us by evaluating our programs with unbiased eyes, and the requirement to periodically review legal and other requirements and the EMS documents themselves provide an opportunity for frequent review to ensure that information remains current and relevant.

\section{Facilitated a structured and systems approach to environmental management}

The implementation and maintenance of the standard was observed to not only prompt the organizations to collect information, but to do so in a structured manner which lead to the organizations improving their approach to data collection and analysis as well as in dealing with environmental issues altogether. This was said to be achieved through the planning requirement, which prompted them to take a proactive rather than reactive approach. In fact, one respondent stated that before they adopted ISO 14001 their approach to environmental issues was not proactive, but rather based on failure. Also, respondents were of the opinion that information and knowledge which they may have overlooked if they did not adopt the standard was brought to light because of this structure. The information and knowledge collected was said to be used to ensure conformance to the standard and for continuous improvement. According to respondents, in the process of acquiring information, the standard prompted them to adopt a systems approach to environmental management; in fact, two respondents were specific in saying that the standard forced them to examine all areas of their organization. An environmental management systems coordinator in the automotive industry said that the standard "forced us to look at all aspects of our operations. In doing that we were able to optimize [our] inputs, activities, and outputs in 
order to reduce risk[s], costs, and redundancy [sic]." Another respondent stated that "the standard directs you to address the elements which usually makes you think of all parts of your business that should be better managed." The adoption of a systems approach was said to in turn lead to an improvement in information acquisition.

\section{Improvement in accountability}

According to a respondent, the ISO 14001 standard, by prompting the continuous collection of information was said to not only keep the organization structured but also to keep employees accountable. The respondent did not provide an example of a requirement that may have assisted with this.

\section{Improvement of environmental performance and overall processes in general}

Through the standard's requirements such as the environmental aspects and the emergency preparedness and response, feedback from respondents suggested that some organizations were prompted to collect information and knowledge as to what their operational risks were and what emergency response techniques applied to their operations. The information was then used to improve areas of their environmental management system such as their procedures and work practices, and emergency response procedures, and to implement the use of environmental indicators, which helped monitor and evaluate their environmental performance. Also, by prompting organizations to collect and trend data regarding their consumption of natural resources, the responses suggested that some organizations were able to use the information to determine opportunities for further improvement. The responses obtained also suggest that through the legal and other requirements component of the standard, some organizations were prompted to identify and collect useful information which enabled them to improve on their performance with respect to environmental compliance. Also, two respondents mentioned that the standard prompted them to undertake research leading to the acquisition of information which in turn enabled them to better understand who their stakeholders were and how the organization's activities, products and services affect the environment. This was said to lead to a change in their way of thinking or mental models with respect to environmental issues and on how to be better environmental stewards. 
Twelve respondents also mentioned specifically that the improvement in the acquisition of information led to an improvement in the overall environmental performance of the organization. Respondents made mention that through the establishment of smart goals, objectives and targets, the audit process, the identification of environmental aspects and impacts, the identification of legal requirements, the feedback from internal and external stakeholders, and the use of the PDCA model, they were able to obtain useful information and knowledge and thus improve their learning processes. This was said to translate into an improvement in areas such as employee participation, legal compliance, environmental programs, and a reduction of the impacts of their organization's activities, products, and services. In fact, one respondent mentioned how information obtained from stakeholders enabled them mitigate noise issues they had, while another stated how through the acquisition of information regarding their organization's environmental aspects and impacts, and the subsequent establishment of objectives and targets, they were able to take care of the noise and air quality issues of their stamping operation, undertake proper disposal of their liquid industrial waste, and undertake waste audits for their solid wastes. Another respondent also mentioned that they were able to reduce the cost of their freight transportation through packaging consolidation, which translated to less truck traffic on the roads, and hence a reduction in their organization's contribution to carbon dioxide pollution. This improvement according to the respondent was also made possible because of management's involvement, which was brought about by the implementation and maintenance of the standard.

\section{B.2.1.2 ISO 14001:2004 and Information Dissemination}

Fifty-six (56) respondents provided feedback with respect to the following question: If you are of the opinion that the standard leads to improved dissemination of useful information, could you comment on how this improvement affected organizational learning that influenced performance within your organization? The main themes, especially as it concerns learning mechanisms/conditions are outlined below. The results regarding the improvements in performance are also presented.

\section{Improvement in knowledge, awareness and understanding of staff and others}

The standard through some of its requirements was said to facilitate the distribution of information internally and externally within the organization, and in turn improve the awareness, 
understanding and knowledge of employees, suppliers and persons working on behalf of the organization such as contractors and temporary employees, and ultimately improve the environmental performance of the organization. Based on the responses received (some of which were individual comments), the distribution of information was facilitated via the distribution of policies and procedures; the organization's intranet and internet sites, and environmental information system; sustainable development reports, newsletters, and environmental bulletin boards; regularly scheduled meetings; daily review/discussion of environmental performance with employees; documentation of metrics; training for new and current employees; the internal and external audits, which were said to stimulate learning and awareness; and communication on the whole. In addition, "information related to the EMS are routinly [sic] shared with the organization through [the] Management Review process, which promotes awareness."

A few respondents were of the opinion that the improvement in the distribution of information and subsequently the improvement in understanding of environmental issues facilitated discussions amongst employees with respect to problem solving in the organization. Another respondent mentioned that they had regular meetings to review the environmental management system to include seeking opportunities for improvement and progress on corrective actions, and that the meetings served as a means to distribute information and knowledge amongst employees. It was also mentioned that "hosting training regularly for employees requires the [sic] everyone be knowledgable [sic] about environmental goals. If the standard were not in place the employee EMS training would not be held. It causes all of the employees to be more environmentally aware."

\section{Improvement in communication}

The standard was said to help organizations focus on ways to improve the dissemination of information which in turn also helped to improve communication on the whole. In fact, it was said to have "forced an evaluation of communication methods, identified methods that worked and formalized the process to communicate information." Also, the quantity and quality of their communications process was said to be enhanced by the standard. Company websites and intranet sites, and bulletin boards were some ways in which environmental activities were communicated within the organizations. A respondent mentioned that 
since the implementaion [sic] of our Environmental Management System in conformance with ISO 14001, we were able to better communicate ideas for improving the environmental conditions of our facilities. The best ideas for improvements came from maintenance staff who are close to the daily operations of our facilities. Executive staff were able to secure resources and guidance to ensure the success of our system.

\section{Improvement in employee engagement and participation}

Respondents suggested that the distribution of information within the organization encouraged the participation of more employees to include top management, in environmental initiatives and activities. According to some respondents, employee participation was seen to improve through the distribution of information via their policies and procedures, training programs for new and current employees, the organization's public websites and social media, and multi-departmental committees.

\section{Improvement in accountability}

One respondent was of the opinion that an improvement in the distribution of information helped them ensure accountability throughout the organization. The respondent mentioned that the standard ensured "accountability from senior managers, to develop strategies to meet environenmnal [sic] policy and objectives through the annual management review. Framework [standard] to identify who is responsible and accountable, at all levels of the organization."

\section{Ensured employees were up to date}

By facilitating information distribution, the standard was said to assist in informing employees of organizational changes (e.g., procedures, responsibilities), and how such changes affected the organization's operations in general. This was achieved through the establishment of policies, procedures, and work instructions as mentioned by one respondent. Such changes eventually became part of the daily activities of the organization. 


\section{Improvement in the distribution of information in general.}

In general, nineteen respondents were of the opinion that the standard through some of its requirements had the ability to facilitate the dissemination of information on the whole. One respondent mentioned that "all our major operating sites maintain and [sic] ISO 14001 registered EMS and as such we are able to share and leverage best practices in a variety of ways." Some of the requirements and features mentioned by respondents included, training and awareness, communication, management review, documentation, objectives and targets, and definition of roles and responsibilities especially for employees whose work has the potential to have an impact on the environment. As mentioned by another respondent, "because the standard forces you to use internal and external communications and monitor their effectiveness, it does help in distributing environmental information."

Outside the requirements of the standard, respondents also mentioned that the adoption of the standard prompted them to institute other processes that helped with the dissemination of information. One respondent mentioned that the implementation of key performance indicators prompted them to share the feedback obtained with top management and other employees as needed. Another mentioned that the standard prompted or motivated them to conduct walk through assessments, and to establish a management of change process which both helped with the dissemination of information. The same respondent also mentioned that the standard prompted them to create certain job positions such as production department coordinators and environmental department liaison officers that helped with the dissemination of information.

Another respondent mentioned especially how through the assistance of the standard they were able to provide the entire organization with information on hazardous waste. Besides helping with the distribution of information on the whole, it was said that "the common information from the EMS ensures that all affected individuals get the same information." This ensured that all employees especially those who have roles in terms of the environmental management system were on the same page. 


\section{B.2.1.3 ISO 14001:2004 and Information Interpretation}

Forty-five (45) responses were received with respect to the following question: If you are of the opinion that the standard leads to improved analysis and interpretation of useful information, could you comment on how this improvement affected organizational learning that influenced performance within your organization? The main themes, especially as it concerns learning mechanisms/conditions are outlined below. The results regarding the improvements in performance are also presented.

\section{Improved the knowledge, awareness, and understanding of employees}

A number of the respondents were of the opinion that the standard by facilitating the process of information interpretation, lead to an improvement in employee knowledge, awareness and understanding and in some cases to an improvement in cooperation amongst employees in terms of dealing with environmental issues. A respondent mentioned that "the standard allowed us to better understand the environmental issues related to the organization and how we impact it and can improve it."

Two respondents mentioned specifically on how training facilitated information interpretation leading to an improvement in awareness for both new and current employees, while another mentioned that the standard helped them improve awareness in general. Another respondent stated that the training requirement, the identification of aspects and impacts, and associated risks, and the management review process helped facilitate the interpretation of information, and in turn lead to an improvement in understanding with respect to best practices, legal and other requirements, and on how to reduce or control their impacts (risks). Through the stated development of understanding, they were able to make improvements in terms of how they responded to changes to regulation and internal processes; maintain a high level of compliance; improve on their communication processes; improve on their consumption of materials; and improve on their environmental performance on the whole especially as it had to do with reducing or controlling their impacts. Another respondent mentioned that through the management review process they were able to establish performance indicators, which helped them monitor their progress on a regular basis as well as determine their needs for resources. The 
standard was also said to prompt them to develop a framework and tool that assisted them in making sense of environmental information.

Other respondents went further to say that not only was there an improvement in understanding, but that employees became more engaged because they had a better understanding of environmental issues. One respondent mentioned how an improvement in understanding lead to a more supportive and willing organization especially when working on problems. Another mentioned that the engagement of employees helped them in achieving their environmental objectives and targets, and with implementing their environmental programs. A third stated that the certification process also facilitated the ongoing analysis and interpretation of information and that the identification of aspects and impacts led to the participation of top management and other employees. Another respondent mentioned that "both the environmental awarness [sic] training and the EMS meetings serve to answer questions and clear up misconceptions on environmental aspects and [other] issues. We see groups working together in teams rather than silos." Finally, another respondent stated that through the monitoring and measurement requirement employees got more involved in ensuring their organization's activity (paint production line) did not have a negative effect on the environment.

Other improvements in organizational processes and environmental performance that were due to the improvement in employee understanding and engagement included the ability to better determine and set the scope and boundary of their operations; the ability to determine and analyze trends; the ability to efficiently and quickly implement corrective actions; the ability to set the appropriate objectives and targets, which were previously lacking; improvement in the development and implementation of training programs based on the analysis of their environmental aspects; and effective development of rules and procedures that ensure staff and contractors carry out their work as required.

\section{Facilitated the development of a shared consensus with respect to terminology}

According to two respondents, by developing a shared interpretation of information, employees in different departments were able to come to a consensus with respect to things like technological terminology and their definitions. One respondent stated that "the consistency in 
definitions enables an "apples to apples" environmental comparison amongst our many divisons [sic]."

\section{Improvements in internal processes/environmental performance}

The analysis and interpretation of information undertaken during the identification and ranking of environmental aspects and impacts was said to enable members of the organization to establish the appropriate environmental programs, and the operational controls to manage their significant impacts, and to subsequently put objectives and targets in place to ensure that the controls were effective. This was also made possible due to the establishment of a dedicated team that met on a regular basis. Also, according to one respondent,

The internal audits provide a framework for not only reviewing comformance $[$ sic $]$ and compliance but also provide[s] a space for ideas interchange between auditor and auditee towards improvement and interpretacion $[\mathrm{sic}]$ of environmental aspects. The Management Review as well as External Audits are also triggers to debate and to analyze our environmental information.

Another respondent said that the improvement in how information was interpreted also led to an improvement in how information was presented to other departments such as the production department thereby enabling them to carry out their jobs in accordance with the standard and in turn meet their respective compliance goals and the overall sustainability goals of the organization.

Some respondents mentioned specifically what improvements were achieved. A respondent said that it helped them establish and implement solid waste controls at their plant, while a second respondent stated that by undertaking waste audits they were able to identify and analyze information in terms of what is to be recycled and how it is to be recycled, which allowed them to improve on their recycling process and in turn reduce the amount of garbage that was sent to the landfill. 


\section{B.2.1.4 ISO 14001:2004 and Organizational Memory}

A total of fifty-one (51) responses were obtained for the following question: If you are of the opinion that the standard leads to improved storage of useful information, could you comment on how this improvement affected organizational learning that influenced performance within your organization? The main themes, especially as it concerns learning mechanisms/conditions are outlined below. The results regarding the improvements in performance are also presented.

\section{Provision of up-to-date information through revision mechanisms}

The standard in enhancing the organization's memory was found to assist employees in ensuring that the information they acquired and the procedures that were developed thereafter could be revised and thus kept up to date. The improvement also ensured that the stored information was available to employees who needed it. This was achieved mainly through the documentation, document control, and records control requirements of the standard. One respondent stated that "the requirement regarding document control forces the organization to implement revision mechanisms, to make those documents available to relevant employees and to continiously [sic] improve them and keep them updated." Another respondent mentioned that the improvement in documentation enabled their environmental department to ensure that employees had the current information that was needed in order to carry out their duties and to ensure compliance to the relevant laws and regulations. This was said to translate to an improvement in their environmental performance.

\section{Improve knowledge, awareness and understanding of employee duties and responsibilities} with respect to the environmental management system

Respondents stated that an improvement in the documentation of procedures and other key components of the organization's environmental management system to include assigning of responsibilities (as mentioned by one respondent) assisted employees in gaining knowledge and understanding on how to undertake their environmental duties properly as well as understanding what their roles were in terms of the environmental management system. This in turn ensured that they carried out their duties in a more consistent and efficient manner. One respondent mentioned that "the standard is the main guidance for defining documentation requirements and document control strategies. The documents provide a tool for training and awareness regarding 
environmental topics." Also, the documentation process was said to introduce rigor and consistency in how organizations managed their environmental management system and environmental issues on the whole according to another respondent.

\section{Improvement in the archiving of historical data}

By contributing to the development of the organization's memory, the standard was said to help ensure that historical data of processes within the organization were stored for a specified length of time. One respondent stated that "because the standard forces you to maintain records in regards to your environmental compliance, it helps you to maintain a history of event [s]." Another mentioned how information on changes that occurred in their facilities that were detected through monitoring and measurement served as historical data. This data was then used for the continuous review and analysis of their environmental aspects and impacts.

\section{Improvement with respect to the tracking of trends and thus feedback}

By improving the archiving of past and current events, organizations are better able to develop

trends over time and to obtain useful feedback from tracking such data. Elements of the standard that were said to assist with this include the documentation of objectives and targets, the management review process, the continuous improvement program, and documentation on the whole. Two respondents mentioned that the management review process prompted them to gather and store useful information from the outcome of the review, which according to one of them was then used to keep track of their continuous improvement program. According to the other respondent, "preparing data trends for quarterly management reviews forces us to consolidate our relevant environmental data." Two other respondents mentioned how through the establishment, tracking, and documentation of their objectives and targets they were able to accumulate information which was then used to track their environmental performance over time.

With respect to the documentation requirement, one respondent stated that the "standard ['s] requirements to maintain documentation allows us to trend progress over time and avoids repeating less efficient practices that may be forgotten." Another respondent specifically mentioned how documentation in the form of waste manifests assisted them with regulatory 
compliance and also how an improvement in documentation enabled them to track and review their energy consumption over periods of time. This enabled them to effectively evaluate their savings after they had switched their lighting systems to LED (light-emitting diode) light fixtures.

\section{Improvement in communication and sharing of information}

Respondents were found to improve the way they communicated and thus share information as a result of an improvement in their organizational memory. One respondent mentioned that the enhancement of their organizational memory in the form of documents helped with the sharing of guidelines and methods amongst the different facilities and locations, especially for a large organization like theirs. Two others mentioned that through the records requirement they saw an improvement in how they managed their records and that the records were communicated to the relevant staff thus facilitating the sharing of information.

\section{General improvement in documentation and records management and other processes}

Some of the respondents made mention of the fact that the standard lead to an overall improvement in the way they handled their documentation, document control and records management. The standard was said to motivate them to improve on their document and records management system; guide them on what information is to be stored; make them more organized as per how and where information is to be stored, in other words prompt them to develop a better retrieval system; assist them with the reduction of redundancies and loss of revisions; and although not a requirement, prompt them to put in place retention times (one respondent mentioned that before they adopted ISO 14001 they always discarded their documents prematurely). As mentioned by a respondent, the standard made them more diligent in the way they kept records and according to the respondent this was of importance because efficient record keeping and storage of information enhances institutional memory, transition planning, and environmental performance. An environmental manager in the iron and steel industry described how the standard through its documentation requirement helped their organization by stating that

I have found that establishing documented procedures has greatly assisted the facility to build a "system-dependent" culture as opposed to a system based on individual 
understanding of a given activity. This has also improved the training program by identifying procedures specific to the significant environmental aspects of the facility for new employees and employee transfers. Documented procedures also incorporate changes based on process modifications and opportunities for improvement identified through internal audits.

Furthermore, two respondents stated that an improvement in their documentation and records keeping and thus organizational memory lead to an improvement in how they managed spills at their facilities. One stated that it enabled them undertake proper root cause analysis and the other said that they were able to monitor their operational equipment more effectively. Finally, by developing and maintaining an emissions summary and dispersion modelling (ESDM) report one respondent said that they were able to better control what chemicals were being used in their products (paints).

\section{B.2.2 Software as a facilitator of Organizational Learning and in turn Environmental Performance}

\section{B.2.2.1 Software and Information Acquisition}

A total of twelve responses were received for the following question: If you are of the opinion

that the software leads to improved acquisition of useful information, could you comment on how this improvement affected organizational learning that influenced performance within your organization? Only five responses were from respondents that used EMS-based software. The main themes, especially as it concerns learning mechanisms/conditions are outlined below.

\section{Improvement in the tracking of information and provision of feedback}

EMS-based software was said to facilitate the tracking of information and in the process provided feedback for the organization with respect to its EMS. A user of Company A's EM software stated that the software "has lead to improved acquisition of useful information by using the Objectives and Targets module ... [The EM software] helps us manage the results by pushing reminders out to the various objective owners. This has greatly improved tracking of our 
corporate goals."

\section{Efficient and timely collection of information}

Company D's software was said to enable members of the organization to collect and disseminate information in an efficient and timely manner, thereby readily providing information to managers to use in order to make important decisions that affect environmental performance.

\section{Ensured information was always up to date}

Two respondents who used Company B's software said that the software in facilitating information acquisition enabled them to ensure that employees had access to up-to-date information. One user in particular mentioned that the software's document control feature enabled "responsible parties to keep procedures up to date".

On another note, a respondent who used Company C's software felt that software did not assist them with information acquisition because the software's capabilities were rather limited, and that it focused mainly on managing the organization's significant environmental impacts, linking those impacts with the appropriate legal requirements, and assisting with taking follow-up actions. However, the respondent did mention that the software was being improved and believes that once the improvements have been made and are fully deployed, that the software will most likely facilitate the four constructs of organizational learning.

Those that used non-EMS-based software were of the opinion that the software they used assisted them in making information readily available for employees, assisted them in tracking information and thus providing feedback, and helped improve their training programs.

\section{B.2.2.2 Software and Information Dissemination}

Thirteen (13) responses were obtained for the following question: If you are of the opinion that the software leads to improved dissemination of useful information, could you comment on how this improvement affected organizational learning that influenced performance within your organization? However, only 6 of the responses were from users of EMS-based software. The main themes, especially as it concerns learning mechanisms/conditions are outlined below. 


\section{Improvement in the tracking of information}

Respondents who used Company A's IM software and Company B's software mentioned that they observed improvements with respect to how they tracked information and obtained feedback, especially since the software had a notification system. This they said helped particularly with their legal compliance obligations, especially since it "ensures that legal deadlines are tracked."

\section{Ensured the timely distribution of information to those who needed it}

A few of the respondents who used EMS-based software were of the opinion that the software in improving information dissemination, ensured that information was provided to the relevant employees and in a timely fashion. This enabled the employees to have the knowledge to carry out their duties more effectively and efficiently. For example, a respondent who used Company A's IM software said that the software enabled "personnel to channel all relevant information to the communication coordinator and ensure[d] that the information [was] distributed to the relevant persons in the organisation." Also, a user of Company A's EM software mentioned that the software's monitoring and measurement module, its document control module, its dashboard, and its reporting capabilities helped them improve the distribution of information. The respondent also mentioned that the document control module enabled them to provide responsible staff who had web access with the relevant documents needed to undertake their duties.

\section{Ensured that consistent information was disseminated within the organization}

A few respondents were of the opinion that EMS-based software helped with the dissemination of the same information within the organization. A respondent who used Company D's software said that not only did the software facilitate the compilation and distribution of information in a timely and consistent manner but that in doing so it enabled management to make informed decisions in a timely manner. A user of Company B's software also agreed with the fact that software can help with the dissemination of consistent information within the organization.

Users of non-EMS-based software mentioned that the software assisted them with the tracking of information, ensured consistent information was distributed, and helped to improve the exchange 
of ideas within the organization.

\section{B.2.2.3 Software and Information Interpretation}

Seven (7) responses were obtained regarding the following question: If you are of the opinion that the software improved your ability to analyze and interpret the useful information, could you comment on how this improvement affected organizational learning that influenced performance within your organization? However, only 3 were from users of EMS-based software. The main themes, especially as it concerns learning mechanisms/conditions are outlined below.

\section{Improvement in training programs}

EMS-based software was said to enable users to interpret information, and to use that information to understand and improve on their training needs. A respondent who used Company A's EM Software said that the software "greatly improved [their] means of understanding training gaps." This was especially the case because they did not have such a process in place before then.

\section{Improvement in understanding and decision making}

Respondents were of the opinion that EMS-based software helped them to better understand the information presented to them, and to therefore make better decisions, especially for top management. A respondent who used Company A's EM software said that the software helped them with the interpretation of information because it had a dashboard that provided real time information to managers in a format that was understandable to them. Also, a user of Company D's software stated that "charts and graphs provided by the software allow[ed] for easier intrepretation [sic] of the information, helping management make decisions and determine the impact of those decisions."

\section{B.2.2.4 Software and Organizational Memory}

Twelve (12) responses were obtained with respect to the following question: If you are of the opinion that the software leads to improved storage of useful information, could you comment on how this improvement affected organizational learning that influenced performance within your 
organization? However, only 5 were from users of EMS-based software. The main themes, especially as it concerns learning mechanisms/conditions are outlined below.

\section{Up-to-date information}

A user of Company A's EM software said that the software via its document control module provided automatic notifications for document review. It therefore enabled the owner of a document to review such documents and to determine if changes were required without having to remember to do so on their own. As such the software ensures that up-to-date information is available and that obsolete information is discarded.

\section{Improved tracking of information and feedback}

Respondents who used EMS-based software were of the opinion that the software enabled them to improve how they stored information and in turn how the information was tracked. The software therefore served as a means to obtain feedback. A respondent who used Company D's software mentioned that the software in enhancing organizational memory enabled them to trend their data over time thereby enabling them to better understand the impact of the variables they dealt with. Also, a user of Company B's software said that "the document archive maintains a continuous history of procedures, internal audit results and chnages [sic] to environmental aspects and impacts."

Users of non-EMS-based software mentioned that the software provided a means to store information as well as to track information and obtain feedback.

\section{B.2.3 Functionality of the ISO 14001:2004 Standard}

\section{B.2.3.1 Most helpful Feature/Requirement of the ISO 14001:2004 Standard}

Respondents were asked the following questions: What would you say is the most helpful feature/requirement of the ISO 14001 standard? Please could you briefly explain why you found this feature/requirement most helpful? For these questions, 72 respondents provided an answer, however, a total of 82 responses were received because a few respondents provided more than one answer even though they were required to provide just one. The different requirements/features are mentioned below along with some of the reasons that were provided. 


\section{Continual improvement}

Four (4) respondents mentioned continuous improvement as being the most helpful requirement/feature of the standard. This was mainly because it forced them to continuously review the environmental management system and therefore determine what was or was not working. Also, because it can be applied to other areas of the organization's business and allowed for small steps in improvement to be taken. As a result, organizations are not under any enormous amount of pressure to attain large increases in performance. One respondent mentioned that it enabled them to focus on specific environmental projects as well as to ensure that such projects were realized.

\section{Management review}

Nine (9) respondents were of the opinion that the management review was most important amongst all the other requirements of the standard. Some of the reasons provided were as follows:

1.) It helped highlight the need for and get buy-in from upper management with respect to environmental issues. One respondent stated that it "defines a process to engage senior management in all environmental aspects of the organization"

2.) It enabled them to prioritize their activities better

3.) It helped facilitate the engagement of employees at all levels of the organization with respect to the development of materials, and helped make environmental issues a focus for all

4.) It helped facilitate an organizational structure in which environmental staff had direct access to top management such as the Chief Executive Officer

5.) It served as a means to develop future environmental initiatives

6.) It helped with the communication of environmental activities within the organization, and

7.) It helped the organization evaluate and review its current status or elements of its environmental management system, such as its significant environmental aspects, and to make changes where necessary. It therefore served as a means to provide feedback on successes and failures for the organization. It also enabled them to address whatever issues that may have arisen by assigning responsibilities during the review process. 


\section{Environmental aspects}

The majority of the respondents (16) felt that the requirement to identify the organization's significant aspects and potential impacts was the most helpful requirement. The majority of them felt so because they saw this requirement as the backbone or cornerstone for developing an environmental management system. As stated by a respondent, "without knowing [the environmental aspects], you can't built [sic] an effective environmental program. The respondents were of the opinion that it was important because it prompted them to scrutinize the entire activities, products, and services of their organizations, and thus enabled them to identify and understand the operational risks and possible impacts that they may have on the environment, thereby enabling them to better prioritize on how to deal with such risks and impacts. Prioritizing included deciding on which control measures to put in place and the necessary resources to include monetary resources that will be required to do so.

Respondents also felt that in identifying their significant aspects they were able to channel the efforts of members of the organization with respect to improving environmental performance; take a proactive approach to risk management; evaluate their activities, products and services on a continuous basis; obtain a realistic picture of the organization's environmental footprint; evaluate the training requirements of employees; and bring about collaboration amongst the various departments leading to a shared understanding of the organization's environmental risks and how such risks can be dealt with proactively. Furthermore, it helps them "maintain [their] commitment to actions that benefit the environment."

\section{Audit}

Six (6) respondents mentioned that they found the audits requirement to be most helpful to them. This was because it provided a structured process for ensuring that one knew and adhered to their legal requirements; it ensured that the environmental management system was continuously being reviewed and that the organization did not become complacent with respect to its environmental goals; it prevented stagnation by prompting the organization to look for opportunities for improvement where possible; it ensured that the environmental management system was in conformance with the standard, in other words, errors were being detected and corrected; and it provided a means to ensure and show continual improvement. The internal audit 
was said to be "a good way to root out potential problems in your environmental system."

\section{Legal compliance}

Five (5) respondents mentioned that they found the requirement on legal compliance to be most helpful. This they said was because it ensured that they remained compliant to the legal and other requirements that were applicable to their organization. In the process, they also gained

knowledge on how to address them. It was said to make them aware of regulations that applied to their organization, which might have otherwise gone unnoticed. It also enabled the organization to save cost by avoiding fines that come with noncompliance, and it served as a means to ensure that reviews and audits were undertaken leading to the discovery of new opportunities for improvement. In fact, it was said to be the "most important in terms of assessing risk," and "should be the core component of an Environmental Standard."

\section{PDCA cycle}

Three (3) respondents mentioned that they found the PDCA cycle most helpful. Reasons provided included the fact that the cycle ensures that the environmental management system will be continuously improved, it offers reasonable and simplified steps of actions to take, and the fact that it can be applied to other areas of the organization's business such as health and safety, and finance.

\section{Objectives and targets, and programs}

Four (4) respondents felt that the requirement to establish objectives and targets, and environmental programs was most helpful. They felt so because it is said to play a major role in terms of improving performance as well as reducing the organization's environmental footprint; it brings about a structured way to collaborate with other departments in order to deliver environmental objectives; and it ensures that the organization remains committed to their goals to protect the environment. The setting of objectives and targets was also said to force an organization to continuously improve on its performance.

\section{Environmental policy}

Two (2) respondents felt that the environmental policy was most helpful to them. This they said 
was because it showed top management's commitment in terms of improving the environmental performance of the organization and it brought about consensus within the organization.

\section{Communication (Internal and External)}

Two (2) respondents found this requirement most helpful, one in particular mentioned that they found it helpful because it lead to an improvement in communication within the organization, which was an area they were deficient in.

\section{Emergency preparedness and response}

One (1) respondent was of the opinion that this requirement was most helpful because it enabled them to have a better understanding of environmental emergencies, and it ensured that the organization was prepared for an emergency should one occur.

\section{Nonconformity, corrective action, and preventative action.}

Four (4) respondents saw this requirement as being most helpful mainly because it helped the organization continually improve its environmental performance over time. This was the case because it served as a means to provide feedback to the organization with respect to problem areas as well as to seek solutions to those problems, and to put corrective measures in place. Because this requirement entails continuous review and follow-up, it was also said to prevent members from overlooking or forgetting about past incidents and near misses from which lessons can be learned.

\section{Integration of environmental issues}

Two (2) respondents mentioned that they found the ability of the standard to facilitate the integration of environmental issues into its daily operations as most helpful for them. In fact, one respondent mentioned that the standard helped 'break the 'silo' approach to environmental management". This was made possible because the standard facilitated linkages within the organization and ensured that environmental roles and responsibilities were shared throughout the organization. Another respondent mentioned that the standard helped them integrate environmental issues into their daily operations from product development to product completion. The same respondent mentioned that not only did it help reduce their impact on the 
environment but that it also helped save cost in terms of material consumption.

\section{Planning}

Three (3) respondents said that they found planning to be the most helpful element of the standard. They were of the opinion that planning in general together with prioritization, provided environmental staff with the management driven motivation needed to deal with environmental issues, especially with limited resources and personnel that tends to affect most companies. Also, that planning lead to the involvement of employees at all levels of the organization and thus enhanced the enrolment/participation of other departments that may otherwise have not taken part with respect to environmental practices. For one of the respondents, planning was most helpful because the other requirements of the standard had already been covered due to the implementation of ISO 9001. So for them, ISO 14001 contributed mainly in terms of identifying aspects and impacts, legal and other requirements, and developing objectives and targets.

\section{Documentation and document control}

Four (4) respondents found documentation and document control most helpful because it prompted them to create an organized system that made it easy to navigate through documents; it allowed for the tracking of procedures and ensured that they were revised if needed; it ensured that consistent and reliable information was being used for operational purposes; and documentation and document control played a vital role in ensuring that other requirements were being met.

\section{Management commitment}

Two (2) respondents felt that the ability of the standard to facilitate management commitment was most helpful to them. They were of the opinion that with management commitment the tenets of the standard were more likely to be accepted by all employees, especially line staff, and that it would ensure that the standard was implemented faster as well as penetrate all levels of the organization. Furthermore, the success of the standard would be an uphill task if the environmental representative was left to champion the cause alone. One of the respondents mentioned that an increase in management commitment in their organization brought about an increase in ownership within the environmental department and the production department, 
which translated into a reduction of their environmental impacts, improved regulatory compliance, and improved sustainability on the whole with respect to the organization's role in society.

\section{Standardized structure and framework}

Five (5) respondents found the fact that the standard provided them with a standardized structure and framework to follow as most helpful to their organization, in other words, it served as a template for organizations interested in setting up an environmental management system. This was in part because its standardized structure meant that it could be integrated with other management systems being used by the organization. Also, because of this structure and its simplicity it could be adopted by any organization irrespective of how complex its operations were. Not only was it found helpful because of its structure but also because of the fact that it is a global standard.

\section{Promote innovation}

One (1) respondent felt that the standard as a whole was helpful because it helped prompt the organization to look outside the box, in other words, it pushed the organization to be innovative. The respondent mentioned how through the adoption of the standard they were prompted to seek out creative methods of recycling.

\section{Promote learning}

Another respondent mentioned that the standard on the whole facilitated the sharing of information such as best practices and opportunities for improvement within the organization, especially because the information was documented and stored in a shared database.

\section{ISO 14001 Annex A}

One (1) respondent found the provision of a guide to the standard in the form of Annex A to be of great use to their organization. With the guide in place organizations are better able to understand how to implement and maintain the standard. 


\section{Implementation and operation}

One (1) respondent found this requirement helpful because it outlines the procedure for the identification and implementation of operational controls, which was found to be important for the success of the standard with respect to its implementation and maintenance.

\section{Systems approach}

One (1) respondent found the systems approach of the standard most helpful. The respondent further mentioned that they liked the fact that the standard was reproducible to the extent that should an employee in charge of the environmental management system leave the company, the new employee would not have much difficulty in taking over the responsibility.

\section{Legal and other requirements}

This requirement was found to be most helpful by five (5) of the respondents because it played a role in ensuring that the organization remained complaint and thus reduced the business risk (fines) that comes with noncompliance; and in terms of being organized, it prompted them to locate all of the information on legal and other requirements in one place.

\section{B.2.3.2 Least helpful Feature/Requirement of the ISO 14001:2004 Standard}

Respondents were asked the following questions: What would you say is the least helpful feature/requirement of the ISO 14001 standard? Please could you briefly explain why you found this feature/requirement least helpful? Sixty-five (65) respondents provided answers to these questions with the majority (12) mentioning that they did not find any of the requirements to be least helpful. One respondent stated that "they are all equally important," while another mentioned that "all elements are needed to fulfill the plan-do-check-act model for continual improvement." Three (3) respondents said they were unsure. With respect to the requirements of the standard, most of the respondents felt that documentation and external audit, followed by the environmental policy were least helpful to them for reasons outlined below. A good number of the respondents were of the opinion that the standard had its limitations in one way or the other.

\section{Environmental policy}

Five (5) respondents were of the opinion that the environmental policy was the least helpful out 
of all the requirements. They felt that the policy was most often generic in nature with little or no impact on the organization; though circulated, the policy did not appear to be read by other employees; and that reading and memorizing the policy does not necessarily translate to an improvement in performance. In fact, two of the respondents felt that the policy is of no more value once the EMS has been implemented. Both had been using the standard for 7 and 14 years respectively. According to one of them, the policy "really never gets used. I know it "sets the frame work' for the program, but once you write the policy, and establish the program, it really never gests [sic] used again."

\section{Documentation}

Six (6) respondents said that they found the documentation requirement least helpful because it added to the amount of paperwork they had to undertake, especially for small organizations and organizations with low impact activities; and also because some of them already had documentation in place through the adoption of ISO 9001, thus making the documentation requirement for ISO 14001 redundant. One respondent mentioned that the burden of documentation could be reduced by incorporating some of the standard's requirements with other business processes. Another respondent mentioned why the documentation requirement was a burden for them by stating that: "we have large facilities with over 5000 employees each and fairly high turnover rates. The majority have only a small specific involvement in our programs. Documenting training for each individualk [sic] can be burdensome."

\section{Emergency preparedness and response}

Two (2) respondents felt that this requirement was not that helpful because planning for emergencies should be part and parcel of the normal business practices of an organization and so the standard did not add any more value. Furthermore, emergency preparedness and response is already required by federal and provincial legislation.

\section{Monitoring and measurement}

One (1) respondent felt that the requirement to undertake and record the calibration of equipment as part of this requirement is of least use to them. The respondent felt that it is not feasible to maintain calibration records for all monitoring equipment, especially for large organizations with 
different sites and different working groups each having their own equipment. This is coupled with the fact that each equipment needs to be calibrated based on the manufacturer's specifications.

\section{Audit}

Six (6) respondents said that they found the audit (external audit in particular) least helpful. According to a respondent, the external audit is not needed until the environmental management system is mature because "auditing too early legally exposes an organization to regulatory enforcement and forced 'front-loading' of environmental programs to make legally-required, rapid changes." Also, it is said to be unnecessary because in the early stages most organizations already have an idea of their strengths and weaknesses. Another respondent's concern was that third party auditors pay too much attention to paperwork and not what the environmental management system has to offer. Others had issues with the frequency of the audit, and felt that it should be conducted once in two years as opposed to once a year. Also, the cost of the external audit and certification thereafter was said to be high and that an "internal audit can provide [the] same level of assurance with less cost." With respect to cost, it was also felt that the number of days the auditors needed to spend on site was too long and thus time consuming and expensive.

\section{Legal compliance}

Two (2) respondents found this requirement redundant because legal compliance should already be a part of an organization's business operations, and also because they already conduct internal and external audits, which would help ensure they are compliant. One of the respondents went further to say that the standard requires an organization to change its mindset and go beyond just being compliant to seeing the value of reducing its environmental impact. As such, including legal compliance as a requirement is not necessary.

\section{External communication}

Three (3) respondents found this requirement to be least helpful because it would be covered by the other requirements of the standard and thus be redundant, and because it is rarely utilized. Also, one respondent was of the opinion that the external communication requirement should either be made mandatory or be removed altogether. This concern may be based on the fact that 
the organization is mandated by the ISO 14001 standard to share only the policy with the general public, and can decide whether or not to publicly share other elements of its environmental management system.

\section{Objectives, targets, and programs}

Three (3) respondents mentioned this requirement as being least helpful. The requirement was said to be redundant because it was covered by other existing business processes. In fact, one respondent mentioned that they were more or less forced to establish targets and programs just because the standard required it and not because it was of any value to them. Another respondent found that the standard was too general with respect to this requirement, and therefore did not provide any proper guidance on how to establish them. Finally, a lot of emphasis was said to be placed on quantifiable targets, which may lead to non-quantifiable but worthwhile targets such as training regimes and instituting best management practices being overlooked.

\section{Management review}

One (1) respondent found the management review requirement to be least helpful but only because it was "too infrequent to address significant issues." The respondent mentioned that the review was held on a quarterly basis at their organization.

\section{Control of records}

Two (2) respondents felt that this requirement was redundant because "keeping adequate records is fundamental in any management system," and because of the existence of the requirement for control of documents. One respondent was of the opinion that the control of documents and control of records requirements should be merged into one because having them as separate requirements creates redundancies.

\section{Control of documents}

Three (3) respondents mentioned document control as being least helpful. One reason was because although important it was said to be the requirement of the standard that posed the most problems. Another reason was the fact that document control had already been established via the adoption of ISO 9001. Finally, it was felt that it would be of more value if it was merged with 
records control.

Although in the 2015 version of the standard the documentation, control of records and control of documents requirements are merged under one clause called documented information, the overall responsibilities of the organization to achieve these requirements remains the same.

\section{Resources, roles, responsibility and authority}

One (1) respondent found this requirement least helpful, especially as it pertained to providing resources because the respondent felt that the standard could not force management to make the necessary resources available as this is usually a business decision.

\section{Environmental aspects}

One (1) respondent found this to be of concern but only because the respondent felt that it was not necessary to evaluate all the activities, products and services of the organization (including those that are known not to have any environmental impacts) only because one wishes to have a list of all the environmental aspects that are related to the organization.

\section{Legal and other requirements}

Two (2) respondents had concerns with this requirement. One respondent mentioned that the preparation of a list can eventually become time consuming and non-functional because the majority of the laws and regulations apply to the operations of their organization. The other respondent felt that the standard is vague with respect to "other requirements", and that in any case, responsible businesses should take into consideration all the legal and other requirements irrespective of the standard.

\section{Operational control}

One (1) respondent felt that this requirement should be the most important component of the standard but found it to be least helpful because the standard's approach to establishing operational controls was too general. 


\section{Limitations of the standard on the whole}

Eleven (11) respondents did not mention a particular requirement of the standard as being least helpful, instead they mentioned issues they were having with the standard on the whole. They are outlined below. First, the implementation and maintenance of the standard was said to be a time consuming process coupled with the fact that some sections of the standard did not apply to their operations. The respondent did not mention any particular section. Second, the standard was said to become non-useful after their organization's product/profile had exhausted its usefulness. The organization had been certified for 12 years at the time of the survey. Third, the standard did not provide clear directions and was not prescriptive enough in some areas. No specific areas were mentioned. Fourth, some of the requirements were already fulfilled via internal standards as well as through industry and regulatory standards, and so they became redundant. Fifth, the content of the standard was said to be still unfamiliar to them because they found it to be too broad. Furthermore, they hardly ever needed to directly consult the standard, and so, it was possible for their environmental management system to deviate from the requirements of the standard. Sixth, the standard did not provide enough control for the environmental staff because for the most part they had to rely on other departments and vendors in order to fulfill its requirements. The procurement of goods and services was one area that was mentioned.

Finally, four respondents mentioned that they had difficulties with the standard because of the different interpretations of the standard by them and the registrars. One respondent said that they had conflicting interpretations between them and the registrar they worked with in terms of how their significant environmental aspects were to be identified, and how they were to be incorporated into the environmental programs. The conflict also affected the ability to be flexible in terms of managing their roles and responsibilities, and with the establishment of their objectives and targets, especially for an organization that was evolving said another. Another respondent mentioned having to do two audits for the same site (internal and external) as requested by the external auditors, which they felt was an additional burden on their staff. Also, another respondent stated that "the different interpretation[s] of the requirements of the standard tend to make the environmental management system more complex that [sic] required. A more complex management system is more difficult to accept and use by the employees." 


\section{Appendix C: Extended Discussions}

\section{C.1 Requirements of the ISO 14001:2004 Standard}

\subsection{General Requirements}

Here the standard mentions generally that the organization is to establish and maintain an environmental management system that is in line with its requirements. It also states that the organization should determine and document the scope of its EMS. For example, the organization is to decide whether the standard applies to the entire organization or a specific unit of the organization. Although not a requirement of the standard, Annex A.1, which is applicable to this requirement, suggests that organizations that are establishing an environmental management system for the first time should conduct an initial environmental review. The latter is to cover the identification of environmental aspects, legal and other requirements, evaluation of current environmental management practices, and examination of past emergency occurrences (ISO 14001:2004). The review may also take into consideration the examination of the organization's performance, the opinions of other parties, and the current organizational systems that can positively or negatively affect the organization's environmental performance (ISO 14004:2004).

\subsection{Environmental Policy}

The environmental policy serves as the driving force for the implementation, maintenance and improvement of the environmental management system with the end result being the improvement in the environmental performance of the organization (ISO 14001:2004). It is proof of top management's commitment and serves as a guide for the development of the environmental objectives and targets. The environmental policy must be communicated to all employees and to people who work on behalf of the organization such as contractors (ISO 14004:2004).

\subsection{Planning}

The planning phase plays a vital role with respect to the execution of the policy and the development and realization of the environmental management system (ISO 14004:2004). It has the following subclauses: 


\subsubsection{Environmental Aspects}

This is defined as the "element of an organization's activities or products or services that can interact with the environment" (ISO 14001:2004, p. 2). When identifying environmental aspects, the organization should consider amongst others emissions to air, water or land; use of raw materials and natural resources; and energy emitted (ISO 14001:2004). Environmental aspects have the potential to cause environmental impacts that may have either a positive or negative effect on the environment. The significant aspects and their associated impacts are to be continually identified by the organization in order to determine if and where an appropriate control or improvement is required. The significant aspects identified must be documented by the organization (ISO 14001:2004).

\subsubsection{Legal and Other Requirements}

The standard stipulates that the organization is to identify the legal requirements in relation to its environmental aspects. Examples include national and international laws and regulations. Examples of 'other requirements' include voluntary codes and agreements with various stakeholders such as public authorities and clients. The organization must continuously review its legal requirements to ensure it has up-to-date information in anticipation of new or changing regulations. Sources to identify and maintain up-to-date legal and other requirements as suggested by the international organization for standardization include all levels of government, industry associations, commercial databases and publications, and consultants (ISO 14004:2004). This requirement provides the organization with knowledge on applicable environmental laws or codes of practice thus enabling it to maintain or improve on its environmental performance (Whitelaw, 2004).

\subsubsection{Objectives, Targets and Program(s)}

In order for the environmental policy to be achieved and for the environmental aspects and associated impacts to be controlled or minimized, objectives and measurable targets are to be set for each of the impacts identified. They could be long term or short term. In order to set the objectives and targets some of the following inputs can be considered: the significant environmental aspects that were identified; the legal and other requirements that apply to the organization; technological options available to the organization to include use of best-available 
techniques; and results of the environmental review (ISO 14004:2004). The objectives are to be set by top management with the input of staff from other levels of the organization for which their participation is vital for the success of the EMS. The objectives can be applicable to the entire organization or be specific for a particular site or department. As such, the participants at different levels and functions of the organization should be identified and made aware of their roles and responsibilities as it applies to the EMS (ISO 14004:2004).

Environmental programs are to be developed in order to fulfill the objectives and targets with the end point being to improve the organization's environmental performance (ISO 14001:2004; ISO 14004:2004). The programs are usually sent to all employees that are involved with the environmental management system (Whitelaw, 2004).

\subsection{Implementation and Operation}

This clause allows for the organization's environmental management system to be put to work while following the requirements of the standard (Whitelaw, 2004). It has the following seven subclauses:

\subsubsection{Resources, Roles, Responsibility and Authority}

Here, specific roles and responsibilities as well as the reporting structure are provided to specific individuals in the organization (Whitelaw, 2004). Top management is to appoint a competent representative whose role will be to directly oversee the performance of the environmental management system. Roles and responsibilities are not limited to the environmental function alone and can include other staff functions such as engineering and quality to mention a few (ISO 14001:2004).

Resources are to be identified and made available in a timely fashion in order for the EMS to be effectively implemented and maintained. They are to be reviewed on an ongoing basis. As stated in the ISO 14004:2004 guide, the following are to be considered when an organization is identifying resources required for the EMS: infrastructure, information systems, training, technology, and other resources (e.g., financial, human, etc.) (ISO 14004:2004). 


\subsubsection{Competence, Training and Awareness}

The standard requires that top management identify training needs and subsequently ensure that all employees and persons whose work may have a sizeable environmental impact are adequately trained. Other persons who work on behalf of the company such as contractors are to show that they are competent or have the required training. Also, the environmental policy, the requirements of the environmental management system and the significant environmental aspects and associated impacts should be made known to all those who work for or on behalf of the organization (ISO 14001:2004). It is recommended that employees or those who work on behalf of the organization should be given the opportunity to provide suggestions that can help improve the company's environmental management system (ISO 14004:2004) thus encouraging participation from internal and external stakeholders. A few types of training as mentioned in the ISO 14004:2004 document include building environmental awareness amongst employees, specialized training as it relates to the requirements of the standard, and skills development for employees (ISO 14004:2004). The knowledge gained via implementation of this requirement should enable employees to make more informed decisions and thus become competent as it relates to environmental issues (Whitelaw, 2004).

\subsubsection{Communication}

The standard requires that information pertaining to its environmental management system is communicated to internal parties, that is, its employees and suggests using methods of communication such as newsletters, bulletin boards, and meetings. Also, the organization can choose whether or not to communicate to external parties such as customers, investors, and nongovernmental organizations. Should it choose to do so, it must have a procedure for it in place. As stated in the standard, external communication can be carried out via annual reports, company websites, and meetings with members of the public (ISO 14001:2004). Through communication, the organization is able to show its commitment as it pertains to environmental management as well as its effort to raise awareness and encourage feedback and dialogue from its stakeholders (ISO 14004:2004). 


\subsubsection{Documentation}

Documentation is required by the standard in order to effectively implement the environmental management system as well as to ensure that the required information is communicated to employees and external parties. It also serves as a means to locate other documents that are related to the environmental management system (ISO 14001:2004; ISO 14004:2004).

Documentation is proof that the system exists and makes it possible for the EMS to be audited based on the standard (Whitelaw, 2004). Some examples of documents include procedures, emergency plans, and policy statements (ISO 14001:2004; ISO 14004:2004). The documents can be in a variety of formats such as paper, photos, electronic, or posters. However, electronic documents are said to have an added advantage because they make it easier for documents to be updated, they are easier to control in terms of access, and they ensure that the most up-to-date documents are being used (ISO 14004:2004). Documentation as it pertains to environmental management is important because it allows for procedures and processes to be carried out in a consistent manner, it assists with communication and training, procedures can be revised with ease, it ensures that there is little or no uncertainty in terms of work procedures, and it serves as evidence of compliance with legal requirements and conformance to the requirements of the standard itself (ISO 14001:2004).

\subsubsection{Control of Documents}

The control of documents plays an important role as part of the environmental management system. It ensures that the documents are reviewed and revised as needed, that the required documents are present at units/departments that play a vital role in the success of the EMS, and it makes it possible to determine which documents belong to a particular organization, department, facility, or person. Finally, it ensures that out of date documents are no more in circulation and being used by employees. However, in some cases old documents are retained (ISO 14004:2004).

\subsubsection{Operational Control}

The day to day operations (for example, production processes, transportation, purchasing) in an organization may be tied to the organization's significant environmental aspects and may have a negative impact on the environment (ISO 14004:2004). In order to minimize or prevent negative 
impacts from occurring, the organization is required to identify if and where operational controls are needed and put them in place (ISO 14001:2004). This will enable the organization to meet its objectives and targets and fulfill the policy. Activities carried out by persons (e.g., contractors) who work on behalf of the firm are to be considered as well when identifying and implementing operational controls. Examples of operational controls as stated in the ISO 14004:2004 guideline include documented procedures, physical controls, work guidelines, and use of competent employees (ISO 14004:2004). These controls should be communicated within the organization and to contractors and suppliers when the need arises. The established controls should be continuously monitored in order to determine their effectiveness and to make corrections if necessary (ISO 14004:2004).

\subsubsection{Emergency Preparedness and Response}

The standard requires that the organization establishes and maintains an emergency preparedness and response procedure in order to identify the potential emergency situations unique to its operations that could have an impact on the environment. The procedures should also provide details on how to respond to such occurrences should they occur. A few things to consider when developing the emergency procedures include the type of hazards present at the site (e.g., flammable liquids), and the actions that should be carried out should there be a spill; training for employees responsible for emergency response; developing a procedure for internal and external communication; and developing a process to evaluate accidents after they have occurred in order to establish corrective and preventive measures (ISO 14004:2004).

\subsection{Checking}

Checking is said to involve "measurement, monitoring and evaluation of an organization's environmental performance" (ISO 14004:2004, p. 28). It is through this requirement that the planned actions and activities are verified (Whitelaw, 2004). It has the following sub-clauses:

\subsubsection{Monitoring and Measurement}

With respect to the ISO 14001 standard, monitoring entails observing and evaluating the planned activities of the organization in order to ensure that they are taking place as required (Whitelaw, 2004). As part of the monitoring process, measurement data is to be acquired: the data can be 
quantitative or qualitative in nature (ISO 14004:2004) and are necessary in order to show for example, the actual amounts of waste being generated, or recycled, and improvements in energy consumption (Whitelaw, 2004). Monitoring and measurement plays a vital role because it enables the organization obtain information/data that can be used to determine its significant environmental aspects and assess the performance of the EMS and the organization on the whole (ISO 14004:2004).

The monitoring and measurement requirement provides data that can be analyzed thereby providing information and knowledge on not only the successes achieved but on failures that may have occurred, with the end goal being to determine what corrective and preventive measures can be put in place (ISO 14001:2004; ISO 14004:2004).

\subsubsection{Evaluation of Compliance}

Organizations are required by the standard to put in place procedures to evaluate and record its compliance with its applicable legal and other requirements (ISO 14001:2004), the frequency of which will be determined by the organization's "size, type and complexity" (ISO 14004:2004, p. 29), and its applicable legal requirements. As stated in the ISO 14004:2004 guideline, the evaluation process can be done through an audit, a facility inspection, a document review, interviews, or facility tours (ISO 14004:2004).

\subsubsection{Nonconformity, Corrective Action and Preventive Action}

The organization is to continuously evaluate its environmental management system's conformance to the requirements of the standard. If it is found to deviate from the requirements (for example, a failure to develop objectives and targets), corrective actions as well as controls or preventive measures need to be put in place to ensure that it is does not happen again. Also, the organization is to ensure via follow-up that the corrective and preventive measures in place are working effectively. A good technique to evaluate nonconformities is said to be through the undertaking of an internal audit (ISO 14004:2004). 


\subsubsection{Control of Records}

Records of an organization's environmental activities serve as proof that the organization is doing or has done what it set out to do in fulfilling its environmental commitments. (ISO 14004:2004; Whitelaw, 2004). The records are usually not amended and thus serve as a permanent source of information for future reference (ISO 14004:2004). As stated in the ISO 14001:2004 document, records may include some of the following: results of the audit; results of the management review process; information on significant environmental aspects; data on environmental performance; calibration records; and information on corrective and preventive measures (ISO 14001:2004). The successful implementation of the environmental management system depends a lot on whether the records are controlled properly (ISO 14004:2004).

For the records to be useful to the organization, "the organization shall establish, implement and maintain a procedure(s) for the identification, storage, protection, retrieval, retention and disposal of records" (ISO 14001:2004, p. 8). Furthermore, they must be readable as well as traceable (ISO 14001:2004).

\subsubsection{Internal Audit}

An internal audit serves as a tool for an organization to assess itself, thereby ensuring that it is in line with its policies and procedures. The standard requires that organizations conduct an internal audit of its environmental management system to ensure that it is meeting the requirements of the standard and other procedures it may have put in place as it pertains to its environmental activities (ISO 14001:2004). The audit may also be used as a means to reveal room for improvement of the EMS. The audits are usually carried out at planned intervals and can be done by a competent member of the organization or a competent external entity (ISO 14004:2004).

The results of an audit serve as feedback for the organization and enables them to correct and prevent any nonconformities that were discovered. It also serves as an input for the management review process (ISO 14004:2004). 


\subsection{Management Review}

At planned intervals, top management and other staff members (e.g., environmental staff, heads of key departments, etc.) are to meet and systematically review the environmental management system to determine if it is in line with the contents of its policy and its objectives and targets (ISO 14001:2004). In general, the management review is a means for the organization to evaluate the effectiveness and adequacy of its environmental management system and to determine what improvements or changes need to be made if necessary (ISO 14001:2004). The review process uses information from different sources to evaluate the EMS, some of which include information on the organization's environmental performance; the findings of internal and external audits; feedback from external stakeholders; feedback regarding the effectiveness of corrective and preventive measures; information on whether objectives and targets are being fulfilled; information on changes as it pertains to science and technology, legal and other requirements, and products and services offered by the organization; information obtained from past emergency situations; and results of previous management reviews (ISO 14001:2004; ISO 14004:2004).

The outcome of the management review process plays a vital role in the continuous improvement element of the standard. Some of the outcomes may include decisions on whether the EMS is functioning as planned; whether additional resources are required; and whether changes to some of the elements of the EMS such as the objectives and targets are needed in order to make it work better (ISO 14001:2004; ISO 14004:2004). 


\section{C.2 Benefits of the ISO 14001 Standard}

Table C.1 Summary of the benefits of the ISO 14001 standard and the corresponding authors

\begin{tabular}{|c|c|}
\hline Benefits of the Standard & Literature \\
\hline Improvement in environmental performance & $\begin{array}{l}\text { Ann et al. (2006); da Silva \& de Medeiros } \\
\text { (2004); Georgiadou \& Tsiotras (1998); } \\
\text { Montabon et al. (2000); Poksinska et al. } \\
\text { (2003); Proto \& Supino (2000); Psomas et al. } \\
\text { (2011); Schylander \& Martinuzzi (2007) }\end{array}$ \\
\hline Improvement of stakeholder relations & $\begin{array}{l}\text { Azzone, Bianchi, \& Noci (1997); da Silva \& } \\
\text { de Medeiros (2004); Morrison, Cushing, Day, } \\
\& \text { Speir (2000); Poksinska et al. (2003); } \\
\text { Potoski \& Prakash (2005); Psomas et al. } \\
\text { (2011); Strachan, Sinclair, \& Lal (2003) }\end{array}$ \\
\hline $\begin{array}{l}\text { Better organizational control of, for example, } \\
\text { work procedures and organizational culture }\end{array}$ & $\begin{array}{l}\text { Poksinska et al. (2003); Proto \& Supino } \\
\text { (2000); Boiral \& Sala (1998) }\end{array}$ \\
\hline Improved corporate image & $\begin{array}{l}\text { Bansal \& Bognar (2002); Boiral \& Sala } \\
\text { (1998); Chavan (2005); Chin et al. (1999); da } \\
\text { Silva \& de Medeiros (2004); del Brio et al. } \\
\text { (2001); Petroni (2000); Poksinska et al. } \\
\text { (2003); Psomas et al. (2011); Schylander \& } \\
\text { Martinuzzi (2007); Strachan et al. (2003) }\end{array}$ \\
\hline Gain more customers and suppliers & $\begin{array}{l}\text { Bansal \& Bognar (2002); da Silva \& de } \\
\text { Medeiros (2004); Poksinska et al. (2003); } \\
\text { Psomas et al. (2011) }\end{array}$ \\
\hline $\begin{array}{l}\text { Enhances an organization's competitive } \\
\text { advantage }\end{array}$ & $\begin{array}{l}\text { Bansal \& Bognar (2002); Boiral \& Sala } \\
\text { (1998); Chin et al. (1999); Fisher (2003); } \\
\text { Hwee Nga (2009); Kirkpatrick \& Pouliot } \\
\text { (1996); Mullin \& Sissel (1995); Proto \& } \\
\text { Supino (2000); Psomas et al. (2011); Rezaee } \\
\text { \& Elam (2000); Rondinelli \& Vastag (2000); } \\
\text { Schylander \& Martinuzzi (2007); Yeung \& } \\
\text { Mok (2005) }\end{array}$ \\
\hline Improved financial performance/profitability & $\begin{array}{l}\text { Ann et al. (2006); Bansal \& Bognar (2002); } \\
\text { Darnall et al. (2008); Hwee Nga (2009); } \\
\text { Proto \& Supino (2000); Psomas, et al. (2011); } \\
\text { Strachan et al. (2003) }\end{array}$ \\
\hline Preemption of regulation & $\begin{array}{l}\text { Darnall et al. (2008); Hwee Nga (2009); } \\
\text { Psomas et al. (2011) }\end{array}$ \\
\hline
\end{tabular}




\section{Table C.1 Continued}

\begin{tabular}{|c|c|}
\hline Benefits of the Standard & Literature \\
\hline Reduced costs & $\begin{array}{l}\text { Bansal \& Bognar (2002); da Silva \& de } \\
\text { Medeiros (2004); del Brio et al. (2001); } \\
\text { Fisher (2003); Hwee Nga (2009); Proto \& } \\
\text { Supino (2000); Psomas, et al. (2011); } \\
\text { Schylander \& Martinuzzi (2007); Strachan et } \\
\text { al. (2003) }\end{array}$ \\
\hline $\begin{array}{l}\text { Serves as a supplement to command and } \\
\text { control regulations }\end{array}$ & Webb (2004) \\
\hline Promotes international trade & $\begin{array}{l}\text { Bansal \& Bognar (2002); Georgiadou \& } \\
\text { Tsiotras (1998); Montabon et al. (2000); } \\
\text { Psomas et al. (2011); Yeung \& Mok (2005) }\end{array}$ \\
\hline Serves as a common global language & $\begin{array}{l}\text { Georgiadou \& Tsiotras (1998); Psomas et al. } \\
\text { (2011) }\end{array}$ \\
\hline $\begin{array}{l}\text { Increases the market share/access of an } \\
\text { organization }\end{array}$ & $\begin{array}{l}\text { Bansal \& Bognar (2002); da Silva \& de } \\
\text { Medeiros (2004); Fisher (2003); Psomas et al. } \\
\text { (2011); Strachan et al. (2003) }\end{array}$ \\
\hline $\begin{array}{l}\text { Enables the organization to attain and } \\
\text { maintain regulatory compliance }\end{array}$ & $\begin{array}{l}\text { Bansal \& Bognar (2002); del Brio et al. } \\
\text { (2001); Fisher (2003); Rezaee \& Elam } \\
\text { (2000); Potoski \& Prakash (2005); Psomas et } \\
\text { al. (2011); Schylander \& Martinuzzi (2007); } \\
\text { Winter \& May (2001) }\end{array}$ \\
\hline Improves organizational efficiency & $\begin{array}{l}\text { Bansal \& Bognar (2002); del Brio et al. } \\
\text { (2001); Boiral \& Sala (1998); Proto \& Supino } \\
\text { (2000); Psomas et al. (2011); Schylander \& } \\
\text { Martinuzzi (2007); Strachan et al. (2003); } \\
\text { Zutshi \& Sohal (2004) }\end{array}$ \\
\hline $\begin{array}{l}\text { Enables multinationals to implement and } \\
\text { maintain their EMS across the globe }\end{array}$ & Bansal \& Bognar (2002) \\
\hline $\begin{array}{l}\text { Lessens the amount of scrutiny by regulatory } \\
\text { authorities and the general public }\end{array}$ & $\begin{array}{l}\text { Bansal \& Bognar (2002); Strachan et al. } \\
(2003)\end{array}$ \\
\hline $\begin{array}{l}\text { Facilitates the improvement of or use of new } \\
\text { technology, and innovation/learning }\end{array}$ & $\begin{array}{l}\text { Montabon et al. (2000); Psomas et al. (2011); } \\
\text { Radonjič \& Tominc (2006) }\end{array}$ \\
\hline Minimizes liabilities & $\begin{array}{l}\text { Chavan (2005); Chin et al. (1999); Fisher } \\
\text { (2003); Proto \& Supino (2000); Psomas et al. } \\
\text { (2011); Rezaee \& Elam (2000); Strachan et } \\
\text { al. (2003) }\end{array}$ \\
\hline
\end{tabular}




\section{Table C.1 Continued}

\begin{tabular}{|l|l|}
\hline \multicolumn{1}{|c|}{ Benefits of the Standard } & \multicolumn{1}{c|}{ Literature } \\
\hline Facilitates the efficient use of resources & $\begin{array}{l}\text { Chavan (2005); da Silva \& de Medeiros } \\
\text { (2004); del Brio et al. (2001); Christensen \& } \\
\text { Rasmussen (1998); Psomas et al. (2011); } \\
\text { Radonjič \& Tominc (2006); Schylander \& } \\
\text { Martinuzzi (2007) }\end{array}$ \\
\hline Facilitates waste reduction & $\begin{array}{l}\text { Chavan (2005); Chin et al. (1999); Psomas et } \\
\text { al. (2011) }\end{array}$ \\
\hline $\begin{array}{l}\text { Builds awareness and understanding of } \\
\text { employees with respect to environmental } \\
\text { issues }\end{array}$ & $\begin{array}{l}\text { Chavan (2005); Psomas et al. (2011); } \\
\text { Rondinelli \& Vastag (2000); Schylander \& } \\
\text { Martinuzzi (2007) }\end{array}$ \\
\hline $\begin{array}{l}\text { Encourages organizations to embrace } \\
\text { environmental protection as part of their } \\
\text { responsibility }\end{array}$ & $\begin{array}{l}\text { da Silva \& de Medeiros (2004); Psomas et al. } \\
\text { (2011) }\end{array}$ \\
\hline $\begin{array}{l}\text { Enables the roles and responsibilities of staff } \\
\text { to be better delineated }\end{array}$ & Proto \& Supino (2000); Psomas et al. (2011) \\
\hline $\begin{array}{l}\text { Fosters goodwill } \\
\text { Enhances the credibility of the organization }\end{array}$ & $\begin{array}{l}\text { Proto \& Supino (2000); Psomas et al. (2011); } \\
\text { Rezaee \& Elam (2000) } \\
\text { (2000); Psomas et al. (2011) }\end{array}$ \\
\hline $\begin{array}{l}\text { Helps improve staff morale } \\
\text { Facilitates sustainable development }\end{array}$ & $\begin{array}{l}\text { Fortuński (2008); Psomas et al. (2011); } \\
\text { Sebhatu \& Enquist (2007) }\end{array}$ \\
\hline $\begin{array}{l}\text { Enables organizations to provide a safe and } \\
\text { healthy work environment } \\
\text { the organization's environmental activities }\end{array}$ & $\begin{array}{l}\text { Radonjič \& Tominc (2006); Psomas et al. } \\
\text { (2011) }\end{array}$ \\
\hline
\end{tabular}

\section{C.3 Contributions from Scholars on Organizational Learning}

\section{C.3.1 Huber's (1991) Constructs and their Subconstructs}

\section{C.3.1.1 Knowledge Acquisition}

1.) Congenital learning occurs when knowledge is brought by individuals into the company when it was just formed as well as when knowledge was acquired before its conception.

2.) Experiential learning entails learning from direct experience and could be systematic or unsystematic. This process has five subconstructs/subprocesses namely, organizational experiments, organizational self-appraisal, experimenting organizations, unintentional or unsystematic learning, and experience-based learning curves. (a.) Organizational experiments 
has to do with the acquisition and evaluation of feedback especially when looking at cause and effect relationships. However, for this process to be successful there has to be a great level of trust in the organization, the organization should be able to tolerate slipups, and the organizational members must have the desire for high standards of performance.

(b.) Organizational self-appraisal emphasizes employee collaboration and involvement, and entails obtaining information on issues that affect employees within the organization as well as involving the employees in identifying and providing solutions to problems. The focus of this process is to improve the wellbeing of the employees and to build relationships, which Huber (1991) sees as important factors for learning. (c.) Experimenting organizations implies a state in which organizations are always looking to change with respect to their goals, structures, processes, and so forth, even when conditions are stable, thereby enabling them to be adaptable to changing and uncertain environments. As such, organizations in this mode tend to be always flexible and have the ability to adjust quickly when in an environment that is not familiar to them. (d.) Unintentional or unsystematic learning is self-explanatory and simply involves acquiring information without actively searching for it. (e.) Experience-based learning curves is based on the premise that experience has a positive effect on performance, and entails using mathematical techniques (e.g., "experience curve" or "learning curve") to determine this relationship and using the results of the predictions as part of the planning process for the organization. Congenital learning and experiential learning both involve first hand learning, the next two involve second hand learning.

3.) Vicarious learning involves gaining second hand experience, in other words, learning from other organizations to include their business techniques and technologies. The information acquired may be through "consultants, professional meetings, trade shows, publications, vendors and suppliers and, in less competitive environments, networks of professionals" (p. 96). Vicarious learning also involves organizations imitating other organizations.

4.) Grafting is the process through which organizations acquire knowledge by bringing in new individuals who possess the requisite knowledge. This may be through mergers or acquisitions. Grafting is a better way of obtaining complicated forms of knowledge when compared to knowledge acquisition via experience or imitation. 
5.) Searching and Noticing: searching is said to be done via scanning, focused search and performance monitoring while noticing is the process through which the organization acquires information unintentionally with respect to its external and internal environment or its performance. (a.) Scanning entails probing the external environment of the company on a broad level. It helps the organization detect changes in its environment and is said to facilitate performance. Boundary-spanning personnel and upper-level managers are said to play a major role in scanning. (b.) Focused search is an intentional but constricted search for information inside and outside the organization's environment and it is usually done when a dilemma arises or when alternate opportunities are being sought. (c.) Performance monitoring involves both scanning and focused search, and is used to determine if the organization is meeting its own goals and the expectations of interested parties. Its main aim is to enhance the performance of the organization. It is important to note that 'searching' may not necessarily be done in order to learn, in some cases it is done to obtain information that will aid in validating a decision that was made based on other findings.

The five subprocesses of knowledge acquisition discussed above can be replaced with each other and some are better than others in certain situations. For example, experiential learning may not be as good as vicarious learning and grafting when it comes to acquiring technical 'know-how".

\section{C.3.1.2 Information Interpretation}

1.) Cognitive maps and framing looks at how one's ingrained convictions or mental representation will affect one's interpretation of new information. Also, the process of interpretation will be influenced by the way information is framed or labeled within the organization: the information has to be uniformly framed in order for the interpretation to be similar. It is important to note that communication media plays a big role in obtaining shared meaning because interpretations are socially constructed.

2.) Media richness determines how information is interpreted. Richness is the "ability of media to change human understanding by clarifying ambiguous issues" (Buchel \& Raub, 2001, p. 520). According to Huber (1991), media richness assists with interpretation via "two underlying dimensions - the variety of cues that the medium can convey and the rapidity of feedback that the 
medium can provide" (p. 103). Better results are obtained when media richness is taken into consideration with respect to the method of communication. A few media for communication include audio-only, computer conferencing groups, face-to-face communication (Huber, 1991), personal written text (e.g., letters and memos), formal written text (e.g., documents and bulletins), and numeric data (Buchel \& Raub, 2001).

3.) Information overload is when members of an organization have more information than they can process. Too much information could lead to poor interpretation. One way to curtail this is to limit the information distribution process even though this may in turn affect organizational learning.

4.) Unlearning and its effects on learning is the process through which knowledge is discarded especially outdated knowledge, which could be misleading. For this subprocess, Huber (1991) adopted the definition of unlearning by Hedberg (1981) who stated that unlearning is "a process through which learners discard knowledge" (Hedberg 1981, p. 18). Unlearning can cause an organization to be briefly dormant in the area in which the unlearned knowledge was used, it may prompt the start of a focused search in the area that the unlearned knowledge was used, and it may facilitate new learning. An example of unlearning within an organization is the layoff of outdated thinking people. Also, new employees can be made to unlearn through socialization.

\section{C.3.1.3 Organizational Memory}

1.) Storing and retrieving information involves the storage of knowledge/information in the form of "hard" information (physical copies) and/or "soft" information (mental storage by humans). Some examples of organizational memory include standard operating procedures (SOPs) and mental storage of "soft" information by employees. Of interest, is whether or not, and how nonroutine information is stored and if it is, whether it is done intentionally?

2.) Computer-based organizational memory involves the use of computer based applications to store information, which in turn also facilitates the retrieval of the same information. The stored information could be information on training records, shipment schedules, or manufacturing schedules. One way of developing this type of memory is by taking "soft" information/ 
knowledge from human experts and placing it in computer expert systems that make the information readily available.

\section{C.3.2 Senge's (2006) Five Disciplines of a Learning Organization}

\section{C.3.2.1 Personal Mastery}

The discipline of personal mastery has to do with the personal growth and learning of individual staff in an organization and is seen as important because individuals are the main agents of organizations and organizations learn when their members learn. Nevertheless, individual learning alone does not guarantee that organizational learning will occur. Likewise, if the members of an organization do not learn, organizational learning will not take place. Personal mastery is regarded as a continuous generative process, which does not only involve improving one's skills but also involves "continually clarifying and deepening our personal vision, of focusing our energies, of developing patience, and of seeing reality objectively" (p. 7). It involves the development and sustenance of what Senge (2006) refers to as creative tension. The latter is said to be the difference between one's vision and one's present reality. Creative tension encourages one to continue learning about how our activities affect our world.

\section{C.3.2.2 Mental Models}

Mental models are "deeply ingrained assumptions, generalizations, or even pictures or images that influence how we understand the world and how we take action" (p. 8). Individuals are most often unconscious of their mental models. Questioning our mental models can bring about positive change, on the other hand, failing to do so can lead to negative outcomes such as the prevention of new market concepts or managerial practices from being implemented. It starts by looking at the man in the mirror and undergoing self-examination, and focuses on the openness needed to uncover shortcomings in our present way of thinking. Planning undertaken by organizations is thought of "as learning and corporate planning as institutional learning" (p. 8) because it facilitates a change in management's shared mental models.

\section{C.3.2.3 Shared Vision}

This discipline focuses on bringing all the members of the organization on the same page with respect to the organization's vision. As Senge (2006) mentions, organizations will have a hard 
time achieving or maintaining excellence if their goals, values, and missions are not entirely ingrained by all its members. In terms of learning, this discipline is of importance because "when there is a genuine vision (as opposed to the all-too-familiar 'vision statement'), people excel and learn, not because they are told to, but because they want to" (p. 9). The development of a shared vision in an organization will encourage true commitment and enrollment in place of compliance.

\section{C.3.2.4 Team Learning}

The discipline of team learning is seen as important because "teams, not individuals, are the fundamental learning units in modern organizations" (p. 10). Also, Senge (2006) believes that the intellectual ability of a team can surpass that of its individual members, and that the development of each individual in the team occurs at a faster rate when the team learns. Team learning brings about collaboration and involves two types of discourse, namely, dialogue and discussion, with the former being of more value as it involves reflecting and criticizing our assumptions and those of our teammates, and allows for new mental models to be built. Dialoguing enables individuals to view the world from a standpoint other than theirs.

\section{C.3.2.5 Systems Thinking}

This discipline entails viewing the interconnectedness of different parts of a system, and how they affect each other and the system as a whole. It is said to integrate the four other disciplines but also requires that the other disciplines be present in order for it to reach its full potential. It is needed more in today's world and today's organizations because of the interdependencies and complexities that exist in our world today. "It is the cornerstone of how learning organizations think about their world" (p. 69), and it prompts one to focus more on interrelatedness in favor of linear cause-and-effect relationships as well as on the change process and not snapshots. An important aspect of systems thinking is feedback because it gives us an idea of whether the outcomes of our actions are good or bad. The feedback perspective requires that problems generated by the system be shared by everyone. 


\section{C.3.3 Garvin's (1993) Building Blocks of a Learning Organization}

\section{C.3.3.1 Systematic Problem Solving}

This involves the use of the scientific method, for example, the Plan, Do, Check, Act, Cycle (PDCA cycle); the use of data and not conjectures to make decisions; and analyzing data using statistical tools such as histograms, and cause and effect diagrams.

\section{C.3.3.2 Experimentation with New Approaches}

Organizations actively seek out new knowledge and put that new knowledge to the test. Information on new work practices and technology are acquired in the process. This activity is usually carried out in order to seek out new opportunities and not for problem solving. He provides a reason for the importance of experimentation by stating that

all forms of experimentation seek the same end: moving from superficial knowledge to deep understanding. At its simplest, the distinction is between knowing how things are done and knowing why they occur. Knowing how is partial knowledge; it is rooted in norms of behavior, standards of practice, and settings of equipment. Knowing why is more fundamental: it captures underlying cause-and-effect relationships and accommodates exceptions, adaptations, and unforeseen events. (p. 84)

Experimentation entails what Garvin (1993) describes as "ongoing programs" and "demonstration projects". Ongoing programs involve frequently undertaking several small experiments that eventually lead to a gradual increase in knowledge. The ongoing programs are facilitated by incentive programs and the encouragement of risk taking. Demonstration projects on the other hand lead to company-wide changes that causes companies to unlearn or discard old practices.

\section{C.3.3.3 Learning from Past Experience}

This involves reflection and self-evaluation. Organizations are to intentionally evaluate their successes as well as their failures and keep records of what led to those successes and failures. 
The records should be made readily available to members of the organization. Garvin (1993), highlights the use of computer data banks to help speed up this learning process.

\section{C.3.3.4 Learning from Others}

This building block entails acquiring information external to your own organization, in other words, learning from other organizations or individuals outside your company. A good technique for learning from others is benchmarking because "the greatest benefits come from studying practices, the way that work gets done, rather than results" (p. 86). Garvin (1993) in citing Camp (1989) states that "benchmarking is an ongoing investigation and learning process that ensures that best industry practices are uncovered, analyzed, adopted, and implemented" (p. 86). Another good means to obtain external information is through customers. However, in order to learn effectively from others, he states that organizations have to be receptive and that organizations need to "cultivate the art of open, attentive listening" (p. 87). He also stresses the fact that managers must be open to criticism.

\section{C.3.3.5 Transferring Knowledge}

For the knowledge gained to be useful and for learning to occur on a wide scale, knowledge must be transferred swiftly and effectively. A few ways in which he says knowledge can be transferred includes reports (written, oral or visual), touring and visiting of different facilities, rotation of personnel, education and training, and incentive programs. While reports and tours are the most preferred means, employee rotation is most effective because other employees gain knowledge directly from others through direct daily contact with such individuals. "Education and training are also powerful tools for transferring knowledge" (p. 88), but to be effective, whatever has been learned needs to be put into practice immediately. Incentive programs are said to help with information sharing because they encourage employees to engage more in innovation and to then share their innovations with other employees.

In general, Garvin (1993) suggests that organizations should create an environment that facilitates learning to include reflection and evaluation, and provide training for employees in areas such as problem solving and brainstorming. There also needs to be open boundaries within the organization in order to allow for the free flow of ideas. This can be done via mediums such 
as conferences, meetings, and project teams that enable employees to interact with one another or with the organization's customers and suppliers. Once the desired environment in the organization has been put in place, the organization can then develop learning forums that are specifically devised to promote learning. These forums can be in the form of strategic reviews, systems audit, internal benchmarking reports, study missions, and symposiums.

\section{C.3.4 The Learning Processes, Learning Orientations and Facilitating Factors by DiBella and Nevis (1998)}

\section{C.3.4.1 The Three Processes}

\section{Knowledge Creation or Acquisition}

For this process, knowledge is obtained either directly from the experience of the organization's employees leading to the creation of knowledge or from the know-how of other organizations, hence acquisition. There is also some amount of interpretation in order for employees to have a shared meaning of the information that was acquired. They distinguish knowledge from information by saying that "we generate knowledge when we give meaning to information or experience" (p. 30). When creating or acquiring knowledge, it is important to consider the source of knowledge, how the knowledge was created and how it became integrated into the organization. Also, one must take into consideration why, where and when the knowledge was acquired. DiBella and Nevis (1998) also see the feedback mechanism as a good means to acquire information especially from past experience. Some avenues through which knowledge external to the company can be obtained include interactions with customers and suppliers, and by monitoring competitors and industry trends.

\section{Knowledge Dissemination}

This involves the transfer or sharing of knowledge within the organization. It is here that tacit and explicit knowledge come into play. "Tacit knowledge pertains to personal insights, intuitions, and abilities; explicit knowledge pertains to knowledge that can be shared and communicated" (p. 33). A formal means to obtain and share tacit knowledge in organizations is through exit interviews of staff that are leaving. They make mention of other means of dissemination to include accident or incident reports, newsletters, computer information systems, productivity reports, employee training seminars, telephone conversations, E-mail 
communications, voice-mail, CEO speeches, and employee conferences. Some of these avenues for dissemination are formal (e.g., reports and documents) while others are informal (e.g., oral presentations and telephone conversations). The dissemination of knowledge can also be achieved through job rotations or career development programs.

\section{Knowledge Use}

The knowledge that was acquired and disseminated should be put to use in order to change decisions, behaviors and culture. Knowledge utilization is what makes the learning cycle complete.

\section{C.3.4.2 The Learning Orientations}

1.) Knowledge Source: this has to do with how knowledge is created or acquired, in other words, whether knowledge is developed by an organization internally or acquired externally. When the knowledge is developed internally it is said to be innovation and when it is acquired externally and modified it is said to be adaptation or imitation.

2.) Content-Process Focus: looks at the preference for knowledge used for product development as opposed to knowledge used for process improvement.

3.) Knowledge Reserve: looks at how knowledge is stored, whether by individuals (personal and in terms of education and experience) or as part of the organization's repository or organizational memory (public knowledge).

4.) Dissemination Mode: this looks at whether information or knowledge is shared formally or informally. Formal modes include written communications and formal education as well as written procedures. Informal modes include interaction with role models, gatekeepers and sharing of experiences amongst work groups when they mingle with one another or through communities of practice.

5.) Learning Scope: this is when there is an inclination for knowledge used for improving what already exists, in terms of capabilities, products and services or for knowledge used for 
establishing new ones or challenging what is already in place. They liken the former to singleloop learning and the latter to double-loop learning. It is also similar to undertaking an efficiency exercise versus an experimental approach, and incremental learning versus transformative learning respectively.

6.) Value-Chain Focus: here a distinction is made between design-and-make and market-anddeliver, and which area to invest more in with respect to learning. Design-and-make is said to involve areas like research and development (R\&D), and engineering and manufacturing, while market-and-deliver is said to involve sales, distribution and service activities. Organizations weigh which fundamental capabilities and learning investments are more important to them.

7.) Learning Focus: for this learning orientation, the emphasis is on whether to develop individual skills or group or team skills. Although a lot of organizational learning scholars emphasize on developing group skills, DiBella and Nevis (1998) see them as both being important. Coordination and decision making are a few examples of team skills. Learning focus is one of the elements in their integrated approach that supports all three processes, that is, knowledge creation/acquisition, knowledge dissemination and knowledge utilization.

\section{C.3.4.3 The Facilitating Factors}

1.) Scanning Imperative: this has to do with the acquisition of information from the external environment. In other words, collecting data on practices that other organizations are undertaking and using the acquired information to improve your own practices. Their studies showed that obtaining information solely from within the organization is sometimes insufficient. Scanning for information can be done through activities such as business conferences and trade shows.

2.) Performance Gap: this is when employees have a shared awareness that the actual performance of the organization differs from the performance they desire. A performance gap is usually revealed through feedback, which indicates that there is a shortfall in performance or when a new vision such as wanting to increase performance is put on the table. This revelation prompts organizations to either create new knowledge or to unlearn what is already known. The 
absence of a systems perspective or a lengthy period of success can prevent the organization from noticing that a performance gap exists.

3.) Concern for Measurement: measurement forms part of the feedback system and thus plays an important role in adaptive learning systems. Putting 'measures' in place enables organizations to determine if things are working as planned and what corrections need to be made if necessary. The development of a metrics system provides new and diverse information from what was on ground and helps open the door for exposing all participant's mental models. It should be seen as a means to learn and not for monitoring and control. The use of measures has been applied successfully to total quality management (TQM).

4.) Organizational Curiosity: this has to do with encouraging continuous experimentation and learning from experience be it positive or negative. There also has to be room for small amounts of failure. According to DiBella and Nevis (1998), "the concept of continuous improvement derives from similar reasoning; it assumes that the way things are done today may not be the way they are done tomorrow" (p. 68).

5.) Climate of Openness: this has to do with the presence of open boundaries, which enables the ease of information flow within the organization as well as the presence of an atmosphere that allows for the participation of employees. A climate of openness ensures that communication or information sharing takes place amongst employees; employees can voice their opinions freely and are able debate amongst themselves; and mistakes will be shared and not covered up and that employees will not be punished thus preventing the development of defensive routines. A climate of openness can be developed through formal and informal means.

6.) Continuous Education: this factor requires that all employees engage in continuous learning, and is similar to the discipline of personal mastery as put forward by Senge (2006). Some examples include on-the-job training and apprenticeships. The availability of adequate resources is very important in order for this facilitating factor to be effective. This element also requires that the organization creates an atmosphere that encourages employees to take control of their own learning whether with the organization or without the organization. 
7.) Operational Variety: this entails creating an atmosphere that supports different means or methods to achieve work goals and objectives. That way, employees will be able to deal with unexpected issues more readily when they occur. Operational variety can be enhanced by creating work groups consisting of people with different backgrounds.

8.) Multiple Advocates: multiple advocates are required if acquired knowledge is to be used effectively. Organizational learning is said to be greatly enhanced when there are more people promoting novel concepts (advocates) as well as bringing knowledge (gatekeepers) into the organization. "The more people who promote a learning mode, the more learning in general is encouraged" (p. 75). When there is only one advocate, that person could be misconceived as a deviant or a troublemaker.

9.) Involved Leadership: this is required in order to improve the acquisition, distribution and utilization of knowledge. Leaders need to be involved in all three learning processes and need to lead by example by showing that they have learned what needs to be learned and what they wish for other employees to learn. As such, they need to be "early developers and students of the knowledge" (p. 76). The leaders must not only develop the vision of the organization, but must be directly involved in ensuring that it is realized. Involved leadership is another element that supports all three processes of the learning cycle.

10.) Systems Perspective: as with Senge (2006), this entails one's reasoning with respect to the entire system and how its parts interact. It has to do with the interdependence that exists between the different units and groups within the organization. A strong systems perspective is needed in order for knowledge dissemination and utilization to be effective. "Organizational learning is limited when staff cannot recognize the relationships among processes, structures, and dispersed actions" (p. 78). Systems perspective is also one of the three elements that supports all three information processes. 


\section{C.3.5 The Three Stages of Learning by Daft and Weick (1984)}

\section{C.3.5.1 Scanning}

This stage involves observing the organization's environment and acquiring information that is seen as useful to the organization. It is characterized by the source of the data and the process for data acquisition. The source of the data with respect to the organization's environment may be external (e.g., when managers themselves collect information from the external environment of the organization) or internal (e.g., other staff members obtain information from outside and pass it on to managers) and personal (e.g., when there is direct interaction with other people) or impersonal (e.g., newspapers and magazines or reports stored by the organization). The acquisition of information could be formal (e.g., data collection systems) or informal (e.g., when employees personally interact with people outside the organization).

\section{C.3.5.2 Interpretation}

They define organizational interpretation as "the process of translating events and developing shared understanding and conceptual schemes among members of upper management" (p. 286). It is through interpretation that information is analysed and given meaning. The process occurs especially when new information is obtained by the organization and it takes place before learning (action).

\section{C.3.5.3 Learning}

This stage involves taking action based on what was interpreted. They are in agreement with the views of Argyris and Schön (1978) in that some form of action or new reaction has to take place in order for learning to occur, and it is the 'action' that differentiates learning from interpretation. They follow the definition of organizational learning by Duncan and Weiss (1979) who state that "organizational learning is the process by which knowledge about action outcome relationship between the organization and the environment is developed" (p. 286).

\section{C.3.6 Knowledge Creation by Nonaka, Toyama, et al. (2001)}

\section{C.3.6.1 The Knowledge Conversion Processes}

1.) Socialization: this process involves the sharing of tacit knowledge (work experiences) when employees engage in collaborative activities. Some examples include sharing tacit knowledge via 
apprenticeships, staff interactions inside and outside the work environment, and the interaction of employees with customers or suppliers. There has to be trust amongst employees for the sharing of tacit knowledge to be effective.

2.) Externalization: for this mode, tacit knowledge is converted into explicit knowledge. It is the most important amongst the four modes because it brings about "new, explicit concepts from tacit knowledge" (p. 495). The explicit knowledge can then be shared easily amongst members of the organization and it serves as a precursor for new knowledge. An example of externalization involves the creation of a manual using the technical skills of an employee.

3.) Combination: involves combining different aspects of explicit knowledge to form a new set of explicit knowledge. The new explicit knowledge is more complicated and systematic than the elements from which it was created. The conversion process can be achieved using documents, meetings, phone conversations, and computer communication networks. Also, "the reconfiguration of existing knowledge through sorting, adding, combining and categorizing can create new knowledge" (p. 497). As an example, new knowledge is created when a financial report is prepared using information from a variety of sources within the organization. The creation of an action plan or a business plan is also regarded as combination. The latter mainly involves acquiring explicit knowledge from the organization's internal or external environment and merging that information, followed by the transfer of the new explicit knowledge within the organization, and then the processing of the new explicit knowledge so that it can be easily applied by members of the organization. Combination can be enhanced by the use of computer communication networks and large databases.

4) Internalization: here, explicit knowledge is passed on to organizational members as tacit knowledge and can be likened to learning-by-doing. The process facilitates the dissemination of knowledge. The "internalized knowledge is used to broaden, extend and reframe organizational members' tacit knowledge" (p. 497). The employees who have now obtained this new tacit knowledge can then share it with other employees via socialization thereby starting the cycle over again. Training, presentations to other departments in the organization, and experimentation (which prompts learning-by-doing) are some ways in which internalization occurs. 


\section{C.3.6.2 The Types of Ba}

1.) Originating $\boldsymbol{B a}$ is the starting point for the process of knowledge creation and it is where tacit knowledge is shared. It is within this $B a$ that people "share feelings, emotions, experiences, and mental models" (p. 499). It facilitates face-to-face interaction, which is needed for the sharing of tacit knowledge.

2.) Dialoguing $\boldsymbol{B} \boldsymbol{a}$ is where externalization takes place, that is, the conversion of tacit knowledge to explicit knowledge. It is usually created intentionally by choosing a selected group of people with a required skill set in the hope that they undertake dialogue and reflection as it pertains to their mental models, and the mental models of others in the group. Like Senge (2006), they see dialoguing and reflection as an important aspect of the knowledge creation process, and learning as a whole.

3.) Systemizing $\boldsymbol{B a}$ is said to be a virtual world, and it is the place where combination occurs. Collaboration takes place in this $B a$ mainly with the aid of information technology (e.g., online networks, groupware, documentation, and databases). Interaction here is said to be group-togroup.

4.) Exercising $\boldsymbol{B} \boldsymbol{a}$ is the place where internalization occurs. In this $B a$, knowledge is conveyed via mediums such as on-the-job-training and active participation.

\section{C.3.6.3 Knowledge Assets}

1.) Experiential knowledge assets: this is shared tacit knowledge brought about through the sharing of knowledge amongst employees as well as between employees and customers, suppliers, or other organizations. Examples of this type of asset are individual employee skills and competencies that are obtained from one's work environment. These assets are developed through socialization. This asset is unique to each organization and hard to copy because of its tacit nature, thereby giving the organization a competitive advantage. 
2.) Conceptual knowledge assets: are explicit in nature and thus easier to learn. They are created through the process of externalization. Some examples of this knowledge asset include brand equity and product designs.

3.) Systemic knowledge assets: are "systematized and packaged explicit knowledge" (p. 502). Examples include, licenses, patents, manuals, and documentation with respect to customers and suppliers. The process of combination allows for these assets to be made explicit in the form of documents or data, which in turn allows them to be exchangeable.

4.) Routine Knowledge assets: is tacit knowledge that has become part of the activities and customs of the firm. Examples include, the firm-specific competencies of employees, company routines, and the culture of the organization in terms of how it undertakes its everyday activities. It is through the process of internalization that routine knowledge assets are established and distributed by the organization. 


\section{References}

Alnes, K., Economides, C., Kong, A., \& Peyraud, C. (2014). Effective CSR data management: How software solutions can drive the sustainable future [White paper]. Retrieved from http://rescore.weebly.com/uploads/3/7/4/6/37462587/effective_csr_data_management.pdf

Alreck, P. L., \& Settle, R. B. (1995). The survey research handbook. (2nd ed.). Chicago: Irwin Press.

Alwin, D. F. (2010). How good is survey measurement? Assessing the reliability and validity of survey measures. In P. V. Marsden, \& J. D. Wright (Eds.), Handbook of survey research (2nd ed., pp. 405-434). Bingley, UK: Emerald.

Ammenberg, J., Wik, G., \& Hjelm, O. (2001). Auditing external environmental auditors?: Investigating how ISO 14001 is interpreted and applied in reality. Eco-Management and Auditing, 8(4), 183-192. doi:10.1002/ema.165

Ann, G. E., Zailani, S., \& Wahid, N. A. (2006). A study on the impact of environmental management system (EMS) certification towards firms' performance in Malaysia. Management of Environmental Quality: An International Journal, 17(1), 73-93. doi:10.1108/14777830610639459 
Antal, A. B., Lenhardt, U., \& Rosenbrock, R. (2001). Barriers to organizational learning. In M. Dierkes, A. B. Antal, J. Child, \& I. Nonaka (Eds.), Handbook of organizational learning and knowledge (pp. 865-885). Oxford: Oxford University Press.

Argent, R. M., \& Grayson, R. B. (2001). Design of information systems for environmental managers: An example using interface prototyping. Environmental Modelling and Software, $16,433-438$.

Argote, L. (1999). Organizational learning: Creating, retaining and transferring knowledge. Boston: Kluwer.

Argyris, C. (1977). Double loop learning in organizations, Harvard Business Review, (SeptOct), 59-72.

Argyris, C., \& Schön, D. A. (1978). Organizational learning: A theory of action perspective. Reading, MA: Addison-Wesley.

Atif, A., Richards, D., \& Bilgin, A. (2012, December, 3-5). Estimating non-response bias in a web-based survey of technology acceptance: A case study of unit guide information systems. Paper presented at the $23^{\text {rd }}$ Australian Conference on Information Systems, Geelong, Australia. Retrieved from https://www.researchgate.net/profile/Amara_Atif/publication/ 280860298_Estimating_Non-Response_Bias_in_a_Web Based_Survey_of_Technology 
_Acceptance_A_Case_Study_of_Unit_Guide_Information_Systems/links/ 57ad257a08ae7a6420c35225.pdf

Azzone, G., Bianchi, R., \& Noci, G. (1997). Implementing environmental certification in Italy: Managerial and competitive implications for firms. Eco-Management and Auditing, 4(3), 98108.

Baker, R., Brick, J. M., Bates, N. A., Battaglia, M., Couper, M. P., Dever, J. A., . . Tourangeau, R. (2013). Summary report of the AAPOR Task Force on non-probability sampling. Journal of Survey Statistics and Methodology, 1(2), 90-143. doi:10.1093/jssam/smt008

Bansal, P., \& Bognar, W. C. (2002). Deciding on ISO 14001: Economics, Institutions, and Context. Long Range planning, 35(3), 269-290.

Bateson, G. (1972). Steps to an ecology of mind: A revolutionary approach to Man's understanding of himself. New York: Ballantine Books.

Beeler, D. L. (1999). Internal auditing: The big lies. Quality Progress, 32(5), 73-78.

Boiral, O. (2002). Tacit knowledge and environmental management. Long Range Planning, 35(3), 291-317. Retrieved from http://resolver.scholarsportal.info/resolve/00246301/ v35i0003/291_tkaem.xml 
Boiral, O., \& Sala, J.-M. (1998). Environmental management: Should industry adopt ISO 14001 ? Business Horizons, 41(1), 57-64. doi:10.1016/S0007-6813(98)90065-9

BSI Group. (2015). Moving from ISO 14001:2004 to ISO 14001:2015: Transition guide [White paper]. Retrieved from http://www.bsigroup.com/LocalFiles/en-GB/iso-14001/Revisions/ ISO-14001-transition-guide-July-2015-FINAL.pdf

Buchel, B., \& Raub, S. (2001). Media choice and organizational learning. In M. Dierkes, A. B. Antal, J. Child, \& I. Nonaka (Eds.), Handbook of organizational learning and knowledge (pp. 518-534). Oxford: Oxford University Press.

Burdick, P. E. D. (2001). American and European ISO 14001 accreditation requirements and their influences on registrar practice and environmental performance. Corporate Environmental Strategy, 8(1), 65-74. doi:10.1016/S1066-7938(00)00088-9

Burström, F. (2000). Environmental management systems and co-operation in municipalities. Local Environment: The International Journal of Justice and Sustainability, 5(3), 271-284.

Burström von Malmborg, F. (2002). Environmental management systems, communicative action and organizational learning. Business Strategy and the Environment, 11, 312-323.

Camp, R. C. (1989). Benchmarking: The search for industry best practices that lead to superior performance. White Plains, New York: Quality Press; Quality Resources. 
Cangelosi, V. E., \& Dill, W. R. (1965). Organizational learning: Observations toward a theory. Administrative Science Quarterly, 10(2), 175-203. doi:10.2307/2391412

Carlsson, M., \& Carlsson, D. (1996). Experiences of implementing ISO 9000 in Swedish industry. International Journal of Quality \& Reliability Management, 13(7), 36-47. doi:10.1108/02656719610128547

Chavan, M. (2005). An appraisal of environment management systems: A competitive advantage for small businesses. Management of Environmental Quality: An International Journal, 16(5), 444-463. Retrieved from http://ezproxy.lib.ryerson.ca/login?url=http://search.proquest.com/ docview/204535419?accountid=13631

Chin, K., Chiu, S., \& Tummala, V. M. R. (1999). An evaluation of success factors using the AHP to implement ISO 14001-based EMS. International Journal of Quality \& Reliability Management, 16(4), 341-362. doi:10.1108/02656719910248226

Chin, K.-S., \& Pun, K.-F. (1999). Factors influencing ISO 14000 implementation in printed circuit board manufacturing industry in Hong Kong. Journal of Environmental Planning and Management, 42(1), 123-134. doi:10.1080/09640569911334 
Christensen, P., \& Rasmussen, B. D. (1998). Implementation of environmental management in the Danish printing house industry. Eco-Management and Auditing, 5(2), 88-94. doi:10.1002/(SICI)1099-0925(199807)5:2<88::AID-EMA80>3.0.CO;2-D

Cohen, M., \& Bacdayan, P. (1996). Organizational routines are stored as procedural memory: Evidence from a laboratory study. In M. Cohen, \& L. Sproull (Eds.), Organizational learning. Thousand Oaks, CA: Sage Publications.

Couper, M. P., \& Bosnjak, M. (2010). Internet surveys. In P. V. Marsden, \& J. D. Wright (Eds.), Handbook of survey research (2nd ed., pp. 527-550.). Bingley, UK: Emerald.

Creswell, J. W. (2003). Research design: Qualitative, quantitative, and mixed methods approaches (2nd ed.). Thousand Oaks, CA: Sage Publications.

Cross, R., \& Baird, L. (2000). Technology is not enough: Improving performance by building organizational memory. Sloan Management Review, 41(3), 69-77.

Crossan, M. M., Lane, H. W., White, R. E., \& Djurfeldt, L. (1995). Organizational learning: Dimensions for a theory. The International Journal of Organizational Analysis, 3(4), 337360. doi:10.1108/eb028835

Cyert, R. M., \& March, J. G. (1963). A behavioral theory of the firm. Englewood Cliffs, New Jersey: Prentice-Hall. 
Da Silva, G. C. S., \& de Medeiros, D. D. (2004). Environmental management in Brazilian companies. Management of Environmental Quality: An International Journal, 15(4), 380_ 388.

Daft, R. L., \& Weick, K. E. (1984). Toward a model of organizations as interpretation systems. Academy of Management Review, 9(2), 284-295. doi:10.5465/AMR.1984.4277657

Darnall, N., Henriques, I., \& Sadorsky, P. (2008). Do environmental management systems improve business performance in an international setting? Journal of International Management, 14(4), 364-376. doi:10.1016/j.intman.2007.09.006

Darnall, N., Seol, I., \& Sarkis, J. (2009). Perceived stakeholder influences and organizations' use of environmental audits. Accounting, Organizations and Society, 34(2), 170-187. doi:10.1016/j.aos.2008.07.002

Day, G. S. (1994a). Capabilities of market-driven organizations. Journal of Marketing, 58 (4), $37-52$.

Day, G. S. (1994b). Continuous learning about markets. California Management Review, 36(4), $9-31$.

De Geus, A. P. (1988). Planning as learning. Harvard Business Review, 66(2), 70-74. 
De Vaus, D. (2006). Editor's introduction: Research design - A review. In D. de Vaus (Ed.), Research design. (Vol. 1, pp. XXIII-LV). Thousand Oaks: Sage Publications.

Del Brio, J.A., Fernandez, E., Junquera, B., \& Vazquez, C.J. (2001). Environmental managers and departments as driving forces of TQEM in Spanish industrial companies. International Journal of Quality \& Reliability Management, 18(5), 495-511.

doi:10.1108/02656710110392638

DiBella, A. J., \& Nevis, E. C. (1998). How organizations learn: An integrated strategy for building learning capability (1st ed.). San Francisco, California: Jossey-Bass.

DiBella, A. J., Nevis, E. C., \& Gould, J. M. (1996). Understanding organizational learning capability. Journal of Management Studies, 33(3), 361-379. doi:10.1111/j.14676486.1996.tb00806.x

Dierkes, M., Antal, A. B., Child, J. \& Nonaka, I. (Eds.). (2001). Handbook of organizational learning and knowledge. Oxford: Oxford University Press.

Dierkes, M., Marz, L., \& Teele, C. (2001). Technological visions, technological development, and organizational learning. In M. Dierkes, A. B. Antal, J. Child, \& I. Nonaka (Eds.), Handbook of organizational learning and knowledge (pp. 282-301). Oxford: Oxford University Press. 
Dodgson, M. (1991). Technology learning, technology strategy and competitive pressures. British Journal of Management, 2(3), 133-149. doi:10.1111/j.1467-8551.1991.tb00022.x

Dodgson, M. (1993). Organizational learning: A review of some literatures. Organization Studies, 14(3), 375-394. doi:10.1177/017084069301400303

Dogui, K., Boiral, O., \& Heras-Saizarbitoria, I. (2014). Audit Fees and Auditor Independence: The Case of ISO 14001 Certification. International Journal of Auditing, 18(1), 14-26. doi:10.1111/ijau.12008

Duncan, R. B., \& Weiss, A. (1979). Organizational learning: Implications for organizational design. In B. Straw (Ed.), Research in organizational behavior (Vol. 1, pp. 75-123). Greenwich, Connecticut: JAI Press.

Easterby-Smith, M. (1997). Disciplines of organizational learning: Contributions and critiques. Human Relations, 50(9), 1085-1113. doi:10.1023/A:1016957817718

Easterby-Smith, M., \& Lyles, M. A. (2011a). The evolving field of organizational learning and knowledge management. In Easterby-Smith, M., \& Lyles, M. A. (Eds.), Handbook of organizational learning and knowledge management (2nd ed., pp. 1-20). West Sussex, UK: John Wiley \& Sons. 
Easterby-Smith, M., \& Lyles, M. A. (Eds.). (2011b). Handbook of organizational learning and knowledge management (2nd ed.). West Sussex, UK: John Wiley \& Sons.

Enviance. (n.d.a). Environmental ERP: Reaching your peak in the cloud [White paper]. Retrieved from http://www.enviance.com/resources/wp-erp-cloud.aspx

Enviance. (n.d.b). The cloudburst: Hitting new heights with cloud-based environmental software [White paper]. Retrieved from http://www.enviance.com/resources/wp-cloudburst.aspx

Enviance. (2010a). Dashboards: Easy business intelligence [White paper]. Retrieved from http://www.enviance.com/resources/wp-dashboards.aspx

Enviance. (2010b). Instituitionalize your environmental memory: Environmental ERP and business continuity [White paper]. Retrieved from http://www.enviance.com/resources/wpbusiness-continuity.aspx

Epple, D., Argote, L., \& Devadas, R. (1991). Organizational learning curves: A method for investigating intra-plant transfer of knowledge acquired through learning by doing. Organization Science, 2(1), 58-70. doi:10.1287/orsc.2.1.58

Epstein, M. J., \& Roy, M. (1997). Using ISO 14000 for improved organizational learning and environmental management. Environmental Quality Management, 7, 21-30. 
Field, A. (2009). Discovering statistics using SPSS. (3rd ed.). Thousand Oaks, California: SAGE Publications Inc.

Finster, M., Eagan, P., \& Hussey, D. (2001). Linking industrial ecology with business strategy: Creating value for green product design. Journal of Industrial Ecology, 5(3), 107-125. doi:10.1162/108819801760049495

Fiol, C. M., \& Lyles, M. A. (1985). Organizational learning. Academy of Management Review, 10(4), 803-813.

Fiorino, D. J. (1999). Rethinking environmental regulation. Harvard Environmental Law Review, 23(2), 441-469.

Fisher, R. M. (2003). Applying ISO 14001 as a business tool for campus sustainability: A case study from New Zealand. International Journal of Sustainability in Higher Education, 4(2), 138-150.

FitzGerald, C. (1992). Trends in environmental computer applications: Integrating environmental management information systems with business systems. Environmental Software, 7(3), 175179. doi:10.1016/0266-9838(92)90014-U

Fortuński, B. (2008). Does the environmental management standard ISO 14001 stimulate sustainable development? An example from the energy sector in Poland. Management of 
Environmental Quality: An International Journal, 19(2), 204-212.

Fowler, F. J. (2002). Survey research methods. (3rd ed.). Thousand Oaks: Sage Publications.

Friedman, V. J. (2001). The individual as agent of organizational learning. In M. Dierkes, A. B. Antal, J. Child, \& I. Nonaka (Eds.), Handbook of organizational learning and knowledge (pp. 398-427). Oxford: Oxford University Press.

Friedman, V. J., Lipshitz, R., \& Overmeer, W. (2001). Creating conditions for organizational learning. In M. Dierkes, A. B. Antal, J. Child, \& I. Nonaka (Eds.), Handbook of organizational learning and knowledge (pp. 757-774). Oxford: Oxford University Press.

Garratt, B. (1987). The learning organization. London: Fontana.

Garvin, D. A. (1993). Building a learning organization. Harvard Business Review, 71(JulyAugust), 78-91.

Georgiadou, M., \& Tsiotras, G. (1998). Environmental management systems: A new challenge for Greek industry. International Journal of Quality \& Reliability Management, 15(3), 286302. 
Gidwani, B. (2015, January 19). Do data management tools improve perceived sustainability performance? Retrieved from http://www.csrhub.com/blog/2015/01/do-data-managementtools-improve-perceived-sustainability-performance.html

Gill, T. G. (1995). High-tech hidebound: Case studies of information technologies that inhibited organizational learning. Accounting, Management and Information Technologies, 5(1), 41-60.

Gleckman, H., \& Krut, R. (1997). Neither international nor standard: The limits of ISO 14001 as an instrument of global corporate environmental management. In C. Sheldon (Ed.), ISO 14001 and beyond environmental management systems in the real world (pp. 45-50). Sheffield: Greenleaf Publishing.

Global Environment and Technology Foundation. (2004). Environmental management system software assessment [White paper]. Retrieved from http://www.peercenter.net/ewebeditpro/ items/O73F4044.pdf.

Goodman, P. S., \& Darr, E. D. (1998). Computer-aided systems and communities: Mechanisms for organizational learning in distributed environments. Management Information System Quarterly, 22(4), 417-440.

Grant, R. M. (1996). Toward a knowledge-based theory of the firm. Strategic Management Journal, 17 (Winter Special Issue), 109-122. 
Haag, S., \& Cummings, M. (2008). Management information systems for the information age (7th ed.). New York, NY: McGraw-Hill//rwin.

Hart, S. L. (1995). A natural-resource-based view of the firm. Academy of Management Review, 20(4), 986-1014.

Hayes, N. (2011). Information technology and the possibilities for knowledge sharing. In M. Easterby-Smith, \& M. A. Lyles (Eds.), Handbook of organizational learning and knowledge management (2nd ed., pp. 83-104). West Sussex, UK: John Wiley \& Sons.

Hedberg, B. (1981), How organizations learn and unlearn. In P. C. Nystrom, \& W. H. Starbuck (Eds.), Handbook of organizational design (Vol. 1, pp. 3-27). London: Cambridge University Press.

Henriques, I., Husted, B. W., \& Montiel, I. (2013). Spillover effects of Voluntary Environmental Programs on Greenhouse Gas Emissions: Lessons from Mexico. Journal of Policy Analysis and Management, 32(2), 296-322. doi:10.1002/pam.21675

Henriques, I., \& Sadorsky, P. (2008). Voluntary environmental programs: A Canadian perspective. Policy Studies Journal, 36(1), 143-166. doi:10.1111/j.1541-0072.2007.00257.x

Hillary, R. (2004). Environmental management systems and the smaller enterprise. Journal of Cleaner Production, 12(6), 561-569. doi:10.1016/j.jclepro.2003.08.006 
Huang, P.-S., \& Shih, L.-H. (2009). Effective environmental management through environmental knowledge management. International Journal of Environmental Science \& Technology, 6(1), 35-50. doi:10.1007/BF03326058

Huber, G. P. (1991). Organizational learning: The contributing processes and the literatures. Organization Science, 2(1), 88-115.

Hwee Nga, J. K. (2009). The influence of ISO 14000 on firm performance. Social Responsibility Journal, 5(3), 408-22.

Intelex. (2014). Best practices in EHS management [White paper]. Retrieved from www.intelex.com

Intelex Technologies Incorporation. (n.d.). Cultivating competence: Leveraging training tools for measurable results [White paper]. Retrieved from http://www.intelex.com/Cultivating_ Competence__Leveraging_Training_Tools_for_Measurable_Results-471-1whitepaper.aspx

International Organization for Standardization (ISO). (2004). ISO 14001: Environmental management systems - Requirements with guidance for use. Geneva: ISO 
International Organization for Standardization (ISO). (2004). ISO 14004: Environmental management systems - General guidelines on principles, systems and support techniques. Geneva: ISO

International Organization for Standardization (ISO). (2015). ISO 14001: Environmental management systems - Requirements with guidance for use. Geneva: ISO

International Organization for Standardization (ISO). (2016). ISO 14004: Environmental management systems - General guidelines on principles, systems and support techniques. Geneva: ISO

Ismail, N. (2012). Environment, health and safety: Going beyond compliance [White paper]. Retrieved from http://www.intelex.com/Aberdeen_Report__Environment_Health _and_Safety_Going_Beyond_Compliance-665-1whitepaper.aspx

ISO. (2009). Environmental management: The ISO 14000 family of international standards [White paper]. Retrieved from http://www.iso.org/iso/theiso14000family_2009.pdf

ISO. (2014). The ISO Survey of Certifications 2014. Retrieved from http://www.iso.org/iso/isosurvey

ISO. (2015). Introduction to ISO 14001:2015 [White paper]. Retrieved from http://www.iso.org/iso/home/standards/management-standards/iso14000.htm) 
Jaffe, A., Peterson, S., Portney, P., \& Stavins, R. (1995). Environmental regulation and the competitiveness of U.S. manufacturing. Journal of Economic Literature, 33(1), 132-163.

Jerez-Gomez, P., Cespedes-Lorente, J., \& Valle-Cabrera, R. (2005). Organizational learning capability: A proposal of measurement. Journal of Business Research, 58(6), 715-725.

Jimenez-Jimenez, D., \& Sanz-Valle, R. (2011). Innovation, organizational learning, and performance. Journal of Business Research, 64, 408-417.

Jørgensen, T. H. \& Simonsen, G. (2002). Prospects of a unified management system. Corporate Social Responsibility and Environmental Management, 9(2), 91-98. Retrieved from http://resolver.scholarsportal.info/resolve/15353958/v09i0002/91_poaums.xml

Kane, G. C., \& Alavi, M. (2007). Information technology and organizational learning: An investigation of exploration and exploitation processes. Organization Science, 18(5), 796812.

Karapetrovic, S. (2002). On the concept of a universal audit of quality and environmental management systems. Corporate Social Responsibility and Environmental Management, 9(3), 147-156. Retrieved from http://resolver.scholarsportal.info/resolve/15353958/v09i0003/ 147_otcoauoqaems.xml 
Karltun, J., Axelsson, J., \& Eklund, J. (1998). Working conditions and effects of ISO 9000 in six furniture-making companies: Implementation and processes. Applied Ergonomics, 29(4), 225-232. doi:10.1016/S0003-6870(97)00061-6

Kim, D. H. (1993). The link between individual and organizational learning. Sloan Management Review, 35(1), 37-50.

Kirkland, L.-H., \& Thompson, D. (1999). Challenges in designing, implementing and operating an environmental management system. Business Strategy and the Environment, 8(2), 128143. doi:10.1002/(SICI)1099-0836(199903/04)8:2<128::AID-BSE193>3.0.CO;2-N

Kirkland, L.-H., \& Thompson, D. (2002). Environmental management systems. In D. Thompson (Ed.), Tools for environmental management: A practical introduction and guide (pp. 19-42). Gabriola Island, BC: New Society Publishers.

Kirkpatrick, D., \& Pouliot, C. (1996). Environmental management: ISO 14000 offers multiple Rewards. Pollution Engineering, 28(6), 62-65.

Kloot, L. (1997). Organizational learning and management control systems: Responding to environmental change. Management Accounting Research, 8(1), 47-73. doi:10.1006/mare.1996.0033 
Krosnick, J. A., \& Presser, S. (2010). Question and questionnaire design. In P. V. Marsden, \& J. D. Wright (Eds.), Handbook of survey research (2nd ed., pp. 263-313). Bingley, UK: Emerald.

Leavoy, P, \& Waggott, B. (n.d.). Demystifying environmental management systems software: Achieving goals and maximizing ROI [White paper]. Retrieved from http://www.intelex.com/ Demystifying_Environmental_Management_Software_Achieving_Goals_and_Maximizing_ ROI-353-1whitepaper.aspx

Lei, D., Hitt, M. A., \& Bettis, R. (1996). Dynamic core competencies through metalearning and strategic context. Journal of Management, 22(4), 549-569.

Leif, E. (2014, May 6). Magic quadrant for environmental, health and safety management systems. Retrieved from http://www.gartner.com/technology/reprints.do?id=11TP5IRQ\&ct $=140507 \& \mathrm{st}=\mathrm{sb}$

Leonard-Barton, D. (1995). Wellsprings of knowledge, building and sustaining the sources of innovation. Boston, MA: Harvard Business School Press.

Levinthal, D. A., \& March, J. G. (1993). The myopia of learning. Strategic Management Journal, 14(S2), 95-112. doi:10.1002/smj.4250141009 
Levitt, B., \& March, J. G. (1988). Organizational learning. Annual Review of Sociology, 14, 319340.

Lineback, J. F., \& Thompson, K. J. (2010). Conducting nonresponse bias analysis for business surveys. Proceedings from the Section on Survey Research Methods, American Statistical Association.

Lipshitz, R., Popper, M., \& Oz, S. (1996). Building learning organizations: The design and implementation of organizational learning mechanisms. Journal of Applied Behavioral Science, 32 (3), 78-98.

Liyin, S., Hong, Y., \& Griffith, A. (2006). Improving environmental performance by means of empowerment of contractors. Management of Environmental Quality: An International Journal, 17(3), 242-257. doi:10.1108/14777830610658674

Lopez, S. P., Peón, J. M. M., \& Ordás, C. J. V. (2004). Managing knowledge: The link between culture and organizational learning. Journal of knowledge Management, 8(6), 93-104.

March, J. G. (1991). Exploration and exploitation in organizational learning. Organization Science, 2(1), 71-87. 
March, J. G., \& Olsen, J. P. (1975). The uncertainty of the past: Organizational learning under ambiguity. European Journal of Political Research, 3(2), 147-171. doi:10.1111/j.14756765.1975.tb00521.x

Marimon, F., Heras, I., \& Casadesus, M. (2009). ISO 9000 and ISO 14000 standards: A projection model for the decline phase. Total Quality Management \& Business Excellence, $20(1), 1-21$.

Marsden, P. V., \& Wright, J. D. (2010). Handbook of survey research (2nd ed.). Bingley, UK: Emerald.

McHugh, D., Groves, D., \& Alker, A. (1998). Managing learning: What do we learn from a learning organization? The Learning Organization, 5(5), 209-220.

Montabon, F., Melnyk, S. A., Sroufe, R., \& Calantone, R. J. (2000). ISO 14000: Assessing its perceived impact on corporate performance. Journal of Supply Chain Management, 36(1), 416. doi:10.1111/j.1745-493X.2000.tb00073.X

Moorman, C., \& Miner A. S. (1997). The impact of organizational memory on new product performance and creativity. Journal of Marketing Research, 34(February), 91-106.

Morrison, J., Cushing, K. K., Day, Z., \& Speir, J. (2000). Managing a better environment: Opportunities and obstacles for ISO 14001 in public policy and commerce [Occasional 
Paper]. Oakland, CA: The Pacific Institute for Studies in Development, Environment, and Security. Retrieved from http://pacinst.org/wp-content/uploads/sites/21/2013/02/managing-abetter-environment-iso-14000.pdf

Moxen, J., \& Strachan, P. A. (2000). ISO 14001: A case of cultural myopia. Eco - Management and Auditing, 7(2), 82-90. Retrieved from http://ezproxy.lib.ryerson.ca/login?url=http:// search.proquest.com/docview/213899511 accountid=13631

Moynihan, D. P., \& Landuyt, N. (2009). How do public organizations learn? Bridging cultural and structural perspectives. Public Administration Review, 69(6), 1097-1105.

Mullin, R., \& Sissel, K. (1995). Managers gear up for global standards. Chemical Week, 157(13), 65-66. Retrieved from http://ezproxy.lib.ryerson.ca/login?url=http://search.proquest.com/ docview/222503690?accountid=13631

Nelson, R., \& Winter, S. (1982). An evolutionary theory of economic change. Cambridge: Harvard University Press.

Nonaka, I. (1991). The knowledge-creating company. Harvard Business Review, 69(6), 96-104.

Nonaka, I. (1996). The knowledge-creating company. In K. Starkey (Ed.), How organizations learn (pp. 18-31). London: Thomson Business Press. 
Nonaka, I., Reinmoller, P., \& Toyama, R. (2001). Integrated information technology systems for knowledge creation. In M. Dierkes, A. B. Antal, J. Child, \& I. Nonaka (Eds.), Handbook of organizational learning and knowledge (pp. 827-848). Oxford: Oxford University Press.

Nonaka, I., Toyama, R., \& Byosiere, P. (2001). A theory of organizational knowledge creation: Understanding the dynamic process of creating knowledge. In M. Dierkes, A. B. Antal, J. Child, \& I. Nonaka (Eds.), Handbook of organizational learning and knowledge (pp. 491517). Oxford: Oxford University Press.

Nonaka, I., Toyama, R., \& Konno, N. (2000). SECI, ba and leadership: A unified model of dynamic knowledge creation. Long Range Planning, 33(1), 5-34. doi:10.1016/S00246301(99)00115-6

Pawlowsky, P. (2001). The treatment of organizational learning in management science. In M. Dierkes, A. B. Antal, J. Child, \& I. Nonaka (Eds.), Handbook of organizational learning and knowledge (pp. 61-88). Oxford: Oxford University Press.

Pawlowsky, P., Forslin, J., \& Reinhardt, J. (2001). Practices and tools of organizational learning. In M. Dierkes, A. B. Antal, J. Child, \& I. Nonaka (Eds.), Handbook of organizational learning and knowledge (pp. 775-793). Oxford: Oxford University Press.

Pedler, M., Boydell, T., \& Burgoyne, J. (1989). Towards the learning company. Management Learning, 20(1), 1-8. doi:10.1177/135050768902000101 
Pedler, M., Burgogyne, J., \& Boydell, T. (1997). The Learning Company: A strategy for sustainable development. (2nd ed.). London: McGraw-Hill.

Pentland, B. T. (1995). Information systems and organizational learning: The social epistemology of organizational knowledge systems. Accounting, Management and Information Technologies, 5(1), 1-21. doi:10.1016/0959-8022(95)90011-X

Petroni, A. (2000). The analysis of customer satisfaction-related elements of ISO 14000 implementation: Evidence from the food machinery industry. Eco-Management and Auditing, 7, 1-10.

Petts, J., Herd, A., \& O’heocha, M. (1998). Environmental responsiveness, individuals and organizational learning: SME experience. Journal of Environmental Planning and Management, 41(6), 711-730.

Poksinska, B., Dahlgaard, J. J., \& Eklund, J. A. E. (2003). Implementing ISO 14000 in Sweden: Motives, benefits and comparisons with ISO 9000. International Journal of Quality \& Reliability Management, 20(5), 585-606. doi:10.1108/02656710310476543

Popper, M., \& Lipshitz, R. (1995). Organizational learning mechanisms: A structural and cultural approach to organizational learning. Journal of Applied Behavioral Science, 34(2), $161-179$. 
Porter, M. E., \& van der Linde, C. (1995). Toward a New Conception of the EnvironmentCompetitiveness Relationship. Journal of Economic Perspectives, 9(4), 97-118. doi:10.1257/jep.9.4.97

Potoski, M., \& Prakash, A. (2005). Green clubs and voluntary governance: ISO 14001 and firm's regulatory compliance. American Journal of Political Science, 49(2), 235-248.

Pouliot, C. (1996). ISO 14000: Beyond compliance to competitiveness. Manufacturing Engineering, 116(5), 51-56. Retrieved from http://ezproxy.lib.ryerson.ca/login?url =http://search.proquest.com/docview/219699127?accountid=13631

Proto, M., \& Supino, S. (2000). Ecomanagement quality system: ISO 14000: The state-of-the-art in Italy. Total Quality Management \& Business Excellence, 11(4), 767-772.

Psomas, E. L., Fotopoulos, C. V., \& Kafetzopoulos, D. P. (2011). Motives, difficulties and benefits in implementing the ISO 14001 Environmental Management System. Management of Environmental Quality: An International Journal, 22(4), 502-521.

doi:10.1108/14777831111136090

Radonjič, G., \& Tominc, P. (2006). The impact and significance of ISO 14001 certification on the adoption of new technologies. Management of Environmental Quality: An International Journal, 17(6), 707-727. doi:10.1108/14777830610702539 
Rapacioli, S., Thimmiah, S., Osborn, J., \& Richardson, S. (2011). Sustainability performance management: How CFOs can unlock value [White paper]. Retrieved from http://www.cimaglobal.com/Thought-leadership/Research-topics/Sustainability/ Sustainability-performance-management-how-CFOs-can-unlock-value/

Rea, L. M., \& Parker, R. A. (2005). Designing and conducting survey research: A comprehensive guide. (3rd ed.). San Francisco: Jossey-Bass.

Real, J. C., Leal, A., \& Roldán, J. L. (2006). Information technology as a determinant of organizational learning and technological distinctive competencies. Industrial Marketing Management, 35(4), 505-521. doi:10.1016/j.indmarman.2005.05.004

Reverdy, T. (2007). Translation process and organizational change: ISO 14001 implementation. International Studies of Management and Organization, 36(2), 9-30.

Rezaee, Z, \& Elam, R. (2000). Emerging ISO 14000 environmental standards: A step-by-step implementation guide. Managerial Auditing Journal, 15(1/2), 60-67.

Robey, D., Boudreau, M.-C. \& Rose, G. M. (2000). Information technology and organizational learning: A review and assessment of research. Accounting Management Information Technology, 10, 125-155. 
Roelker-Denker, L. (2011). Environmental management systems in learning organizations in health care. In P. Golinska, M. Fertsch, \& J. Marx-Gomez (Eds.), Information technologies in environmental engineering, environmental science and engineering (Vol. 3, pp. 389-395). Heidelberg, Berlin: Springer. doi:10.1007/978-3-642-19536-5_30

Roloff, K. S., Woolley, A. W., \& Edmondson, A. C. (2011). The contribution of teams to organizational learning. In M. Easterby-Smith, \& M. A. Lyles (Eds.), Handbook of organizational learning and knowledge management (2nd ed., pp. 249-271). West Sussex, UK: John Wiley \& Sons.

Romme, G., \& Dillen, R. (1997). Mapping the landscape of organizational learning. European Management Journal, 15(1), 68-78.

Rondinelli, D., \& Vastag, G. (2000). Panacea, common sense, or just a label? European Management Journal, 18(5), 499-510. doi:10.1016/S0263-2373(00)00039-6

Roome, N. J., \& Wijen, F. (2006). Stakeholder power and organizational learning in corporate environmental management. Organization Studies, 27(2), 235-263.

Ruiz-Mercader, J., Merono-Cerdan, A. L., \& Sabater-Sanchez, R. (2006). Information technology and learning: Their relationship and impact on organisational performance in small businesses. International Journal of Information Management, 26, 16-29. 
Sadler, P. (2001). Leadership and organizational learning. In M. Dierkes, A. B. Antal, J. Child, \& I. Nonaka (Eds.), Handbook of organizational learning and knowledge (pp. 415-427). Oxford: Oxford University Press.

Salkind, N. J. (2009). Exploring research (7th ed.). Upper Saddle River, NJ: Pearson Prentice Hall.

Schaltegger, S., \& Synnestvedt, T. (2002). The link between 'green' and economic success: Environmental management as the crucial trigger between environmental and economic performance. Journal of Environmental Management, 65(4), 339-346. doi:10.1006/jema.2002.0555

Schein, E. H. (1993). How can organizations learn faster? The challenge of entering the green room. MIT Sloan Management Review, 34(2), 85-92.

Schreuder, H. T., Gregoire, T. G., \& Weyer, J. P. (2001). For what applications can probability and non-probability sampling be used? Environmental Monitoring and Assessment, 66(3), 281-291. doi:10.1023/A:1006316418865

Schylander, E., \& Martinuzzi, A. (2007). ISO 14001 - experiences, effects and future challenges: A national study in Austria. Business Strategy and the Environment, 16(2), 133-147. doi:10.1002/bse.473 
Searcy, C., Morali, O., Karapetrovic, S., Wichuk, K., McCartney, D., McLeod, S., \& Fraser, D. (2012). Challenges in implementing a functional ISO 14001 environmental management system. International Journal of Quality \& Reliability Management, 29(7), 779-796. doi:10.1108/02656711211258526

Sebhatu, S.P., \& Enquist, B. (2007). ISO 14001 as a driving force for sustainable development and value creation. The TQM Magazine, 19(5), 468-482.

Senge, P. M. (2006). The fifth discipline: The art and practice of the learning organization. London, England: Random House.

Shrivastava, P. (1983). A typology of organizational learning systems. Journal of Management Studies, 20(1), 7-28. doi:10.1111/j.1467-6486.1983.tb00195.x

Simon, H. A. (1991). Bounded rationality and organizational learning. Organization Science, 2(1), 125-134. doi:10.1287/orsc.2.1.125

Simonin, B. L. (1997). The importance of collaborative know-how: An empirical test of the learning organization. Academy of Management Journal, 40(5), 1150-1174.

Slater, S. F., \& Narver, J. C. (1995). Market orientation and the learning organization. Journal of Marketing, 59(July), 63-74. 
Stata, R. (1989). Organizational learning: The key to management innovation. Sloan Management Review, 30(3), 63-74.

Strachan, P. (1997). Should environmental management standards be a mechanistic control system or a framework for learning? The Learning Organization, 4(1), 10-17.

Strachan, P. A., Sinclair, I. M., \& Lal, D. (2003). Managing ISO 14001 implementation in the United Kingdom Continental Shelf (UKCS). Corporate Social Responsibility and Environmental Management, 10(1), 50-63. doi:10.1002/csr.29

Templeton, G. F., Lewis, B. R., \& Snyder, C. A. (2002). Development of a measure for the organizational learning construct, Journal of Management Information Systems, 19, 175-218.

Tibor, T., \& Feldman, I. (1996). ISO 14000 (1996): A Guide to the new environmental management standards. Burr Ridge, IL: Irwin Professional Publishing.

Tippins, M. J., \& Sohi, R. S. (2003). IT competency and firm performance: Is organizational learning a missing link? Strategic Management Journal, 24(8), 745-761.

Trochim, W. M. K. (2001). The research methods knowledge base (2nd ed.). Mason, OH: Thomson Custom Solutions. 
Tsang, E. (1997). Organizational learning and the learning organization: A dichotomy between descriptive and prescriptive research. Human Relations, 50, 73-89.

Turk, A. M. (2009). ISO 14000 environmental management system in construction: An examination of its application in Turkey. Total Quality Management \& Business Excellence, 20(7), 713-733. doi:10.1080/14783360903036996

Veleva, V., \& Ellenbecker, M. (2001). Indicators of sustainable production: Framework and methodology. Journal of Cleaner Production, 9, 519-549.

Visser, M. (2007). Deutero-learning in organizations: A review and a reformulation. Academy of Management Review, 32(2), 659-667.

Wagner, M., Schaltegger, S., \& Wehrmeyer, W. (2001). The relationship between the environmental and economic performance of firms. Greener Management International, 34, $95-108$.

Walley, N., \& Whitehead, B. (1994). It's not easy being green. Harvard Business Review, 72(3), $46-51$.

Webb, K. (2004). Voluntary codes: Where to from here? In K. Webb (Ed.), Voluntary codes: Private governance, the public interest and innovation (pp. 379-402). Ottawa: Carlton University. 
Whitelaw, K. (2004). ISO 14001 environmental systems handbook (2nd ed.). Amsterdam: Elsevier Butterworth Heinemann.

Winter, S. C., \& May, P. J. (2001). Motivation for compliance with environmental regulations. Journal of Policy Analysis and Management, 20(4), 675-698. doi:10.1002/pam.1023

Wood, B. D., \& Waterman, R. W. (1993). The dynamics of political-bureaucratic adaptation. American Journal of Political Science, 37(2), 497-528. doi:10.2307/2111382

Woodside, A. G., \& Wilson, E. J. (2003). Case study research methods for theory building. Journal of Business and Industrial Marketing, 18(6/7). 493-508.

Yeung, G., \& Mok, V. (2005). What are the impacts of implementing ISOs on the competitiveness of manufacturing industry in China? Journal of World Business, 40(2), 139_ 157.

Yin, R. K. (2003). Case study research: Design and methods. (3rd ed.). Thousand Oaks, CA: Sage Publications.

Zutshi, A., \& Sohal, A. S. (2004). Adoption and maintenance of environmental management Systems: Critical success factors. Management of Environmental Quality: An International Journal, 15(4), 399-419. 
Zwetsloot, G. I. (1995). Improving cleaner production by integration into the management of quality, environment and working conditions. Journal of Cleaner Production, 3(1-2), 61-66. doi:10.1016/0959-6526(95)00046-H 